Florida International University FIU Digital Commons

$3-21-2013$

\title{
Selection and Passage of County Land Preservation Voter Referendum: The Role of Government
}

Susan P. Beaghen

Florida International University, sbeagh01@fiu.edu

DOI: $10.25148 /$ etd.FI13042513

Follow this and additional works at: https://digitalcommons.fiu.edu/etd

Part of the Public Affairs, Public Policy and Public Administration Commons

\section{Recommended Citation}

Beaghen, Susan P., "Selection and Passage of County Land Preservation Voter Referendum: The Role of Government" (2013). FIU Electronic Theses and Dissertations. 887.

https://digitalcommons.fiu.edu/etd/887

This work is brought to you for free and open access by the University Graduate School at FIU Digital Commons. It has been accepted for inclusion in FIU Electronic Theses and Dissertations by an authorized administrator of FIU Digital Commons. For more information, please contact dcc@fiu.edu. 


\title{
FLORIDA INTERNATIONAL UNIVERSITY
}

\author{
Miami, Florida
}

\section{SELECTION AND PASSAGE OF COUNTY LAND PRESERVATION VOTER REFERENDUM: THE ROLE OF GOVERNMENT}

\author{
A dissertation submitted in partial fulfillment of the \\ requirements for the degree of \\ DOCTOR OF PHILOSOPHY \\ in \\ PUBLIC AFFAIRS \\ by \\ Susan Peabody Beaghen
}

2013 
To: Dean Kenneth G. Furton

College of Arts and Sciences

This dissertation, written by Susan Peabody Beaghen, and entitled Selection and Passage of County Land Preservation Voter Referendum: The Role of Government, having been approved in respect to style and intellectual content, is referred to you for judgment.

We have read this dissertation and recommend that it be approved.

Shaoming Cheng

$\begin{array}{r}\text { N. Emel Ganapati } \\ \hline \text { John Stack }\end{array}$

Allan Rosenbaum, Major Professor

Date of Defense: March 21, 2013

The dissertation of Susan Peabody Beaghen is approved.

$\begin{array}{r}\text { Dean Kenneth G. Furton } \\ \text { College of Arts and Sciences } \\ \hline \begin{array}{r}\text { Dean Lakshmi N. Reddi } \\ \text { University Graduate School }\end{array}\end{array}$

Florida International University, 2013 
(C) Copyright 2013 by Susan Peabody Beaghen

All rights reserved. 


\section{DEDICATION}

To the memory of my parents, George W. Beaghen

and M. Augusta Stanton Beaghen. 


\section{ACKNOWLEDGMENTS}

I am indebted to many individuals, without whom this research could not have been completed. My deepest gratitude is extended to my major professor Dr. Allan Rosenbaum whose guidance, encouragement and patience were instrumental in my progress toward completion of this dissertation. I am also grateful to committee members Dr. Shaoming Cheng, Dr. N. Emel Ganapati and Dr. John Stack for their valuable comments throughout the process.

A special note of appreciation is extended to the FIU University Graduate School, College of Arts and Sciences, and Dr. Meredith Newman, former Chair of the Department of Public Administration, for continuing to support and nurture my academic goals. The administrative personnel within the Department of Public Administration provided helpful assistance in furnishing logistical and organizational guidance, primarily Carlota Valdes and Liga Replogle.

This project would not have been possible without the valuable contributions of twelve county public administrators/managers who graciously volunteered their time for interviews. Their recall of county land preservation voter referendums and their expert witness to local government and regional governance factors relevant to this research provided important information, unforeseen concepts, and a professional pragmatism for having lived it.

I am thankful for my friends and colleagues and their enduring tolerance and understanding of my total commitment to completing this dissertation. Finally, a special tribute to my loyal rescued animals for their faithful companionship and unconditional love during the long days and nights of study. 


\title{
ABSTRACT OF THE DISSERTATION \\ SELECTION AND PASSAGE OF COUNTY LAND PRESERVATION VOTER \\ REFERENDUM: THE ROLE OF GOVERNMENT
}

\author{
by
}

\author{
Susan Peabody Beaghen
}

Florida International University, 2013

Miami, Florida

Professor Allan Rosenbaum, Major Professor

County jurisdictions in America are increasingly exercising selfgovernment in the provision of public community services through the context of second order federalism. In states exercising this form of contemporary governance, county governments with "reformed" policy-making structures and professional management practices, have begun to rival or surpass municipalities in the delivery of local services with regional implications such as environmental protection (Benton 2002, 2003; Marando and Reeves, 1993).

The voter referendum, a form of direct democracy, is an important component of county land preservation and environmental protection governmental policies. The recent growth and success of land preservation voter referendums nationwide reflects an increase in citizen participation in government and their desire to protect vacant land and its natural environment from threats of over-development, urbanization and sprawl, loss of open space and farmland, deterioration of ecosystems, and inadequate park and recreational amenities. 
The study's design employs a sequential, mixed method. First, a quantitative approach employs the Heckman two-step model. It is fitted with variables for the non-random sample of 227 voter referendum counties and all non-voter referendum counties in the U.S. from 1988 to 2009. Second, the qualitative data collected from the in-depth investigation of three South Florida county case studies with twelve public administrator interviews is transformed for integration with the quantitative findings. The purpose of the qualitative method is to complement, explain and enrich the statistical analysis of county demographic, socio-economic, terrain, regional, governance and government, political preference, environmentalism, and referendum-specific factors.

The research finds that government factors are significant in terms of the success of land preservation voter referendums; more specifically, the presence of self-government authority (home rule charter), a reformed structure (county administrator/manager or elected executive), and environmental interest groups. In addition, this study concludes that successful counties are often located coastally, exhibit population and housing growth, and have older and more educated citizens who vote democratic in presidential elections. The analysis of case study documents and public administrator interviews finds that pragmatic considerations of timing, local politics and networking of regional stakeholders are also important features of success. Further research is suggested utilizing additional public participation, local government and public administration factors. 


\section{TABLE OF CONTENTS}

CHAPTER

PAGE

I. INTRODUCTION TO THE STUDY

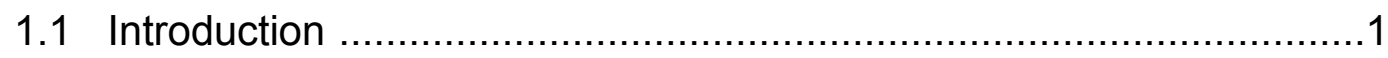

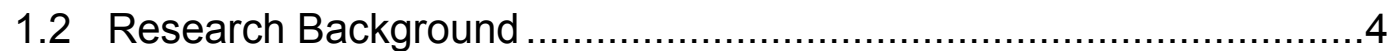

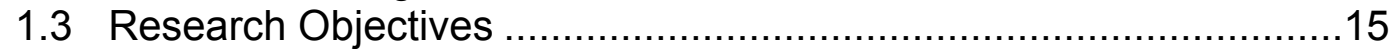

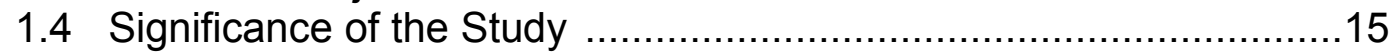

1.5 Overview of the Research Design ...........................................17

1.6 Organization of the Dissertation ...............................................

II. THEORETICAL FRAMEWORK AND LITERATURE REVIEW

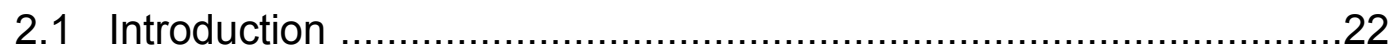

2.2 Direct Democracy and Citizenship..............................................24

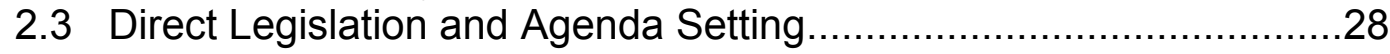

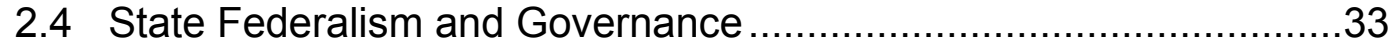

2.5 Reformed County Government ...............................................48

2.6 Nature Theory: Land Preservation, Parks and Recreation ..............52

2.7 Land Preservation Voter Referendum: Empirical Studies................64

2.8 Interest Group Theory and Environmentalism ...............................67

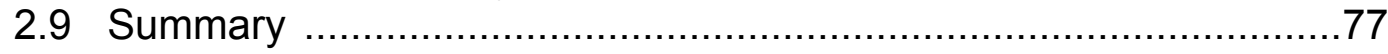

III. METHODOLOGY

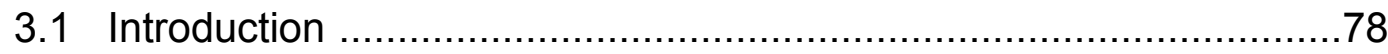

3.2 Sequential Mixed Methods Research Design .................................79

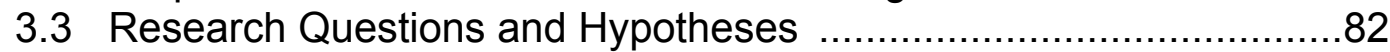

3.4 Analytical Framework for the Research Design ............................89

3.5 Quantitative Methodology with Heckman Two-Step Model .............92

3.6 Qualitative Methodology with Case Study Model ..........................111

3.7 Integration of Quantitative and Qualitative Approaches ...............127

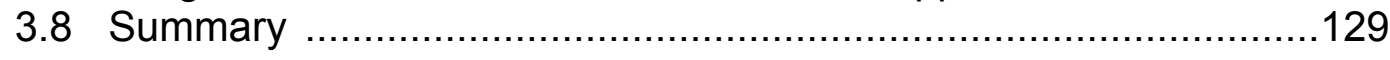

IV. QUANTITATIVE HECKMAN TWO-STEP APPROACH

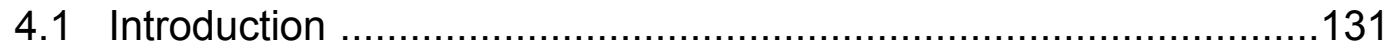

4.2 Analytical Framework for Quantitative Approach ........................131

4.3 Data Collection ...............................................................132

4.4 Descriptive Statistics for 1990 and 2000 Benchmark Years ...........155

4.5 Application of the Heckman Two-Step Probit Model.......................164

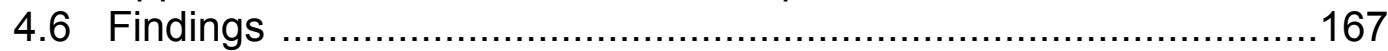

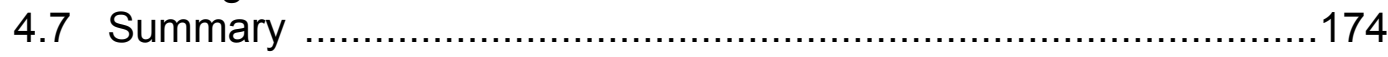

V. QUALITATIVE CASE STUDY APPROACH

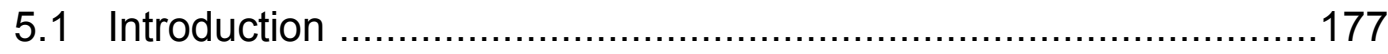

5.2 Analytical Framework for Qualitative Approach .........................177 
5.3 Collection of Document Data .................................................179

5.3.1 Overview of South Florida and Three Case Counties...........180

5.3.2 Case 1: Broward County, Florida ......................................185

5.3.3 Case 2: Miami-Dade County, Florida ..............................213

5.3.4 Case 3: Palm Beach County, Florida ..............................248

5.4 In-Case/Between Case Data Analysis .....................................266

5.5 Integration with Pattern Matching ….....................................271

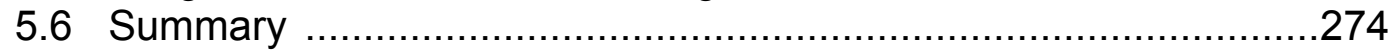

VI. FINDINGS OF MIXED METHODS RESEARCH

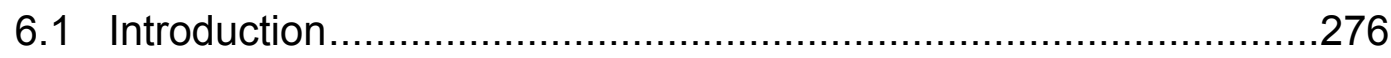

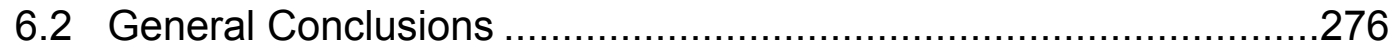

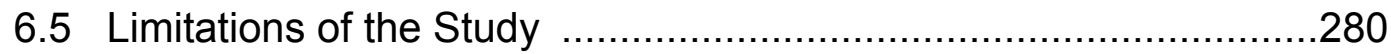

6.6 Suggestions for Future Investigation ....................................282

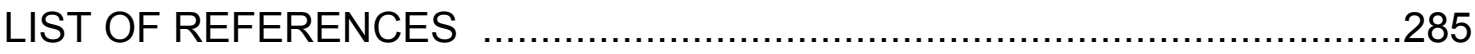

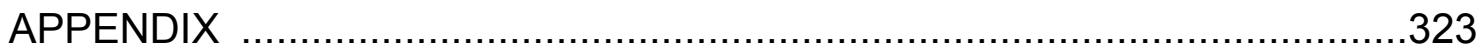

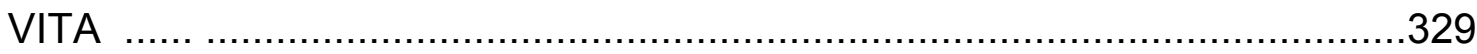




\section{LIST OF TABLES}

TABLE

PAGE

1.1 Urbanization in the United States from $1945 \ldots \ldots \ldots \ldots \ldots \ldots \ldots \ldots \ldots \ldots \ldots \ldots \ldots . . .4$

1.2 U.S. Land Preservation Voter Referendums by Year: 1988-2009

State, County, Municipal and Special District .10

1.3 U.S. Land Preservation Voter Referendums by Year: 1988-2009 County or County Entity

1.4 U.S. Land Preservation Voter Referendums by State 1988-2009 County or County Entity.

2.1 Contexts of Interest Group Scholarship: 1966-2011 68

3.1 Number of Counties by State and Benchmark Years 1990 and 2000. Total Counties: $1990(3,043)$ and $2000(3,034)$...

3.2 County Land Preservation Voter Referendums by 34 States and Two Benchmark Years of 1990 and 2000. 98

3.3 United States Demographic Data: $1980-2010 \ldots \ldots \ldots \ldots \ldots \ldots \ldots \ldots \ldots \ldots \ldots . . . .101$

3.4 Most Different Analysis with Three Case Counties ...........................116

3.5 Different Case Selection of Three South Florida Counties.................117

4.1 American States Exercising Dillon's Rule ....................................138

4.2 Local Government Autonomy Rankings of 50 American States .........139

4.3 Categories of County Home Rule Authority by States .......................141

4.4 Number of Counties with a Home Rule Charter by State And 1990 and 2000 Benchmark Years 143

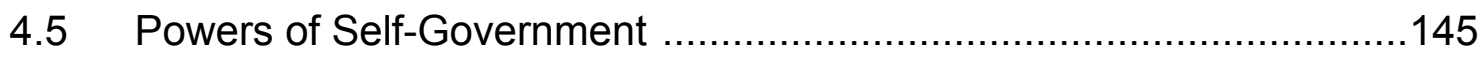

4.6 U.S. Census Bureau's Regions and Divisions …...........................146

$4.7 \quad$ U.S. NOAA Coastal Counties by State …...................................147 
4.8 Types and Numbers of Environmental and Conservation Organizations in 2005

4.9 Data Collection for 50 U.S. States: Categories of Environmental and Conservation Organizations

4.10 County Land Preservation Voter Referendums by Region, by Benchmark Group, by U.S. Census Region and Division, by State, by County Selection and by Voter Passage

4.11 Descriptive Statistics for County Dependent Variables: 1990 Benchmark Group (1988-1999) 156

4.12 Descriptive Statistics for County Independent Variables of Demographic, Socio-Economic, Terrain, Political, Environmental Factors: 1990 Benchmark Group (1988-1999)

4.13 Descriptive Statistics for County Independent Variables of Governance, Government Form, Charter, and Regional Factors: 1990 Benchmark Group (1988-1999)

4.14 Descriptive Statistics for County Independent Variables of County Land Preservation Voter Referendum-Specific Factors: 1990 Benchmark Group (1988-1999)

4.15 Descriptive Statistics for County Dependent Variables: 2000 Benchmark Group (2000-2009) 160

4.16 Descriptive Statistics for County Independent Variables of Demographic, Socio-Economic, Terrain, Political, Environmental Factors: 2000 Benchmark Group (2000-2009) 161

4.17 Descriptive Statistics for County Independent Variables of Governance, Government Form, Charter, and Regional Factors: 2000 Benchmark Group (2000-2009) 161

4.18 Descriptive Statistics for County Independent Variables of County Land Preservation Voter Referendum-Specific Factors: 2000 Benchmark Group (2000-2009) 161

4.19 Estimating with Heckprob Probit Selection Model by All U.S. Counties and Passage Model of Land Preservation Voter Referendum Counties 167

5.1 List of Main Features of Three Case Counties 181 
5.2 List of Eleven Case County Land Preservation Voter

Referendums (1988-2009)

5.3 Broward County, FL: Historical Population and Change by Decade 186

5.4 Broward County, FL Business Patterns by NAICS Code ...................197

5.581 Florida Environmental Organizations ........................................199

5.6 Broward County, FL: Top 15 Special Interest Industries or Groups .....205

5.7 Change Indicators for USA, Florida and Three South Florida Case Counties 207

5.8 Broward County, FL Growth of Diversity: $1970-2000 \ldots \ldots \ldots \ldots \ldots \ldots \ldots \ldots . . .207$

5.9 Broward County, FL Population In/Out Migration …........................208

5.10 Miami-Dade County, FL Population Change: 1840 - 2010 ...............219

5.11 Home Rule Charter Counties in Florida ......................................229

5.12 Miami-Dade County, FL: Existing Land Uses ................................239

5.13 Palm Beach County, FL: Population Change by Decade ..................252

5.14 Household Income, Palm Beach County, FL: 2011 Estimates............259

5.15 Palm Beach County, FL Migrant and Seasonal Farmworkers (MSFW) Field Agriculture, Nursery Greenhouse and Food Processing 260

5.16 In-Case/Between Case Analysis of Three County Cases .....................266

5.17 Key Observations of the Quantitative Approach ...............................272

5.18 Key Observations of the Qualitative Case Studies ...........................273

5.19 Hypothesis Testing After Data Integration ..................................... 274 


\section{LIST OF FIGURES}

FIGURE

PAGE

1.1 Map of 50 U.S. States and County Entities. List of Number of Counties by State: $1990(3,043)$ and $2000(3,034)$

3.1 Diagram of Sequential Mixed Methodology .82

3.2 Analytical Framework for Sequential Mixed Methods Research Design 92

3.3 Analytical Framework for the Quantitative Approach ..........................93

3.4 Analytical Framework for the Qualitative Case Study Approach ..........113

4.1 Analytical Framework for the Quantitative Approach .......................132

5.1 Analytical Framework for the Qualitative Case Study Approach ..........178

5.2 Map of Southeast Florida Case Study:

Broward, Miami-Dade and Palm Beach Counties 180

5.3 Map of Three County Cases: Urbanized, Conservation and Rural/Agricultural Areas

5.4 Map of Broward County, FL Waterways …...................................187

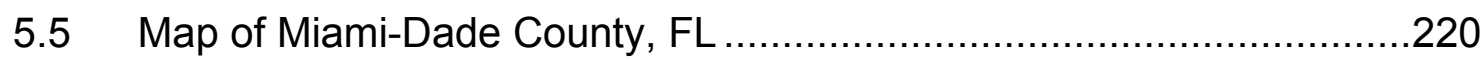

5.6 Map of Miami-Dade County, FL Urban Development Boundary (2006) 221

5.7 Map of Miami-Dade Urban Development Boundary 2006, 2015 and Proposed 2025 Urban Expansion Areas

5.8 Map of Palm Beach County, FL (Incorporated and Unincorporated Areas)

5.9 Map of Palm Beach County, FL (Wildlife and Conservation Areas) 253

5.10 Map of Palm Beach County, FL (Managed Growth Tier System,1999) 263 


\section{LIST OF ABBREVIATIONS AND ACRONYMS}

AENSTU

Audubon of Florida, Environmental Land Use Law Center, National Parks Conservation Association, Sierra Club, Tropical Audubon Society, and Urban Environment League of Greater Miami

APA

American Planning Association

ASPA

American Society of Public Administration

BBC

Building Better Communities

$\mathrm{BC}$

Broward County, FL

BOARD

Board of County Commissioners

CAC

Citizens Advisory Committee

CWI

Coalition for Wilderness Islands

DERM

Department of Environmental Management

CERP

Comprehensive Everglades Restoration Plan

EEL

Environmentally Endangered Lands Program

EIN

Employer Identification Number

EEL

Environmentally Endangered Lands

ERM

Environmental Resources Management

ESL

Environmentally Sensitive Lands

FAU

Florida Atlantic University

FLACo

Florida Association of Counties

FLDEP

Florida Department of Environmental Protection

FLOEDR

Florida Office of Economic and Demographic Research

FLUCS

Florida Land Use Classification System 


\begin{tabular}{|c|c|}
\hline FS & Florida Statutes \\
\hline GFOA & Government Finance Officers Association \\
\hline GMA & Florida Growth Management Act of 1985 \\
\hline GOB & General Obligation Bond \\
\hline IRS & Internal Revenue Service \\
\hline MDC & Miami-Dade County, FL \\
\hline NACo & National Association of Counties \\
\hline NAICS & North American Industry Classification System \\
\hline NCCS & National Center for Charitable Statistics \\
\hline NCSC & National Center for the Study of Counties \\
\hline NEPA & National Environmental Policy Act \\
\hline NGO & Non-Governmental Organization \\
\hline NOAA & National Oceanic and Atmospheric Administration \\
\hline NRRIPS & Natural Resources Research Information Pages \\
\hline NTEE & National Taxonomy of Exempt Entities \\
\hline PAC & Political Action Committee \\
\hline PBC & Palm Beach County, FL \\
\hline SFWMD & South Florida Water Management District \\
\hline TPL & The Trust for Public Land \\
\hline UMSA & Unincorporated Municipal Service Area \\
\hline UDB & Urban Development Boundary \\
\hline USCB & United States Census Bureau \\
\hline USEPA & United States Environmental Protection Agency \\
\hline
\end{tabular}




$\begin{array}{ll}\text { USFS } & \text { United State4s Forest Service } \\ \text { USSR } & \text { United States Soviet Republic } \\ \text { VAP } & \text { Voting Age Population } \\ \text { Vref } & \text { Voter Referendum } \\ \text { WRDA } & \text { Water Resource Development Act }\end{array}$




\section{CHAPTER I}

\section{INTRODUCTION}

\subsection{Introduction}

Land acquisition by state, county and other local area governments in America is a recent trend in the public's attempt to preserve the natural environment from threats of land development and overpopulation; loss of farmland, forests and other types of open spaces; deterioration of valuable ecosystems; diminishment of the quality of air, water and soil; and inadequate parks and recreation opportunities. The provision of local public goods has been a central focus of the urban political economy literature since Charles Tiebout's seminal work (1956). Despite the recent economic downturn, the trend of increased suburban sprawl that the United States experienced during the decades of the 1990 s and 2000 s is predicted to continue into the foreseeable future (Lang 2004; Lang and LeFurgy 2007; Knudson, 2011).

The voter referendum is one mechanism that sub-federal U.S. governments utilize as part of their jurisdictional decision-making process. In general, the voter referendum as a form of direct democracy has become an important component of the American system of representative democracy (Lupia and Matsusaka, 2004). With direct democracy, citizens play an unequivocal role in public policy-making (Lupia and Matsusaka, 2004). By casting their affirmative vote on a governmentally-selected ballot referendum to preserve land for open space, conservation, parks or other purposes, American 
registered voters determine the future land use policy of their state, county or other local area government.

County governments are organized local governments authorized in state constitutions and statutes. Counties and county-equivalents form the first-tier administrative division of the 50 American states. County governments in the United States have increasingly adopted greater autonomy and degree of selfgovernment as authorized or permitted by their state legislature. In many metropolitan and fast-growing areas (for example, in the South and Western regions), and in jurisdictions that have adopted more "modern" or "reformed" government structures and professional management practices, counties have begun to rival or overtake many municipal governments in the provision and implementation of a number of public services (Benton 2002b, 2003; Marando and Reeves, 1993).

Briffault (2000) contends that local direct democracy, problem solving, and rational land usage are best achieved through regionalism. Whereas some land use decisions do not have consequences beyond county or municipal governmental borders, an array of others do. Therefore, local, regional and state governance becomes important when considering land preservation and conservation programs that involve multiple governmental jurisdictions.

Over the past several decades, the idea of "regional government" has gained popularity in cities and towns across the United States. Regional governments are government entities that extend beyond city or town borders, but are different from county government. Regional governments are attractive 
because they allow jurisdictions to combine resources and spend tax dollars more efficiently. The most common regional government entities include: citycounty consolidations (e.g., Miami and Dade County, Florida), federations (e.g., regional coordinating councils), regional councils (e.g., multipurpose, multijurisdictional, public organizations created to respond to federal and state programs), city mergers (e.g., annexing neighboring municipalities), sale of services (e.g. local governments contract with larger cities and counties for basic services like police, water, sanitation, fire, etc.), and single-purpose entities (e.g., port authorities).

A mixed methodology is used to determine the significance and strength of county variables, governance factors, government structure, and environmental interest groups in relationship to the selection and passage of land preservation voter referendums ${ }^{1}$. Also, documents and expert witness interview data pertaining to three South Florida county cases are analyzed for the purposes of enriching the quantitative data analysis and investigating the influence of county-specific phenomena on the land preservation voter referendum process. Important theoretical and empirical contributions of this dissertation to the scholarly literature are its focus on the role of county government in the selection and passage of county land preservation voter referendums.

Chapter I begins by introducing the dissertation topic of U.S. county land preservation voter referendums and mixed methodology. Section 1.2 provides

\footnotetext{
${ }^{1}$ For this dissertation, referendums is used as the preferred plural form of referendum. Source: The American Heritage Dictionary.
} 
background information about land acquisition, voter referendum and county government. This leads into a presentation of the research objectives and significance of the study in sections of 1.3 and 1.4 respectively. Following a brief description of the research methodology in Section 1.5, the organization of this dissertation is outlined in Section 1.6.

\subsection{Research Background}

Public support of land preservation is an important component of livable communities (TPL, 2010). Increasing developer and market demands seek to convert open land to urbanized uses (Glickfeld, Jacques, Kieser, and Olson, 1995). Urbanized land $^{2}$ in the United States increased by $353.56 \%$ between 1950 and 2010. See Table 1.1. The rate of urbanization, i.e., the changing of land use from forest or agricultural uses to suburban and urban uses, is projected to continue to increase through 2050 (Nowak and Walton, 2005).

Table 1.1 Urbanization in the United States from 1945

\begin{tabular}{lrrrrrrrrr} 
& 1945 & 1950 & 1960 & 1970 & 1980 & 1990 & 2000 & 2010 & Change \\
\hline DEMOGRAPHICS & & & & & & & & & \\
Urban Land Area (square miles ${ }^{1}$ ) & 23,456 & 30,048 & 40,238 & 54,103 & 73,930 & 87,376 & 92,505 & 106,386 & $353.56 \%$ \\
Urban Population (in thousands) & 86,513 & 96,468 & 125,269 & 149,647 & 167,051 & 187,053 & 222,353 & 249,253 & $188.11 \%$ \\
Urban Households (estimated) & 23,736 & 27,881 & 36,884 & 46,668 & 59,828 & 69,152 & 83,340 & 96,237 & $305.45 \%$ \\
& & & & & & & & & \\
DENSITY (per square mile) & & & & & & & & & \\
Popuation Density & 3,688 & 3,211 & 3,113 & 2,766 & 2,260 & 2,141 & 2,404 & 2,343 & $-36.47 \%$ \\
Household Density & 1,012 & 928 & 917 & 863 & 809 & 791 & 901 & 905 & $-10.57 \%$ \\
& & & & & & & & & \\
PERCENT CHANGE (by decade) & & $28.10 \%$ & $33.90 \%$ & $34.50 \%$ & $36.60 \%$ & $18.20 \%$ & $5.90 \%$ & $15.00 \%$ & $353.56 \%$ \\
Urban Land Area & & $11.50 \%$ & $29.90 \%$ & $19.50 \%$ & $11.60 \%$ & $12.00 \%$ & $18.90 \%$ & $12.10 \%$ & $188.11 \%$ \\
Urban Population & $17.50 \%$ & $32.30 \%$ & $26.50 \%$ & $28.20 \%$ & $15.60 \%$ & $20.50 \%$ & $15.50 \%$ & $305.45 \%$ \\
Urban Households & $-13.00 \%$ & $-3.00 \%$ & $-11.20 \%$ & $-18.30 \%$ & $-5.30 \%$ & $12.30 \%$ & $-2.50 \%$ & $-36.47 \%$ \\
Population Density & $-8.30 \%$ & $-1.20 \%$ & $-5.90 \%$ & $-6.20 \%$ & $-2.20 \%$ & $13.80 \%$ & $0.40 \%$ & $-10.57 \%$ \\
Household Density & & & & & & &
\end{tabular}

${ }^{1}$ One square mile $=640$ acres.

Sources: US Census Bureau and Department of Agriculture Economic Research Service.

\footnotetext{
${ }^{2}$ Urban areas, as defined by the U.S. Census Bureau (2010), are densely developed residential, commercial and other nonresidential areas with 50,000 people or more.
} 
According to the 2010 U.S. Census, urban areas account for 80.7 percent of the U.S. population, which is a slightly faster pace than the 79.0 percent increase between 1990 and 2000. However, in 1940 only 48 percent of Americans were living in metropolitan areas (Hobbs and Stoops, 2002). The average population density of the U.S. is 87 people per square mile. The average population density of metropolitan areas (MSA) is 320 people per square mile; in New York, the population density is 8,159 people per square mile (U.S. Census Bureau, 2009).

The loss of open land contributes to traffic congestion, lack of affordable housing, urban sprawl, and vanishing ecosystems and imperiled species (Baldassare, 2001; Ewing, Kostyack, Chen, Stein and Ernst, 2005). On the other hand, open space and parks are found to provide health, economic, environmental, and social benefits for communities (Sherer, 2006). In response to the growth in population numbers and economic developments, many American communities, governments and citizens have shown a readiness to spend public funds to conserve remaining open space in America (Myers, 1999).

U.S. governmental awareness of environmental issues has been growing since the 1960s, when it became widely recognized that population activities were having harmful and large-scale effects on the environment. Earlier in the century (on August 25, 1916) President Woodrow Wilson created the National Park Service for the purpose of managing and preserving large tracts of the environment for future generations. The 1970 s marked the beginning of modern environmental policy making when President Nixon signed the 1970 National 
Environmental Policy Act (NEPA), followed by the Clean Air Act amendments of 1970 and the Federal Water Pollution Control Act amendments of 1972. More recently, federal environmental policy has moved toward long-term issues, like climate change and global warming. Furthermore, regional and local land preservation activities are being delegated to state and local area governments, land trusts, and private investment interests.

A basic principle of American federalism is taken from the Tenth Amendment (ratified in 1791) to the Constitution which states: "The powers not delegated to the United States by the Constitution, nor prohibited by it to the States, are reserved to the States respectively, or to the people. ${ }^{3}$ The strongest arguments in favor of federalism are found in the Federalist Papers (Madison, Hamilton, and Jay, 1787). Advocates of a devolution of power and authority to sub-national governments claim that they provide more effective policy outcomes because they are "closer to the people" (Kelleher and Yackee, 2004). In addition, various researchers have supported the strengthening of governance or intergovernmental relationships (Richardson, 2011; Kelleher and Yackee, 2004; Garman, Haggard and Willis, 2001; Conlan, 1998).

During most of the twentieth century the national government served as the prime mover of federalism. Beginning in the late 1970s, however, the states resurged as responsive, responsible, and progressive players in American federalism. Enabled by various "new federalism" initiatives and buoyed by reformed political and administrative institutions, the states became the leading

\footnotetext{
${ }^{3}$ United States Constitution, Bill of Rights, Amendment X (ratified December 15, 1791).
} 
policy innovators, displacing a highly contentious and occasionally impoverished national government. In terms of sub-state governmental jurisdictions, the reality of second order federalism is that legalistically local governments are "creatures of the state," subject to state statutory and constitutional grants of authority and discretion. Any powers of counties, municipalities, towns, townships, or other general-purpose local governments are not mentioned in the U.S. Constitution; these powers are to be granted expressly by the states through laws, charters, or broad home rule provisions. Some state legislatures have granted them to local governments in various degrees, resulting in extensive interstate variance in local discretionary powers of self-government

Although scholarly literature addresses first-order devolution, little is known about the consequences of second-order devolution (Wright and Cho, 2000). For example, Richardson's analysis (2011) concludes that Dillon's Rule and home rule are neither exclusive nor unsuitable measurements of local government autonomy because each signifies different concepts that preclude a direct comparison. As perhaps an over-simplification of these models, Dillon's Rule is more aligned with limited local government authority, while home rule provides the opportunity for broader powers of local self-government. When authorized or permitted by state legislatures, county governments in particular have increasingly adopted greater autonomy for determining local area policies and procedures. County governments are also adopting a local home rule charter, and implementing a more reformed government structure. A reformed government relates to the administrative and/or policy leadership role 
Figure $1.1 \quad$ Map of 50 U.S. States and Their Counties

Number of Counties by State and Decade: $1990(3,043) \& 2000(3,034)$

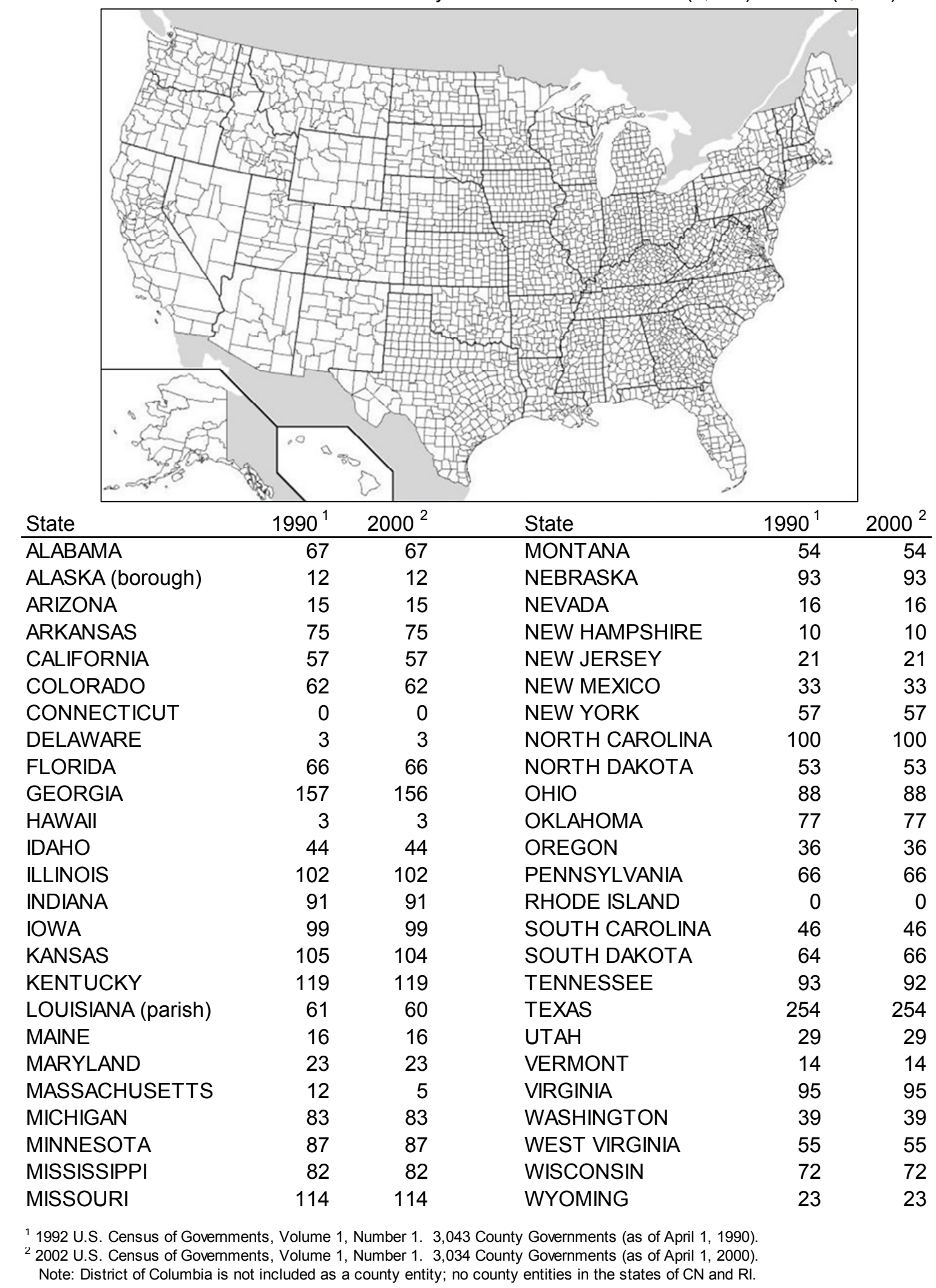


being vested in an elected chief executive or an appointed professional administrator or manager (Schneider and Park, 1989; Duncombe, 1977; DeGrove and Lawrence, 1977).

Figure 1.1 illustrates a map of the United States divided into 50 states and county boundaries within each state. Although Connecticut and Rhode Island afford county boundaries, these counties are not administratively functional. Also, some city-county mergers are treated as counties by the U.S. Census Bureau. Included is the number of counties by state and 1990 and 2000 U.S. Census.

In the past 30 years, county government scholarly research increased markedly and became more analytical and explanatory (Menzel et al., 1992; Cigler, 1994; Menzel, 1995; Benton, 2002a, 2005; Benton et al, 2007; Callahan, 2007). Today, American county governments have been rediscovered for both practical and scholarly investigation (Benton, 2005, 2007).

Government support for land preservation voter referendums increased at state, county and municipal levels during the 1980s to 2000s (Butler and Ranney, 1994; Banducci, 1998; Hug, 2004, TPL, 2010). Public support for the ballot measure process in general is documented through citizen satisfaction surveys (Hagen and Lascher, 1998; Citrin, 1996; Bowler and Donovan, 2002; Hibbits, 1999; Craig, Kreppel and Kane, 2001), and by increased voter turnout (Barber, 1984; Budge, 1996; Butler and Ranney, 1994). Moreover, the sources of these ballot box referendums are quite diverse; some result from popular support at the grass-roots level, while others are government-inspired as a land use planning tool and financial resource (Banzhaf, Oates, Sanchirico, 2008). 
The Trust for Public Land (TPL) is a national, nonprofit land conservation organization that promotes and assists governments in the protection of many types of land preservation issues. From 1988 through 2009, the TPL LandVote ${ }^{\circledR}$ database collected and maintained data for 2,252 land preservation voter referendums that appeared on state, county and other local area ballots in 45 of 50 American states. 1,699 (75.4 percent) of these ballot measures passed, representing citizen approval of nearly $\$ 124$ billion in future public spending for a wide variety of land preservation projects.

Table 1.2 U.S. Land Preservation Voter Referendums 1988-2009 State, County, Municipal and Special District

\begin{tabular}{lcrr}
\hline Year & $\begin{array}{c}\text { Measures } \\
\text { Selected }\end{array}$ & $\begin{array}{r}\text { Measures } \\
\text { Passed }\end{array}$ & $\begin{array}{r}\text { Total Funds } \\
\text { Approved }\end{array}$ \\
\hline 1988 & 26 & 24 & $1,951,633,862$ \\
1989 & 29 & 22 & $1,409,488,521$ \\
1990 & 42 & 25 & $2,376,796,066$ \\
1991 & 16 & 10 & $187,802,360$ \\
1992 & 36 & 26 & $2,038,626,000$ \\
1993 & 23 & 19 & $600,869,860$ \\
1994 & 51 & 33 & $1,044,541,125$ \\
1995 & 41 & 33 & $1,339,112,844$ \\
1996 & 99 & 71 & $5,371,324,178$ \\
1997 & 83 & 69 & $2,600,753,306$ \\
1998 & 174 & 142 & $7,114,354,744$ \\
1999 & 110 & 98 & $2,426,825,522$ \\
2000 & 207 & 168 & $11,230,270,431$ \\
2001 & 198 & 138 & $1,802,683,640$ \\
2002 & 184 & 136 & $8,573,159,162$ \\
2003 & 126 & 95 & $1,771,740,328$ \\
2004 & 215 & 161 & $26,032,263,413$ \\
2005 & 141 & 111 & $2,618,811,630$ \\
2006 & 183 & 136 & $29,082,431,422$ \\
2007 & 100 & 66 & $11,102,012,360$ \\
2008 & 128 & 91 & $1,059,164,056$ \\
2009 & 40 & 25 & $\$ 123,980,420,756$
\end{tabular}

Source: Trust for Public LandVote Database, 2012. 
Table 1.2 displays a list of all land preservation voter referendums, for all governmental jurisdictional types, as recorded in the TPL LandVote ${ }^{\circledR}$ database from 1988 through 2009. The majority of referendums passed by a considerable margin; the median received approximately 60 percent 'yes' votes. Most land preservation voter referendums require a majority approval for passage; however, the requirements of several referendums stipulate a supra-majority vote, and may either passed with this factor met or failed by a simple majority.

Focusing on county government participation, 456 land preservation referendums were selected by 227 counties in 34 states between 1988 and

Table 1.3 Land Preservation Voter Referendums by Year 1988-2009 U.S. County or County Entity

\begin{tabular}{|c|c|c|c|}
\hline Year & $\begin{array}{l}\text { Measures } \\
\text { Selected }\end{array}$ & $\begin{array}{l}\text { Measures } \\
\text { Pass }\end{array}$ & $\begin{array}{r}\text { Total Funds } \\
\text { Approved }\end{array}$ \\
\hline 1988 & 8 & 7 & $210,200,000$ \\
\hline 1989 & 14 & 11 & $972,314,220$ \\
\hline 1990 & 15 & 7 & $712,181,066$ \\
\hline 1991 & 7 & 3 & $115,245,000$ \\
\hline 1992 & 11 & 8 & $700,522,000$ \\
\hline 1993 & 6 & 5 & $212,123,200$ \\
\hline 1994 & 19 & 11 & $115,177,360$ \\
\hline 1995 & 6 & 6 & $314,700,000$ \\
\hline 1996 & 27 & 21 & $1,685,559,000$ \\
\hline $\begin{array}{l}1997 \\
1998\end{array}$ & $\begin{array}{l}21 \\
30\end{array}$ & $\begin{array}{l}15 \\
22\end{array}$ & $\begin{array}{l}2,021,753,470 \\
1,291,758,092\end{array}$ \\
\hline 1999 & 22 & 21 & $1,244,652,525$ \\
\hline 2000 & 50 & 30 & $2,667,381,940$ \\
\hline 2001 & 22 & 17 & $862,799,842$ \\
\hline 2002 & 31 & 29 & $783,787,292$ \\
\hline 2003 & 13 & 10 & $854,380,000$ \\
\hline 2004 & 49 & 38 & $24,231,392,881$ \\
\hline 2005 & 17 & 13 & $789,790,000$ \\
\hline 2006 & 38 & 30 & $14,352,594,820$ \\
\hline 2007 & 17 & 13 & $1,375,140,000$ \\
\hline 2008 & 28 & 19 & $1,341,609,230$ \\
\hline \multirow[t]{2}{*}{2009} & 5 & 4 & $499,000,000$ \\
\hline & 456 & 340 & $\$ 57,354,061,938$ \\
\hline
\end{tabular}

Source: Trust for Public LandVote Database, 2012. 
2009. Citizens voted 'yes' to pass 340 (74.8 percent) of these county referendums, approving more than $\$ 57$ billion in future public spending (TPL, 2012). Table 1.3 renders the number of land preservation voter referendums selected by county governments by year, the number of measures that passed, and the total funds approved by voters at the ballot box.

Table 1.4 Land Preservation Voter Referendums by State 1988-2009 U.S. County or County Entity

\begin{tabular}{|c|c|c|c|c|c|}
\hline & State & $\begin{array}{c}\text { Number of } \\
\text { Counties }\end{array}$ & $\begin{array}{c}\text { Measures } \\
\text { Selected }\end{array}$ & $\begin{array}{c}\text { Measures } \\
\text { Passed }\end{array}$ & $\begin{array}{r}\text { Total Funds } \\
\text { Approved } \\
\end{array}$ \\
\hline 1 & Alaska & 1 & 1 & 0 & \\
\hline 2 & Arizona & 3 & 5 & 4 & $\$ 340,050,000$ \\
\hline 3 & California & 12 & 22 & 12 & $\$ 32,559,400,000$ \\
\hline 4 & Colorado & 26 & 51 & 38 & $\$ 1,925,991,521$ \\
\hline 5 & Florida & 27 & 64 & 52 & $\$ 7,375,073,012$ \\
\hline 6 & Georgia & 14 & 23 & 17 & $\$ 2,728,774,008$ \\
\hline 7 & Hawaii & 4 & 4 & 4 & $\$ 177,434,820$ \\
\hline 8 & Idaho & 1 & 1 & 1 & $\$ 20,000,000$ \\
\hline 9 & Indiana & 11 & 2 & 1 & $\$ 3,500,000$ \\
\hline 10 & Illinois & 1 & 24 & 20 & $\$ 1,172,000,000$ \\
\hline 11 & Kansas & 1 & 1 & 1 & $\$ 6,000,000$ \\
\hline 12 & Kentucky & 1 & 1 & 0 & \\
\hline 13 & Louisiana & 2 & 2 & 1 & $\$ 135,000,000$ \\
\hline 14 & Massachusetts & 2 & 1 & 0 & \\
\hline 15 & Maryland & 1 & 13 & 13 & $\$ 111,610,000$ \\
\hline 16 & Michigan & 5 & 7 & 4 & $\$ 84,263,230$ \\
\hline 17 & Minnesota & 2 & 3 & 2 & $\$ 40,000,000$ \\
\hline 18 & Missouri & 4 & 6 & 6 & $\$ 544,700,000$ \\
\hline 19 & Montana & 6 & 9 & 6 & $\$ 50,000,000$ \\
\hline 20 & North Carolina & 2 & 26 & 18 & $\$ 890,005,000$ \\
\hline 21 & New Jersey & 21 & 44 & 41 & $\$ 3,722,502,720$ \\
\hline 22 & New Mexico & 2 & 8 & 8 & $\$ 84,446,000$ \\
\hline 23 & NevaDA & 3 & 4 & 1 & $\$ 38,300,000$ \\
\hline 24 & New York & 9 & 9 & 8 & $\$ 1,057,500,000$ \\
\hline 25 & Ohio & 17 & 35 & 18 & $\$ 914,070,645$ \\
\hline 26 & Oklahoma & 1 & 2 & 0 & $\$ 8,200,000$ \\
\hline 27 & Pennsylvania & 9 & 10 & 9 & $\$ 402,500,000$ \\
\hline 28 & South Carolina & 3 & 8 & 5 & $\$ 1,393,360,000$ \\
\hline 29 & Texas & 7 & 16 & 15 & $\$ 375,005,000$ \\
\hline 30 & Utah & 2 & 4 & 3 & $\$ 61,000,000$ \\
\hline 31 & Virginia & 10 & 27 & 23 & $\$ 843,783,200$ \\
\hline 32 & Washington & 12 & 18 & 6 & $\$ 251,140,000$ \\
\hline 33 & Wisconsin & 3 & 3 & 1 & $\$ 30,000,000$ \\
\hline \multirow[t]{2}{*}{34} & Wyoming & 2 & 2 & 2 & $\$ 8,453,782$ \\
\hline & Total & 227 & 456 & 340 & $\$ 57,354,062,938$ \\
\hline
\end{tabular}


Table 1.4 shows the number of county governments selecting a land preservation voter referendum by state, the number of measures selected (noting that some counties select multiple measures over time), measures passed, and total funds approved.

The degree of scholarly interest in county-level land preservation voter referendums is neither broad nor thorough. Szabo (2007) writes that the rise of open space ballot measures is one of the most important developments in land conservation during the past decade. Banzhaf et al. (2010) find that local area land preservation voter referendums are more likely to be held where they are more likely to succeed. This correlation appears to be driven by observable demographics and land use factors that include communities that are wealthier, more racially homogeneous, experienced population growth or losses in open space, low unemployment rates, highly educated, and environmentally concerned residents (Kline and Wichelns, 1994; Howell-Moroney, 2004; Kotchen and Powers, 2006; Nelson Uwasu and Polasky, 2006). Unobservable factors do not appear to contribute to this pattern, according to these researchers.

Kline (2006) examines county referendums that occurred between 1999 through 2004; his results suggest how key socio-economic trends motivate interest and support for preserving open space. Banzhaf et al. (2010) investigated both municipalities and counties from 1998-2006 with findings that essentially support previous research. Both scholars suggest that future study occur in minority and middleclass neighborhoods, in suburban fringe areas, and in the southeast. 
Scholars suggest that national and regional environmental organizations target promising communities for potential voter referendums by utilizing the same observable factors (Kline, 2006; Kotchen and Powers, 2006; Nelson Uwasu and Polasky, 2006). The "interest group" framework of local politics may provide an understanding of local area environmental policy. Interest group models predict that groups that are better able to deliver political resources to local elected officials are more likely to receive their preferred policies. The interest group model also provides a theoretical basis for "growth machines" ruled by political alliances between local government officials and land development interests (Molotch, 1976; Logan and Molotch, 1987).

Both pro-development and pro-environmental interest groups feature important differences in their geographic base of organization (Lubell, Feiock and Ramirez, 2005). This political science analysis portrays environmental interests as a diffuse, unorganized constituency that favors some general form of environmental protection. Some local environmental interests, for example, are unorganized citizens who worry about uncontrolled growth. However, many local environmental interests are what Clarke and Gaile (1989) call "territorial groups" with links to a specific geographical location. These groups are often main players in 'not-in-my-backyard' politics and include neighborhood organizations, homeowners associations, and citizen activists located within geographically defined constituencies. These geographic groups often dominate the politics of land use, when they resist locally unwanted land uses such as major roads, or 
lobby for improved environmental amenities like parks and recreation and conservation of environmentally sensitive lands.

\subsection{Research Objectives}

Based on the conceptual framework discussed in Chapter II, the research objectives of the dissertation are to gain a better understanding of the significant factors of state governance, county government form, interest group and various community characteristics that influence a county government to select a land preservation voter referendum, and encourage citizens to vote for passage of that referendum at the ballot box.

It is anticipated that the findings of this study, its conclusions and suggestions for further study, will provide fresh insights for researchers, county government policy makers and public administrators, land planners, and elected officials in relationship to the predictability of county government selection of land preservation and citizen passage with 'yes' votes of approval at the ballot box.

\subsection{Significance of the Study}

This research offers both academic and practical significance. First, this study examines the American direct democracy practice of the land preservation voter referendum from the perspectives of county government, governance, environmental interest groups, and community traits that researchers in the field have found to be relevant. Until recently, direct democracy scholarship has been descriptive or normative, by focusing mostly on process traits and deficiencies (Boyle, 1912; Lupia, 1994). Similarly, the land preservation voter 
referendum scholarly literature concentrates primarily on the observable characteristics of the community that inspire its citizens to vote for passage. Even though some community features are considered relevant, the study also investigates less observable attributes of state/county governance, county government structure, and influences of environmental and other interest groups.

A quandary facing many county governments has been the expectation of functioning as a full-service local government while providing an ever increasing array of costly local services without the legal authority, revenue-raising ability, and organizational capability to do so (Benton et al, 2007).

Second, the predictions of this research assign considerable relevance to the theory of federalism and second order devolution of authority and power from state to county governments. Scholarly research has not previously investigated the relationship between a county's degree of self-government and its government's decision to select a land preservation voter referendum as a local area land use tool (Kelleher and Yackee, 2004). The presence (or absence) of a county home rule charter is chosen as the determinant of a county's power and authority to self-govern.

Third, Benton (2003) discusses the important topic of altering the structure of local government. If the customary commission-only structure of county government (branded as the "traditional commission" form) is modified to a contemporary "reformed" or "modernized" government (e.g., commission structure plus an elected executive or appointed administrator/manager), researchers claim greater efficiency and effectiveness with home rule. 
Finally, the theory of interest groups, particularly those promoting environmental protection and land conservation, is built into the research. Multiple studies of land preservation voter referendum have alluded to the potential influence of environmental groups, but none have operationalized it with relevant interest group data.

\subsection{Overview of the Research Design}

The analytical framework of the research design is grounded in the conceptual foundations explained in detail in Chapter II.

This study employs a sequential mixed methodology that integrates a quantitative strategy designed to statistically analyze numbers, a multiple case study approach intended to complement and complete the study with complex characteristics of real-life situations, and the addition of public expert witness interview testimony with experiential narratives and real-life stories (Creswell and Clark, 2011; Yin, 1994). Chapter III explores the study methodology in detail.

First, data is collected for 227 U.S. counties with a history of 456 county land preservation voter referendum held between 1988 and 2009, and all nonreferendum counties. To improve the integrity of the relationship been the date of collected data and the date when the county land preservation voter referendum is placed before the voters, two benchmark groups of referendums are created and analyzed separately. These two groups correlate with the U.S. Census Bureau decennial benchmark years of 1990 and 2000, or closely correlated dates for data collection purposes. Vote referendums held in the group 
of years 1988-1999 represent the 1990 benchmark year, while voter referendums proposed in years 2000-2009 refer to the benchmark of 2000 .

The nature of the study is explanatory. The primary dependent variable is voter passage; the secondary dependent variable is county government adoption of the voter referendum model. Groups of independent variables are categorized as demographic, socio-economic, terrain, political preference, U.S. Census Bureau regional divisions, environmental public interest groups, governance by county home rule charter, reformed county government structure, and land preservation voter referendum-specific factors.

The Heckman two-step probit model is applied to estimate the regression in a situation where sample selection bias occurs (Heckman, 1979). The model adapts well to the two-stage voter referendum selection and passage process. Dependent and independent variables are fitted for estimation and analysis with this model to determine both strength and significance of factors. The quantitative methodology is discussed more fully in Chapter IV.

Second, for the study a qualitative case study approach is designed to expand and enhance the quantitative research. The county case selection criteria and methodology are specified in Chapter V. Several criteria are: (1) factor characteristics that fit the norms or standards of a most-different case selection process; (2) case county history of multiple land preservation voter referendums and voter passage; (3) case counties located in Florida with the most referendum counties (\#27); and (4) each case county presents with a distinctive phenomenon 
that merits research and analysis because of its relevancy to the selection and passage of county land preservation voter referendums.

The qualitative case study approach embraces an in-depth analysis of three South Florida case counties (Broward, Miami-Dade and Palm Beach Counties). Data collection involves case-specific documentation and transcripts of verbal data from twelve expert witness semi-structured interviews (four public administrators/managers per county case). Qualitative data is reduced through a process of sorting, coding, consolidation and weighting to several thematic contexts. Finally, in case and between case techniques provide quantitative data from the qualitative analysis.

Integration of quantitative and qualitative data is achieved through pattern matching techniques. Study findings are clarified, conclusions reached, and suggestions for future research presented in Chapter VI.

\subsection{Organization of the Dissertation}

The dissertation consists of six sections. Chapter 1 introduces a summary of the research background, objectives of the study, its significance to the field to public administration and public policy, and an overview of the study methodology. The outline of the conceptual framework of the dissertation is established in Chapter I.

Chapter II provides a literature review of relevant theoretical and empirical scholarly studies as to the conceptual foundation of the research. The theoretical constructs of this study are grounded in direct democracy, second order federalism and governance, reformed county government, nature and 
environmentalism, land preservation, and interest group theories. With direct democracy, county citizens directly participate in public policy-making, such as land use planning or environmental protection. Through second order federalism, state legislatures direct or authorize certain powers and authorities to county governments enabling them to select a land preservation voter referendum tool. The reformed government literature focuses on structural and functional reforms in county structure. Finally, interest group theoretical literature examines the relationships between citizen environmentalists and government policy-making.

Chapter III describes the methodology and research design of this sequential mixed methods study. Five research questions and five research hypotheses are discussed and stated. The analytical foundation of the study is presented. For the quantitative approach, the theoretical foundation of the Heckman two-step probit model is offered, together with a discussion of dependent and independent variables. For the subsequent qualitative approach, an overview of the county case selection, data collection, data transformation processes, and integration with the quantitative findings is presented.

Chapter IV explains the application and outcomes of the quantitative methodology of this study. The quantitative analytical foundation provides a schematic overview of how the dependent and independent variables are fitted to the Heckman two-step probit model for estimating the selection and passage equations and analyzing the significance and strength of factors.

Chapter $\mathrm{V}$ discusses the application and outcomes of the qualitative methodology of this study. The qualitative analytical foundation summarizes this 
approach and its complementary purpose for the study. The county case selection is most-different. Data collection comes from documentation and public expert witness interviews. The qualitative data is coded and reduced to several thematic contexts which are weighted and transformed into quantitative data for integration with the quantitative findings.

Chapter VI presents the final analysis of the integrated quantitative and qualitative approaches by reporting of the research findings, hypothesis testing, conclusions, limitations of the study, and recommendations for future scholarly research. 


\section{CHAPTER II}

\section{THEORETICAL FRAMEWORK AND LITERATURE REVIEW}

\subsection{Introduction}

Chapter II provides theoretical and empirical literature review of scholarly research and studies associated with the conceptual construct of this dissertation. The conceptual framework includes theories of direct democracy and citizenship; direct legislation and agenda setting; second order federalism and governance; reformed county government and bureaucracy; nature including land preservation, parks and recreation; and interest group with environmentalism.

Democratic theory begins with the justification of government by the people, usually in terms of the rights of individual citizens or the need to protect their interests effectively. It then proceeds to ask what government by the people and how, if at all, it can be implemented. Direct democracy is a broad term that utilizes a variety of forums (e.g., town meetings, recall elections, citizen initiatives, and government referendums) in which citizens directly participate in their community's public policy-making (Lupia and Matsusaka, 2004).

Federalism and governance theories relate to divided legislative power. Government and legislation are best divided between the federal state and its constituent states, departments or areas. Such division of power is normally regulated by a written constitution (e.g., U.S. Constitution, Amendment X), with a supreme or constitutional court to adjudicate in disputes between overall federal states and the separate component states (e.g., Dillon's Rule). Devolution in 
America refers the federal government's transfer of power and functions its 50 states (often without funding), or otherwise yields control over policy that has been federally controlled. Second order federalism (devolution), describes a grander decentralization process that grants a greater degree of authority for self-rule to sub-central units (e.g., U.S. counties, municipalities, and special districts).

The theory of reformed (or modernized) county government argues that county governments functioning with a home rule charter and led by an elected chief executive or appointed professional administrator are in a better position, both legally and administratively, to satisfy the service expectations of county residents (Benton, 2003). As an extension of Max Weber's theory of bureaucracy (Merton, 1957), public bureaucracy is characterized as a form of organization in government in which responsibility is vested in full-time public administrators whose livelihood is derived from their salaries and who are appointed on merit.

Finally, interest groups use various forms of advocacy to influence public policy and/or opinion; advocacy and lobbyists play an important part in the development of political and social systems. The pluralist theorist argues that interest group activity brings representation to all by competing in the political marketplace. Interest groups act as counterweights to each other, and therefore avert undue concentrations of power through veto power (Held, 1987).

\subsection{Direct Democracy and Citizenship}

The institutions of direct democracy - citizen initiative, recall, and voter referendum - have become an important component of American democracy 
(Lupia and Matsusaka, 2004). The majority of American state, county and city governments make available the initiative and referendum process. Nearly 70 percent of the U.S. population resides in communities where direct democracy is practiced (Matsusaka, 2004). Direct democracy is prospering outside the United States as well (Hug and Sciarini, 2000).

The concept of direct democracy originates from early Greece societies. One of the hallmarks of the ancient Greek civilization was the "polis", or citystate. However, the scale of the "polis" was small. In Politics, Aristotle (384-322 B.C.) discusses the origins of the "polis" suggesting that "it is necessary for the citizens to be of such a number that they knew each other's personal qualities and thus can elect their officials and judge their fellows in a court of law sensibly." Equally for Plato (c.427-347 B.C.), the criteria of the size of the "polis" was that all citizens know one another, and be intimately and directly involved.

In On Democracy in America, Alexis de Tocqueville (1835-40) describes the American democratic social state of equality. The Puritan colonialists arrived as equals in education and middle class, while contributing to a synthesis of religion and political liberty in America that was then uncommon in Europe. However, the Constitution of the United States (1787) created a representative democracy for America that is founded on the principle that citizen elects individuals to represent a group of people (e.g. administrative or legislative elected officials at the federal, state, and local levels of government. Thus, the concept of representative government places citizens in a position of being once removed from the public policy-making process of direct democracy. 
Robert Dahl (1956) observes that there is no single theory of democracy today, only a family of theories. Direct democracy is a broad term that comprises a variety of decision processes grounded in the American town meetings, citizen petitions for election recalls and initiatives, and various forms of the governmental referendums. Fundamentally, this family of democratic theories shares a vision of "good government" by equal and unrestricted citizenry who participates in their own governance in an environment of free speech, assembly, and conscience; in turn their elected public officials bear responsibility and accountability to their civilian voters (Terchek and Conte, 2001).

John Matsusaka (2005) suggests that his interpretation of direct democracy encompasses three notions: principal-agent problems, asymmetric information and issue bundling. Each of these ideas yields interesting insights concerning when direct democracy is likely to be helpful or harmful, and aids in interpreting the empirical evidence. First, and perhaps the best known result in a political economy, is the median voter theorem (Downs, 1957; Hotelling, 1929) when under certain situations, competition causes public policy to resort to the position of the median voter. Since ballot propositions are filtered through the registered voter, only policies that the median voter feels will make his/her better off can achieve approval in an election, or credibly challenge the legislature.

Second, a recurrent criticism of direct democracy is that ordinary voters lack the information and expertise to make sensible policy decisions. In turn, there are legislative situations where their judicious policy-making may require information that is not always known to them or their expert advisors. Direct 
democracy can be effective when the electorate is more informed than its legislature, as well as when voters have no more or even worse information than legislators (Matsusaka, 2005). If policy disagreements arise from different bundles of information rather than different underlying personal preferences, and if each citizen receives the appropriate information about the best course of action, aggregating the opinions of a million voters at the ballot box can be highly accurate by the law of large numbers even if each voter's chance of being right is small (McLennan, 1998; Lupia, 2001).

Voter competence is a common aspect of direct democracy research. In a larger empirical analysis, Bowler and Donovan (1998) conclude that while voters are not "fully informed" about most of the details of the initiative or referendum before them, many of these voters "appear able to figure out what they are for and against in ways that make sense in terms of their underlying values and interests. Failing that, others appear to use a strategy of voting "no" when information is lacking or when worries about general conditions of the proposal are greatest." Finally, Lupia and McCubbins (1998) assess conditions under which voters who use "information shortcuts" cast the same vote they would have cast if they were better informed.

Third, legislatures often bundle issues together, known as 'logrolling', into one omnibus bill (Matsusaka, 2005). Political candidates also bundle multiple public concerns, and voters must accept or reject the total package. One view is that the issue of bundling allows for an intensity of preferences to be considered, creating an efficiency model (Buchanan and Tullock, 1962). Another view is that 
the issue of bundling is inefficient because it leads to excessive spending and dispersion of costs over multiple voting districts (Buchanan and Tullock, 1962). However, when a political candidate or voter referendum focuses on only one or a few issues, it gives the citizenry a chance to cast their vote on a specific, uncomplicated proposition.

To measure the impact of direct democracy on policy, Matsusaka (2005) posits that it is not enough to study only the referendum propositions that are approved by the voters. Measuring the impact of direct democracy requires tracing the effect back to the availability (e.g., selection by a government entity) of the referendum. The usual approach is to compare the policies of a group of similar or dissimilar governmental jurisdictions that have experienced direct democracy with those that have not, controlling for other factors that may have driven policy, and attribute the dissimilarities to the availability of direct democracy.

The most obvious difference between direct democracy and more traditional legislative processes (i.e., representative democracy), is the direct participation of voters (Lupia and Matsusaka, 2004). Until recently, direct democracy scholarship has been descriptive or normative, while focusing on process deficiencies (Boyle, 1912; Lupia, 1994). Also, some researchers have increasingly sought to examine direct democracy from a more scientific perspective. Gerber and Phillips (2005) find that public policy measures adopted though the ballot box are significantly more stringent than those adopted by 
municipal legislatures. In addition, these researchers report that citizen initiative voter measures are both more restrictive and more difficult to amend.

Direct democracy scholars argue that with citizen participation in governance, there is a favorable impact on voter turnout at the polls (Barber, 1984; Cronin, 1984; Budge, 1996; Butler and Ranney, 1994). Elite and mass opinions concerning the rise of direct democracy, however, are mixed. American and European surveys consistently reveal a strong citizen support for direct democracy (Hagen and Lascher, 1998; Citrin, 1996; Bowler and Donovan, 2002; Hibbits, 1999; Craig, Kreppel and Kane, 2001), while surveys of journalists and the political elite are skeptical (Lupia and Matsusakal, 2004).

\subsection{Direct Legislation and Agenda Setting}

Scholarly literature reflects a sizable consensus that American forms of direct legislation (through the initiative and referendum process) affect policy outcomes (Tsebelis, 2000; Hug and Tsebelis, 2002; Hug, 2011). However, Cronin (1989) and several others argue that policies do not differ between governmental entities that permit direct democracy. As early as the writings of Key and Crouch (1939), the policy effects of direct legislation are of two different types (Hug, 2011).

First, the legislative policy outcomes themselves may be direct, as though policies were adopted by voters, but which would have failed in the normal legislative process. Second, governments permitting direct democracy may experience indirect effects when their legislatures adopt policies which it would not have adopted without the existence of voter policy-making options. 
Occasionally these indirect effects surface when interest groups pressure to influence legislatures with their own agendas, attempting to achieve them through their form of direct legislation (Matsusaka, 2000).

The theoretical literature addresses both indirect and direct effects as consequences of direct lawmaking (Steunenberg, 1992; Gerber, 1996, 1999; Moser, 1996; Besley and Coate, 2001; Matsusaka and McCarty, 2001; Hug and Tsebelis, 2002; and Hug, 2004). Two other important components occur from these theoretical models (Hug, 2011). First, there is the difficulty of differentiating between direct and indirect effects because the two create an interaction between themselves. Second, these theoretical models reveal that the policy effect of lawmaking, either direct or indirect, is dependent on the preferences of both voters and their governmental legislature. Because the majority of these studies comprise interest groups, or an opposition, it triggers direct legislation which makes their preferences empirically less important (Hug, 2011).

Beginning with Romer and Rosenthal's $(1978,1979)$ pivotal research, scholars have recognized the importance of agenda setting in direct democracy. Agenda setting theory describes the ability of mass communication systems to influence the salience of topics on the public agenda. As more scholars published articles on agenda setting theories, their findings indicate that the process involves not only the active role of media organizations, but also the participation of the public (Erbring, Goldenberg, Miller, 1980; Lang and Lang, 1981) as well as policymakers (Berkowitz, 1992). 
Rogers and Dearing (1988) argue that mass communication research has focused mostly on public agenda setting (McCombs and Shaw, 1972) and media agenda setting, but has largely ignored policy agenda setting. These authors suggest that scholars pay more attention to how the media and public agendas might influence elite policy makers' agendas. Writing in 2006, Walgrave and Van Aelst took up Rogers and Dearing's suggestions, creating a preliminary theory of political agenda setting, which examines factors that might influence the agendas of policy makers (Walgrave and Van Aelst, 2006).

Rogers and Dearing (1988) describe the difference between agenda setting and agenda building based on the dominant role of the media or the public. Thus "setting" an agenda means the effect of the media agenda on the community and the transfer of the media agenda to the public agenda. The "building" of an agenda includes "some degree of reciprocity" between the public's mass communication systems and the community where both the media and public agendas influence public policy.

Berkowitz (1992) has implemented a finer distinction analysis of agenda setting and agenda building theories by introducing the terms of policy agenda setting and policy agenda building. He argues than when researchers investigate only the connections between media and policymakers, it is still appropriate to use the idea of policy agenda setting. However, when the focus is placed on both policymakers' personal agendas (citizen and/or legislative) and the broader relevant public issues, the media represents only one indicator of public's attitudes and opinions. 
Recent non-political scholarship has been studying agenda setting in the context of 'branding'. A brand is defined as what resides in the minds of individuals about an idea, process, product or service. A brand community is described as a "specialized, non-geographically bound community based on a structured set of social relations among admirers of a brand" (Ragas and Roberts, 2009). Also, the theory has been applied to business influences on federal policy, public and private sector products and services, roles of social groups, public opinion, and more (Berger, 2001).

The literature on the use of public initiatives offers a well-developed understanding of who uses the process, what is their agenda, and under what conditions (Danmore, Bowler, Nicholson, 2012). By comparison, the study of voter referendums used by state, county and municipal legislatures falls significantly behind the investigation of citizen initiatives. There is little scholarship examining how the referendum is used in practice and for what purposes. This lack of research is surprising since referendums appear on the voter ballot twice as often as initiatives (Magleby 1984).

Because the voter referendum originates within the state, county or municipal legislature, one would expect that the preferences of legislators, as opposed to other actors such as interest groups, would be preeminent. But organized interests may have goals (i.e., mobilization, networking, membership growth, etc.) besides policy change for helping to qualifying an initiative or referendum. With referendums, legislatures must also considered factors affecting the likelihood of voter passage. 
The small literature on voter referendum usage suggests that government decision-makers (e.g., board of county commissioners) may have political motivations for using them. Gazey (1971) argues that legislators will use the referendum to "pass the buck" to the electorate on tax increases to avoid politically difficult decisions. This finding is similar to Romer and Rosenthal's (1979) model of agenda setting where politicians use the referendum for budget maximization. However, if referendum use is driven by a mix of policy goals and political motivations, legislators should be constrained in their ability to use the process. Qualifying a legislative referendum proposal is no guarantee that the proposal will be approved by voters at the ballot box.

There exists some scholarly research (King 2000; Squire 1992; 2007) focused on distinguishing between amateur and professional legislatures, and the consequences that professionalism has for representation, turnover, and decision making. The proliferation of term limits has further complicated these dynamics (Kousser 2005; Moncrief, Niemi, and Powell 2004). Holding other factors constant, the skills needed to successfully package referendum proposals may be less prevalent in amateur or term-limited legislatures, and as a consequence, these legislatures may produce fewer referendums that gain the support of the electorate (Danmore, Bowler, Nicholson, 2012).

Agenda power over the timing of a voter referendum may be particularly influential in the local political setting because of the importance of election synchronization in affecting voter turnout. The largest determinant of local election voter participation is the concurrency of a local election with an election 
for a state or federal office (Hajnal and Lewis, 2003; Woods, 2002). Furthermore, differences in turnout tendency in both stand-alone and simultaneous local elections are understood to be related to outcome preferences (Meredith, 2008).

\subsection{State Federalism and Governance}

Federalism is a way of organizing a nation so that two or more levels of government have formal authority over the same area and people. The relationships among federal, state, and local governments may be complex and overlapping, but federalism is at the heart of critical fights over the nature and scope of public policy in the United States. The federal system not only decentralizes our politics; it also decentralizes our policies. The history of the federal system demonstrates the tensions that exist between the states and the national government about who controls policy and what it should be. Because of the overlapping powers of the two levels of government, most of our public policy debates are also debates about federalism.

The U.S. Constitution does not refer directly to federalism. However, the framers carefully defined the powers of state and national governments. The framers also dealt with a question that still evokes debate: which level of government should prevail in a dispute between the states and the national government? Advocates of strong national powers generally emphasize the supremacy clause. In Article VI (the "supremacy clause"), three items are listed as the supreme law of the land: the Constitution; laws of the national government (when consistent with the Constitution); and treaties. However, the national government can only operate within its appropriate sphere and cannot usurp 
powers of the states. By contrast, advocates of states' rights believe that the Tenth Amendment means that the national government has only those powers specifically assigned by the Constitution.

Federalism was instituted largely to enhance democracy in America, and it strengthens democratic government in many ways. Different levels of government provide more opportunities for participation in politics and increase access to government. Since different citizens and interest groups will have access to the different levels, federalism also increases the opportunities for government to be responsive to demands for policies. Moreover, it is possible for the diversity of opinion within the country to be reflected in different public policies among the states. Different economic interests are concentrated in different states, and the federal system ensures that each state can establish a power base to promote its interests. By handling most disputes over policy at the state and local level, federalism also reduces decision making and conflict at the national level.

Conversely, diverse state policies and the large number of local governments also create some impediments to democracy. Since the states differ in the resources they devote to services like public education, the quality of such services varies greatly from one state to another. Diversity in policy can also discourage states from providing services that would otherwise be available, for example, states are deterred from providing generous benefits to those in need when these benefits attract poor people from other states with lower benefits. Federalism may have a negative effect on democracy when local 
interests are able to thwart national majority support of certain policies. Having so many different governments (federal, state and local area) and different levels of federalism make it difficult for many American citizens to know which government is responsible for certain functions.

While the national government has grown in scope relative to state governments, it has not done so at the expense of state governments. The latter continue to carry out all the functions they have typically done. The national government has instead grown as it has taken on new responsibilities viewed as important by the public.

The concept of intergovernmental relations, or governance, refers to the entire set of interactions among national, state, and local governments in a federal system. The American federal system decentralizes our politics. For example, senators are elected as representatives of individual states and not of the nation. Moreover, with more layers of government, more opportunities exist for political participation; there are more points of access in government and more opportunities for interests to be heard and to have their demands for public policies satisfied.

\subsubsection{Second Order Federalism: State Legislature to Local Jurisdictions}

Local government autonomy refers to "the power to regulate private activities in order to protect the public health, safety and morals" (Gray and Eisinger, 1997). McManmon, Bell and Brunori (2010) define local autonomy as a "multi-dimensional concept in which local government units have an important role to play in the economy and the intergovernmental system, have discretion in 
determining what they will do without undue constraint from higher levels of government, and have the means or capacity to do so". Although many research studies have attempted to operationalize and measure local government autonomy, no true consensus exists about how to identify or measure this concept (Richardson, 2011).

In the United States, local jurisdictions (counties, municipalities and other) reside in a precarious position within the intergovernmental system described as "at the bottom of the fiscal food chain" (Pagano and Johnston, 2000). Local governmental jurisdictions are dependent on their state governments for adequate power and discretion to function effectively and efficiently (Bowman and Kearney, 2012).

Little is known of the consequences of second-order devolution in the United States, from states to counties and/or other local governing jurisdictions, which may or may not mimic the consequences of first-order devolution. A greater understanding of second-order devolution could provide fundamental understandings into the theoretical questions of federalism, such as the consequences of shifting of power and responsibility for policy development, and implementation to sub-state officials and public administrators across multiple areas of local governments (Wright and Cho, 2000).

Scholarly discussions regarding devolution have centered on concerns of effectiveness and equality in policy outcomes. Advocates of devolution usually claim that sub-national levels of government provide more effective policy outcomes because they are more closely tied to their respective constituencies, 
that is "closer to the people" (Kelleher and Yackee, 2004). Others suggest that devolution should be pursued because it allows for policy experimentation and innovation (Osbourne, 1988). Further arguments in support of devolution include: local-level bureaucracies are more responsive to citizen preferences than centralized bureaucracies, devolved authority promotes political participation, and sub-national control enhances policymaking legitimacy (Eggers and O'Leary, 1995; Kincaid, 1998, 2001; Landy and Teles, 2001; Murray, 1984).

Those opposed to devolution often base their arguments on questions of equality. They believe that although devolved authority may be more effective, poorer states and local areas are placed at a severe disadvantage. Therefore, devolution may intensify inequalities among jurisdictions because some local areas are ill equipped and lack the personnel and policy-making capacities which are essential to address their new authority (Kenyon and Kincaid, 1991). Some scholars even forecast that devolution may result in a "race to the bottom" because there is little incentive for local areas to offer the best services while encouraging more individuals to reap those public benefits (Landy and Teles, 2001; Peterson, 1981, 1996; Peterson and Rom, 1989, 1990).

Many other scholars have also examined the circumstances surrounding the initial devolution of policy-making power by the authorizing government. This scholarship mostly targets the national government's role in devolving power to the state. For example, Conlan (1998) offers an historical account of devolution over the past 25 years. Walker (2000) focuses on the pressures placed on the government to both centralize and devolve policy-making authority. Others study 
the comparative politics perspective that frames the initial act of devolution as a strategic one driven by the short and/or long term motivations of the political party in control (Garman, Haggard and Willis, 2001; Sawyer, 1969).

Kelleher and Yackee (2004) argue that a complete understanding of the policymaking process requires a focus on the policy impacts of devolution at the subnational level. A few scholars have assessed the consequences of policy decentralization. Francis (1999) looked at how the actions of state officials have impacted public policy after the 1996 U.S. welfare legislation. Nathan and Gais (1998) highlight the difficulties of information systems and management associated with devolved welfare policies. Multiple researchers studied the political consequences of devolving federal responsibilities to the states (Kincaid, 1998; Tannenwald, 1998; Hedge and Scicchitano, 1992).

\subsubsection{State Grant of Local Government Autonomy}

Wolman, McManmon, Bell and Brunori (2010) describe a conceptual definition of "local government autonomy" across U.S. states based upon several dimensions and sub-dimensions which they believe are fundamental to the concept. In addition, these researchers identify variables to operationalize those dimensions and utilize factor analysis to combine their variables into underlying component factors. The outcome of this research is a Local Government Autonomy Index that ranks American state local area governments (e.g., counties, cities, and other local areas) from most state- dependent to most selfgoverning. 
The Wolman et al. overall local autonomy ranking by 50 American States consolidates the seven equally weighted dimensions of the index (Wolman et al, 2010). These researchers explain local area autonomy in terms of three primary local area dimensions: (1) importance, (2) discretion, and (3) capacity. To capture the meaning of the dimensions, three or more appropriate variables for each dimension are used to perform a factor analysis. The retained factors are then converted into continuous variables, a factor score is calculated for each unit (state system of local government), and the states are ranked.

Factor scores and autonomy rankings of states are established for the following seven dimensions: (1) local government outputs, revenue, and expenditure in the state and intergovernmental system; (2) importance of local public employment in the state and intergovernmental system; (3) local government structure and functional responsibility, and legal scope; (4) tax, spending, and debt limits; (5) assessment limits; (6) unconstrained local revenue; and (7) diversity of local revenue sources. High scores indicate more autonomy based on the operationalization of the variables within the dimension.

Many scholarly efforts to define local government autonomy from state dependence apply Dillon's Rule and home rule as basic barometers (Weeks and Hardy, 1984; Krane, Rigos and Hill, 2001; Geon and Turnbull, 2004). Other commentators reject the application of the Dillon's Rule and home rule classifications as reliable measurements because each emphasizes disparate factors (Richardson, Gough and Puentes, 2003; Bluestein, 2006). 


\subsubsection{State Exercise of Dillon's Rule.}

Judge John F. Dillon first set out this rule that would later bear his name in Clark v. City of Des Moines [1865] (Richardson, Gough and Puentes, 2003). Dillon's Rule is a rule of statutory construction. Courts use rules of statutory construction in interpreting all types of legislation, but Dillon's Rule specifically applies to grants of authority from state legislatures to local governments. When states delegate authority to local governments, courts are often called in to rule upon the latitude of the powers granted. If the legislation is explicit, the court may rely on the clear language of the statute. When the legislative grant may be interpreted in several ways, however, courts must attempt to determine the legislative intent (Richardson, 2011).

A statute is "a command issued by a superior body (the legislature) to a subordinate body (the judiciary)" (Posner, 1990). A court must interpret statutes so as to follow this legislative command (Mikva and Lane, 1997). Therefore,

Dillon's Rule relates to the separation of powers. A court must not impose its own interpretation on a statute, but defer to the state legislature.

Rules of statutory construction are "judicially crafted maxims for determining the meaning of statutes" (Mikva and Lane, 1997). These rules have also been described as "guidelines for evaluating linguistic or syntactic meaning" (Eskridge, Frickey and Garrett, 2006). These rules are not mandatory, but provide guidelines to assist the courts in establishing legislative objective (Chickasaw Nation v. U.S., 2001). There may be times when other evidence of legislative intent may override a rule of statutory construction. These rules serve 
to hinder the court from imposing the personal opinions of the judge by formalizing the process by which legislative intent is determined (Mica and Lane, 1997).

The Supreme Court of each state makes the final determination of which rules of statutory construction will be adopted in each state's court systems. Different states may approve different rules. The United States Supreme Court makes the final determination on the rules of statutory construction that apply in the federal courts. However, the state legislatures and Congress may essentially override the respective court systems by specifying rules of statutory construction legislatively. These statutes may determine general rules of statutory construction or instruct the courts with respect to interpreting a single or category of grant(s) of authority (Richardson, 2011)

In effect, Dillon's Rule merely reflects the settled legal principles derived, in part, from the Tenth Amendment of the United States Constitution (Richardson, Gough and Puentes, 2003). Local governments exist only as organisms, delegates, and agents of the state, and states exercise complete dominion over local governments. However, courts can still determine how to interpret delegation of authority from a state to its local government(s) (Richardson, 2011).

\subsubsection{State Authorization of Home Rule}

Popular belief equates home rule with expansive local area government autonomy. However, to view the home rule movement as seeking enlargement of local control ignores the more nuanced reality (Barron, 2003). The idea of 
state supremacy over local area governments engendered no controversy until around the mid-1800's (Grumm and Murphy, 1974). During that time, cities grew at a rapid rate, as did changes in society. State legislatures began to pass laws controlling local affairs.

Home rule advocates opposed the "creature of the state" characterization of local governments and sought local control over matters of local concern (Richardson, 2011). However, instead of expanding the scope of local government control, home rule sought to prevent state legislatures from delegating authority to local governments, often through special legislation, that reformers felt exceed the scope of what ought to lie within the realm of local government control (Krane, Rigos and Hill, 2001; Barron 2003, 2277-2322).

Approximately the same time as Judge Dillon was articulating the rationale behind his Dillon's Rule, a directly opposing view was solidifying among some jurists and in some states. In his concurring opinion for People v. Hurlburt (1871), Judge Thomas M. Cooley of Michigan Supreme Court outlined what would become known as the Cooley Doctrine. The Cooley Doctrine relies on the principle that local governments hold the inherent right of self-governance (Gere, 1982). While Cooley acknowledged the prevailing view that local governments were mere "creatures of the state," he maintained that limits on state authority existed as a matter of law and principle (Richardson, 2011).

Indiana, lowa, Kentucky, and Texas adhered to the Cooley Doctrine at various times (ACIR 1981). However, once the United States Supreme Court 
upheld Dillon's Rule in Atkins v. Kansas (1903), the Cooley Doctrine disappeared from prominence, at least in the United States court systems.

Home rule refers to a state constitutional provision or legislative action that provides a local area government with a greater measure of self-government ability (Black 1990). Used in this way, home rule encompasses two components: (1) the power of local area governments to manage "local" affairs, and (2) the ability of local area government to avoid interference from the state (Timmons, Grant, Popp and Westby, 1993). In effect, this definition of home rule narrows the divide between state government authoritarianism and its grant of select powers and autonomy to local area governments.

Theorists have classified types of home rule in at least four different ways (Richardson, Gough and Puentes, 2003). The first uses the system that the grant operates, or operational categorization. Operational home rule may occur in two different ways. First, the state may grant authority to local governments to act in certain areas with legislative authority. Second, the state may be limited in its ability to regulate certain local government affairs (Welch, 1999).

Structural categorization classifies home rule according to the structure of the delegation (Mead, 1997; Krane, Rigos and Hill, 2001). One type of structural home rule attempts to carve out an area of exclusively local concerns where local governments have the exclusive right to regulate. The second merely transposes Dillon's Rule, as described above (Richardson, Gough and Puentes, 2003).

Some scholars classify home rule based on the source of the authority (Welch, 1999). If the source is found in the state constitution, then the doctrine is 
referred to as constitutional home rule. Legislative home rule derives from a grant by the state legislature to local area governments (Richardson, Gough and Puentes, 2003). Finally, Richardson Gough and Puentes (2003) set forth a fourth classification method. Under this classification system, legislative or constitutional provisions are categorized based upon whether the provision grants powers to local governments or sets the rule of statutory interpretation for judicial review of state grants of authority to local governments (Richardson, Gough and Puentes, 2003).

Regardless of the classification system, no category of home rule equates with total autonomy for local area governments from state oversight (Richardson, Gough and Puentes, 2003). And only the rule of statutory construction that assumes that local governments hold the authority to act unless denied by the state legislature, can objectively be compared to Dillon's Rule. Similar to the courts' Dillon's Rule, this one classification of home rule affects local government autonomy indirectly.

Krane, Rigos and Hill (2001) define the "ideal" of home rule as "the ability of a local government to act and make policy in all areas that have not been designated to be of statewide interest through general law, state constitutional provisions, or initiatives and referenda". This definition of home rule attempts to delineate areas of purely local concern that should be the sole domain of the local government. Only when local decisions impact other communities or the state should local decision-making be constrained (Krane, Rigos and Hill 2003). The carving out of certain policy decisions as "purely local" and others as 
implicating "statewide interest" is problematic in practice for both state and local area governments.

Geon and Turnbull (2004) studied a sampling of county jurisdictions in each of 38 American states to determine the strength of the states' home rule or non-home rule categorization. Drawing from the insights provided by various studies, Geon and Turnbull developed four categories of home rule authority based upon how narrowly each state restricts the range of policies and functions devolved to county governments. State categorization was guided by the state constitutional, legislative, and institutional characteristics reported in Krane et al. (2001). The four categories are: strong non-home rule, weak non-home rule, weak home rule, and strong home rule. Strong non-home rule infers the state retains the majority of the power and authority over its local area governments, while strong home rule indicates a respectable degree of devolution of power and authority to local area governments.

The many meanings of home rule are cause for some scholarly and practitioner concern. The Chicago Home Rule Commission (1954) opined that "[t]here is perhaps no term in the literature of political science or law that is more susceptible to misconception and variety of meaning than 'home rule"'. In addition, "the term 'home rule' has acquired an almost talismanic aura over the years and often, inaccurately, connotes almost total freedom of local government from state control" (Richardson, Gough and Puentes, 2003). In practice, however, home rule rarely provides substantial autonomy and freedom from state interference (Bluestein, 2006, 2003). 


\subsubsection{Public Sector Governance}

Public sector governance, or the act of governing, is called "regimes of law, rules, judicial decisions, and administrative practices that constrain, prescribe, and enable the provision of publicly supported goods and services" between informal and formal relationships with representatives in both the public and private sectors (Lynn, Heinrich and Hill, 2000, 2001).

The literature regarding the movement toward governance as a reformed concept for public management/administration is united with a perceived shift from the bureaucratic state and direct government to a hollow state and "thirdparty government" (Frederickson, 1997; Milward and Provan, 1993; Salamon, 1981). Frederick and Smith (2003) contend, "The administrative state is now less bureaucratic, less hierarchical, and less reliant on central government authority. Accountability for conducting the public's business is increasingly about performance rather than discharging a specific policy goal within the confines of the law."

Many scholars in the field of public administration support the concept of governance as a framework for the ongoing discussion of public management reform (Garvey, 1997; Kettl, 2000, 2002; Peter and Pierre, 1998; Salamon, 2002). Governance, as a structuring concept for governmental reform, describes a growing but not universal, conviction that the focus of public administration practice is moving from hierarchical government toward a greater reliance on hybridized and associational types of government (Hill and Lynn, 2005). Kettl 
(2002) and Salamon (2002) find this to be true in recent analyses of "new public management".

To distinguish the term governance from government, governance is what a government structure does to provide public services. Public governance is an outcome of a dynamic process that Lynn, Heinrich and Hill $(2000,2001)$ define as "core logic". This process connects different levels of collective action in terms of hierarchical interactions (Lynn, Heinrich and Hill, 2000, 2001). These scholars describe exchanges between: (1) public interests and public choice; (2) public choice and government structures; (3) structures and governance (discretionary public management/administration); (4) governance and core/primary work; (5) primary work and governance outputs/performance; (6) performance and stakeholder assessments; and (7) stakeholder assessments and public interests.

An example of participation and collective action with governments and governance is the $20^{\text {th }}$ century growth and influence of environmentalism. The idea of citizen participation mainly builds on the theories and practices of democracy, which is particularly the case in Western democracies (Fiorinao, 1990; Laird, 1993). Environmental issues typically involve multiple interests with regard to political, societal, economic and public interests. Stakeholder and public participation is a central topic in contemporary conservation, environmental and environmental health policy and assessment (Pohjola and Tuomisto, 2011). 


\subsection{Reformed County Government}

Marando and Thomas (1977), writing 30 years ago, referred to county governments in the title of their book as the Forgotten Governments. Schneider and Park (1989) continued to refer to county governments as the "still forgotten governments". Historically, counties were important providers of traditional services like welfare, health and hospitals, roads and highways, police, corrections, legal and judicial systems, and tax assessment and collections (Benton, 2002).

County governments were never intended to be or equipped with sufficient authority to serve as a full-service local government as are municipalities. They were envisioned to be, and were established, as political or administrative sub-

divisions of their state government (Benton, 2003). In that capacity, county government was to ensure that a variety of principally state functions (i.e., health care and hospitals, public welfare, law enforcement, highways and bridges, courts and corrections, agricultural assistance, conservation of natural resources, tax assessment and administration, and so forth) were available at the local level.

However, as the population of counties increased during the early 20th century, citizen expectations of counties changed markedly regardless of their legal status. Citizens expected county government to be more responsive to their service needs, similar to municipalities (Benton, 2002a; Duncombe, 1977; Benton, 2005). New areas of county service include fire protection, utilities, libraries, planning and zoning, and protective inspections. The other sector is in regional or urban-type services - sanitation, sewage and solid waste disposal, 
parks and recreation, natural resource conservation, mass transit and parking, housing and urban development, and airports.

In many metropolitan and fast-growing areas (for instance the American South and West) and in jurisdictions that have adopted more modern, reformed governance structures and professional management practices, counties have begun to rival, or overtake, many municipalities in the provision and implementation of regional public services (Benton 2002b, 2003). The quandary facing many county governments has been the expectation of functioning as a full-service local government by providing an ever increasing array of costly local services, but without the legal authority, revenue-raising ability, and organizational capability to do so (Benton et al, 2007).

Traditional or "unreformed" forms or structure of county government have been regarded as less capable of responding to the challenges of metropolitan growth and service deliver than have "reformed" or "modernized" county governments (Duncombe, 1977; DeGrove and Lawrence, 1977).

Altering the structure of local government is an important topic for researchers in the fields of local government, politicians, public administrators, governance groups, and the media (Benton, 2003). In particular, scholarly examinations of local government structural reform are a foundation of county and urban literature (Marando and Reeves, 1993). Two primary topical issues have emerged and are linked. First, should the present structure of local government (branded a "traditional commission" form) be maintained or changed 
(typically labeled as "reformed" or "modernized" government)? Second, what will be the likely consequences of each decision (Benton, 2003)?

Scholars argue that county governments that have been granted a charter and are run by an elected chief executive or an appointed professional administrator are in a better position both legally and administratively to satisfy the service expectations of county citizens (Benton, 2003). Schneider and Park (1989) report that this principal has led to "a new structure of government [being] advocated as a means to increase the level of professionalism and as a means by which counties can expand their service role."

Additional studies provide descriptions of the governmental context of counties. For instance, DeSantis and Renner (1993) define the nature and significance of variations in county authority, different forms of county government, and different types of election or voting systems. They conclude that states have come to recognize the need to permit greater degrees of discretionary authority (devolution), more progressive structures (either commission-appointed administrator or commission-elected executive), and more flexibility in electoral systems (for instance, a mix of at-large and district elections for county legislators) in order to keep the county government organization and management capacities in line with their increasing service demands.

In a similar vein, MacManus (1996) takes a closer look at county governing boards, partisanship, and elections, and speculates about which factors may have prompted progressive changes in these features. Correspondingly, Sokolow (1993) systematically examines changes in the 
organization and functioning of county boards over time in their dual role as administrators and policy makers. However, these scholars state that little is still known about whether the progressive reforms they observed made county governments more efficient, effective, responsive, or accountable.

County reform efforts have stressed structural changes over functional and fiscal ones as the most vital for effective local area government. It has been argued, for example, that "[T]he most serious weakness in county government is lack of a county executive." (Snider, 1952). There are three principal types of structural reform which has been promoted consistently: form of government, a merit personnel system and clearly defined job descriptions. Scholars claim that reforms that alter form of government are the most significant (Murphy, 2009).

Part of the gap in the knowledge base concerning county government reforms has been filled by studies that investigate changes in a county's population and socio-economic environment, and the county's response to the service needs created by those changes (Benton, 2002, 2003; Benton and Mezel, 1993; Hoene, Baldassare, and Shires, 2002; Park, 1996; Steel and Lovrich, 2000). Moreover, Benton $(2002,2003)$ provides a global view of counties responding to changes in their environment. The central finding of these studies is that the counties that are most responsive to citizen expectations for urban-type services urban are found in moderate to rapid-growth counties. This central finding is also true for those counties located in states with political cultures that support an expansive role for counties, and are most responsive to 
citizen needs and expectations for both municipal and urban-type services (Benton, 2005).

2.6 Nature Theory: Land Preservation, Parks and Recreation

The original nature theory, arguably, underlying the human experience is the notion that 'returning to nature' is good. This could perhaps be called "Garden of Eden" theory. Throughout the ages, shifting from urbanized, complex environments to more natural environments has seen as valuable for relaxing, calming, healing, re-connecting, and strengthening human beings.

Research findings in health, medicine and psychology also appear to be supportive of the proposition that nature has some inherently positive effects on physical and psychological well-being for humans (and other animals). Two of the best known researchers in this area are Dr. Robert Ulrich who found psychological benefits to patient recovery with exposure to natural landscapes (1984, 1991a, 1991b, 1993), and Dr. Howard S. Frumkin (2001) reviewed the research literature on the physical health benefits of natural environments. What seems to be lacking, however, is a well-developed theory for explaining exactly how natural environments may influence human beings.

The most popular, scientific-type "nature is good" hypothesis is Edward O. Wilson's biophilia hypothesis (1984), which proposes that the positive effects are due to our long evolutionary (and consequently genetic) links to having a preference for being in natural environments. Wilson's biophilia hypothesis has been debated and critiqued. One of the issues appears to be that Wilson based his ideas on the study of insects and that the idea is too simplistic to fully account 
for human's relations with natural environments, since clearly humans have also shown a capacity to adapt to artificial environments.

Contemporary forms of environmental degradation present one of the most complex dilemmas of modernity (Goldblatt, 1996). The population growth and economic expansion of the previous century and half hold consequences for national and global environments. Depletion of the ozone layer, air pollution, loss of forests and bio-diversity, extinction of plant and animal species, loss of marine live, soil and water pollution, and the potential for climate change have occurred at an alarming rate (Munshi, 2000). Particularly in post-war years, release of toxic matters into the environment, worldwide expansion of nuclear energy, acid rains, new pesticides, non-biodegradable plastics and other harmful chemicals have come to pose a threat to life itself. More recently, the United States has witnessed environmental politics in the growth of environmental movements and conflicts, which is predicted to play a role in ameliorating the deterioration of the natural environment at the local, national and global levels.

U.S. federal, state and local governments conserve land as 'open space' for four general reasons: 1) for production ('working landscapes' for continued production of economically valuable commodities, e.g. timber, fish, grazing and food); 2) for human recreational use including parks and the conservation of fish, fowl, and game for recreational hunting; 3) to preserve high value natural areas described as 'the crown jewels' - exceptional examples of scenic beauty or important ecosystems; and 4) to maintain natural environmental systems - 
ecosystems, watersheds, wetlands, and habitat systems for the survival of specific plant and animal species (California Resources Agency, 2001).

State-sponsored open space and farmland protection programs have been in existence since 1893 (State of Massachusetts, 2001). The objectives and implementation mechanisms behind open space programs vary widely. Examples of program types include direct acquisition programs, purchase and transfer of development rights, tax relief and differential assessment, as well as programs to protect wetlands and watersheds, farmland, wildlife habitat, parklands, forestlands, and native grasslands (Hilliker et al. 2001).

The diversity of these programs is reflected in a growing body of literature dedicated to the analysis and critique of these programs (Mayer and Somerville, 2000; Skidmore and Peddle, 1998; Nickerson and Lynch, 2001; Plantinga and Miller, 2001; Thorsnes and Simons, 1999). Some of these studies examine the relationship between the success and extent of open space and farmland protection programs and other characteristics of the regions that support them.

Bright et al. (2001) tested the consistency of individual attitudes toward the protection of natural areas in different geographic regions. The study was conducted on residents living in both the city and suburbs of Chicago. The purpose was to determine how consistent people's attitudes were toward natural area protection locally (Chicago area), regionally (Midwestern United States), and globally (tropical rainforests of South America, Africa, and Asia). The study found that those people who felt environmental issues were of high importance had the highest level of consistency among their attitudes regarding protection at 
all of the geographic levels. Those who viewed environmental issues of lesser importance did not display the same level of consistency; their attitudes toward the protection of local areas were not as positive as their attitudes toward protecting global and regional environments.

Polls conducted by the Pew Center for Civic Journalism and Smart Growth America confirm the importance of growth issues to Americans (Myers and Puentes, 2001). Basic principles have emerged as guideposts in the search for more livable, sustainable communities: revitalization of cities and older, inner ring suburbs; more compact development; expanded transportation choices; preservation of open space; fairness to stakeholders, including low income and minority citizens and a balanced (but not prohibitive) approach to development (Pew Center, 2000).

In the United States, land conservation and open space protection has been utilized to either shape metropolitan growth or to give urban residents access to non-urban settings (Hollis and Fulton, 2002). In the 19th century, urban designers such as Frederick Law Olmsted advocated the development of regional systems that included large urban parks, parkways, playgrounds and nature preserves (Garvin, 2000). They succeeded in designing, and at least partially implementing, such systems in some cities including New York, Chicago and Boston. In 1902, Charles Eliot, who worked with Olmsted on the design of Boston parks, proposed that open space serves two fundamental purposes providing structure to the city, and maintaining the functions of natural processes in the urban environment (Wiese, 1987). 
During the early 20th century, Benton MacKaye, a forester and preservationist, observed that Eastern cities were growing beyond their former boundaries and merging into a metropolitan "conurbation", in the process developing the rural land that had previously surrounded and separated them (Stein, 1957). MacKaye realized that planning for urban development and land preservation were part of the same process, and should take place at the regional level. Partly for this reason, MacKaye proposed what is now the Appalachian Trail, running from Maine to Georgia. His concept was that the trail would be the backbone of a linked system of parks and nature preserves in each region, protecting wilderness and also shaping the East Coast conurbation. MacKaye later joined with others, such as Clarence Stein and Lewis Mumford, to propose theories of regional planning that rested heavily on open space as the backbone of regional form (Stein, 1957).

Throughout the 20th century, various public policy initiatives sought to increase the amount of park and recreation space in urban areas, and to protect ecosystems and farmland on the metropolitan fringe (Hollins and Fulton, 2002). In some cases, these efforts have been endorsed by federal policy. The long list of federal policies that have promoted conservation of open space - especially within metropolitan areas - includes the Land and Water Conservation Fund (1964), The National Environmental Policy Act of 1969, The Endangered Species Act of 1973, the Clean Water Act of 1972, the Safe Drinking Water Act (1974), and the North American Wetland Conservation Act (1989). In many cases, 
however, open space protection has been secondary to the environmental goals of these sustainability programs.

Most strategies to use open space to consciously shape metropolitan areas have been initiated by states or localities. For example, efforts in the City of Boulder, Colorado, have protected nearly 30,000 acres of land since the late 1950s, and have been successful in limiting development (Lorentz and Shaw, 2000). The states of New Jersey (beginning in the 1960s) and Florida (beginning in the 1970s) have long provided funding for local governments to acquire open space land in metropolitan areas. Many states that have been active in open space acquisition - including Maryland, Florida, and New Jersey - have also been active in creating growth management systems that have consciously sought to shape metropolitan growth (Hollis and Fulton, 2000).

A more integrated philosophy has emerged in the last decade concerning planning for open space. In 1991, the National Recreation and Park Association recommended the use of a "systems" approach to open space planning (McMahon, 2000). During the 1990s several states completed innovative state plans such as the statewide greenways plans in Florida and Pennsylvania and a new 'Bio Map' in Massachusetts (Daley, 2001). In August 1999, The Conservation Fund joined with other national leaders to form the Green Infrastructure Working Group to develop a set of principles to guide open space planning at the state, regional and local levels (Benedict, 2000).

Public Parks and Recreation. During the second half of the 19th century, American cities built grand city parks to improve their residents' quality of life, 
including New York's Central Park and San Francisco's Golden Gate Park (Sherer, 2006). Inspired by "an anti-urban ideal that dwelt on the traditional prescription for relief from the evils of the city - to escape to the country" (Cranz, 1982), municipal officials viewed parks as refuge from crowded and polluted cities where citizens could experience fresh air and sunshine, a place for recreation in a democratizing public space where rich and poor mixed on equal terms.

However, starting with the Great Depression era and continuing through much of the 20th century, spending on city parks declined (Sherer, 2006). The wealthy and white residents abandoned the cities for the suburbs, and city parks fell into decay. Municipalities cut park maintenance funds, parks deteriorated, and crime rose; many urban dwellers viewed places like Central Park as too dangerous to visit (Cranz, 1982). The suburbs that increased at the edges of major cities mostly did not build public parks.

Beginning in 1990, a number of municipalities began requiring developers to include open space in their building projects. But these open spaces were often unavailable to the general public because the newer subdivisions often placed open space in the center of the development, surrounded by a labyrinth of streets that required residents of older, low- and middle-class neighborhoods to drive to find these recreation spaces (Harrison, 2003).

More recently, urban parks have experienced a renaissance which has benefited cities unequally (Sherer, 2006). As part of a general urban renewal program, government authorities, civic groups, and private agencies throughout 
the United States have revitalized run-down city parks, built greenways along formerly polluted rivers, converted abandoned railroad lines to trails, and planted community gardens in vacant lots. For example, The Park at Post Office Square in Boston is a beautiful 1.7 acre park, completed in 1992, that has enhanced and changed the entire neighborhood (Garvin and Berens, 1997).

Yet residents of many municipalities in the United States continue to lack adequate access to parks and open space near their homes. For example, in Atlanta, GA, parkland covers only 3.8 percent of the urban area. Atlanta has no public green space larger than one-third of a square mile (Harnik, 2003). The city has only 7.8 acres of park space for every 1,000 residents, compared with 19.1 acre average for other medium-low population density cities (Harnick, 2003). The story is similar in Los Angeles, San Jose, New Orleans, and Dallas. Even in cities that have substantial park space as a whole, the residents of many neighborhoods lack access to nearby parks. In New York City, for example, nearly half of the city's 59 community board districts have less than 1.5 acres of parkland per 1,000 residents (New York, 1995).

From an equity perspective, low-income neighborhoods populated by minorities and recent immigrants are disproportionately short of park space (Sherer, 2006). In Los Angeles for example, white neighborhoods (with white residents constituting 75 percent or more) have 31.8 acres of park space for every 1,000 population, compared with 1.7 acres in African-American neighborhoods and 0.6 acres in Latino neighborhoods (Pincetl et al, 2003). Even when government or voters have allocated funding for park acquisition, there is 
significant risk that wealthier and better-organized districts will take a greater share of the allocation (Sherer, 2006). Between 1998 and 2000, in the Los Angeles neighborhood of South Central (with the city's second-highest poverty rate, highest share of children, and lowest access to nearby park space) received approximately one-half of the per-child parks funding as affluent West Los Angeles from Proposition K (Wolch et al, 2002).

There is increasing evidence that the use of parks and open space provides health-related benefits (Godbey, Roy, Payne and Orsega-Smith, 1998; Tinsely et al, 2002); forms of recreation that promote physical activity (OrsegaSmith, Payne, and Godbey, 2003; Raymore and Scott, 1998; Scott, 1997); benefits from stress reduction (Godbey et al., 1998; Hull and Michael, 1995; Parsons, Tassinary, Ulrich, Hebl and Grossman-Alexander, 1998), social support and self-determination (Iso-Ahola and Park 1996; Iwasaki, Zuzanek and Mannell, 2001), and opportunities to observe nature and other benefits of an undeveloped environment (Golbey et al, 1998; Tinsely et al., 2002).

A 1996 comprehensive report issued by the U.S. Surgeon General found that people who engage in regular physical activity could substantially improve their health and quality of life by including moderate amounts of physical activity in their daily lives (CDC, 1996). The benefits extend to psychological health through horticultural therapy as mental health treatment in community-based programs (Ulrich, 1984); feelings of peacefulness, relaxation and tranquility (Ulrich, 1984), and exposure to nature and greenery (de Vries et al., 2001). 
The economic benefits of parks and recreation include increased property values, revitalization, and tourism. In his 2000 report, Crompton reviewed 25 studies investigating whether parks and open space contributed to property values of neighboring properties, and found that 20 of the results indicated such an increase. The higher the value of these homes translates into higher property taxes for local government. A University of Southern California study (Pinctl, 2003) found the same positive relationship holds true in neighborhoods where the residents are mostly immigrants and poor - an 11 percent increase in the amount of green space within a radius of 200 to 500 feet from a house leads to an approximate increase of 1.5 percent in the expected sales price of the house.

The economic benefit for commercial property values is similar, e.g. between 1990 and 2000, rents for commercial office space near the renovated Bryant Park in New York City increased between 115 and 225 percent, compared with increases of between 41 and 73 percent in the surrounding submarkets, according to a study conducted by Ernst and Young (2003).

A 1998 real estate industry report calls livability "a litmus test for determining the strength of the real estate investment market .... If people want to live in a place, companies, stores, hotels and apartments will follow" (Lerner and Poole, 1999). Dallas used green space to revitalize itself by dramatically expanding new parks and open spaces (Hicks, 2003). The green space surrounding Portland, Oregon, helped build its reputation as one of the country's most livable cities (Lerner and Poole, 1999). Finally, a park often becomes one of a city's signature attractions, a prime marketing tool to attract tourists, 
conventions and businesses; e.g. the Boston Public Garden, Baltimore's Inner Harbor, Minneapolis's Chain of Lakes Regional Park, San Antonio's Riverwalk Park (Megan, 2002; Crompton, 2000).

Green space in urban areas provides substantial environmental benefits, including pollution abatement and cooling, and control of storm water runoff. The U.S. Forest Service calculated that over a 50-year lifetime, one tree generates $\$ 31,250$ worth of oxygen, provides $\$ 62,000$ work of air pollution control, recycles $\$ 37,500$ worth of water, and controls $\$ 31,250$ work of soil erosion (USDA PamphletR1-92-100). Trees also act as natural air conditioners to keep cities cooler, mitigating the effects of concrete and glass. American Forests (a conservation organization) estimates that trees in the nation's metropolitan areas save the cities $\$ 400$ billion in the cost of building storm water retention facilities (Lerner and Poole, 1999). However, natural tree cover has declined by as much as 30 percent in many cities over the last several decades (www.americanforests.org).

Among the most important benefits of city parks is their role as community development tools. City parks make inner-city neighborhoods more livable; offer recreational opportunities for at-risk youth, low-income children, and low-income families; and they provide places in low-income neighborhoods where people can experience community. Access to public parks and recreation facilities has been linked to reductions in crime (TPL, 1994) and juvenile delinquency (Witt and Crompton, 1996). Furthermore, playing as learning has proven to be a critical element in a child's development (Isenberg and Quisenberry, 2002). Finally, a 
study by the University of Illinois and the University of Chicago found that for urban public housing residents, green space builds stronger neighborhood social ties (Kuo et al., 1998). A 2003 study conducted by the University of Missouri-St. Louis for the community development organization Gateway Greening found that St. Louis neighborhoods with community gardens were more stable than other neighborhoods (Tranel, 2003).

Ho, Sasidharan, Eolmendorf, Willits, Graefe and Godbey (2005) studied gender and ethnic variations in urban park preferences, visitation and perceived benefits. Using a self-administered questionnaire mailed to samples of residents in two metropolitan areas (Atlanta, GA and Philadelphia, PA), the overall response rate of $27 \%$ provided 1,570 usable questionnaires. Three separate MANOVA analyses were carried out to test the relationships of ethnicity and gender (and their interaction). Although women were more likely than men to evaluate some park characteristics as "important", there were no significant gender differences/variations in the types of visits or the perceived benefits of parks. However, there was significant ethnic variation in preferred park attributes, frequency, and type of visits, and perceptions of the positive and negative effects of parks. Yet, the effects of ethnicity were not found to differ for men and women.

In studying both municipal and county land preservation voter referendum, the research of Banzhaf, Oates and Sanchirico (2010) first hypothesize that if national conservation organizations, or grassroots members, are managing the initiative process in these local areas, they will use their resources to direct local 
efforts to advance their conservation efforts in jurisdictions with more endangered species and more surface water. Second, the scholars hypothesize that advancing the objectives of national conservation organizations by using the initiative process, other things being equal, results in conserving more land with greater ecological value.

The conclusions of the Banzhaf, Oates and Sanchirico study (2010) are that "conservation referenda are more likely to be held in communities where there is more surface water and more endangered species, suggesting greater ecological values". In addition, these scholars found that national conservation organizations have "apparently been quite successful at targeting communities based on observable factors." Their study supports previous work on the "demand-side factors" of land conservation (Kline, 2006; Kotchen and Powers, 2006; Nelson, Uwasuand Polasky, 2007; Sundberg, 2006).

Finally, their research design does not take into account other local factors (e.g., governance and government) that could significantly influence the selection and passage of local area land preservation voter referendums. Nor does the study specific numbers or figures related to the environmental culture of the region as evidenced by the state presence of IRS-registered environmental organizations.

\subsection{Land Preservation Voter Referendums: Empirical Studies}

Banzhaf, Oates and Sanchirico (2008) used a polychotomous sample selection estimator to analyze which local (municipal) jurisdictions were most likely to place land preservation referenda on the ballot and the outcomes of 
these referenda. Kline (2006) estimated a single logit model of the probability of a community approving its referendum. Sundberg (2006) extends Kline's analysis to account for the level at which a referendum passes.

Neither of the last two studies controls for potential sample selection issues, even though there is substantial evidence that environmental organizations try to target the most promising jurisdictions for conservation referenda. For instance, The Conservation Fund and The Trust for Public Land have published manuals that provided detailed guidance on "the how and where" of designing and introducing conservation referenda (Hooper, Cook, 2004;

McQueen, McMahon, 2003). Under such circumstances, jurisdictions that hold referendums may differ significantly from each other.

Two recent papers that address the sample selection issue are Kotchen and Powers (2006) and Nelson et al (2007). Along with a national analysis of referenda, which did not address selection, Kotchen and Powers (2006) extensively analyze municipal referenda in New Jersey and Massachusetts, two active states in the area. Nelson et al (2007) include an analysis of municipalities nationwide, comparing municipalities with referenda to a random sample of control jurisdictions. Both papers jointly estimate the propensity to hold referenda and the outcomes of those referendums using a basic Heckman TwoStage model (1979).

Recent studies utilizing Trust for Public Lands (TPL) LandVote $®$ Database suggest a reoccurrence of significant variables. The Trust for Public Land itself points out in its Conservation Finance Handbook (Hooper and Cook, 2004) that 
"the first step [in planning a referendum] is to find out precisely who lives and votes in your community" (e.g., demographic characteristics of residents, including age, income, education, rate of homeownership). Zeman, Hilliker, Koles and Marcouiller (2003) assessed factors that explain state-sponsored land protection programs; these researchers conclude that per capita and median household income and population density were significant variables.

Examining national, state and local open space referenda, the Kotchen and Powers (2006) empirical investigation of the factors that influence the appearance and success of voter referenda provide evidence that: (1) jurisdictions tend to have greater population growth, greater household incomes, greater home values, and greater homeownership rates; (2) voters are far more likely to vote in favor of open space policy that approves bond financing rather than a tax increase; (3) substantiation that collectively provided open space is a normal good, but inconsistent results for age and other socio-economic characteristics; and (4) support for a relationship between existing patterns of open space and voter continued support for open space referenda.

Factors that Nelson, Uwasu and Polasky (2007) found that increased support for passage of the referendum at the municipal level were rapid growth, low unemployment rates, highly educated residents, and no new taxes; these referenda may not align with overall conservation priorities. Finally, Banzhaf, Oates and Sanchirico (2008) conclude that important drivers for success include: communities with more educated communities, fewer children, and those voting democratic in presidential elections; a bond financing mechanism; higher rate of 
homeownership; in ecologically sensitive areas; and that land trusts as a group, by design or not, are targeting with successful strategies.

\subsection{Interest Group Theory and Environmentalism}

The theory of interest groups seeks to explain how people in a democracy organize to influence the government in matters of policy, regulation and redistribution of wealth. Within the overarching interest group theory, first hypothesized in the late19th century and later codified by Olson (1965) and Stigler (1971), there are competing branches that attempt to describe the behavior of special interest groups more accurately and address the perceived failings of other theories (Garson; 1978).

Berry, Portney, Liss, Simoncelli and Berger (2006) attempt to reunite interest group theory with the study of local area politics in contrast to the national venue. Dahl's seminal Who Governs? (1961) analyzes the interaction of lobbyists with city policymakers and elites in the mid-sized American city of New Haven, Connecticut. The book was offered as a representation of American democracy, "warts and all". Who Governs? is a criticism of the theory of competing interest groups in municipal politics found in Floyd Hunter's Community Power Structure (1953), an elitist view of Atlanta, Georgia. Although the same debate over pluralism and elitism was carried out in the literature on national politics (Truman, 1951; Mills 1956), the studies of Dahl and Hunter continued to question of whether America was truly a democracy. 


\subsubsection{Influencing Policy Change}

Hojnacki et al. (2012) observed a sample of large-scale and longitudinal organizational advocacy and policy influence studies published between 1996 and 2011. To be included, the work had to give substantial attention to the

Table 2.1 Context of Interest Group Scholarship, 1966-2011

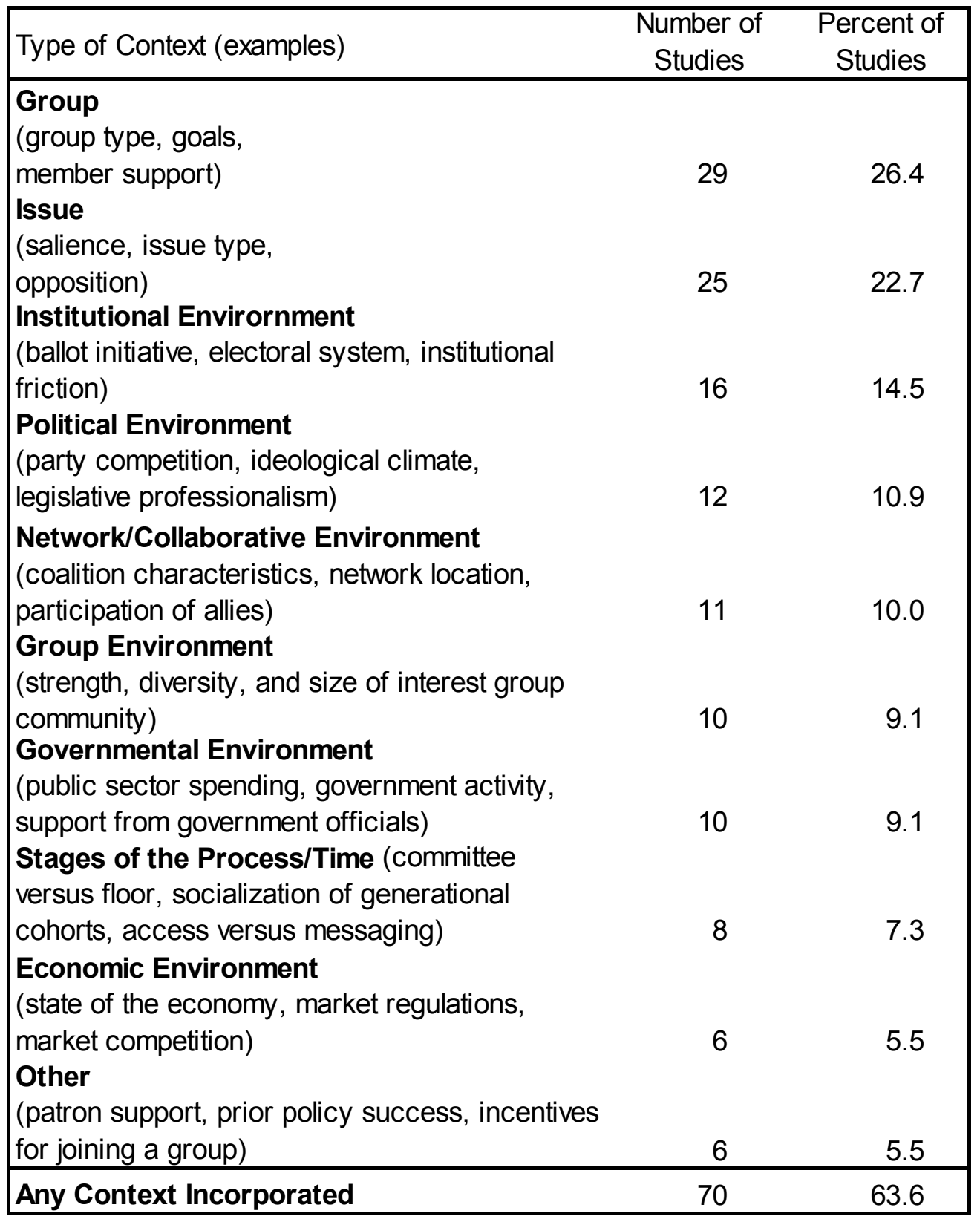

Source: Hojnacki, Kimball, Baumgartner, Berry, and Leech, 2012.

There are 110 studies in the sample of the literature; 2 are excluded. 
activities of organized interests or social movements, or the outcomes of their efforts. These criteria produced a diverse set of 110 books and articles. The purpose of the study was to assess whether this body of research has become more theoretically coherent, more attentive to context, and broader in scope and focus than a previous review by Baumgartner and Leech (1998). They observed some advancement in all areas, but found opportunities for further accumulating systematic knowledge about groups and public policy remain. See Table 2.1 for a summary of study contexts found by Hojnacki et al (2012).

Stachowiack (2007) provide a range of ideas about how policy change occurs. First, "large leaps" theory (punctuated equilibrium theory) recognizes that change can happen in sudden bursts (when conditions are conducive) that represent significant departures from the past, as opposed to small incremental changes that do not radically change the status quo. Scholars Frank Baumgartner and Brian Jones (1993) developed this model and have used it in longitudinal studies of agenda-setting and decision-making. Next, "coalition" theory (advocacy coalition framework), as developed by Paul Sabatier and Hank Jenkins-Smith (1999), proposes that individuals have core beliefs about policy areas, including an issue's significance, its causes, society's ability to solve the problem, and promising solutions to correct it. Advocates who apply this theory believe that policy change occurs through coordinated activities among stakeholders and individuals with the same core policy beliefs.

Stachowiack's third concept is "policy window" theory of change (agenda setting theory). John Kingdon's (1995) classic theory of agenda setting attempts 
to clarify why some issues capture attention in the policy process and others do not. To increase the likelihood that an issue will receive serious attention or be placed on the "policy agenda", at least two conditions need to converge at the critical moment of policy window of opportunity. The three conditions are: the way social conditions are defined as problems to policymakers, the ideas generated to address the problem, and the existing political factors of society or citizenship "mood", interest group and advocacy campaigns, and changes in elected officials.

With the "messaging and frameworks" theory (prospect theory), Amos Tversky and Daniel Kahnerman (1981) challenged a conventional school of thought that suggests people make rational decisions by weighing the costs and benefits of different options, and they choose the one that will benefit them the most. Their research proved that individuals develop different preferences based on how the information is presented or how options are framed. Therefore, decisions can be inconsistent, that is less beneficial and risker than expected, because of an inclination to react to and rely on the type and form of evidence provided.

Fifth, the "power politics" theory (political or power elites theory) proposes that the power to influence policy is concentrated in the hands of a few. This history theory can be traced to C. Wright Mills' seminal book, The Power Elites (1956), that describes the power and class structures in America (e.g., political, military and economic elites), and how they interrelate with the community and government, and thus impact public policy. 
Finally, proponents of "grassroots" theory (community organizing theory) view power as changeable and dynamic, not possessed exclusively by elites. They believe that groups are able to create power by assuming mutual action to achieve social action. Saul Alinsky laid the foundation for this theory about community organizing in his book entitled Rules for Radicals (1971).

\subsubsection{Environmentalism}

The attack that environmentalism is "elitist" has been set forth in a number of environmental conflicts. It is also a constant theme in general debates about environmentalism's credibility and viability as an interest group (Garson, 1978; Gibson, 2003). Proponents of neo-corporatism, one faction of interest group theory, argue that not all citizens have equal access to resources, and those with greater resources are more able to organize successfully and lobby government (Streeck, 2003). It can also be argued that democracy is maintained because for every special interest group with one agenda, there are other organizations pressing for alternatives (Berry, 1989).

Environmental scholar Samuel Hayes (1993) examines the transformation of the pre-World War II environmental movement focused on conservation and scientific management of natural resources to one characterized by complicated, post-industrial concerns for aesthetics, recreation, and health expressed by a larger and more varied group of political actors, privileged and influential persons, and organizations. According to Hayes, this new ethos prompted by a new mass middle class, larger and far better educated, more affluent and active that predecessors, wanted not to replace but rather to supplement the existing 
industrial values of social and economic growth (Dunlap, Van Liere, Mertig and Jones, 2000; Hayes, 1993; Ladd and Bowman, 1996; and Lake, 1983).

Scholars routinely proclaim the emergence of public support of the environmentally progressive policies without fully detailing the basis for such support - no clear definition of environmental values, an assumption of broad public support with no empirical evidence, and no causal connection between public opinion, the role of interest groups, and governmental bodies in the formation of environmental policy (Dell, 2009). One example of these scholarly assumptions can be found in James Gustave Speth's (2004) book entitled Red Sky at Morning in which he writes "let us turn now to the agenda of large-scale environmental concerns to which governments and others have paid attention" without further empirical clarification.

Another example is Al Gore's (2006) book and documentary entitled An Inconvenient Truth. Mr. Gore and the Intergovernmental Panel on Climate Change's (IPCC) award of the 2007 Nobel Peace Prize "for their efforts to build up and disseminate greater knowledge about man-made climate change, and to lay the foundations for the measures that are needed to counteract such change" was criticized by the media on the grounds of political motivation and because the winners' work was not directly related to ending conflict (Spetalnick, 2007).

Lubell, Feiock and Ramirez (2005) developed a political market framework to empirically explain the circumstances under which Florida counties would supply environmental goods in the form of conservation amendments to county general plans. Their findings reinforce the importance of developing theories of 
urban politics in which local political institutions are not transparent. These scholars focus on the structure of political institutions was different from two other major theoretical frameworks that have developed to explain local environmental policy.

The "property rights" framework reasons that environmental policies will emerge in the face of scarcity and the overconsumption of common resources (Libecap, 1989; Alchian and Demsetz, 1973). This perspective is linked to Tiebout (1956) models, which often argue that communities have an optimum size for delivery of local public goods. In general, the property rights framework predicts conservation amendments and/or voter referendums will become more frequent as land becomes scarce, population increases, and infrastructure becomes strained (Lubell, Feiock and Ramirez, 2005).

The "interest group" framework of local politics provides a second popular explanation of local policy. Interest group models predict that groups that are better able to deliver political resources to local elected officials are more likely to receive their preferred policies. The interest group model provides the theoretical basis for "growth machines" ruled by political alliances between local government officials and development interests (Molotch, 1976; Logan and Molotch, 1987). Development interests have the upper hand in local politics because they receive concentrated benefits for pro-development policies and are better organized than diffuse public interests. Of course, public entrepreneurs can often organize diffuse public interests to effectively participate in local political decisions, and local governments are certainly capable of pro-environmental policies (Elkins, 
1995; Goetz, 1990, 1994; Feiock, 2002). Regardless, interest group models have a modern pluralist perspective that views policy change as a result of interest group competition.

Economic and development interests have a substantial concern for county government land use decisions because of consequences for return on their investments and production activities (Lubell, Feiock and Ramirez, 2005). Like other business interests, development interests are often organized and well financed, making them strong candidates to become powerful articulators of political demand. These characteristics give development interests an advantage in translating their preferences to county politicians. Another advantage that business interests possess is their perceived importance to local economies (Schneider, 1989). A number of studies suggest a substantial degree of cooperation between business and public officials (Fleischmann 1986; Stone 1989) and real estate or finance industries.

Pro-development and environmental interests feature important differences in their geographic basis of organization (Lubell, Feiock and Ramirez, 2005). A political science analysis portrays environmental interests as a diffuse, unorganized constituency that favors some general form of environmental protection. Some local environmental interests (e.g., unorganized citizens who worry about uncontrolled growth), do have this type of structure. However, many local environmental interests are what Clarke and Gaile (1989) identify as "territorial groups" with links to a specific geographical location. These groups are often main players in "not-in-my-backyard" politics and include neighborhood 
organizations, homeowners associations, and citizen activists located within geographically defined constituencies. These geographic groups often dominate the politics of land use, as they resist unwanted land uses such as major roads, or clamor for improved environmental amenities like parks and preservation areas (Lubell, Feiock and Ramirez, 2005).

The environmental public interest group movement in the United States arguably began in the 1850's when the Department of Interior was established. The late 1800 s and early 1900 s brought concerns about resource management with forest practices the center of many environmental and resource conflicts (Simler, 2001). John Muir was perhaps the most notable early spokesperson for the preservation of wilderness areas. The Sierra Club was founded in 1892 by John Muir to "do something for the wilderness and make the mountains glad" (Sierra Club, 2012). The National Audubon Society was founded in 1905. By 1919, the National Parks and Conservation Association (NPCA) was created to protect and preserve the National Park System.

Despite Olson's prediction that well-organized interests groups are likely to trump more diffuse public interests, comprehensive environmental protection programs were adopted and then strengthened by Congress during the 1970s and 1980s. The Federal Environmental Protection Agency (EPA) was formed in 1970, as were several environmental laws regulating air and water pollution. New environmental legislation expanded citizens' standing to sue. Citizens and public interest groups could now affect policy decisions through litigation. 
Environmental policy was most affected by this new citizen right. For example, there was an average of one court case per year brought against the United States Forest Service (USFS) in the 1960s. In the 1970s there were about 25 court cases (Clary, 1986). Between the years of 1975 and 1988, there were 218 cases decided in the federal court regarding environmental issues involving the USFS (Ellefson, 1992). Idea-based groups, such as environmental interest groups, were now players in the policy process.

Environmentalism is arguably the most popular social movement in the United States today (Walls, 2008). On the local level approximately 6,000 environmental groups are active today. In 1965, there were no more than a halfdozen national conservation organizations with membership and little degree of influence (Walls, 2008).

The essence of environmental activism is collective action (Lubell, 2001). While political economists have long-recognized the public good nature of environmental activism, models of individual behavior developed in environmental studies rarely address the logic of collective action. Consequently, models that relate environmental activism to perceived environmental threats, socio-demographic characteristics, and environmental values do not provide a satisfactory account of individual decision-making that explains why these variables matter (Elliot, Seldon, and Regens, 1997; Jones and Dunlap, 1992; Mohai, 1985; Pelletier, Legault and Tuson, 1996; Rohrschneider, 1990; Samdahl and Robertson, 1989; Seguin, Pelletier and Hunsely, 1998). Many of these studies treat the influence of these factors as self-evident (e.g., people who 
perceive environmental threats and have environmental values are more likely to act). Lubell's (2001) research produced a model of individual decision-making that was explicitly linked to the logic of collection action.

\subsection{Summary}

Chapter II presents the conceptual framework for this dissertation by reviewing the relevant theoretical and empirical scholarly literature that forms the foundation of the study. This includes a discussion of the theories of direct democracy; federalism and governance; reformed county government and bureaucracy; nature theory; protection of land, parks and recreation; land preservation voter referendums, the pluralism of interest group activity, and

environmentalism. A review of empirical studies relating to land preservation voter referendums is also included.

Chapter III explains the sequential mixed methodology of the research design. The U.S. county or county entity is the unit of analysis. The research is initiated with a statistical analysis of relevant dependent and independent variables applicable to referendum and non-referendum counties from 1988 to 2009 (Chapter IV). Quantitative findings are explored in depth by conducting three county case studies including expert witness interviews (Chapter V). Finally, data from quantitative and qualitative approaches are integrated in order to obtain overall research findings and conclusions as presented in Chapter VI. 


\section{CHAPTER III}

\section{METHODOLOGY}

\subsection{Introduction}

Chapter III explains the sequential mixed methodology of the research design which is grounded in the contextual foundations, research questions and hypotheses of the study. First, the research questions and hypotheses are discussed and stated. Next, the analytical framework of the research design shapes the sequencing and eventual integration of the two methods utilized for quantitative and qualitative data collection, analysis, and general conclusions. Finally, the limitations of the study and suggestions for future research are given.

According to Creswell and Clark (2011), Johnson and Onwuegbuzie (2004), and Yin (1994), the mixed method research paradigm incorporates a strategy designed to collect and analyze numbers (e.g., quantitative statistical model) and the pragmatic, complex characteristics of real-life events (e.g., qualitative case study model). Gaining an understanding of the individual strengths and weaknesses of quantitative and qualitative methods enables the researcher to mix or combine strategies and to use what Johnson and Turner (2003) call the fundamental principle of mixed research. According to this principle, researchers collect multiple types of data with different strategies, approaches, and methods so that the resulting mixture or combination is likely to result in a research design with complementary strengths and no overlapping weaknesses (Johnson and Onwuegbuzie, 2004; Brewer and Hunter, 1989). 


\subsection{Sequential Mixed Methods Research Design}

In the literature of the social sciences, contemporary mixed methods research has become increasingly more popular and is now considered a legitimate, stand-alone design (Creswell, 2002, 2003: Greene, Caracelli and Graham, 1989; Tashakkori and Teddlie, 1998, 2003). It is defined as "the collection or analysis of both quantitative and qualitative data in a single study in which the data are collected concurrently or sequentially, are given a priority, and involve the integration of the data at one or more states in the process of research" (Creswell, Planno Clark, Gutmann and Hanson, 2003).

Onwuegbuzie and Teddlie (2003) state that there are two major rationales for conducting mixed methods analyses. These justifications are "representation and legitimation". Representation means the ability to extract enough information from underlying data, while legitimation represents the validity of data interpretation. Proponents of mixed research apply a combination of research methods that offer a depth of findings unachievable with either method alone.

Several purposes capture the major reasons for using mixed methods in public administration research. Researchers may seek to view problems from multiple perspectives so as to enhance and enrich the meaning of a singular perspective. They also may want to contextualize the information, to take a macro picture of a system (e.g., a county) and add-in information about public officials and administrators (e.g., employed at different levels within the organization). Another reason is to merge quantitative and qualitative data to develop a more complete understanding of a problem; to develop a 
complementary picture; to compare, validate, or triangulate results; to provide illustrations of context for trends, or to examine processes/experiences along with outcomes (Plano Clark, 2010).

Another reason to use a mixed methods study is to have one database build on another. For instance, when the quantitative phase is followed by the qualitative phase, the intent may be to help determine the best participants with which to follow up or to explain the mechanism behind the quantitative results (Plano Clark, 2010; Bryman, 2006). Results of precise, instrument-based measurements may, likewise, be augmented by contextual, field-based information (Greene and Caracelli, 1997).

Understanding the purposes for which mixing qualitative and quantitative methods are deemed appropriate in a research inquiry is important for three reasons (Venkatesh, V., Brown, S, and Bala, H., 2012). First, unlike qualitative and quantitative approaches, a mixed methods approach is typically not a natural methodological choice in social and behavioral sciences. Researchers have to overcome considerable paradigmatic, cultural, cognitive, and physical challenges to be able to conduct mixed methods research (Mingers 2001). Mixed methods research approach should serve one or more purposes beyond the core purpose of a research methodology (e.g., assist researchers conduct scientific research inquiries).

Mixed methods research incorporates quantitative and qualitative research approaches, either concurrently (i.e., independent of each other) or sequentially (e.g., findings from one approach inform the other), to understand a 
phenomenon of interest (Venkatesh, Brown, and Bala, 2012). Second, an explicit identification and/or recognition of these purposes by researchers employing a mixed methods approach provides a better understanding of the goals and outcomes of the mixed methods research. Finally, an unambiguous understanding of mixed methods research purposes helps researchers make informed decisions about the design and analysis components of a mixed methods inquiry.

The explicit research purposes for which mixing qualitative and quantitative methodology is deemed appropriate for this dissertation are completeness, complementarity and corroboration. Mixed methods designs are used to make a complete picture of the research topic of interest. For example, Soffer and Hader (2007) used an holistic view of their phenomenon by conducting a qualitative study to gain additional insights into the findings from a quantitative study. Mixed methods are used in order to gain complementary views about the same phenomenon. The intended purpose of the Piccoli and Ives (2003) and Hackney et al. (2007) studies was to incorporate qualitative data and results for providing rich explanations of the outcomes from quantitative data and analysis. Finally, mixed methodology is used in order to assess the credibility of inferences obtained from one approach (strand). For example, Bhattacherjee and Premkumar (2004) conducted a qualitative study to confirm the findings from a quantitative study.

In order to test study theories and hypotheses through the integration of numeric and non-numeric data variables, this research employs an explanatory, 
sequential mixed methods design (Ivankova, Creswell and Stick, 2007). Social inquiry is targeted toward various resources and the many levels that influence the study problem (i.e., the role of government in the selection and voter passage of the county land preservation voter referendums). First, the deductive, quantitative study approach is ideal for measuring the correlation of the known phenomena and central patterns of association, including inferences of causality. Figure 3.1 simplifies the relationship between the primary quantitative approach and the secondary qualitative approach of the study.

Figure 3.1 Sequential Mixed Methods Study Design

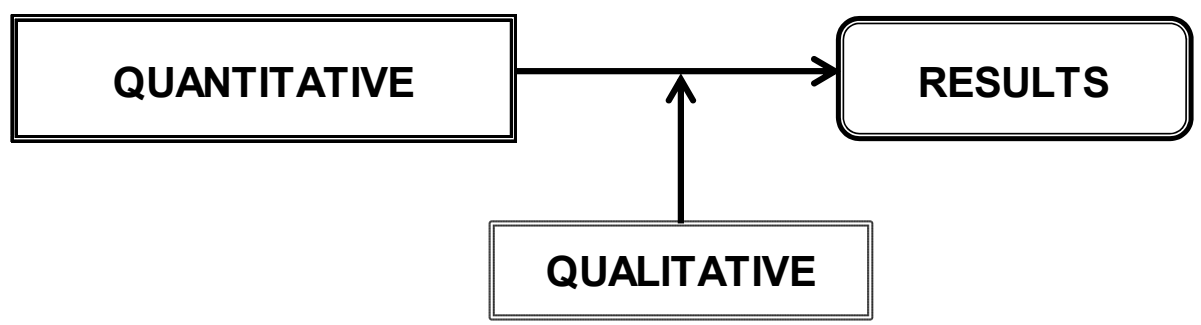

Next, the inductive, qualitative case study approach furnishes completeness, complementarity and corroboration for the quantitative analysis because of its in-depth study of selected land preservation voter referendum county cases and expert public administrator observations. Finally, the foundation for the final research analysis is the integration of outcomes from both quantitative and qualitative approaches through pattern matching of similarities.

\subsection{Research Questions and Hypotheses}

The research question is the methodological point of departure for implementation of the scholarly research. Mixed methods research questions 
address the mixing or integration of the quantitative and qualitative data. Mixed methods research questions are necessary because both quantitative and qualitative data collection are central to this form of inquiry, and they raise distinct questions in addition to the qualitative or quantitative questions. Answers to the mixed methods research questions are found in the results and final discussion section of a research study (Creswell and Plano Clark, 2011).

For the study, the research questions are predetermined and based upon the theoretical or conceptual foundations expressed in Chapter II, prior empirical research on the topic of land preservation voter referendums, pragmatism and practice in a real world setting, and disciplinary considerations. This approach is used in a convergent design when the data collection has been determined in advance (Plano Clark and Badiee, 2010). However, in sequential mixed method designs, there is the possibility that additional research questions might also be emergent and occur during the design, data collection, data analysis, or interpretation of the study (Creswell and Plano Clark, 2011). For example, Christ (2007) defined new questions that emerged within an exploratory, longitudinal mixed methods study.

Research questions in mixed methods are able to be linked conceptually or framed so that they are independent of each other (Plano Clark and Badiee, 2010). The independent type of questioning, where one research questions is not dependent on the results of another question(s), often occurs in a concurrent design in which two separate and distinct strands of data (quantitative and qualitative) are collective. The dependent type of research question often occurs 
in sequential types of research designs that are explanatory, exploratory, or sequential in the embedded, transformative, and multiphase designs (Creswell and Plano Clark, 2011). However, other variations are also acceptable if justifiable to the overall contextual foundations and research design.

There are three models for writing a mixed methods research question, and authors recommend a combination model because it is the most complete (Creswell and Plano Clark, 2011). These three methods are: method-focused, content-focused, and combination model. The explanatory design mixed methods research questions should address the use of qualitative data to help explain the quantitative results.

\subsubsection{Research Mixed Methods Purpose Statement}

The mixed methods purpose statement conveys the overall intent of the research project. The purpose statement for this research is: to examine the U.S. county jurisdiction in terms of government selection of a land preservation voter referendum and citizens voting "yes" to pass the referendum proposal on election day.

Mixed methods research questions and hypotheses are predetermined, and are either dependent or independent; the study may reveal emergent questions and hypotheses as well.

The implementation of the two-phase, explanatory mixed methods study is to first obtain statistical quantitative results from the data analysis of a nonrandom sample of 227 land preservation voter referendum counties from 1988 through 2009 and all non-referendum counties; the relationship of demographic, 
socio-economic, terrain, political preference, environmental interest groups, state governance, reformed government form, and referendum-specific factors will passage of the voter referendums at the ballot box is examined. A follow-up qualitative case study method investigates several referendum counties to explain and add detail, depth and real life experience; the coding and consolidation of qualitative data from case county documentation and twelve semi-structured expert witness interviews is converted to numerical data and integrated with quantitative findings to arrive at general study conclusions.

\subsubsection{Research Questions}

The following research questions narrow the scope of the purpose statement, and include quantitative, qualitative and mixed methods formats:

Q1: What (and why) is the difference in perceived barriers to U.S. county governments selecting a land preservation voter referendum between counties that have selected a voter referendum and the counties that have not?

Q2: What (and why) is the difference in perceived barriers to U.S. county voters voting "yes" for passage of a land preservation voter referendum between referendum counties experiencing success at the ballot box and those that endured failure?

Q3: What (and why) are significant demographic, socio-economic, terrain, regional, political preference, state governance, reformed county government and/or voter referendum-specific factors impacting the selection and passage of county land preservation voter referendums? 
Q4: How (and why) do county case study phenomena contribute to the difference between U.S. counties whose government selected and citizens passed a land preservation voter referendum?

Q5: How (and why) do county case study documentation and semistructured interviews with case county expert witness public administrators help to explain quantitative results and/or contribute to a more comprehensive and nuanced understanding of the selection and passage of county land preservation voter referendums?

\subsubsection{Research Hypotheses}

First, it is predicted that second order federalism or county home rule powers (e.g., state government authorization or direction of devolution of certain powers and authority to county governments) increases the probability that county governments will select a land preservation voter referendum. Increasingly state governments are devolving responsibility and authority for services and programs. In order to implement these services and programs, county governments require authorization and power to act upon these local issues from their state legislations. For this research, county autonomy, authority and powers of self-government to select a land preservation voter referendum is measured by the presence or absence of a county home rule charter and a reformed county government structure.

$\mathrm{H}_{1}$ (Alternative Hypothesis 1): As a result of its county home rule charter ordinance, there is a greater probability that a county government will select a land preservation voter referendum. 
$\mathrm{H}_{01}$ (Null Hypothesis 1): The probability of a county government selecting a land preservation voter referendum is not improved by the presence of a county home rule charter.

$\mathrm{H}_{2}$ (Alternative Hypothesis 2): With a reformed county government structure (e.g., a board of commissioners with an appointed administrator/manager or elected executive/mayor), there is a greater likelihood that a county government will select a land preservation voter referendum.

$\mathrm{H}_{02}$ (Null Hypothesis 2): The likelihood of a county government selecting a land preservation voter referendum is not increased by the presence of a reformed county government structure.

Second, another prediction is that the dedicated presence of state, regional and local area environmentalism (e.g., organizations, interest groups, clubs and grassroots volunteers) enhances the likelihood that county governments will select, and voters will approve a land preservation voter referendum. Stakeholder and public participation in government is a central topic in the contemporary American land conservation and environmental health movement (Fiorinao, 1990; Laird, 1993).

Prior empirical research in land preservation voter referendums infers, but does not find, that environmental organizations play a role in advising, educating, and helping state and local area governments to organize county land preservation projects (TPL, 2010). These studies also indicate that certain community factors (e.g., a population that is more urban, white, older, educated, 
democratic, and wealthy) is linked to its preferences for environmental goods ${ }^{4}$. Their collective actions influence both a county government's selection of a land preservation voter referendum, and the subsequent outcome (passage) by citizen affirmative vote at the ballot box.

$\mathrm{H}_{3}$ (Alternative Hypothesis 3): The influence of state, regional, and local area environmental interest groups and grassroots activism improve the prospects of a county government selecting, and citizens passing, a county land preservation voter referendum.

$\mathrm{H}_{03}$ (Null Hypothesis 3): Environmental interest group and grassroots activism have no influence on the prospects of a county government selecting and citizens passing a land preservation voter referendum.

$\mathrm{H}_{4}$ (Alternative Hypothesis 4): Some county demographic, socio-economic, terrain, regional, and political preference factors improve the prospect of a county government selecting and voters passing a land preservation voter referendum.

$\mathrm{H}_{04}$ (Null Hypothesis 4): No community factors increase the prospect of a county government selecting and citizens passing a land preservation voter referendum.

Third, a final prediction is that the inductive, qualitative case study approach with expert witness interviews furnishes completeness, complementarity, corroboration and real-life pragmatism for the quantitative results. The merger of quantitative and qualitative findings expands and enriches the research because it combines and expands the study findings.

\footnotetext{
${ }^{4}$ See Videras (2012)
} 
$\mathrm{H}_{5}$ (Alternative Hypothesis 5): The results of the analysis of qualitative county case study documentation, case-specific phenomena of interest, and expert public administrator interviews confirm, corroborate, complement and enhance the quantitative results; when quantitative and qualitative results are integrated, the findings provide a comprehensive and nuanced understanding of the factors for success of county land preservation voter referendums.

$\mathrm{HO}_{5}$ (Null Hypothesis 5): The qualitative approach does not contribute to the findings of the quantitative approach; the integration of quantitative and qualitative results has no effect on the significant factors for success of county land preservation voter referendums.

\subsection{Analytical Framework of the Research Design}

To provide worthwhile outcomes, scholars must not only determine "what should be the focus of research" (Behn, 1995) but also "what data and methodology would be most helpful in answering [the] field's questions". At issue is not the legitimacy of the quantitative or qualitative method; rather, it should be about the application of the chosen method(s) that build confidence in research findings. As Lan and Anders (2000) discuss, the field needs to "move beyond arguments as to which research methodology [quantitative or qualitative] is more legitimate, toward discussions as to whether the methods have been appropriately used". Although attempts to evaluate the identification and selection of research problems in public administration typically have biased toward the standards of quantitative analysis (Box, 1992), scholars have begun to recognize the fundamental differences in the two approaches and focus on 
standards specific either to quantitative (Cozzetto, 1994) or to qualitative (Brower, Abolafia and Carr, 2000) methods.

The research design is grounded in the theoretical framework and literature review of this dissertation (Chapter II). This knowledge contributes to the identification of gaps in theory and literature on the American voter referendum (direct democracy), federalism of the second-order (to county and local area governments), reforms in autonomy and government structure, land preservation, county governance, and environmental interest groups. These theories are postulated to explain the principal research objective of the dissertation: to identify significant government and governance factors that influence the selection and passage of a county land preservation voter referendum in 50 United States.

Polit and Hungler (1999) describe the research design as a blueprint, or outline, for conducting the study is such a way that maximizes control over factors that could interfere with the validity of the research results. The research design is the researcher's overall plan for obtaining answers to the research questions guiding the study. Burns and Grove (2001) state that designing a study helps researchers to plan and implement the study in a way that will help them obtain the intended results, thus increasing the chances of obtaining information that could be associated with a real life situation.

From a purely methodological perspective, several early scholarly works on 'triangulation' provide guidance on combining quantitative and qualitative methods (Denzin and Lincoln, 1994; Jick, 1979; Van Maanen, 1979; Webb et al., 
1966). Van Maanen (1979) and Jick (1979) were among the first organizational researchers to systematically examine the benefits of combining multiple methods as a way to 'triangulate' findings for theory development and enhancement. Van Maanen reasoned that 'qualitative methodology and quantitative methodology are not mutually exclusive', while Jick demonstrates the usefulness of including a more systematic approach to qualitative work with a more observational approach to survey research.

An analytical framework for this research design is created to organize, collect, sort, prioritize and interpret a variety of existing data and information about the U.S. counties and county land preservation voter referendums to be analyzed. Ragin (1994) defines the analytic frame as one of the four components of social research, with the other three being conceptual theory, evidence (data) and images (findings with new ideas coming from existing data).

Furthermore, the purpose of an analytical framework is to give the study a disciplined methodology of structural input, process and output. The study's analytic frame outlines the research design with an analytical framework consisting of a systematic evaluation of the unit of analysis (U.S. county jurisdiction), data related to the selected dependent and independent variables, sequential mixed method approaches, and integration of quantitative and qualitative analyses, and testing of the research hypotheses.

Figure 3.2 models the analytical framework of this research design which is an explanatory, sequential mixed methods with a quantitative method using the 
Heckman two-step model followed by a qualitative methodology with a similar case study treatment.

Figure 3.2 Analytical Framework for Sequential Mixed Methods Research Design

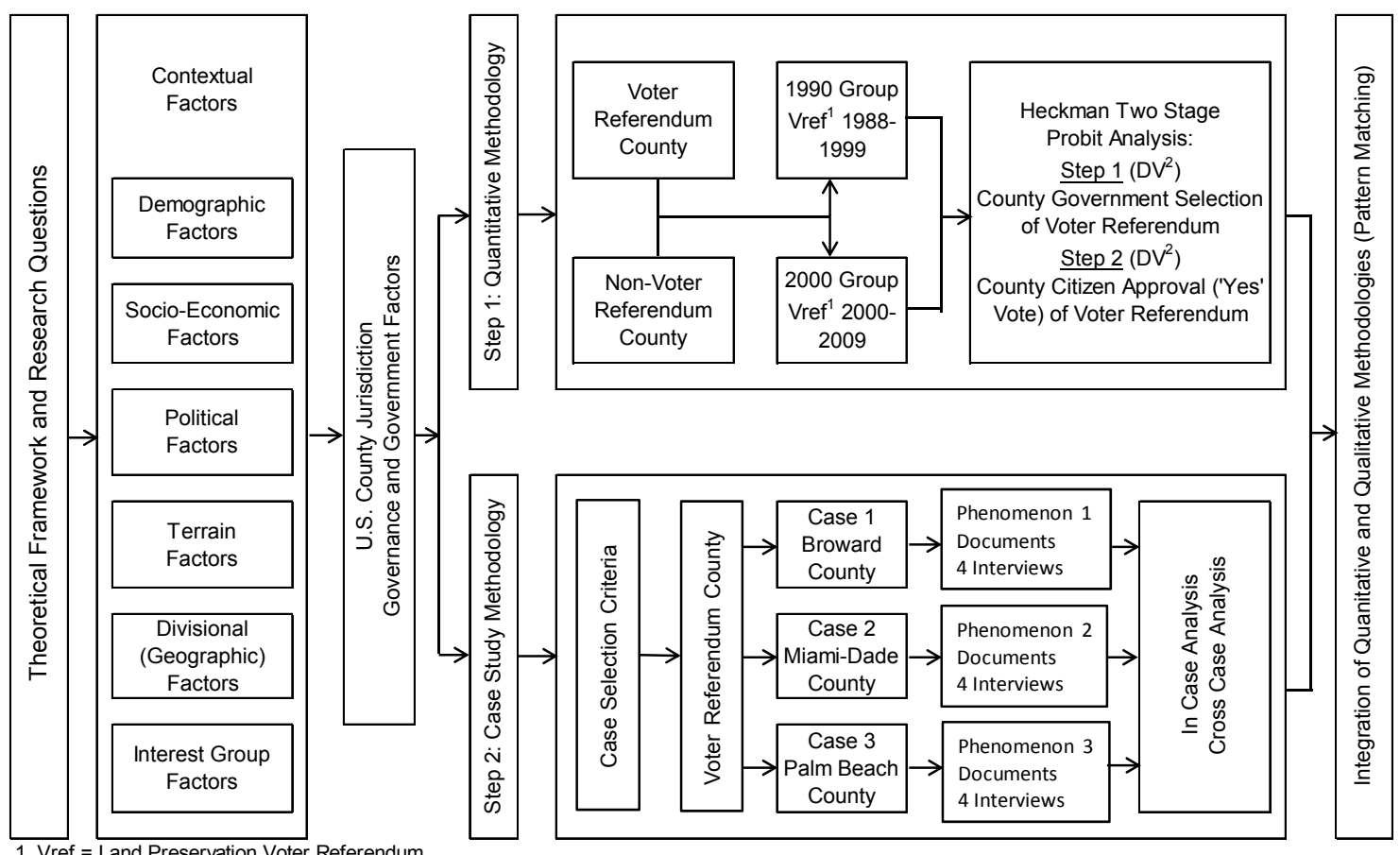

2 DV = Dependent Variable

\subsection{Quantitative Methodology with Heckman Two-Step Model}

Crestwell (1994) defines quantitative methods as "the kind of research that involves the tallying, manipulation, or systematic aggregation of quantities of data". In quantitative research, the aim is to determine and quantify the relationship between one thing (an independent variable) and another (a dependent or outcome variable) in a population. In structuring the quantitative approach for the study, the research method incorporates five primary steps: the research design, the population and sample to be studied, study variables, model or instrumentation, and data analysis. 


\subsubsection{Quantitative Research Design}

The quantitative research design for this study is an explanatory, descriptive, empirical study of the U.S. county or county entity. An explanatory and descriptive research design asks why something is occurring and what are the causal relationships between significant contextual factors. See Figure 3.3.

Figure 3.3 Analytical Framework for Quantitative Analysis

U.S. County (Land Preservation Voter Referendum)

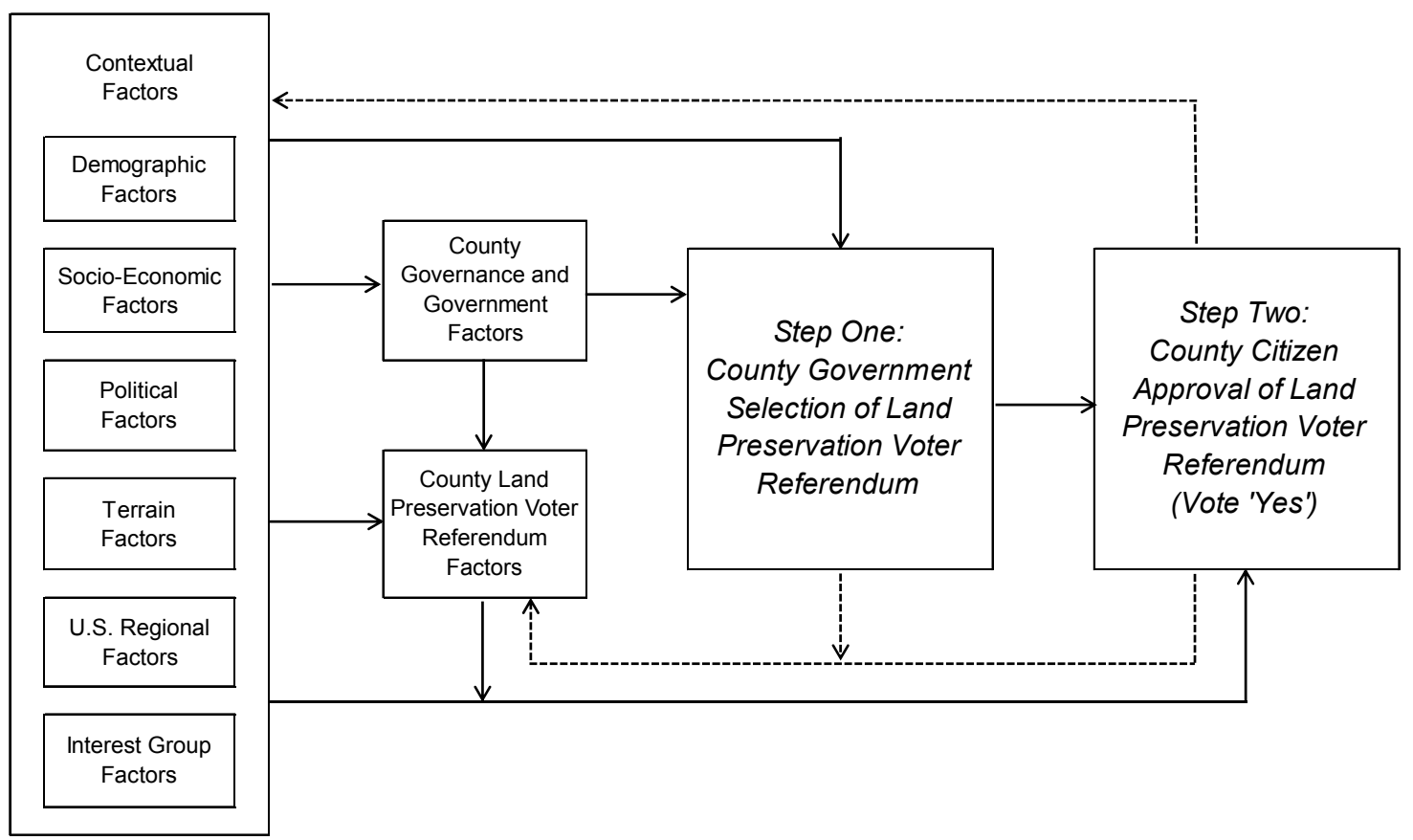

The theoretical foundations of this study are the fundamental building blocks of the research design. It is grounded in the theories of direct democracy; federalism and governance; reformed county government and bureaucracy; nature theory; protection of land, parks and recreation; land preservation voter referendums, the pluralism of interest group activity, and environmentalism.

Some of the expectations for the estimated selection model are guided by Matsusaka's (2005) governance theory of direct democracy which involves three 
conceptual frameworks: the principal-agent notion of the median voter theorem, the quality of legislative and/or citizenship policy issue information, and issue bundling of candidate elections with other ballot items like land preservation voter referendum propositions. Each of these ideas yields interesting insights concerning when direct democracy is likely to be helpful or harmful, and aids in the interpretation of empirical evidence.

The fact that elected officials may have limited information gives rise to the idea of the external costs of representative government. It is also possible that representatives of the electorate make erroneous decisions based upon faulty or incomplete information. In situations where the information necessary to make the "right" decision is widely dispersed in the population, centralized decisionmaking by a select group of representatives can be inefficient compared to the (decentralized) direct decision-making by the populace (Matsusaka, 1992).

For example, representative government decision-making is likely to be efficient for narrow technical issues like the safety standards for a proposed dam because the necessary information can be collected from a small group of experts. However, these same experts may not provide representative government with enough information to decide whether the power generated from the dam is worth the potential of environmental damage from a flooding upriver from the dam. This larger problem requires information about the preferences of the neighboring population and the opinions of citizen residents regarding the tradeoff between power costs and environmental amenities (Matsusaka and McCarty, 2001). 
The objectives of the quantitative research approach are to: (1) statistically analyze the correlation of data variables of the study population or a sample of it; (2) manage the measurement precision of the study's validity and reliability; (3) identify significant correlations or causal connections that may provide answers to the research questions; (4) provide a means to test the research hypotheses; and (5) identify study findings and reach conclusions.

\subsubsection{Study Population and Non-Random Sample}

For this quantitative methodology, the unit of analysis is the U.S. county or county equivalent. Study of the county jurisdiction is important because of a contemporary trend for county governments to accept second order devolution of power and authority from their state, and their growing importance as the regional unit of government closest to the people in any given locality.

The research population is all active county jurisdictions found in 50 U.S. states as of the 1990 and 2000 U.S. Census Bureau decennial database. The research sample group is the 227 county governments in 41 states that selected 456 land preservation voter referendums between 1988 and 2009.

To improve the integrity of the relationship between the date of collected data and the date when the county land preservation voter referendum is placed before the voters, two sub-samples of U.S. counties are created. Each of these two benchmark groups identify with the U.S. Census Bureau decennial years of 1990 and 2000. The 1990 benchmark group includes counties that presented land preservation voter referendums to voters during 1988-1999 and all nonreferendum counties as of the 1990 U.S Census. In turn, the 2000 benchmark 
group includes counties that presented land preservation voter referendums to voters during 2000-2009 and all non-referendum counties as of the 2000 U.S Census. In order to prevent a confounding problem, if a county government held a voter referendum in only one of the benchmark groups, that county was not counted as a non-referendum county in the other benchmark group.

Table 3.1 displays the number of county jurisdictions by state and by the two study benchmark years of 1990 and 2000. Connecticut and Rhode Island do not maintain active county governments; the District of Columbia is not included in the list of counties as it is not found within an American state. According to the

Table 3.1 Number of Counties by State and Benchmark Years 1990 and 2000 Total Counties: $1990=3,043 ; 2000=3,034$

\begin{tabular}{lrrlrr}
\hline State & $1990^{1}$ & $2000^{2}$ & State & $1990^{1}$ & $2000^{2}$ \\
\hline ALABAMA & 67 & 67 & MONTANA & 54 & 54 \\
ALASKA (borough) & 12 & 12 & NEBRASKA & 93 & 93 \\
ARIZONA & 15 & 15 & NEVADA & 16 & 16 \\
ARKANSAS & 75 & 75 & NEW HAMPSHIRE & 10 & 10 \\
CALIFORNIA & 57 & 57 & NEW JERSEY & 21 & 21 \\
COLORADO & 62 & 62 & NEW MEXICO & 33 & 33 \\
CONNECTICUT & 0 & 0 & NEW YORK & 57 & 57 \\
DELAWARE & 3 & 3 & NORTH CAROLINA & 100 & 100 \\
FLORIDA & 66 & 66 & NORTH DAKOTA & 53 & 53 \\
GEORGIA & 157 & 156 & OHIO & 88 & 88 \\
HAWAII & 3 & 3 & OKLAHOMA & 77 & 77 \\
IDAHO & 44 & 44 & OREGON & 36 & 36 \\
ILLINOIS & 102 & 102 & PENNSYLVANIA & 66 & 66 \\
INDIANA & 91 & 91 & RHODE ISLAND & 0 & 0 \\
IOWA & 99 & 99 & SOUTH CAROLINA & 46 & 46 \\
KANSAS & 105 & 104 & SOUTH DAKOTA & 64 & 66 \\
KENTUCKY & 119 & 119 & TENNESSEE & 93 & 92 \\
LOUISIANA (parish) & 61 & 60 & TEXAS & 254 & 254 \\
MAINE & 16 & 16 & UTAH & 29 & 29 \\
MARYLAND & 23 & 23 & VERMONT & 14 & 14 \\
MASSACHUSETTS & 12 & 5 & VIRGINIA & 95 & 95 \\
MICHIGAN & 83 & 83 & WASHINGTON & 39 & 39 \\
MINNESOTA & 87 & 87 & WEST VIRGINIA & 55 & 52 \\
MISSISSIPPI & 82 & 82 & WISCONSIN & 23 & 72 \\
MISSOURI & 114 & WYOMING & 23 \\
\hline
\end{tabular}

Sources:

11992 U.S. Census of Governments, Volume 1, Number 1 (1990 Census data).

2002 U.S. Census of Governments, Volume 1, Number 1 (2000 Census data). 
U.S. Census Bureau, the total number of active counties in 1990 is 3043 , while the total number of active counties in 2000 is 3034 .

The research non-random sample group is the 227 county governments in 41 states that selected 456 land preservation voter referendums with voters passing 340 of them with their 'yes' vote.

Table 3.2 outlines the number of referendum counties by state and number of county referendums selected and passed by state and three time frames: total study years (1988-2009), 1990 benchmark years (1988-1999), and 2000 benchmark years (2000-2009).

For the 1990 benchmark group analysis, there are 117 referendum counties (in 25 states) and 2,926 non-referendum counties. County governments selected 186 land preservation voter referendums and voters passed 137 of them $(73.7 \%)$.

For the 2000 benchmark group analysis, there are 187 referendum counties (in 32 states) and 2,847 non-referendum counties. County governments selected 270 land preservation voter referendums and voters passed 203 of them $(75.2 \%)$.

If a particular county government selected more than one voter referendum for its voters' evaluation between 1988 and 2009, each county referendum is considered a separate county referendum case. 
Table 3.2 County Land Preservation Voter Referendums (Vref) 1988 - 2009

By 34 States and Two Benchmark Years of 1990 and 2000

\begin{tabular}{|c|c|c|c|c|c|c|c|c|c|c|}
\hline & \multirow[b]{2}{*}{ U.S. State } & \multicolumn{3}{|c|}{ Years: 1988 - 2009 (All) } & \multicolumn{3}{|c|}{ Years: 1988 - $1999(1990)$} & \multicolumn{3}{|c|}{ Years: 2000 - 2009 (2000) } \\
\hline & & $\begin{array}{l}\text { VRef } \\
\text { County }\end{array}$ & $\begin{array}{c}\text { Vref } \\
\text { Select }\end{array}$ & $\begin{array}{l}\text { VRef } \\
\text { Pass }\end{array}$ & $\begin{array}{r}90 \text { VRef } \\
\text { County }\end{array}$ & $\begin{array}{r}90 \text { Vref } \\
\text { Select }\end{array}$ & $\begin{array}{r}90 \text { VRef } \\
\text { Pass }\end{array}$ & $\begin{array}{r}00 \text { VRef } \\
\text { County }\end{array}$ & $\begin{array}{r}00 \text { Vref } \\
\text { Select }\end{array}$ & $\begin{array}{r}\text { 00VRef } \\
\text { Pass }\end{array}$ \\
\hline & USA & 227 & 456 & 340 & 117 & 186 & 137 & 187 & 270 & 203 \\
\hline 1 & ALASKA & 1 & 1 & 0 & 0 & 0 & 0 & 1 & 1 & 0 \\
\hline 2 & ARIZONA & 3 & 5 & 4 & 2 & 2 & 1 & 2 & 3 & 3 \\
\hline 3 & CALIFORNIA & 12 & 22 & 12 & 5 & 11 & 6 & 10 & 11 & 6 \\
\hline 4 & COLORADO & 26 & 51 & 38 & 11 & 25 & 20 & 22 & 26 & 18 \\
\hline 5 & FLORIDA & 27 & 64 & 52 & 19 & 29 & 24 & 22 & 35 & 28 \\
\hline 6 & GEORGIA & 14 & 23 & 17 & 3 & 3 & 2 & 13 & 20 & 15 \\
\hline 7 & HAWAll & 4 & 4 & 4 & 0 & 0 & & 4 & 4 & 4 \\
\hline 8 & IDAHO & 1 & 2 & 1 & 1 & 1 & 0 & 1 & 1 & 1 \\
\hline 9 & ILLINOIS & 11 & 24 & 20 & 4 & 9 & 7 & 11 & 15 & 13 \\
\hline 10 & IOWA & 1 & 1 & 1 & 0 & 0 & 0 & 1 & 1 & 1 \\
\hline 11 & KANSAS & 1 & 1 & 1 & 1 & 1 & 1 & 0 & 0 & 0 \\
\hline 12 & KENTUCKY & 1 & 1 & 0 & 0 & 0 & 0 & 1 & 1 & 0 \\
\hline 13 & LOUISIANA & 2 & 2 & 1 & 0 & 0 & 0 & 2 & 2 & 1 \\
\hline 14 & MARYLAND & 2 & 13 & 13 & 2 & 8 & 8 & 1 & 5 & 5 \\
\hline 15 & MASSACHUSETTS & 1 & 1 & 0 & 1 & 1 & 0 & 0 & 0 & 0 \\
\hline 16 & MICHIGAN & 5 & 7 & 4 & 2 & 2 & 1 & 5 & 5 & 3 \\
\hline 17 & MINNESOTA & 2 & 3 & 2 & 0 & 0 & 0 & 2 & 3 & 2 \\
\hline 18 & MISSOURI & 4 & 6 & 6 & 0 & 0 & 0 & 4 & 6 & 6 \\
\hline 19 & MONTANA & 6 & 9 & 6 & 1 & 2 & 1 & 6 & 7 & 5 \\
\hline 20 & NEVADA & 2 & 4 & 1 & 1 & 1 & 0 & 2 & 3 & 1 \\
\hline 21 & NEW JERSEY & 21 & 44 & 41 & 17 & 23 & 22 & 15 & 21 & 19 \\
\hline 22 & NEW MEXICO & 2 & 8 & 8 & 2 & 3 & 3 & 2 & 5 & 5 \\
\hline 23 & NEW YORK & 3 & 9 & 8 & 2 & 4 & 4 & 3 & 5 & 4 \\
\hline 24 & NORTH CAROLINA & 9 & 26 & 18 & 6 & 12 & 8 & 6 & 14 & 10 \\
\hline 25 & $\mathrm{OHIO}$ & 17 & 35 & 18 & 8 & 11 & 7 & 17 & 24 & 11 \\
\hline 26 & OKLAHOMA & 1 & 2 & 0 & 1 & 1 & 0 & 1 & 1 & 0 \\
\hline 27 & PENNSYLVANIA & 9 & 10 & 9 & 4 & 4 & 3 & 6 & 6 & 6 \\
\hline 28 & SOUTH CAROLINA & 3 & 8 & 5 & 0 & 0 & 0 & 3 & 8 & 5 \\
\hline 29 & TEXAS & 7 & 16 & 15 & 4 & 5 & 4 & 7 & 11 & 11 \\
\hline 30 & UTAH & 2 & 4 & 3 & 1 & 1 & 1 & 2 & 3 & 2 \\
\hline 31 & VIRGINIA & 10 & 27 & 23 & 7 & 11 & 9 & 8 & 16 & 14 \\
\hline 32 & WASHINGTON & 12 & 18 & 6 & 11 & 15 & 4 & 3 & 3 & 2 \\
\hline 33 & WISCONSIN & 3 & 3 & 1 & 1 & 1 & 1 & 2 & 2 & 0 \\
\hline 34 & WYOMING & 2 & 2 & 2 & 0 & 0 & 0 & 2 & 2 & 2 \\
\hline
\end{tabular}

Sources: Trust for Public Land's LandVote ${ }^{\star}$ Database, 2012; U.S. Census Bureau, 1990 and 2000.

* Note: Some county governments select multiple VRef within one set of benchmark years and/or in both benchmark years. Therefore, the sum of 1990 and 2000 Vref counties exceeds the data for all years.

\subsubsection{Quantitative Study Variables}

Study variables are selected on the basis of relevant theories, conceptual models and study hypotheses, to assure consistency with previous study findings and feasibility with the Heckman two-step model for analysis. 


\subsubsection{Dependent Variables (DV)}

The primary dependent variable for this research is the passage of a county land preservation voter referendum by its citizens. The secondary dependent variable is the selection of a land preservation voter referendum by county government.

Selection bias is present because the sample of voter referendum cases is self-selected by county jurisdictions in a non-random manner. If selection bias is not accounted for, the outcome of the quantitative analysis could be erroneously attributed to the phenomenon under study rather to the method of sampling. In addition, sample selection bias undermines the external validity of a test (the ability of its results to be generalized to the population) and its internal validity (the differences or similarities found within the sample of voter referendum counties). Therefore, the research design applies the Heckman two-step probit model because of its remedy for sample selection bias (Heckman, 1979).

\subsubsection{Independent Variables (IV)}

For this research design, study independent variables are classified as identifying, explanatory and relevant factor characteristics of the land preservation voter referendum.

\subsection{Identifying Independent Variables}

Five categories of identifying independent variables capture attributes of state government second order federalism and reformed county government. The five identifying independent variables are: (1) state Dillon's Rule; (2) state 
autonomy ranking; (3) state ranking of home rule authority; (4) county home rule charter; and (5) reformed county government structure.

To estimate the assumption of institutional capacity, the following governance and reformed government vectors are included in the selection equation only: (1) a dummy variable that $=1$ if a county's parent state government exercises Dillon's Rule; (2) categorical variable associated with the degree of local government autonomy as measured by its parent state's autonomy ranking; (3) two dummy variables that $=1$ if the state legislature is classified as embracing county government strong home rule authority or weak home rule authority; (4) a dummy variable $=1$ if a county government has a home rule charter ordinance; and (5) two separate dummy variables that $=1$ if a county government's legislative structure is a commission with an elected executive, or a commission with an appointed professional administrator/manager.

\subsection{Explanatory Independent Variables}

The six categories of explanatory independent variables are selected on the basis of the theoretical foundations of the research, variables of significance utilized in prior empirical research about land preservation voter referendums, and scholarly literature and articles that suggest additional factors for future research in this area of study.

First, demographic IVs include decennial census data related to county population variables: total population, population change per decade, median age, and percent of population that is classified as white. Table 3.3 outlines five demographic factors for the United States by four U.S. Census decennial years. 
Table 3.3 United States Demographic Data: 1980 - 2010

\begin{tabular}{rrrrrr}
\hline & $\begin{array}{c}\text { Total } \\
\text { Population }\end{array}$ & $\begin{array}{c}\text { Population } \\
\text { Change ** }\end{array}$ & $\begin{array}{c}\text { Population } \\
\text { Density } \\
\text { SQM }\end{array}$ & $\begin{array}{c}\text { Resident } \\
\text { Median } \\
\text { Age }\end{array}$ & $\begin{array}{c}\text { Population } \\
\% \text { White }\end{array}$ \\
\hline 1980 & $226,545,805$ & 11.5 & 64.0 & 30.0 & * \\
1990 & $248,709,873$ & 9.8 & 70.3 & 32.9 & * \\
2000 & $281,421,906$ & 13.1 & 79.6 & 35.3 & 69.1 \\
2010 & $308,745,538$ & 9.7 & 87.4 & 37.2 & 63.7 \\
\hline
\end{tabular}

* U.S. Census Bureau data collection for 'white race' was modified in 2000 to exclude persons of Hispanic or Latino heritage which was included in 1980 and 1990 data.

** Population change represents growth from previous decennial data; e.g., $1980=1970$ to $198 \mathrm{c}$ Source. U.S. Census Bureau's USA Counties database.

Second, socio-economic categories are a measure of a combination of an individual's or family's economic and social position in relation to others, based on income, education, and occupation. Variables included in this study are the population's share of educational achievement of bachelor's degree of higher, percent of unemployed, median income per household, share of owner-occupied housing, and value of owner-occupied housing.

Third, terrain variables refer to how and where county land is used and geographically located. IVs selected for this group of variables include a NOAA coastal county designation; land area per square mile; share of urbanized land per square mile; and change in housing growth by decade.

Fourth, the data for three political preference variables incorporate the county's share of democratic voters by county in the national presidential elections of 1992 and 2000, state voting age population in 1992 and 2000, and the share of registered voters by state in 1992 and 2000. The democratic party supports a socially liberal and progressive platform that is based on community and shared citizen responsibility. Prior research findings suggest that 
communities with a higher democratic party preference are more inclined to support land preservation voter referendums.

Fifth, the U.S. Census Bureau defines four geographical regions northeast, midwest, south and west. The study's four regional IVs are a dummy variable that $=1$ if a county is located in one of these regions.

Sixth, environmentally-focused organizations in the United States have a core of high-profile interest groups, many of them national in scope. However, the literature describes a loosely organized, broader set of small groups, clubs and volunteers at the grassroots level. The IV for environmental interest groups is the number of state environmental non-profit organizations classified as performing one of the following functions: natural resources alliance and advocacy, forest conservation, land resources conservation, natural resources conservation and protection, professional societies and associations, or water resources, wetlands conservation and management.

\subsection{Voter Referendum-related Descriptive Independent Variables}

Descriptive independent variables represent the three characteristics of a voter referendum: finance mechanism, purpose and selected date for citizen vote.

First, three dummy variables that $=1$ if the referendum funds will be raised through a bond issue, a form of taxation, or monies will be raised by another financial vehicle.

Second, four dummy variables that $=1$ if the purpose of the voter referendum is environmental protection (e.g., open space, park, wildlife, trails, 
forests, greenways, and wetlands); recreation; watershed protection; or farm (e.g., farming, agriculture and ranchlands). Most land preservation voter referendum proposals identify more than one purpose.

Third, three dummy variables that $=1$ if the public vote is held on a presidential election date in November of 1988, 1992, 1996, 2000, 2004, 2008; a non-presidential November election date; or a non-November election date.

\subsubsection{Instrumentation with the Heckman Two-Step Model}

Quantitative research refers to the systematic empirical investigation of social phenomena via statistical, mathematical or computational techniques. One objective of the quantitative research design is to develop and apply the appropriate mathematical models to the study theories, research questions, and hypotheses that relate to the social phenomena under investigation. The process of measurement is central to quantitative research because it provides the fundamental connection between empirical observation and mathematical expression of quantitative relationships. If the appropriate research design and mathematical model is chosen and the study numerical data is analyzed with suitable statistical techniques and programs, the outcomes of the analysis will yield an unbiased result (Given, 2008).

\subsubsection{Testing for Validity and Reliability}

The relationship between validity and reliability is important. Reliability does not imply validity. That is, a reliable measure that is measuring something consistently, may not be measuring what the researcher wants to be measuring. 
while there are many reliable tests of specific abilities, not all of them would be valid for predicting. In terms of accuracy and precision, reliability is analogous to precision, while validity is analogous to accuracy.

\subsection{Validity}

Validity refers to the degree to which inferences can legitimately be made from the operationalizations in this research design to the theoretical constructs on which those operationalizations were based.

Internal validity is concerned with the degree of certainty that observed effects in a quantitative research are actually the result of the data collection independent variables, rather than intervening, extraneous or confounding variables. Internal validity is enhanced by increasing the control of these other variables. Face validity is a simple form of content validity, in which several individuals (dissertation committee) provide oversight of the progress of the research to confirm that the independent variables provide appropriate coverage. Criterion validity is usually measured using a correlation coefficient - when the correlation is high, the outcome can be considered valid. Finally, construct validity tests the linkage between a measurement and the theoretical foundations, and is also measured by using a correlation coefficient.

External validity is concerned with the degree to which research findings can be applied to the real world, beyond the controlled setting of the research. This is the issue of generalizability. Attempts to increase internal validity are likely to reduce external validity as the study is conducted in a manner that is increasingly unlike the real world. 


\subsection{Reliability}

Reliability has to do with the quality of measurement. In its everyday sense, reliability is the "consistency" or "repeatability" of the measures. In the functionalist paradigm, the goal of replication is the service of theory testing and refinement: data should be collected and analyzed in such a way that another researcher collecting and analyzing similar data under similar conditions will find similar results, thus helping establishing the legitimacy of the theory (Shah and Corley, 2006).

This study estimates a measure of reliability when the same statistical test is applied on two different occasions. This approach assumes that there is no substantial change in the construct being measured between the two occasions. Another approach to test for reliability is the parallel forms of the reliability testing modality. Using the Heckman two-stage selection model, parallel statistical tests are run to test for the reliability of the research model.

\subsubsection{The Theoretical Heckman Two-Step Model}

Heckman's (1979) seminal paper examined the bias that results from using non-randomly selected samples to estimate behavioral relationships as an ordinary specification error or "omitted variables" bias. Heckman adapted a simple multiple regression model by proposing a two-stage estimator that enables the researcher to utilize simple regression methods to estimate behavioral functions by probit. The asymptotic distribution of the estimator is derived (Heckman, 1979). 


\subsection{Two Dependent Variables}

Heckman's sample selection model ${ }^{5}$ is based upon the following two latent dependent variable models:

$$
\begin{aligned}
& y_{1}{ }^{*}=\beta 1 x+\varepsilon 1 \\
& y_{2}{ }^{*}=\beta_{2} x+\varepsilon_{2}
\end{aligned}
$$

where $\mathrm{x}$ is a vector of regressors, and possibly containing common components including intercepts. The error terms $\varepsilon_{1}$ and $\varepsilon_{2}$ are independent of $x$, and follow a bivariate normal distribution.

The first equation (1) is the model of interest. However, the latent variable $\mathrm{y}_{1}{ }^{*}$ is only observed if $\mathrm{y}_{2}{ }^{*}>0$. Therefore, the actual dependent variable is:

$$
\begin{gathered}
y=y_{1} \text { if } y_{2}>0 \\
y=\text { missing value if } y_{2} \leq 0
\end{gathered}
$$

The latent dependent variable $\mathrm{y}_{2}$ itself is not observable, only its sign. As a result, if $y$ is observable, then $y_{2}>0$, but if $y$ is not observable then $y_{2} \leq 0$. Accordingly, a sample selection problem could arise such that variance of $\varepsilon_{2}$ is equal to 1.

\subsection{Heckman Step One (Selection)}

In this analysis, the Heckman procedure uses a probit model to estimate step 1, e.g., the selection by a county government of a land preservation voter referendum. This research employs a binary choice (dichotomous) model. The two choices

\footnotetext{
${ }^{5}$ Heckman, J.J. (1979): Sample selection bias as a specification error. Econometrica 47: 153-161. (awarded Nobel prize)
} 
are that a county government either selects a land preservation voter referendum or it does not. Further, this model assumes that the unobserved terms are distributed by standard normal instead of logistically, and with known attributes of county ' $n$ ' but no attributes of the alternative.

The probability that the county government ' $n$ ' chooses alternative ' $i$ ' is expressed as: $\quad$ Prni $=\mathrm{G}(\mathrm{xi}, \mathrm{x})$

The utility of a regression with a this model is the net benefit obtained by taking the action of selecting the voter referendum alternative, as opposed to not taking that action. When the utility ' $U$ ' of $G$ county government $\left(y_{i}\right)$ to take the action is beneficial $\left(1\right.$, if $\left.U_{i}>1\right)$, including independent variable specifications $\left(s_{i}\right)$, and an error term of $\varepsilon_{\mathrm{i}}$, the equation is written as follows:

$$
\begin{aligned}
& U_{\mathrm{n}}=\beta \mathrm{s}_{\mathrm{i}}+\varepsilon_{\mathrm{i}} \\
& \mathrm{y}_{\mathrm{n}}=\left\{\begin{array}{l}
\left\{1, \text { if } \mathrm{U}_{1}>1\right. \\
0, \text { if } \mathrm{U}_{1} \leq 1
\end{array}\right. \\
& \varepsilon_{\mathrm{i}} \sim \text { standard normal }
\end{aligned}
$$

A reduced-form equation for the binomial discrete choice formula of the Heckman Selection (step 1) model is:

$$
\operatorname{Pr}\left(\mathrm{y}_{\mathrm{i}}=1\right)=\phi\left(\beta_{1} \mathrm{~s}_{\mathrm{i} 1}+\beta_{2} \mathrm{~s}_{\mathrm{i} 2}+\ldots++\beta_{\mathrm{k}} \mathrm{s}_{\mathrm{ik}}\right)+\varepsilon_{\mathrm{i}}
$$

\subsection{Heckman Step Two (Results)}

The value of the dependent variable, a "yes" vote for passage at the ballot box, is defined as a linear combination of the multiple explanatory independent variables plus an error term, where $Y$ is a binary variable, the $\beta$ s are the 
regression coefficients, ' $x$ 's are the independent variables, ' $k$ ' is the number of independent variables, and $\varepsilon$ is a vector of the errors of prediction:

$$
Y=\beta_{0}+\beta_{1} x_{1}+\beta_{2} x_{2}+\beta_{k} x_{k}+\varepsilon_{i}
$$

The errors are assumed to be normally distributed with an expected value of zero and a common variance.

The logistic formulas are stated in terms of the probability ' $p$ ' that $y=1$. The probability that $y=$ " 0 " is $(1-p)$. 'Log' refers to a natural logarithm. The regression equation is:

$$
\log (p / 1-p)=\beta_{0}+\beta_{1} x_{1}+\beta_{2} x_{2}+\ldots \beta_{k} x_{k}
$$

The likelihood ratio test (G): a chi-square difference test using the "null" or constant-only model. Instead of using the deviance to judge the overall fit of a model, another statistic is usually used that compares the fit of the model with and without the predictor(s). The deviance is expected to decrease, because the degree of error in prediction decreases as we add another variable.

Estimated Inverse Mill's Ratio (IMR) for Heckman Model $(\sigma \lambda)$. The Inverse Mill's Ratio is a function that controls for selection bias. The estimates of $\gamma$ from Heckman's step one are used to construct consistent estimates of the Inverse Mill's Ratio term. Step two applies the constructed value of the Inverse Mill's Ratio. Coefficient $\sigma>1$, and indicates the correlation between the unobservables of both stages. Coefficient $\lambda$ is obtained by multiplying rho with sigma.

Standard Errors $(\varepsilon)$. Included in the Heckman model's standard errors are the following: (1) the additional variance that results from the generated 
regressor, namely the Inverse Mill's Ratio term; (2) there will be more truncation and thus a lower variance of the error term because of the selection and heteroskedasticity; and (3) spatial dependence is induced by the fact that a common $\gamma$ is used to construct the estimated Inverse Mill's Ratio for all of the observations in the model.

The Heckman selection, bias-corrected results equation (step two) for the probability ' $p$ ' that $y=1$ is:

$$
\log (p / 1-p)=G\left(\beta_{0}+\beta_{1} x_{1}+\beta_{2} x_{2}+\beta_{k} x_{k}\right)+\sigma \lambda_{i}+\varepsilon_{i}
$$

\subsection{Heckman Selection Model Assumptions}

Several concerns when applying the Heckman selection model have been noted by some researchers. First, the model requires an exclusive restriction/instrument or the model is identified solely on the distributional assumptions of a regular regression model (Satori, 2003). Second, the model is very sensitive to the assumption of bivariate normality (Winship and Mare, 1992).

Third, the ' $p$ ' parameter is very sensitive in some common applications (Brandt and Schneider, 2004); e.g., Satori (2003) finds that the 95\% confidence interval is from $p=-0.999999$ to +0.99255 .

\subsubsection{Quantitative Analysis: Inferential Statistics of the Variables}

Referendum results are determined by collecting and consolidating the results of the votes of the individuals who voted. Under standard assumptions, a voter chooses the option that provides the greatest utility function to him/her. However, only the collective count of all votes on the referendum is determined. 
Using individual utility maximization as the foundation for explaining referendum outcomes requires that individual votes in a county be aggregated by majority rule or other standard (e.g., supra-majority requirement).

Various researchers have provided appropriate theory, justification and empirical approach for such aggregation (Deacon and Shapiro, 1975; Fair, 1978; Fischel, 1979). Equation (2) is consistent with the voter aggregate literature. Specifically, the empirical referendum result equation used in this analysis is a linear measurement of a voter aggregation model that does not consider nonparticipation in the referendum vote (Kline and Wichelns, 1994; Kahn and Matsusaka, 1997; Kotchen and Powers, 2004).

This study predicts that land preservation voter referendums will be more successful in county entities that are delegated greater autonomy for selfgovernment by their state legislature and that have adopted governmental reforms (e.g., home rule charter ordinance and either an elected chief executive plus commission or appointed county administrator/manager plus commission.

It is expected that the odds of a "yes" vote in an open space referendum will be an increasing function of the size and growth of the population, a higher median age, a more highly educated electorate (B.A. degree or higher), a higher household income, a larger share of white citizens, and positive attitudes toward publicly-provided environmental issues and land preservation.

It is also anticipated that the type of the voter referendum finance mechanism proposed through the referendum will affect the outcome of the vote; specifically, new taxes are expected to decrease the odds of a "yes" vote the 
most, bond financing and the continuation of existing open space taxes will have less of an adverse effect on referendum support, and a reallocation of existing public funds will be the financing option least objectionable to referendum voters.

Also, it is predicted that one or more of the purpose(s) of the referendum ballot measure will have a positive impact on the voter outcome.

Finally, counties within states and regions that maintain significantly large affiliations with environmental organizations (as of 2000) are more likely to support local area 'grassroots' momentum necessary to influence a county government to select and place a land preservation voter referendum on the ballot for citizen decision-making on election day.

\subsection{Qualitative Methodology with Case Study Model}

Creswell (2007) describes five types of qualitative research: narrative research, phenomenology, grounded theory, case study, and ethnography.

There are several reasons why the case study approach is selected for this research. The first reason is to be able to investigate specific manifestations of the land preservation voter referendum county in which there are many more variables of interest than quantitative data points. A mixed methodology that incorporates both quantitative and qualitative approaches is able to rely on multiple sources of evidence that are both written and verbal. Finally, this type of research benefits from the prior development of a theoretical framework to guide that qualitative research design, data collection, and data analysis (Yin, 2003).

The case study is the method of choice when the data to be collected about a situation will come from many sources including people, observation, 
records, etc. (Yin, 2003). Case method is most useful when the research is focused on a "specific, unique, bounded system" (Stake, 1998), and often employs a combination of qualitative and quantitative data collection techniques (Yin, 2003). The focus of the case can be an individual, an event, a family, an organization, or a place (Mariano, 1995). The uniqueness of case method lies in the focus of the study on the case (Stake, 1998).

Denzin and Lincoln (1994) offer a generic definition of the case study model: "Qualitative research is multi-method in focus, involving an interpretive, naturalist approach to its subject matter." Through case study methods of documentation and interviews, a researcher is able to go beyond the quantitative statistical results and understand the behavioral conditions through the expert witnesses' perspective. By including both quantitative and qualitative data, case study helps explain both the process and outcome of a phenomenon through complete observation, reconstruction and analysis of the cases under investigation (Tellis, 1997).

\subsubsection{Qualitative Case Study Research Design}

The qualitative research design for this study is explanatory, descriptive and empirical (Guba and Lincoln, 1981; Mariano, 1995). Explanatory and descriptive research designs ask "why" something is occurring and "how" are the causal relationships between factors significant. Because the focus of the case study approach is on the contemporary, real-life experiences of sample county cases with the land reservation voter referendum, it is an empirical inquiry. 
A research study can be designed to study a single case, or multiple cases. A single case may be a typical case or it may be something that is unique (Mariano, 1995). Multiple cases are used when the researcher is interested in the same issue in different situations, or to understand a particular situation from different perspectives. Case method is a research design that is often guided by a framework, and is useful to investigate a complex contemporary phenomenon using multiple data sources (Yin, 2003). Figure 3.4 offers a diagram of the analytical framework for the qualitative sample county case research design.

Figure 3.4 Analytical Framework for the Qualitative Case Study Approach

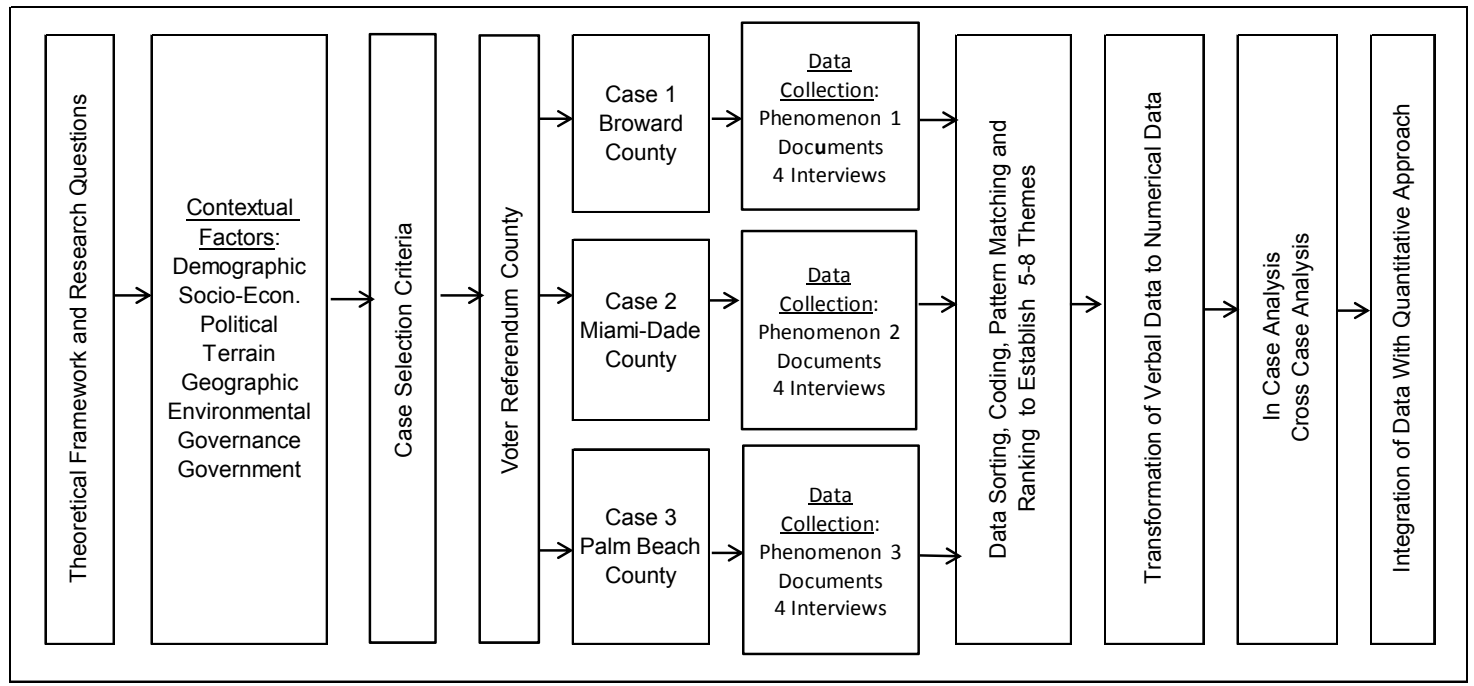

Based upon the theoretical foundations of this research, the case study research design is limited in scope by its in-depth investigation of only several county cases. However, it is anticipated that the findings of the case study approach will point attention to any omissions in the prior quantitative research findings and suggest possible logical patterns and linkages between statistical findings and the general circumstances of the case counties to be studied. 
The unit of analysis for the qualitative case study design is the causal process by which the county land preservation voter referendum is passed by voters at the ballot box. In this sequential, mixed methodology, the qualitative approach is complimentary to and descriptive of the quantitative statistical analysis of its unit of analysis, the U.S. county. (Yin, 1994).

In summary, the qualitative research provides a conceptual and analytical framework which includes an action plan for obtaining pragmatic and real life referendum county data, conversion of qualitative data to numerical data, and finally the integration with the prior quantitative data findings. The preliminary criteria for interpreting the qualitative findings include the application of in case and between case techniques. However, there is no precise method for setting the definitive criteria until the case studies are in progress and/or completed because the outcome of the data collection may inspire similar or different evaluation criteria.

\subsubsection{Selecting the Sample of County Cases}

Despite the importance of the subject, and its evident complexities, the question of case selection has received relatively little attention from scholars since the pioneering work of Eckstein (1975), Lijphart (1971, 1975), and Przeworski and Teune (1970). In the absence of detailed, formal treatments, scholars continue to lean primarily on pragmatic considerations such as time, money, expertise, and access (Seawright and Gerring, 2008); however, this set of factors is not methodological in character and does not bear well on the validity of an inference stemming from a case study. 
Eisenhardt (1989) suggests limiting the number of cases to the point where the incremental contribution of extra cases is only marginal, but with the flexibility of adding additional cases if necessary (Benbasat et al., 1987). In identifying the appropriate case study counties, these scholars also suggest that each case exhibit relative independence, as measured by separation of their internal county government authority.

For this study, the focus of county case selection depends upon the crosscase characteristics of a case: how each case fits into the theoretically specified population. Seawright and Gerring (2008) identify seven cross-case methods of case selection and analysis: typical, diverse, extreme, deviant, influential, most similar, and most different.

The most different method of case selection is utilized for this research because its confirmatory use provides evidence of the existent of the causal relationship. The most different method seeks to identify cases where one (or one group of) independent variable(s) as well as the dependent variable covary, and all other plausible independent variables show different values. These are deemed most different cases, though they are similar in two essential respects: the causal variable (or variables) of interest $\left(\mathrm{X}_{1}\right)$ and the outcome $(\mathrm{Y})$.

Two or more cases are selected for this study that are 'different' according to these qualifications. Most different cases that are broadly representative of the population will provide the strongest basis for generalization. Table 3.4 provides a representation of the relationships of the dependent and independent variables in a most different case selection design. 
Table 3.4 Most Different Analysis with Three Cases

\begin{tabular}{crcc} 
Variable & Case 1 & Case 2 & Case 3 \\
\hline Y & + & + & + \\
X 1 & + & + & + \\
X 2 & - & - & - \\
X 3 & - & - & - \\
X 4 & - & - & - \\
X 5 & - & - & - \\
\hline
\end{tabular}

Note: Plusses and minuses respresent the score by a case on a particular variable $(X)$ coded dichotomously. $X_{1}=$ the variable of theoretical interest; $X_{2-5}=$ backup variables; $Y=$ the outcome.

Of the 227 U.S. county jurisdictions selecting and proposing land preservation voter referendums for their citizens' vote, the State of Florida demonstrates the most voter referendum counties at 27 .

The key to the most different case selection design is to understand that very different units/cases have the same outcome ( $\mathrm{Y}$ variable). The search is then for a key explanatory variable common to the cases where other independent variables appear different from each other. Based on the criteria of the most different case selection method and an overview of 27 Florida counties, three South Florida counties are chosen for this research. Table 3.5 demonstrates how and why these three counties fit the most different case selection methodology. 
Table 3.5 Different Case Selection of Three South Florida Counties

\begin{tabular}{|c|c|c|c|c|}
\hline & Referendum Variables (2000) & Broward & Miami-Dade & Palm Beach \\
\hline \multirow[t]{2}{*}{$\mathrm{Y}$} & Voter Referendums Pass & All & All & All \\
\hline & Number of Voter Referendum & 2 & 5 & 4 \\
\hline${ }^{*} \times 1$ & Reformed Government & Yes & Yes & Yes \\
\hline${ }^{*} \times 2$ & 2nd Order Federalism & High & High & High \\
\hline${ }^{*} \times 3$ & Environmental Organizations & High & High & High \\
\hline$\times 4$ & Home Rule Charter & County & Two Tier & County \\
\hline$\times 5$ & County Government Form & Admin & Elec Exec & Admin \\
\hline$\times 6$ & Population Density & 13.469 & 11.579 & 5.73 \\
\hline$\times 7$ & Population Growth \% & 29.3 & 16.3 & 31 \\
\hline$\times 8$ & Median Age & 37.8 & 35.6 & 41.8 \\
\hline$\times 9$ & Education (BA and Higher) \% & 24.5 & 21.7 & 27.7 \\
\hline$\times 10$ & Mean Household Income (1K) & 17.381 & 12.938 & 20.304 \\
\hline X 11 & Housing Growth \% & 17.9 & 10.5 & 20.5 \\
\hline$\times 12$ & Urban land \% & 99.86 & 99.29 & 98.34 \\
\hline$\times 13$ & Land Area (sq. mi.) & 91.34 & 80.04 & 82.73 \\
\hline$\times 14$ & Water Area (sq.mi.) & 114.2 & 485.2 & 421.2 \\
\hline$\times 15$ & Conservation Area (sq.mi.) & 787 & 1,527 & 556 \\
\hline$\times 16$ & Farmland/Agriculture (acre) & 23,741 & 90,373 & 513,670 \\
\hline$\times 17$ & Residents in Unincorp. Areas & $8 \%$ & $52 \%$ & $41 \%$ \\
\hline$\times 18$ & Number of Municipalities & 30 & 35 & 38 \\
\hline$\times 19$ & Democratic Preference \% & 67.4 & 52.6 & 62.3 \\
\hline
\end{tabular}

\subsubsection{Conducting the Case Study}

Once the case selection protocol has been developed and implemented, there are several interrelated tasks for executing the case studies. In this phase, the primary activity is data collection. In case studies, data collection should be treated as a design issue that will enhance the construct and internal validity of the study, as well as the external validity and reliability (Yin, 1994). Most of the field methods described in the literature treat data collection in isolation from the other aspects of the research process (Yin, 1994), but that would not be productive in case study research. 


\subsubsection{Qualitative Data Collection}

This study applies Yin's (1994) three principles of data collection: to use multiple sources of data, build a case study database, and maintain a chain of evidence. The rationale for using multiple sources of data is the triangulation of evidence. Triangulation increases the reliability of the data and the process of gathering it. In the context of data collection, triangulation serves to corroborate the data gathered from other sources.

A variety of data gathering methods are employed to produce significant evidence and data that leads to a better understanding of each of the three South Florida county study cases, while responding to the theoretical foundations and the research questions. The multiple sources of evidence and data are government and stakeholder documentation; national, state and county-specific websites and databases; archival records; and expert witness interviews. No single source has a particular advantage over another (Yin, 1994). Therefore the use of multiple sources is intended to be cumulative, complementary and contributory to the robustness and rigor of the case study design.

Case study documents include letters, memoranda, agendas, study reports, or any items that should be added to the case study data base. The validity of the documents is carefully reviewed so as to avoid incorrect data being included in the data base. One of the most important uses of documents is to corroborate evidence gathered from other sources. The potential for overreliance on document as evidence in case studies has been criticized. 


\subsubsection{Expert Witness Interviews}

Expert interviews are one of the most important sources of case study information. For this research a case study expert is defined as a county government professional who has acquired policy, administration and management knowledge and skills through study and practice over multiple years in the field of land preservation voter referendum. The breadth and depth of the expert's opinion may be helpful in fact-finding, problem-solving or understanding the research topic in the realistic domain of its real-life implementation. An additional criterion requires that the expert testimony falls within the theoretical framework of the study, research questions and hypotheses, and prior quantitative analyses of statistical county factors. Finally, the expert interviewee responses provide insightful and causal inferences to be conjoined to the research design.

One of the strengths of the expert interview is that it focuses directly on the case study topic. However, limitations of this data collection device are that an expert may embrace a previously unknown bias, provide inaccuracies due to poor recall, or offer reflexivity whereby the interviewee furnishes what the interviewer desires to hear. Also, the length and quality of the interview depends upon the expertise and skill of the researcher interviewer (Yin, 1994).

Key informants from the case counties are "privileged witnesses", or people who, because of their position, activities or responsibilities, have varying perspectives and opinions about their county's governance, government, community characteristics, and land preservation voter referendums. These 
witnesses are also citizens of the case county targeted by the study, and thus have a citizen's interest in the implications of the passage (or failure) of land preservation voter referendum.

Four expert witnesses per county case are chosen for interview (a total of twelve) based upon their managerial or senior administrative position and experience with a case county government's land preservation voter referendum and other study variables. Multiple expert witnesses per case county are important in order to capture the viewpoints of a range of professional employee responsibilities and to compensate for potential informational recall shortcomings. However, the number of interviews is restricted by the availability of qualified key informants who agree to the terms of the semi-structured interview process.

\subsubsection{Semi-Structured Interview Questionnaire}

Flick (1998) postulates approaches to verbal data as "methodological currents in qualitative research." In these approaches, different strategies are applied to achieve openness toward the topic under study and the views of the interviewee in the discussions. This scholar puts forth four points of reference to consider in the researcher's decision between different methods. First, create study criteria that are based on comparison of the various forms of collecting verbal data. Next, select the appropriate method and check its application to the research design. Then, evaluate the appropriateness of the method to the study topic. Finally, fit the selected methodology into the research design and process. 
This qualitative research design follows acceptable semi-structured interviewing protocols (Merton and Kendall 1946; Merton, Fiske and Kendall, 1956; Kvale, 1996; Seidman, 1998), and evaluation of this protocol with appropriate techniques for qualitative data analysis (King, Feltey and Susel, 1994; Miles and Huberman 1994; Rubin and Rubin, 1995; Silverman 2004). The semi-structured interview is selected because of the expectation that the county government expert witnesses' points of view are more likely to be expressed in a relatively informal and conversational environment. Secondly, expert interviews of this type are suited to working with small samples, and are useful for supplementing and validating information derived from other sources (e.g., the outcome of a prior quantitative research).

The nature of the interview questioning is flexible, open-ended, two-way communications, yet focused on obtaining information about land preservation voter referendums and point of view about the phenomenon of study for each case county. In addition, since the semi-structured interview provides access to perceptions and opinions, it is effective in gaining insight into case problems that were not immediately perceptible, but nonetheless important, to the research project. Subjects are encouraged to explore their experiences in depth and share personal stories that will add richness and texture to the data collection.

There are a number of benefits in utilizing a semi-structured interview protocol. This format is useful for studying specific phenomenon or for supplementing and validating information obtained from the prior quantitative research analysis of the study topic. In addition, the main interview questions 
can be prepared ahead of time with a goal of seeking to clarify complex questions and issues raised by the quantitative analysis. A selection of predetermined secondary and clarifying questions probe for an in-depth understanding of a phenomenon.

Because of its informal and conversational format, a semi-structured interview format is conducive to an interviewee's willingness to share stories, perception, opinions, and insight into issues that were not perceptible from a research of the scholarly literature or the quantitative analysis of data. Informants are given the freedom to express their views in their own terms, and the output can provide reliable, comparable qualitative data for enrichment purposes.

The verbal data collection protocol includes the following steps. First, the researcher contacts prospective expert witness public administrators representing land preservation voter referendum experience in Broward, MiamiDade and Palm Beach Counties, FL. Prior to the interview, both interviewee and researcher complete a FIU Adult Consent to Participate in a Research Study. Samples of both documents can be found in the Appendix of this research document. The twelve expert witness interviews arranged and were completed during the month of September 2012.

The researcher captures the verbal data by recording the interview on an audio device and taking notations. The recorded interview is transcribed using a speech recognition software technology. Finally, the transcripts are manually coded, combined, categorized, value-ranked and analyzed by major themes. 


\subsubsection{Qualitative Data Coding}

Coding is a process for both categorizing qualitative data and for describing the implications and details of these categories. Initially one does open coding, considering the data in minute detail while developing some initial categories. Later, one moves to more selective coding where one systematically codes with respect to a core concept.

Data coding is "a systematic way in which to condense extensive data sets into smaller analyzable units through the creation of categories and concepts derived from the data" (Lockyer, 2004). Coding values for case study expert witness interviews are developed inductively during data collection and during data analysis (Miles and Huberman, 1994).

The purpose of the initial coding of the interview transcripts is to establish a word or short phrase that symbolically assigns a summative, salient, essencecapturing and/or evocative attribute for a segment of the verbal data. A coding pattern is characterized as similarity, difference, frequency, sequence, correspondence and/or causation. Hatch (2002) states that borders of coding patterns are often irregular, not rigid.

A recoding or refinement of the preliminary coding patterns ascertains broad categories and themes. Richards and Morse (2007) declare that "categorizing is how we (researcher) get 'up' from the diversity of data to the shapes of the data, the sorts of things represented. Concepts are how we get up to more general, higher level, and more abstract constructs." 
The actual number of codes, categories, themes and concepts vary depending on many contextual factors. Lichtman (2006) projects that most qualitative research studies will generate $80-100$ codes that translate into $15-20$ categories which are then synthesized into 5-7 propositional-sized units. For this research, the county expert witnesses' recall of events and stories can be optionally represented either as a causal chain (Trabasso and van den Broek, 1985) or a tree of goals and sub goals (Means and Voss, 1985).

Seeking patterns in the depicted data is not unlike looking for patterns in other types of dependent measures, such as reaction time plots, in which one looks for linear trends or U-shaped functions. Quantifying the pattern that emerges is comparable to capturing the structure of the representation. However, for this research study it is possible that coherence and structure in the depicted data can be assessed without a quantitative tallying. For example, if one depicted data is a causal chain of events for a story, one might capture coherence of the causal chain in terms of whether all the relevant events were part of the causal chain, as did van den Broek (1989), or whether subjects represented the events of a story in a hierarchical or sequential manner. In this case, coherence really refers to the structure of the representation, such as whether all the events of a story are related to the main causal chain of the story.

Interpretation of the perceived pattern in the depicted data, as in the pattern-seeking stage and other stages of the analyses, again depends entirely upon the hypotheses being tested, the research questions being asked, and the theoretical orientation of the study. Data can be interpreted in terms of the 
strategies and processes, or the structure and content of the knowledge base, or both.

One way to validate an interpretation is to substantiate it with additional evidence that is a complement approach in which qualitative analysis is coupled with quantitative such as this mixed methods research design. Another way to achieve validity is to code the data twice, in something like a two-pass approach methodology.

\subsubsection{Analysis of Qualitative Data}

Qualitative research excels at "telling the story" from the case study documentation and expert witness interviewees' viewpoint, providing the rich descriptive detail that sets the outcomes of the quantitative approach into its human context. Because qualitative research excels at generating information that is very detailed, document and verbal data coding summarizes and shapes the final tabulation of major ideas and thematic generalizations.

To examine the historical, contextual, governance and government, and case county-specific phenomena of interest, the focus of the analysis is to link numerous observations within a case in such a way as to provide causal inferences. This research applies both within case and between or cross case analysis to provide a causal linkage of key themes to account for empirical evidence. The within-case analysis focuses on examining individual causal linkages (Eisenhardt, 1989). The purpose of the within-case analysis is to trace key factors in each case county and its phenomenon of interest and discover a causal mechanism that is complementary to the analytical framework. 
This qualitative research proposes to specify some commonalities and differences found in and between the three cases. As Gerring (2004) claims, the tradeoff between comparability and representativeness is intrinsic to the case study choice of research design. Since the three selected cases are different but mutually related because of primary study contextual factors and each holding multiple county land preservation voter referendums between 1988 and 2009, the cross-case analysis is used to comparatively generalize some commonalities of key features with regard to the county-specific phenomena of interest and the land preservation voter referendum process in general.

Guba and Lincoln (1989) propose four standards for judging the soundness of qualitative research. First, the credibility criteria involves establishing the believability of the document and verbal data; for this study, credibility is based upon the public administrators' years of public service and experience with land preservation voter referendums. Second, the transferability standard means the degree to which the qualitative outcomes can be transferred to or generalized about other county jurisdictions; the judgment potential of the researcher is improved by conducting multi-case studies, thoroughly researching documentation, and carefully coding verbal data. Third, this qualitative approach constructs various hypothetical theory or notions about the phenomena of interest as an alternative to the quantitative assumption of reliability or replicability. Fourth, the confirmability criteria refers to the degree to which the study outcomes could be endorsed by others; to minimize the assumption that 
researchers bring a unique perspective to the study, outputs of multiple case studies and expert interviews are verified.

\subsubsection{Case Study Assumptions}

Scholars have noted several challenges to utilizing qualitative research techniques. First, the technical aspects of collecting documentation, the skill of interviewing expert witnesses, transcribing data, and controlling other aspects of the qualitative data transformational methods require time for careful thought and planning to ensure that the results obtained are as accurate as possible. A second apprehension is that qualitative data analysis provides a guide to general trends and cannot be mathematically analyzed in the same comprehensive way as quantitative research. A third criticism of qualitative research design is its uniqueness and inability to be exactly recreated or replicated.

\subsection{Integration of Quantitative and Qualitative Approaches}

A major goal of the Onwuegbuzie and Leech (2006) framework is to illustrate that research questions and data analysis procedures in mixed method studies are linked and should occur logically and sequentially. The principal research objective of this study is to identify significant government, governance and environmental factors that influence both the selection and passage of a county land preservation voter referendum in 50 United States. The research questions are designed to respond to this objective and probe for significant factors most relevant to the research problem. 
There are several ways to integrate quantitative and qualitative methods by which the secondary qualitative approach completes, compliments, and enriches the initial quantitative analysis. Blending qualitative and quantitative research does not necessarily refer to the analysis of the easily quantifiable aspects of qualitative data, such as counting the frequency of occurrence of a given word in the transcription of verbal data.

The most straightforward way to integrate the two methods is to apply some form of quantitative measures in concert with the qualitative measures. This "complement approach" has been used widely, such as collecting scores of the problem-solving success along with the verbalizations of problem solving, or collecting IQ or achievement test scores along with the verbalizations. In the former case, the quantitative data collected can serve as confirmation of the qualitative analyses and vice versa. Both the quantitative and qualitative data are treated more or less with equal weights.

This study utilizes an explanatory, sequential mixed methodology, the "interpretive approach" that Chi, Feltovich and Glasser (1981) used in some of their research. The thematic patterns from the outcome of the qualitative approach can be treated as similarity judgment data, and quantitatively analyzed using factor analysis and correlation matrices. This research uses the qualitative data as an aid in the interpretation and understanding of the quantitative outcomes, but no claim is made about the qualitative data per se. Hence, the primary emphasis of the study remains with the initial quantitative approach. 


\subsection{Summary}

Chapter III presents the methodology for conducting this research. The nature of the study is explanatory.

A sequential mixed methods approach is chosen to investigate the causal relationships of the county jurisdiction from the perspective of selecting and passing a land preservation voter referendum or not.

First, the five research questions and five study hypotheses are describe and stated. The research design, grounded in the conceptual framework of the research, is presented in terms of an analytical framework.

Second, the quantitative method applies the Heckman two-step probit model to community factors, voter referendum characteristics, second order federalism or governance variables; reformed county government factors; and environmental interest group features. The county and factor data is collected in two time-sensitive groups based on U.S. Census Bureau years1990 and 2000.

Third, the qualitative sample selection method of most different is used to identify three South Florida county cases from a population of 227 land preservation voter referendum counties nationwide, and 27 in Florida. The most different cases are used to explain, describe and confirm the quantitative findings and validate county-specific phenomena of interest, while the similar dependent variable (measure passage) and three independent variables of theoretical interest are held constant. Data is collected from county case documentation and twelve public administrator interviews; once transcribed, the data is coded, ranked, sorted and summarized into several thematic contexts. Both within and 
cross-case analysis are conducted. Integration of the quantitative and qualitative components takes the "interpretive" findings of the qualitative analysis as a means to complete, enrich and humanize the quantitative findings through pattern matching. 


\section{CHAPTER IV}

\section{QUANTITATIVE APPROACH}

\subsection{Introduction}

Chapter IV presents the quantitative research approach of this study, grounded in the study's theoretical foundations, research design and research questions. Discussion of the data collection process and databases ensures that the quantitative research data is well defined and accurate, and that decisions based upon consideration of the findings are valid. Heckman two-step model is fitted with study dependent and independent variables. Descriptive statistics of the dependent and independent variables are presented for two groups of referendum and non-referendum counties based upon the benchmark years of 1990 (1988-1999) and 2000 (2000-2009).

With the Heckman two-step model, estimates of the probit sample selection and passage equations are given. The statistical analysis of study data also tests for the strength of the predicted probability of the model, the sign and magnitude of the coefficients of independent variables, and the p-value of independent variables. Significance is determined by a confidence level of 90 percent or higher. Quantitative research findings contribute to the integration of the quantitative and qualitative study outcomes.

\subsection{Analytical Framework for the Quantitative Approach}

The analytical framework for assessing the factors that influence a U.S. counties to select, and their voters to pass, land preservation voter referendums 
guides the quantitative approach from theoretical concepts through regression of contextual factors and data collection of numerical details and regression of contextual factors. This follows a long tradition in statistics called the hypothetical-deductive model. See Figure 4.1.

Figure 4.1 Analytical Framework for Quantitative Analysis

U.S. County (Land Preservation Voter Referendum)

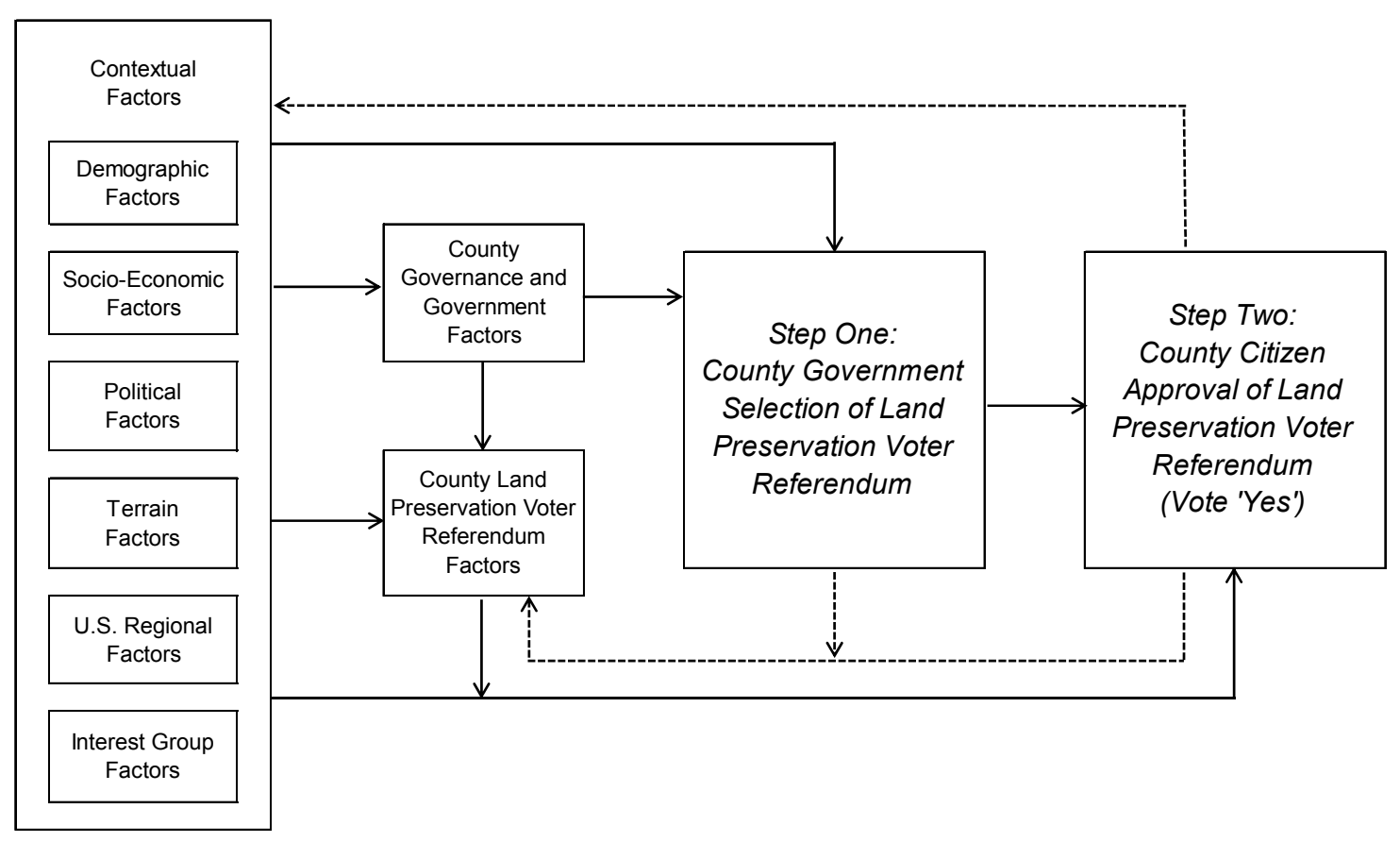

\subsection{Data Collection}

The basic reason for collecting data in any research study is to gather information that responds to research questions and hypotheses (Creswell and Plano Clark, 2011). The intent of probabilistic sampling in quantitative research is to select a sample that represents a segment of the population. For this quantitative approach, the non-random sample is 227 land preservation voter referendum counties of the total population of all U.S. counties. Other 
considerations for quantitative data collection are the theoretical foundations, research design, research questions and benchmark groups of 1990 and 2000, dependent and independent variables, database resources, and the study instrumentation model.

For this quantitative research approach, data is obtained from a number of non-profit and governmental web-based databases, books, scholarly journals, research papers, and governmental documents. The reason for employing webbased resources as a source of data and information for this study is because of its accessibility, reliability and breadth of coverage. Other resources include national and state professional organizations, e.g. National Association of Counties (NACo), National Center for the Study of Counties (NCSC), statespecific association of counties, American Society of Public Administration (ASPA), International City/County Management Association, and National Association of County Planners.

\subsubsection{The Trust for Public Lands LandVote $®$ Database}

The Trust for Public Land (TPL) is a national, non-profit land conservation organization that promotes the preservation of open space, parks, gardens, historic sites, rural areas, and natural or threaten conservation areas. The Trust for Public Land works throughout America to guide and assist public agencies and communities conserve land for public use and public benefit. TPL assists governmental jurisdictions plan solutions, raise funds, complete their conservation acquisitions, and assist with the implementation of successful projects. 
The national TPL LandVote $®$ database provides a comprehensive archive of state, county, local, and special district governments' land preservation voter referendum data (1988 through present). Information collected about each referendum includes: date, state, jurisdiction name and type, TPL regional classification, purpose ${ }^{6}$ of the referendum, funds at stake, finance mechanism ${ }^{7}$, number and percent of votes "yes", number and percent of votes "no", referendum pass/fail, total funds approved, and total funds lost.

For this research, data extracted from the TPL LandVote ${ }^{\circledR}$ database is restricted to county voter referendums held from 1988 through 2009. Based on the theoretical foundation and research questions, referendum-specific data collected for this study is related to the ballot measure date, purpose of the land preservation referendum, its financing mechanism, percent and share of votes "yes" for passage ${ }^{8}$, whether the ballot measure passed or not, and the total funds approved if the voter approved the ballot measure.

\subsubsection{United States Census Bureau and USA Counties ${ }^{\mathrm{TM}}$}

A significant resource concerning United State county or county equivalent data is the U.S. Department of Commerce, United States Census Bureau and its 'USA Counties ${ }^{\mathrm{TM}}$ ' database. USA Counties ${ }^{\mathrm{TM}}$ features more than 6,600 data items for the United States, its states, District of Columbia, and counties from a

\footnotetext{
$6 \quad$ The pupose of the referendum is determined by The Trust for Public Land.

7 Note: All taxing mechanisms (e.g. sales, property and real estate transfer taxes are combined for this quantitative analysis in order to streamline the number of independent variables).

${ }^{8}$ Note: A few county referendum measures required a supra-majority for passage, and may have failed with only a simple majority of voters' approval.
} 
variety of resources. USA Counties is part of a series of products featuring county-level data. The data files include all of the data published for counties in the latest editions of the State and Metropolitan Area Data Book and the County and City Data Book, and more. Emphasis has been placed on extending time series in contrast to most other statistical files, which feature data for the recent period.

These data files contain a collection of numbers and figures assembled from the U. S. Census Bureau and other Federal agencies, such as the Bureau of Economic Analysis, the Bureau of Labor Statistics, the Federal Bureau of Investigation, the Internal Revenue Service and the Social Security Administration. Data resources vary from item to item within USA Counties.

The records of this database include demographic, economic, and governmental data that are presented for the purpose of multi-county comparisons like this research. The data files cover the following general topics: accommodation and food services, age, agriculture, ancestry, banking, building permits, county business patterns, civilian labor force, crime, earnings, education, elections, employment, geography, government, health, race, households, housing, income, local government (revenue and debt), manufactures, non-employer statistics, population, poverty, race and Hispanic origin, retail trade, social programs, survey of business owners, taxes, veterans, vital statistics, water use, wholesale trade and more.

The time intervals covered for each data item also vary. Generally, for data resources that are available on an annual basis, several years of data are 
presented (e.g., personal income data from the Bureau of Economic Analysis is available from 1969 through 2007). For decennial and economic census data, comparable information from a prior census is available (e.g., 1930, 1940, 1950, 1960, 1970, 1980, 1990 and 2000 population; 1979, 1989 and 1999 per capita money income).

USA Counties ${ }^{\mathrm{TM}}$ categories of data collected for in study include county demographic information, socio-economic characteristics, terrain or land features, and political party preference. The benchmark years of 1989 (for the 1990 group of county referendums) and 1999 (for the similar 2000 group) are collected for per capita income data. Finally, election result data is collected on non-presidential election Novembers, and all other election dates.

\subsubsection{State Dillon's Rule Data}

Perhaps the most complete definition of local government autonomy comes from Clark (1984). Clark defines local autonomy in terms of two levels. Level one includes autonomy received through constitutions, rules, standards, and mandates. Level two refers to autonomy received through implementation and political interpretation of the social institutions. Conflict abounds at the second level, surrounding the issues of application and adjudication of rules.

The theory of state preeminence over local governments was expressed as Dillon's Rule in in an 1868 case: "Municipal corporations owe their origin to, and derive their powers and rights wholly from, the legislature. It breathes into them the breath of life, without which they cannot exist. As it creates, so may it destroy. If it may destroy, it may abridge and control." The rule clearly 
recognizes the state legislature as the sovereign power and the local government as subordinate (Richardson, et al. 2003).Dillon's rule is the "strict construction" interpretation of local government powers by courts.

Dillon's Rule is used in interpreting state law when there is a question of whether or not a local government has been granted a certain power. When states delegate authority to local governments, courts are often called upon to rule upon the scope of the powers granted. Where the legislature speaks unambiguously, the court may rely on the clear language of the statute. Where the legislative home rule grant may be interpreted in more than one way, however, courts must attempt to ascertain the legislative intent. The Dillon's rule and home rule are not similar concepts.

Critics of the rule have argued that it imposes unreasonable constraints on the ability of counties and local area governments to function with a degree of self-government, and so undermines the theoretical foundations of a democratic nation. It has also been suggested that the application of Dillon's Rule derives from the contemporary view that cities are inherently corrupt political organizations (Sellers and Byers, 2010).

Some empirical studies of land preservation voter referendums have collected data for a factor representing the concept of local government autonomy or second order devolution. Dillon's Rule and home rule are such measurements (Weeks and Hardy, 1984; Krane, Rigos and Hill, 2001; Geon and Turnbull, 2004.

Refer to Table 4.1 for an identification of the 38 Dillon's rule states. 
Table 4.1 American States Exercising Dillon's Rule

\begin{tabular}{|c|c|c|c|}
\hline State & $\begin{array}{c}\text { Dillon's } \\
\text { Rule State }\end{array}$ & State & $\begin{array}{c}\text { Dillon's } \\
\text { Rule State }\end{array}$ \\
\hline Alabama & yes & Montana & no \\
\hline Alaska & no & Nebraska & yes \\
\hline Arizona & yes & Nevada & yes \\
\hline Arkansas & yes & New Hampshire & yes \\
\hline California & yes & New Jersey & no \\
\hline Colorado & yes & New Mexico & no \\
\hline Connecticut & no & New York & yes \\
\hline Delaware & yes & North Carolina & yes \\
\hline Florida & uncertain & North Dakota & yes \\
\hline Georgia & yes & Ohio & no \\
\hline Hawaii & yes & Oklahoma & yes \\
\hline Idaho & yes & Oregon & no \\
\hline Illinois & no & Pennsylvania & yes \\
\hline Indiana & no & Rhode Island & no \\
\hline lowa & no & South Carolina & no \\
\hline Kansas & no & South Dakota & uncertain \\
\hline Kentucky & yes & Tennessee & yes \\
\hline Louisiana & no & Texas & yes \\
\hline Maine & yes & Utah & no \\
\hline Maryland & yes & Vermont & yes \\
\hline Massachusetts & no & Virginia & yes \\
\hline Michigan & yes & Washington & yes \\
\hline Minnesota & yes & West Virginia & yes \\
\hline Mississippi & yes & Wisconsin & yes \\
\hline Missouri & yes & Wyoming & yes \\
\hline
\end{tabular}

Source: Sellers, NACo Research Division, 2010.

4.3.4 The Wolman, McManmon, Bell and Brunori (2010) Local Government Autonomy Index by U.S. State

Authors present a conceptual definition of "local government autonomy" for 50 American states based on dimensions fundamental to the concept. They identify variables to operationalize those dimensions and use factor analysis to combine those variables into underlying component factors. This creates an overall Local Government Autonomy index that can be used as a measure in future state and local finance, land planning and decentralization research. 
Table 4.2 lists U.S. states according to their autonomy ranking. The counties are ranked 1 to 50 , where 1 represents the highest degree of local government autonomy and 50 means that the local jurisdiction relies on the state legislature for local government decision-making.

Table 4.2 Local GovernmentAutonomy Rankings of 50 American States

\begin{tabular}{|cll|cll|}
\hline Rank $^{2}$ & State & Index & Rank $^{2}$ & State & Index \\
\hline 1 & New York & 0.845 & 26 & California & 0.043 \\
2 & Tennessee & 0.681 & 27 & Indiana & 0.015 \\
3 & Kansas & 0.620 & 28 & South Dakota & 0.006 \\
4 & Ohio & 0.599 & 29 & Nebraska & 0.004 \\
5 & Louisiana & 0.520 & 30 & Massachusetts & -0.022 \\
6 & Missouri & 0.477 & 31 & Oklahoma & -0.033 \\
7 & Maryland & 0.475 & 32 & Washinton & -0.073 \\
8 & Wyoming & 0.464 & 33 & Wisconsin & -0.121 \\
9 & Texas & 0.438 & 34 & Michigan & -0.175 \\
10 & Illinois & 0.390 & 35 & Oregon & -0.220 \\
11 & Alabama & 0.388 & 36 & Idaho & -0.250 \\
12 & Florida & 0.378 & 37 & NewJersey & -0.255 \\
13 & Colorado & 0.295 & 38 & Arkansas & -0.258 \\
14 & Virginia & 0.262 & 39 & Kentucky & -0.331 \\
15 & South Carolina & 0.201 & 40 & Montana & -0.337 \\
16 & Utah & 0.191 & 41 & North Dakota & -0.381 \\
17 & New Mexico & 0.191 & 42 & Minnesota & -0.389 \\
18 & Arizona & 0.172 & 43 & Maine & -0.446 \\
19 & North Carolina & 0.131 & 44 & New Hampshire & -0.544 \\
20 & Mississippi & 0.129 & 45 & Hawaii & -0.685 \\
21 & Georgia & 0.129 & 46 & Vermont & -0.703 \\
22 & lowa & 0.124 & 47 & Rhode Island & -0.728 \\
23 & Nevada & 0.103 & 48 & Connecticut & -0.753 \\
24 & Alaska & 0.098 & 49 & West Virginia & -0.769 \\
25 & Pennsylvania & 0.085 & 50 & Delaware & -0.982 \\
\hline
\end{tabular}

' Source: Wolman, H., McManmon, R., Bell, M., and Brunori, D., 2010.

${ }^{2}$ Ranking: $1=$ most autonomous; $50=$ least autonomous.

\subsection{5: Strength of State Delegation of Home Rule to Local Governments}

Local area government authority and power are not identified in the United

States Constitution. This exclusion leads to the unavoidable characterization of 
local governments as 'creatures' or political subdivisions of the state. Therefore, any authority that local governments hold must originate from grants by the state, either by documentation in the state constitution, state enabling authority, or charter.

In the United States, the legislative authority granted to local governments varies by state. In some states, referred to as 'home rule states', an amendment to the state constitution grants counties the ability to pass laws to govern themselves as long as they adhere to conditions of state and federal constitutions and ordinances.

In 2004, Geon and Turnbull examined the extent to which local fiscal behavior reflected the rules or laws granting counties freedom to pursue a range of activities on their own (home rule), or constrain county government actions. State home rule authority, if part of state legislative mandate, removes some restrictions on the range of activities that local governments can undertake, freeing them to better serve their constituents. With this view, the judicial restrictions embodied in the Dillon's rule (if the state exercises Dillon's Rule) impose some potential constraints on local governments to define and establish public services needs at the local rather than state level, particularly during periods of rapid growth and emergency situations.

Table 4.3 delineates which of the 50 American states grants either strong or weak home rule, of maintains strong or weak non-home rule status. 
Table 4.3 Categories of County Home Rule Authority by State

\begin{tabular}{|lcl|lcl|}
\hline State & Counties & Authority & State & Counties & Authority \\
\hline ALABAMA & 67 & Weak non HR & NEBRASKA & 93 & Strong non HR \\
ARIZONA & 75 & Weak HR & NEW JERSEY & 21 & Weak non HR \\
CALIFORNIA & 57 & Weak HR & NEW MEXICO & 33 & Strong non HR \\
COLORADO & 62 & Strong HR & NEW YORK & 57 & Weak HR \\
FLORIDA & 66 & Weak HR & NORTH CAROLINA & 100 & Strong non HR \\
GEORGIA & 157 & Weak HR & NORTH DAKOTA & 53 & Strong HR \\
IDAHO & 44 & Strong non HR & OHIO & 88 & Strong HR \\
ILLINOIS & 102 & Weak HR & OKLAHOMA & 77 & Strong non HR \\
INDIANA & 91 & Weak HR & OREGON & 36 & Strong HR \\
IOWA & 99 & Weak HR & PENNSYLVANIA & 66 & Weak non HR \\
KANSAS & 105 & Strong HR & SOUTH CAROLINA & 46 & Strong HR \\
KENTUCKY & 119 & Weak non HR & SOUTH DAKOTA & 64 & Strong HR \\
LOUISIANA & 61 & Strong HR & TENNESSEE & 93 & Weak non HR \\
MARYLAND & 23 & Weak HR & TEXAS & 254 & Strong non HR \\
MICHIGAN & 83 & Weak non HR & UTAH & 29 & Strong HR \\
MINNESOTA & 87 & Strong non HR & WASHINGTON & 39 & Weak non HR \\
MISSISSIPPI & 82 & Weak non HR & WEST VIRGINIA & 72 & Strong HR \\
MISSOURI & 114 & Strong HR & WISCONSIN & 55 & Strong non HR \\
MONTANA & 54 & Strong HR & WYOMING & 23 & Strong non HR \\
\hline
\end{tabular}

Source: Geon and Turnbull, 2006. Note: Study includes 38 of 50 U.S.States

The Geon and Turnbull home rule categories are based on how narrowly states restrict the range of state authority and powers that can be assumed by county governments. These authors use four categories ranging from no home rule (strong state control over local governance) to strong home rule (strong local constitutional, legislative, and institutional characteristics reported in the Krane, Rigos and Hill (2001) comparative study. Of the thirty-eight states in the study sample: twelve are strong home rule states, nine are weak home rule states; eight are weak non-home rule states; and nine are strong non-home rule states.

\subsubsection{County Government Reform: Home Rule Charter Data}

One measurement of county government reform is its degree of autonomy and acceptance of devolution of authority from its state government. Home rule is the power of a local county to establish and amend portions of its own system of 
self-government without always seeking approval from its parent state. County home rule is permitted under some state constitutions and legislation. Therefore, the authority to act in local affairs is loosely transferred from state law to county government. Other county jurisdictions seek voter approval of an official county home rule charter that becomes a part of the county's code of ordinances; all amendments require voter approval.

A home rule charter shifts much of the responsibility for local government from the state legislature to the local community. A county that adopts a home rule charter has the ability to adjust its governmental organization and powers to suit the needs of its local community. A home rule charter is, in essence, a local government constitution.

However, a home rule county is still subject to restrictions delineated within the United States Constitution, its state constitution, and state laws applicable to all of its counties. While not restricted to only powers specifically authorized by state law, home rule counties are able to establish policies not specifically forbidden by state or federal law.

County government home rule charter data for the 1990 benchmark year of 1988-1999 voter referendums is collected from a 1989 publication of the National Association of Counties (NACo), entitled "County Government Structure: A State by State Report"9. For the 2000 benchmark of years $2000-2009$, county government home rule charters effective as of 2000 are collected from a second publication of the National Association of Counties (NACo), entitled "County

\footnotetext{
${ }^{9}$ Jeffery, Salant and Boroshok, 1989.
} 
Government Structure: A State by State Report" ${ }^{\prime 10}$. Table 4.4 outlines the number of counties and the number of home rule charter counties by state and year.

Table 4.4 Number of Counties with an Home Rule Charter by State and

by Benchmark 1990 (years 1988-1999) and 2000 (years 2000-2009)

\begin{tabular}{|c|c|c|c|c|c|c|c|c|c|}
\hline & $\begin{array}{c}1990 \\
\text { Total } \\
\text { Counties }^{1}\end{array}$ & $\begin{array}{c}\text { 1988-99 } \\
\text { HR } \\
\text { Counties }^{2}\end{array}$ & $\begin{array}{c}2000 \\
\text { Total } \\
\text { Counties }^{1}\end{array}$ & $\begin{array}{c}2000-09 \\
\text { HR } \\
\text { Counties }^{2}\end{array}$ & & $\begin{array}{c}1990 \\
\text { Total } \\
\text { Counties }^{1}\end{array}$ & $\begin{array}{c}1988-99 \\
\text { HR } \\
\text { Counties }^{2}\end{array}$ & $\begin{array}{c}2000 \\
\text { Total } \\
\text { Counties }^{1}\end{array}$ & $\begin{array}{c}\text { 2000-09 } \\
\text { HR } \\
\text { Counties }^{2}\end{array}$ \\
\hline USA & 3,043 & 117 & 3,034 & 149 & & & & & \\
\hline ALASKA (borough) & 12 & 5 & 12 & 5 & NEBRASKA & 93 & 0 & 93 & 0 \\
\hline ARIZONA & 15 & 0 & 15 & 0 & NEVADA & 16 & 0 & 16 & 0 \\
\hline COLORADO & 62 & 3 & 62 & 2 & NEW MEXICO & 33 & 0 & 33 & 0 \\
\hline CONNECTICUT & 0 & 0 & 0 & 0 & NEW YORK & 57 & 19 & 57 & 21 \\
\hline DELAWARE & 3 & 0 & 3 & 0 & NORTH CAROLINA & 100 & 0 & 100 & 0 \\
\hline FLORIDA & 66 & 12 & 66 & 19 & NORTH DAKOTA & 53 & 1 & 53 & 5 \\
\hline GEORGIA & 157 & 0 & 156 & 0 & $\mathrm{OHIO}$ & 88 & 1 & 88 & 1 \\
\hline HAWAII & 3 & 4 & 3 & 4 & OKLAHOMA & 77 & 0 & 77 & 0 \\
\hline KANSAS & 105 & 0 & 104 & 1 & SOUTH DAKOTA & 64 & 2 & 64 & 2 \\
\hline KENTUCKY & 119 & 0 & 119 & 0 & TENNESSEE & 93 & 0 & 92 & 2 \\
\hline LOUISIANA (parish) & 61 & 14 & 60 & 23 & TEXAS & 254 & 0 & 254 & 0 \\
\hline MAINE & 16 & 0 & 16 & 2 & UTAH & 29 & 0 & 29 & 0 \\
\hline MARYLAND & 23 & 8 & 23 & 9 & VERMONT & 14 & 0 & 14 & 0 \\
\hline MASSACHUSETTS & 12 & 3 & 5 & 1 & VIRGINIA & 95 & 2 & 95 & 3 \\
\hline MICHIGAN & 83 & 1 & 83 & 1 & WASHINGTON & 39 & 5 & 39 & 6 \\
\hline MINNESOTA & 87 & 0 & 82 & 1 & WEST VIRGINIA & 55 & 0 & 55 & 0 \\
\hline MISSISSIPPI & 82 & 0 & 82 & 0 & WISCONSIN & 72 & 0 & 72 & 0 \\
\hline MISSOURI & 114 & 2 & 114 & 3 & WYOMING & 23 & 0 & 23 & 0 \\
\hline
\end{tabular}

Sources: ${ }^{1} 1992$ and 2002 U.S. Census of Governments, Volume 1, Number 1.

2 National Association of Counties Research Division: Jeffery et al. (1989) and Murphy, K. (2009)

\subsubsection{County Government Reform: County Government Structure Data}

Counties have always been at the center of state and local politics, and they continue to be the subject of efforts to modernize and reform governmental structures (Benton et al., 2007). An assessment of research on the American counties in the 1990s found the agenda included its "structure, reform, and performance" (Benton, 2005).

A follow-up assessment of American county research finds that the reform effort in counties has been more incremental and partial than in cities (Benton et

${ }^{10}$ Murphy and Byers, 2009. 
al., 2007). These scholars note that there has been a "model county manager law" since 1930 and Model County Charter since 1956 recommending strengthened executives, reduction of elected row (constitutional) officers, and expanded home rule. These changes parallel those incorporated into the model city charter developed by the National Civic League. Unlike cities, however, in which more than half of the municipalities have adopted the council-manager form and streamlined their charters and in which a substantial portion of mayorcouncil cities have strengthened the mayor and added an administrator officer, counties adopt reforms in a piecemeal fashion (Cowan and Salant, 1999).

Structural authority encompasses the ability to alter current county form to attain greater efficiency, accountability, and/or implementation of governmental responsibilities appropriate to each county's needs (Salant, 2010). The most common structural changes focus on three areas of county government. The most common reform effort is directed at developing a focal point for county administrative responsibility and authority. A chief executive most often represents this focal point of government - presence of an appointed administrator or elected executive in addition to the Board of County Commissioners. Table 4.5 is a framework for the three powers of local authority by domain optional forms (state) and county home rule charter. 
Table 4.5

\begin{tabular}{|lll|}
\hline & Domain Optional Forms & Charter Government \\
\hline Structural & Appointed Administrator & $\checkmark$ Appointed Administrator \\
& Elected Executire & $\checkmark$ Elected Executive \\
& Appointed Row Officers & $\begin{array}{l}\text { Appointed Row Officers } \\
\text { Board President } \\
\text { Board Size }\end{array}$ \\
& & \\
& Optional Service Delivery \\
\hline Functional & Interlocal Agreements & \\
& Special District Oversight & \\
& Planning and Zoning & \\
\hline Fiscal & Taxing Authority & \\
& Benefit Service District & \\
& Issuing Bonds & \\
& Raising Debt Limitiations & \\
\hline
\end{tabular}

Source: Murphy, K. (2009) County Government Structure: A State by State Report (NACO).

A structural reform for this study is the governing board itself, and centers on adjustments to the number of board members. Alternative reforms might include single member district versus at large elections, or the status of county row officers that are to be appointed rather than elected positions (Grouby and Wasseman, 1978).

Data collection for the category of reformed government structure is the presence or absence of a chief executive. County government structure information is collected from the 1989 and 2009 publications of The National Association of Counties, both entitled "County Government Structure: A State by State Report"' (Jeffery, Salant and Boroshok, 1989; Murphy, 2009).

\subsubsection{U.S. Census Bureau-designated Regions Data}

The U.S. Census Bureau categorizes four geographic regions: northeast, south, Midwest, and west. The Census Bureau further classifies nine divisions 
within these regions. This study used U.S. Census Bureau region categorizations for consistency in data collection resources. See Table 4.6.

Table 4.6 U.S. Census Bureau Geographical Regions and Divisions

$\begin{array}{lllll}\text { Region 1 } & \text { NE Region } & \text { Division 1 } & \text { New England } & \text { CN, ME, MA, NH, RI, VT } \\ \text { Region 1 } & \text { NE Region } & \text { Division 2 } & \text { Middle Atlantic } & \text { NJ, NY, PA } \\ \text { Region 2 } & \text { Midwest Region } & \text { Division 3 } & \text { East North Central } & \text { IN, IL, MI, OH, WI } \\ \text { Region 2 } & \text { Midwest Region } & \text { Division } 4 & \text { West North Central } & \text { IA, KS, MN, MO, NE, ND, SD } \\ \text { Region 3 } & \text { South Region } & \text { Division } 5 & \text { South Atlantic } & \text { DE, FL, GA, MD, NC, SC, VA WV } \\ \text { Region 3 } & \text { South Region } & \text { Division 6 } & \text { East South Central } & \text { AL, KY, MS, TN } \\ \text { Region 3 } & \text { South Region } & \text { Division 7 } & \text { West South Central } & \text { AR, LA, OK, TX } \\ \text { Region 4 } & \text { West Region } & \text { Division } 8 & \text { Mountain } & \text { AZ, CO, ID, NM, MT, UT, NV, WY } \\ \text { Region 4 } & \text { West Region } & \text { Division } 9 & \text { Pacific } & \text { AK, CA, HI, OR, WA }\end{array}$

Source: U.S. Census Bureau, 2012.

\subsubsection{NOAA U.S. Coastal Counties Data}

Coastal counties are defined by the United States National Oceanic and Atmospheric Administration (NOAA, 1992) as those counties with at least fifteen percent of their land area either in a coastal watershed or in a coastal cataloguing unit (an individual drainage basin). In addition, NOAA indexes its 672 coastal counties according to their proximity to the Atlantic Ocean, Gulf of Mexico, Pacific Ocean and the Great Lakes.

Habitat restoration and protection ranked number one among coastal issues according to a National Association of Counties (2007) survey of county respondents. A watershed is the land area that drains to a common body of water, such as a stream, lake, estuary, wetland, or even the ocean via a coastal county. The Department of Environmental Protection Administration (EPA) promotes using a watershed approach to manage land and water resources in the United States (Center for Watershed Protection). The scientific basis for this approach is documented by research on the important connection between land 
use and watershed health. Finally, coastal counties support $53 \%$ of the nation's population (Crossett et al., 2004). Table 4.7 lists the number of NOAA coastal counties by state.

\begin{tabular}{|c|c|c|c|}
\hline \multirow{2}{*}{$\begin{array}{l}\text { Table } 4.7 \\
\text { State }\end{array}$} & \multicolumn{2}{|c|}{$\begin{array}{l}\text { U.S. NOAA Coastal Counties by State } \\
\text { Number of Coastal County Areas }{ }^{1}\end{array}$} & \multirow[b]{2}{*}{ Number } \\
\hline & Number & State & \\
\hline Alabama & 8 & Montana & 0 \\
\hline Alaska (borough) & 23 & Nebraska & 0 \\
\hline Arizona & 0 & Nevada & 0 \\
\hline Arkansas & 0 & New Hampshire & 6 \\
\hline California & 29 & New Jersey & 20 \\
\hline Colorado & 0 & New Mexico & 0 \\
\hline Connecticut (areas) & 8 & New York & 39 \\
\hline Delaware & 3 & North Carolina & 37 \\
\hline Florida & 61 & North Dakota & 0 \\
\hline Georgia & 28 & Ohio & 24 \\
\hline Hawaii & 5 & Oklahoma & 0 \\
\hline Idaho & 0 & Oregon & 12 \\
\hline Illinois & 2 & Pennsylvania & 13 \\
\hline Indiana & 9 & Rhode Island (areas) & 5 \\
\hline lowa & 0 & South Carolina & 22 \\
\hline Kansas & 0 & South Dakota & 0 \\
\hline Kentucky & 0 & Tennessee & 0 \\
\hline Louisiana (parish) & 38 & Texas & 41 \\
\hline Maine & 14 & Utah & 0 \\
\hline Maryland & 20 & Vermont & 0 \\
\hline Massachusetts & 12 & Virginia & 61 \\
\hline Michigan & 74 & Washington & 19 \\
\hline Minnesota & 4 & West Virginia & 0 \\
\hline Mississippi & 12 & Wisconsin & 23 \\
\hline Missouri & 0 & Wyoming & 0 \\
\hline
\end{tabular}

Source: U.S. Department of Commerce, National Oceanic and Atmospheric Administration (NOAA), 1992.

\subsubsection{County Community Political Preference Data}

Leip's Elections Atlas is an internet data resource providing information concerning of U.S. presidential elections, and other state and local election data. 
This resource collects evidence from a number of official resources. Their website $^{11}$ provides detailed election results for the major and minor candidates for U.S. President in the general (November) presidential election dates from 1789 through 2012 at four-year intervals. Also, there are individual state results pages for the Presidential Elections from 1892 through 2012. County-level maps and data are available for the elections from 1960 through 2008.

Previous research in the field of land preservation voter referendums has utilized the Leip's Elections Atlas database to collect various political preference and election data (Nelson, Uwasu and Polasky, 2007; Press, 2003; and Banzhaf, Oates and Sanchirico, 2008).

For this research, the Leip's Atlas data collection consists of the share of county voters' democratic party preference cast in the Presidential November election years of 1992 and 2000. Additional voter elections data is obtained for the number of registered voters and the voting age populations by state.

\subsubsection{Environmental Interest Group Data}

A discussion of interest group theory, including the history of environmentalism, is discussed in chapter II.

The conclusions of the Banzhaf, Oates and Sanchirico research (2010) are that "conservation referenda are more likely to be held in communities where there is more surface water and more endangered species, suggesting greater ecological values". In addition, these scholars found that national conservation

\footnotetext{
${ }^{11} \mathrm{http}$ ://uselectionatlas.org.
} 
organizations have "apparently been quite successful at targeting communities based on observable factors."

In studying both municipal and county land preservation voter referendum, the Banzhaf, Oates and Sanchirico (2010) study first hypothesized that if national conservation organizations, or grassroots members, are managing the initiative process in local areas, they will use their resources to direct local efforts to advance their conservation efforts in jurisdictions with more endangered species and more surface water. Second, these authors hypothesized that advancing the objectives of national conservation organizations by using the initiative process, other things being equal, results in conserving more land with greater ecological value.

Their study supports previous work on the "demand-side factors" of land conservation (Kline, 2006; Kotchen and Powers, 2006; Nelson, Uwasu and Polasky, 2007; Sundberg, 2006). Finally, their research results do not take into account other local factors (e.g., governance and government) that could influence the selection and passage of land preservation voter referendums, nor the environmental culture of the region as evidenced by the state presence of IRS-registered environmental organizations.

The community of environmental and conservation organizations in the United States has a core of high-profile organizations, many of them national in scope, which have sometimes interacted with the U.S. environmental movement as a whole. Examples of organizations with local and state chapters of national environmental interest groups are: Sierra Club, National Audubon Society, 
National Parks Conservation Association, Environmental Defense Fund, League of Conservation Voters and The Trust for Public Land.

For lack of information concerning the broader set of smaller organizations and volunteer groups, the national organizations have become the principal representatives of U.S. environmentalism. This perception has opened the door to accusations that the environmental movement in the United States has more recently accomplished little and is stuck in an elitist "inside the Beltway" super pac mentality (Baird and Pollack, 2008).

Baird and Pollack (2008) conclude that despite the recent economic downturn, the environmental movement has broadened. Its revenue became less concentrated in the larger environmental organizations and less in the major national nonprofits. It was outside the Washington metropolitan area that new organizations grew fastest. These researchers found that the web of regional, state, and local organizations became denser, and probably better able to address environmental issues at a level closer to the individual citizen.

In order to obtain an understanding of the breadth and health of the environmental and conservation sector, the Urban Institute's National Center for Charitable Statistics undertook a study to look at the full set of Internal Revenue Service (IRS) data on environmental and conservation organizations. Taken as a whole, the environmental movement appears to have grown in number of organizations, members, and in total revenues almost every year since 1960. 
TABLE 4.8 TYPES AND NUMBER OF ENVIRONMENTAL AND CONSERVATION ORGANIZATIONS IN 2005

$\begin{array}{lr}\text { Alliances \& Advocacy } & 1,140 \\ \text { Management assistance } & 188 \\ \text { Professional associations } & 1,208 \\ \text { Research and public policy } & 372 \\ \text { Single organization support } & 462 \\ \text { Fundraising and distribution } & 426 \\ \text { Support - others } & 56 \\ \text { Pollution abatement } & 695 \\ \text { Recycling centers } & 443 \\ \text { Natural resource conservation } & 6,565 \\ \text { Water resources and } & 7,291 \\ \text { Land resources conservation } & 1,522 \\ \text { Energy conservation and development } & 338 \\ \text { Forest resources } & 670 \\ \text { Botanical and landscaping services } & 156 \\ \text { Botanical gardens } & 565 \\ \text { Native plant societies } & 79 \\ \text { Environmental beautification } & 1,062 \\ \text { Environmental education } & 1,213 \\ \text { Environmental - other } & 500 \\ \text { Wildlife preservation and protection } & 659 \\ \text { Endangered species } & 139 \\ \text { Bird species } & 225 \\ \text { Fisheries } & 153 \\ \text { Wildlife sanctuaries } & 412 \\ \text { Global sustainability } & 9 \\ & 26,548\end{array}$

Source: $\quad$ Straughan, B. and Pollak, T. (2008) The Broader Movement: Nonprofit Environmental and Conservation Organizations, 1989-2005. Published by the National Center for Charitable Statistics at the Urban Institute. Washington, D.C. Retrieved 9/1/12 from http://www.nccs.urban.org/projects/index.cfm.

Despite the perception that they engage mainly in advocacy, a majority of environmental and conservation groups are focused on conservation of land, water, and wildlife through projects and public education (Straughan and Pollack, 2008). From this 2005 research, Table 4.8 lists the Urban Institute's NCCS study's categories of environmental and conservation organizations, together 
with the number of interest groups that are registered with the Internal Revenue Service (IRS).

For this dissertation, the data for state environmental and conservation interest groups is collected from charitystat.com, a website service offering of Implu Corporation. The primary resource for this non-profit database is the Internal Revenue Service (IRS). Utilizing its general organizational specialty of "environment", the number of environmental interest groups per state is gathered from the following categories: alliances and advocacy, forest conservation, land resources conservation, natural resources conservation and protection, professional societies and associations, and water resources/wetlands conservation and management.

Refer to Table 4.9 for a list of the organizational categories of environmental and conservation data collected from the charitystat.com database of national, state and local interest groups. These types of environmental interest groups are functioning in 50 states, and operating at the national, state, regional county and local levels.

Table 4.9 DATA COLLECTION FOR 50 US STATES: CATEGORIES OF ENVIRONMENTAL AND CONSERVATION ORGANIZATIONS

Alliance and Advocacy
Forest Conservation
Land Resources Conservation
Natural Resource Conservation
Professional Societies and Associations
Water Resources and Wetlands Conservation and Management
Source: Charitystat.com retrieved April $2011 \mathrm{http} / / /$ charitystat.com/browse 


\subsubsection{Limitations of the Data Collection Process}

One limitation of the quantitative data collection is that the selected resources provide secondary data. The data is assembled by those parties to meet the requirements of the collecting organizations' research or assembling objectives. Secondary data, though dated, is the only possible source of information for this research because of the inability of the researcher to independently collect the diverse and complex numbers as primary data.

Another limitation to the data collection process is a function of different general benchmark time intervals for resource documentation. For instance, study data collection uses numbers and figures from the United States Census Bureau's decennial years of 1990 and 2000 (or closest available depending upon the secondary resources). Other data resources may collect information by dates other than U.S. decennial Census surveys.

Additional limitations to the USA Counties ${ }^{\mathrm{TM}}$ data are provided by the U.S. Census Bureau website. First, the data comes from different years and from different source agencies and different programs within the same source agency. Second, this database contains secondary data is subject to associate error in its collection. Third, Census geography defines independent cities as county equivalents; however, many sources combine the data for these cities with the surrounding or adjacent counties. Three states (Maryland, Missouri, and Nevada) have one independent city; Virginia has 39 independent cities. Fourth, Alaska has had several major changes in the way county areas have been handled over the years. However, USA Counties ${ }^{\mathrm{TM}}$ footnotes provide additional information 
concerning the data or geography of unusual state and county circumstances that, when incorporated into the study, improve the threat of external validity from any of these limitations.

Limitations of the environmental interest groups data collection are its lack of clarity, definition and availability of figures within the overall category. The National Center for Charitable Statistics database groups environmental organizations into 26 categories by the classification system most widely used in the nonprofit section: National Taxonomy of Exempt Entities (NTEE). NTFF classifications do not distinguish environmental justice groups as a separate category; many of those actually do not classify themselves primarily as "environmental" organizations at all, because they tend to work on a wider range of community concerns (Straughan and Pollak, 2008). Within the 2005 IRS Business Master File are 13 groups with the words "environmental justice" attached to their name, and only seven of those are classified as environmental organizations. The other six fall within public interest law, public health, or community development, a reflection of the fact that for many minority communities, the issues of unemployment, healthcare, pollution, and crime are inextricably linked. The quantitative data from the IRS from 1989 to 2005 reveals the core of national organizations; surrounding this core is a larger, faster growing segment of lightly staffed and all-volunteer organizations formed to address specific, often local area, challenges (Straughan and Pollak, 2008). 


\subsection{Descriptive Statistics for 1990 and 2000 Benchmark Variables}

Descriptive statistics are used to describe the basic features of the data selected for estimate in this quantitative approach. It is presented in a simplified, manageable format. Descriptive statistics show the mean prevalence of each variable in the dataset.

Table 4.10 County Land Preservation Voter Referendums (VRef) 1988 - 2009

Selected and Passed in 34 States, 4 U.S.Regions, and 2 Benchmark Years (1990: Years 1989-1999 and 2000: Years 2000-2009)

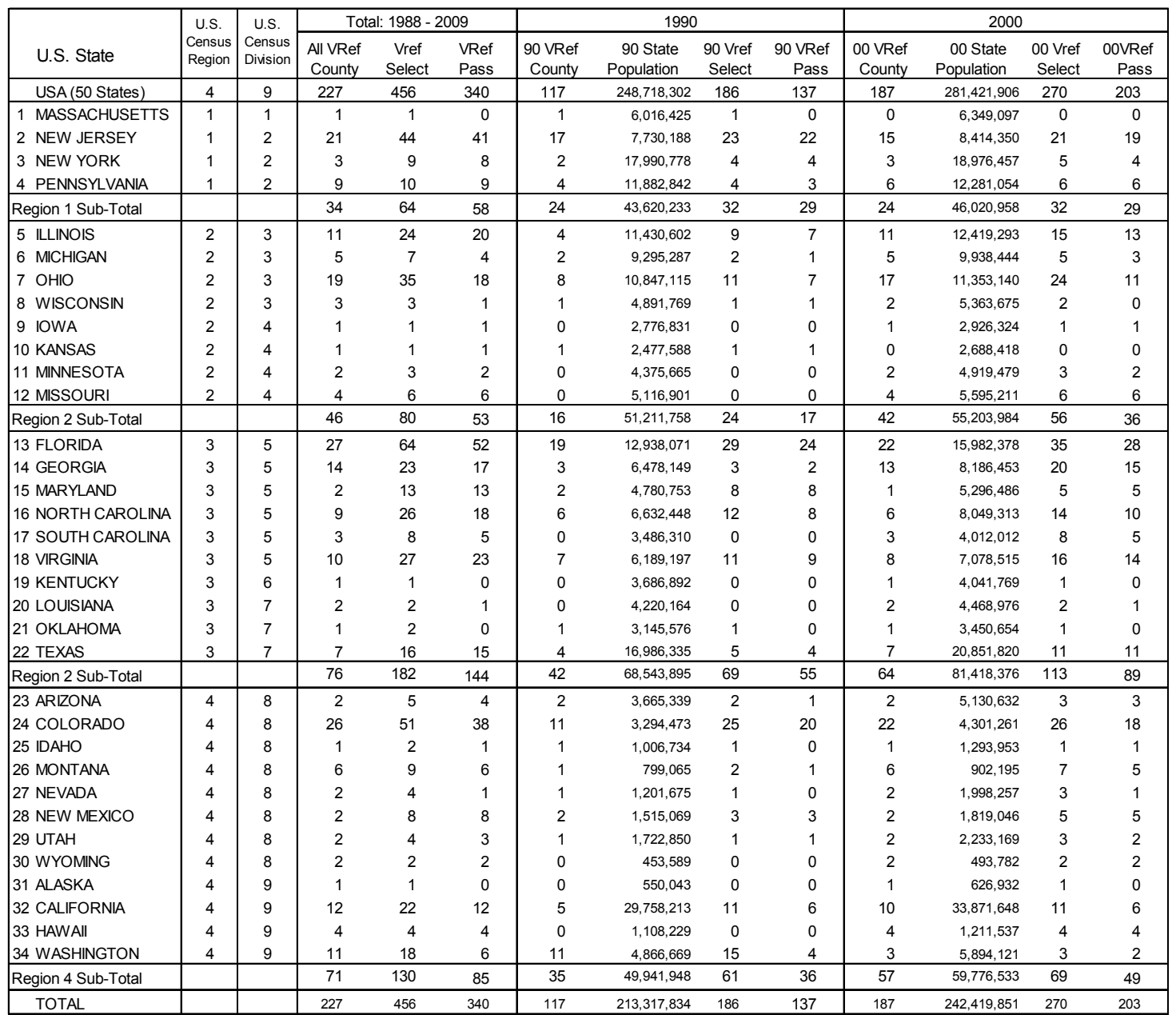

Sources: Trust for Public Land's LandVote» Database, 2012; U.S. Census Bureau, 1990 and 2000.

* Note: Some County governments select multiple VRef within each time interval and within both time intervals which explains the reason that the addition of 90 Vref County and 00 Vre County data does not equal the 1988 to 2009 VRef total of 227 Counties.

To check and detect any outlier errors in the dataset, the descriptive statistics are useful to look for a minimum prevalence of zero, a maximum prevalence of 99.90 (which could be indicative of missing information), and 
standard deviations that are higher than a mean value (indicating some extreme values since the bivariates cannot be less than zero or more than "1").

\subsubsection{Data Review for Benchmark Year 1990 (1988-1999)}

This group includes 186 land preservation voter referendums selected by 117 county governments; 137 (73.7\%) were approved by voters with a 'yes' vote. Refer to Table 4.2 for county numbers by state, including the population of states according to the 1990 decennial U.S. Census Bureau count. Based on the 1990 U.S Census Bureau decennial count, there are 2,864 non-referendum counties included in this population.

The following tables provide 1990 referendum and non-referendum descriptive statistics: Table 4.11 -dependent variables for step 1 (selection of a voter referendum) and step 2 (passage by electorate); Table 4.12 - demographic, socio-economic, terrain, political, and environmental interest group factors. Table 4.13 - governance and government factors. Table 4.14 - land preservation voter referendums-specific.

Table 4.11

1990 Benchmark County Descriptive Statistics 186 Land Preservation Voter Referendums in 117 Counties: 1989 - 1999 Dependent Variables for Selection and Outcome Equations

\begin{tabular}{|c|c|c|c|c|}
\hline \multirow{2}{*}{ Variable } & \multirow{2}{*}{ Type } & \multirow{2}{*}{ Description } & \multicolumn{2}{|c|}{ Descriptive Statistics } \\
\hline & & & \multicolumn{2}{|c|}{$W_{i}=1$} \\
\hline vr_90pass & DV & Observed dichotomous value determined by electorate voting to pass ('yes') 137 referendums. & 0.737 & $(0.442)$ \\
\hline vr_90 & DV & Observed dichotomous value determined by 117 county governments selecting 186 referendums. & 1 & 0 \\
\hline
\end{tabular}


186 Land Preservation Voter Referendums in 117 Counties and 2,864 Non-Referendum Counties Demographic, Socio-Economic, Terrain, Political, Regional, Environmental Contextual Factors

\begin{tabular}{|c|c|c|c|c|c|c|}
\hline \multirow{3}{*}{$\begin{array}{l}\text { Variable } \\
\text { pop90 }\end{array}$} & \multirow{3}{*}{$\begin{array}{c}\text { Type } \\
\text { D }\end{array}$} & \multirow{3}{*}{$\begin{array}{l}\text { Description } \\
\text { County resident population in units of } 10,000 \text { in } 1990 .\end{array}$} & \multicolumn{4}{|c|}{ Descriptive Statistics } \\
\hline & & & \multicolumn{2}{|c|}{$W_{i}=1$} & \multicolumn{2}{|c|}{$\mathrm{W}_{\mathrm{i}}=0$} \\
\hline & & & 6.102 & $(13.046)$ & 0.524 & $(1.536)$ \\
\hline pop90grow & D & The share of county population growth from 1980 to 1990 . & 26.098 & $(27.746)$ & 2.631 & $(14.697)$ \\
\hline pop90whtp & SE & The share of population that is white in 1990. & 86.824 & (9.549) & 87.469 & $(15.681)$ \\
\hline pop90ed & SE & $\begin{array}{l}\text { The share of county adults } 25 \text { years old or older that achieved a bachelor's degree or } \\
\text { higher as of } 1990 \text {. }\end{array}$ & 26.902 & $(9.342)$ & 12.578 & $(5.534)$ \\
\hline inc89housesq & SE & The median household income in the county in units of 1000 squared for 1989. & 14.064 & (6.785) & 5.639 & (3.037) \\
\hline hs90ownoccp & SE & The share of county housing that was owner-occupied in 1990 . & 67.217 & $(9.544)$ & 73.053 & (7.409) \\
\hline hs90ownval & SE & The average value of county owner-occupied housing in 1990. & 12.263 & $(6.621)$ & 4.894 & (2.320) \\
\hline hs90grow & $\mathrm{T}$ & The share of county housing growth from 1980 to 1990 . & 32.639 & $(29.151)$ & 10.631 & $(14.966)$ \\
\hline coastalcty & $\mathrm{T}$ & The share of counties classified by U.S. NOAA as coastal in units of 100 in 1994. & 0.602 & $(0.491)$ & 0.180 & $(0.384)$ \\
\hline st92regut & $\mathrm{P}$ & The share of the county's state registered voters who voted in 1992. & 78.416 & (4.385) & 75.228 & $(5.496)$ \\
\hline reg1ne & $\mathrm{R}$ & A dummy variable $=1$ if county is located in the Northeast region*. & 0.215 & $(0.412)$ & 0.064 & $(0.245)$ \\
\hline reg2mw & $\mathrm{R}$ & A dummy variable $=1$ if county is located in the Midwest region*. & 0.129 & $(0.336)$ & 0.352 & $(0.478)$ \\
\hline reg3so & $\mathrm{R}$ & A dummy variable $=1$ if county is located in the South region*. & 0.328 & $(0.471)$ & 0.461 & $(0.499)$ \\
\hline reg4wt & $\mathrm{R}$ & A dummy variable $=1$ if county is located in the West region* & 0.328 & $(0.471)$ & 0.124 & $(0.329)$ \\
\hline envstallnon & $\mathrm{E}$ & Environmental non-profit organizations registered in the county's state & 141.639 & $(104.221)$ & 88.717 & $(73.789)$ \\
\hline
\end{tabular}

1990 Benchmark County Descriptive Statistics

186 Land Preservation Voter Referendum in 117 Counties and 2,864 Non-Referendum Cour Governance and County Government Identifying Contextual Factors

\begin{tabular}{|c|c|c|c|c|c|c|}
\hline \multirow{3}{*}{$\begin{array}{l}\text { Variable } \\
\text { dillon04 }\end{array}$} & \multirow{3}{*}{$\begin{array}{c}\text { Type } \\
G\end{array}$} & \multirow{3}{*}{$\begin{array}{l}\text { Description } \\
\text { A dummy variable that }=1 \text { if the county's state legislature implements Dillon's Rule. }\end{array}$} & \multicolumn{4}{|c|}{ Descriptive Statistics } \\
\hline & & & \multicolumn{2}{|c|}{$W_{i}=1$} & \multicolumn{2}{|c|}{$W_{i}=0$} \\
\hline & & & 0.941 & $(0.237)$ & 0.858 & $(0.349)$ \\
\hline gautork08 & G & Categorical variable measuring degree of state delegation of autonomy to local area government. & 18.715 & $(10.853)$ & 21.062 & $(13.162)$ \\
\hline stronghr & G & A dummy variable that $=1$ if the degree of government home rule authorized by the state to counties is strong. & 0.000 & $(0.000)$ & 0.267 & $(0.442)$ \\
\hline weakhr & G & A dummy variable that $=1$ if the degree of governmant home rule authorized by the state to counties is weak. & 0.505 & $(0.501)$ & 0.221 & $(0.415)$ \\
\hline 90.ctyhrctr & G & A dummy variable that $=1$ if county voters have approved an ordinance for a home rule charter by 1990 . & 0.054 & $(0.226)$ & 0.037 & $(0.189)$ \\
\hline elecex89 & G & A dummy variable that $=1$ if county government form is an elected executive (mayor) and commission/council. & 0.151 & $(0.359)$ & 0.120 & $(0.325)$ \\
\hline commad89 & G & A dummy variable that $=1$ if county government form is an appointed county administrator and commission. & 0.694 & $(0.462)$ & 0.235 & $(0.424)$ \\
\hline
\end{tabular}

Table 4.14

1990 Benchmark County Descriptive Statistics 186 Land Preservation Voter Referendums in 117 Counties County Land Preservation Voter Referendum-Specific Contextual Factors

\begin{tabular}{|c|c|c|c|c|}
\hline Variable & Type & Description & Descripti & e Statistics \\
\hline $\operatorname{taxfin}$ & VR & A dummy variable that $=1$ if the referendum financing mechanism is a form of taxation. & 0.505 & $(0.501)$ \\
\hline otherfin & VR & A dummy variable that $=1$ if the referendum financing mechanism is other than a bond or taxation. & 0.032 & $(0.177)$ \\
\hline envirprot & VR & A dummy variable that $=1$ if a referendum purpose includes open space, parks, wildlife, trails, forestry, greenways. & 0.968 & $(0.177)$ \\
\hline recreate & VR & A dummy variable that $=1$ if a referendum purpose includes recreation and recreational amenity protection. & 0.344 & $(0.476)$ \\
\hline watrshed & VR & A dummy variable that $=1$ if a referendum purpose includes watershed protection. & 0.199 & $(0.400)$ \\
\hline farm & VR & A dummy variable that $=1$ if a referendum purpose includes farm, ranchland and agricultural protection. & 0.204 & $(0.404)$ \\
\hline othvote & VR & A dummy variable that $=1$ if citizens vote on a referendum proposal on a non-November election ballot. & 0.183 & $(0.388)$ \\
\hline
\end{tabular}


Following study expectations, a number of explanatory variables for factors of the 1990 referendum counties exhibit higher mean values than comparable factors for non-referendum counties. These are: actual population numbers (about twelve times higher), population growth from 1980 to 1990 , level of education, average household income, county housing growth between 1980 and 1990, classification as a coastal county, degree of urbanization, and state presence of environmental non-profit organizations (almost twice as many environmental groups).

The median age of the population of referendum counties (34.153 years) is slightly lower than the median age of the non-referendum counties (34.472 years).

Comparing the share (percentage) of county entities per U.S. Census Bureau region (see Table 4.3), the northeast and west regions of the county exhibit a higher proportion of voter referendum counties that their counterpart regions of non-referendum counties, based upon the mean of these two factors.

The median for factors of non-referendum counties is higher in the following areas: share of white population, percentage of county owner-occupied housing, and total land area of the county. Even though the share of owneroccupied housing is higher in non-referendum counties, the mean value of owner-occupied housing is higher in the referendum counties.

The mean for political preference factors is similar between referendum and non-referendum county groups for the presidential election years of 1988 and 1992 that occurred during 1990 benchmark years. 
For the identifying independent variables of governance and government, the median for the presence of a home rule charter ordinance and a reformed government structure with an appointed county administrator or manager is higher in referendum counties, particular for government structure (more than three times greater). Residing in a Dillon's rule state, the mean for referendum counties is slightly higher than the average of non-referendum counties. However, referendum counties score higher on the state autonomy index (lower ranking number). Although the averages are fairly close, referendum counties score slightly higher in categories of weak home rule and a government structure with a commission and elected executive.

Descriptive statistics for the 186 land preservation voter referendums that were selected between 1988 and 1999 in 117 counties provide the following information: 36 percent of these counties held more than one voter referendum during this timeline. Regarding the financing mechanism, 46.2 percent seek bond, 50.5 percent pursue a type of taxation, and 3.2 percent look for other means (e.g., benefit assessment, parcel tax, or charter amendment).

The majority of county land preservation voter referendums call for more than one purpose intended to be implemented by the government proposal. In general, most referendums included "open space" which is reflected in the 96.8 percentile outcome for the mean of the environmental protection category. Other purpose means are: recreation (34.4 percent), watershed protection (19.9 percent) and farming/agriculture (20.4 percent). 
50 percent of the 1990 benchmark voter referendum elections took place on a non-presidential November ballot. 31.7 percent are part of the presidential November election ballot of 1988 and 1992. 18.3 percent of the referendum elections were held on other dates throughout the years.

\subsubsection{Data Review for Benchmark Year 2000}

This group includes 270 land preservation voter referendums selected by 187 county governments; $203(75.2 \%)$ were approved by voters with a 'yes' vote. Refer to Table 4.2 for range of total county values by state, including the population of states according to the 2000 decennial U.S. Census Bureau count. Based on the 2000 U.S Census Bureau decennial count, there are 2,856 nonreferendum counties included in this population of 3,034 counties.

The following tables provide descriptive statistics for the benchmark 1990 (years 1988 through 1999): Table 4.7 looks at the dependent variables for step 1 (selection of a voter referendum) and step 2 (passage by electorate). Table 4.8 lists demographic, socio-economic, terrain, political preference, and environmental interest group factors of interest to this research. Table 4.9 defines the identifying variables of governance and government factors for the selection equation only. Table 4.10 describes the land preservation voter referendumsspecific factors of interest.

\begin{tabular}{|c|c|c|c|c|}
\hline Table 4.15 & \multicolumn{2}{|r|}{$\begin{array}{c}270 \text { Land Preservation Voter Referendums in } 187 \text { Counties: } 2000 \text { - } 2009 \\
\text { Dependent Variables for Selection and Outcome Equations }\end{array}$} & & \\
\hline \multirow{2}{*}{ Variable } & \multirow{2}{*}{ Type } & \multirow{2}{*}{ Description } & \multicolumn{2}{|c|}{ Descriptive Statistics } \\
\hline & & & \multicolumn{2}{|c|}{$W_{i}=1$} \\
\hline vr_00pass & DV & Observed dichotomous value determined by electorate voting to pass ('yes') 203 referendums. & 0.752 & $(0.433)$ \\
\hline vr_00 & DV & Observed dichotomous value determined by 117 county governments selecting 270 referendum: & 1 & 0 \\
\hline
\end{tabular}




\begin{tabular}{|c|c|c|c|c|c|c|}
\hline \multirow{3}{*}{$\begin{array}{l}\text { Variable } \\
\text { pop00 }\end{array}$} & \multirow{3}{*}{$\begin{array}{c}\text { Type } \\
\text { D }\end{array}$} & \multirow{3}{*}{$\begin{array}{l}\text { Description } \\
\text { County resident population in units of } 10,000 \text { in } 2000 .\end{array}$} & \multicolumn{4}{|c|}{ Descriptive Statistics } \\
\hline & & & \multicolumn{2}{|c|}{$W_{i}=1$} & \multicolumn{2}{|c|}{$W_{i}=0$} \\
\hline & & & 4.141 & $(5.242)$ & 0.578 & $(1.667)$ \\
\hline pop00grow & $\mathrm{D}$ & The share of county population growth from 1990 to 2000 . & 27.918 & $(24.129)$ & 9.910 & $(14.61)$ \\
\hline pop00midage & D & The median age of the County population. & 35.917 & $(4.241)$ & 37.274 & (3.945) \\
\hline pop00whtp & SE & The share of population that is white from 1990 to 2000 . & 80.762 & $(13.511)$ & 84.941 & $(16.382)$ \\
\hline pop00ed & SE & $\begin{array}{l}\text { The share of county adults } 25 \text { years old or older that achieved a bachelor's degree or } \\
\text { higher as of } 2000 \text {. }\end{array}$ & 30.140 & $(10.289)$ & 15.385 & $(6.494)$ \\
\hline pop00unempl & SE & The share of the civilian labor force that is unemployed in 2000 . & 4.535 & $(1.509)$ & 5.872 & $(2.864)$ \\
\hline inc99house & SE & The median household income in the county in units of 1000 for 1999 in 1,000 & 4.990 & (1.188) & 3.414 & $(0.759)$ \\
\hline inc99housesq & SE & The median household income in the county in units of 1000 for 1999 squared in 1,00 ( & 26.308 & $(12.857)$ & 12.233 & $(5.934)$ \\
\hline hs00ownoccp & SE & The share of county housing that was owner-occupied in 2000 . & 69.864 & $(9.481)$ & 74.527 & $(6.996)$ \\
\hline hs00ownval & SE & The average value of county owner-occupied housing in 2000 & 15.776 & (7.355) & 7.733 & $(3.213)$ \\
\hline hs00grow & $\mathrm{T}$ & The share of county housing growth from 1990 to 2000 . & 25.453 & $(20.637)$ & 12.583 & $(13.647)$ \\
\hline coastalcty & $\mathrm{T}$ & The share of county classifed by U.S. NOAA as a coastal in units of 100 in 1994. & 0.482 & $(0.501)$ & 0.179 & $(0.383)$ \\
\hline land90sqmip & $\mathrm{T}$ & The share of the total area of the county that is land in 2000. & 90.032 & $(16.614)$ & 95.911 & $(10.563)$ \\
\hline land00urbp & $\mathrm{T}$ & The share of county resident population that live in urban areas $(+50,000)$ in 2000 . & 77.257 & $(24.206)$ & 36.719 & $(29.172)$ \\
\hline elec00dem & $\mathrm{P}$ & The share of county voting democratic in presidential eletion of 2000 . & 44.493 & $(10.710)$ & 39.135 & (11.555) \\
\hline sto0vap & $\mathrm{P}$ & The share of the county's state voting age public that voted in presidential election of 2000 . & 50.411 & $(5.439)$ & 51.922 & (6.491) \\
\hline st00regvote & $\mathrm{P}$ & The share of county's state registered voters who voted in 2000 & 65.887 & $(5.260)$ & 64.615 & $(5.97)^{\prime}$ \\
\hline reg1ne & $\mathrm{R}$ & A dummy variable $=1$ if county is located in NorthEast region*. & 0.137 & $(0.345)$ & 0.062 & $(0.241)$ \\
\hline reg2mw & $\mathrm{R}$ & A dummy variable $=1$ if county is located in MidWest region*. & 0.207 & $(0.406)$ & 0.354 & $(0.478)$ \\
\hline reg3so & $\mathrm{R}$ & A dummy variable $=1$ if county is located in South region*. & 0.400 & $(0.491)$ & 0.461 & $(0.499)$ \\
\hline reg4wt & $\mathrm{R}$ & A dummy variable $=1$ if county is located in West region*. & 0.256 & $(0.437)$ & 0.124 & $(0.329)$ \\
\hline envstallnon & $E$ & Environmental non-profit organizations registered in the county's state. & 123.837 & $(92.427)$ & 88.456 & $(73.646)$ \\
\hline
\end{tabular}

Table 4.17

2000 Benchmark County Descriptive Statistics

270 Land Preservation Voter Referendum in 187 Counties and 2,856 Non-Referendum Counties

Governance and County Government Identifying Contextual Factors

\begin{tabular}{|c|c|c|c|c|c|c|}
\hline \multirow{3}{*}{$\begin{array}{l}\text { Variable } \\
\text { dillon04 }\end{array}$} & \multirow{3}{*}{$\begin{array}{c}\text { Type } \\
G\end{array}$} & \multirow{3}{*}{$\begin{array}{l}\text { Description } \\
\text { A dummy variable that }=1 \text { if the county's state legislature implements Dillon's Rule. }\end{array}$} & \multicolumn{4}{|c|}{ Descriptive Statistics } \\
\hline & & & \multicolumn{2}{|c|}{$W_{i}=1$} & \multicolumn{2}{|c|}{$\mathrm{W}_{\mathrm{i}}=0$} \\
\hline & & & 0.723 & $(0.431)$ & 0.868 & $(0.336)$ \\
\hline gautork08 & G & Categorical variable measuring degree of state delegation of autonomy to local area government. & 17.681 & $(10.978)$ & 21.033 & $(13.158)$ \\
\hline stronghr & G & A dummy variable that $=1$ if the degree of government home rule authorized by the state to counties is strong. & 0.306 & $(0.442)$ & 0.276 & $(0.425)$ \\
\hline weakhr & G & A dummy variable that $=1$ if the degree of governmant home rule authorized by the state to counties is weak. & 0.374 & $(0.467)$ & 0.232 & $(0.401)$ \\
\hline 00.ctyhrctr & G & A dummy variable that $=1$ if county voters have approved an ordinance for a home rule charter. & 0.222 & $(0.417)$ & 0.027 & $(0.163)$ \\
\hline elecex99 & $\mathrm{F}$ & A dummy variable that $=1$ if county government form is an elected executive (mayor) and commission/council. & 0.156 & $(0.363)$ & 0.129 & $(0.336)$ \\
\hline commad99 & $\mathrm{F}$ & A dummy variable that $=1$ if county government form is an appointed county administrator and commission. & 0.637 & $(0.482)$ & 0.321 & $(0.467)$ \\
\hline
\end{tabular}

Table 4.18

2000 Benchmark County Descriptive Statistics 270 Land Preservation Voter Referendums in 187 Counties County Land Preservation Voter Referendum-Specific Contextual Factors

\begin{tabular}{|c|c|c|c|c|}
\hline Variable & Type & Description & Descripti & ve Statistics \\
\hline vr_priorvref & VR & A dummy variable that $=1$ if a county selected and held a prior land preservation voter referendum in 2000-2009. & 0.604 & (0.490) \\
\hline bondfin & VR & A dummy variable that $=1$ if the referendum financing mechanism is a bond. & 0.433 & $(0.496)$ \\
\hline taxfin & VR & A dummy variable that $=1$ if the referendum financing mechanism is a form of taxation. & 0.541 & $(0.499)$ \\
\hline otherfin & VR & A dummy variable that $=1$ if the referendum financing mechanism is other than a bond or taxation. & 0.03 & $(0.170)$ \\
\hline envirprot & VR & A dummy variable that =1 if a referendum purpose includes open space, parks, wildlife, trails, forestry, greenways. & 0.948 & $(0.222)$ \\
\hline recreate & VR & A dummy variable that $=1$ if a referendum purpose includes recreation and recreational amenity protection. & 0.419 & $(0.494)$ \\
\hline watrshed & VR & A dummy variable that $=1$ if a referendum purpose includes watershed protection. & 0.252 & $(0.435)$ \\
\hline farm & VR & A dummy variable that $=1$ if a referendum purpose includes farm, ranchland and agricultural protection. & 0.215 & $(0.411)$ \\
\hline presvotenov & VR & A dummy variable that $=1$ if citizens vote on a referendum proposal on a presidential Novemberelection ballot. & 0.322 & $(0.468)$ \\
\hline othvotenov & VR & A dummy variable that $=1$ if citizens vote on a referendum proposal on a non-presidential November election ballot. & 0.478 & $(0.500)$ \\
\hline othvote & VR & A dummy variable that $=1$ if citizens vote on a referendum proposal on a non-presidential November election ballot. & 0.200 & $(0.401)$ \\
\hline
\end{tabular}


Following study expectations, a number of explanatory variables for the 2000 benchmark referendum counties exhibit higher mean values than do the non-referendum counties. These include the following factors: actual population numbers, population growth from 1990 to 2000, level of education, mean household income, county housing growth between 1990 and 2000, classification as a coastal county (about four times greater), degree of urbanization, and state presence of environmental non-profit organizations (almost twice as many environmental groups).

The mean age of the 2000 population of referendum counties ( 35.9 years) is slightly higher than the 1990 group, but much lower than the average population age of non-referendum counties (37.3 years).

The average rate of unemployment is higher in the non-referendum counties than the referendum counties. This is a reversal from the 1990 descriptive statistics that found unemployment to be higher in referendum counties.

Referencing Table 4.3 and the share (percentage) of county entities per U.S. Census Bureau region, the northeast and west regions of the county exhibit a higher proportion of referendum counties that their counterpart regions of nonreferendum counties. In comparison to the 1990 benchmark years, increase means are reflected for counties as a group in region 2 (South) and 3 (Midwest), while counties collectively in regions 1 (Northeast) and 4 (west) held fewer land preservation voter referendums. 
The mean for factors of non-referendum counties is found to be higher in the following areas: share of white population, percentage of county owneroccupied housing, and total land area of the county. Even though the share of owner-occupied housing is higher in non-referendum counties, the mean value of owner-occupied housing is higher in the referendum counties.

The average age of the population of referendum counties (34.153 years) is slightly lower than that of the non-referendum counties (34.472 years).

In the 2000 benchmark group, the mean for the political preference factor for voting democratic in a presidential November $(2000,2004$ and 2008) is higher in referendum counties than non-referendum counties (44.5 percent and 39.1 percent respectively). Other factor averages in this category are similar.

For the identifying independent variables of governance and government, the mean of the presence of a home rule charter ordinance and a reformed government structure with an appointed county administrator or manager are higher in referendum counties. The means for having a home rule charter in referendum counties increased significantly between 1990 (5.4 percent) and 2000 (22.2 percent). Residing in a Dillon's rule state, the mean for referendum counties is slightly lower than the average of non-referendum counties; this finding is a reversal of the 1990 benchmark years'. Referendum counties continue to score higher on the local government autonomy index, which is continuing improvement from the preceding 10 years. The mean of the referendum county 2000 group is also higher in government categories of weak home rule and a structure with a commission plus elected executive. 
Descriptive statistics for the 270 land preservation voter referendums that were selected between 2000 and 2000 in 187 counties provide the following information. $60.4 \%$ of these counties experienced more than one voter referendum from 1988 until the election date of the referendum. Regarding the financing mechanism utilized, 43.3 percent are bond, 54.1 percent are a type of taxation, and 3.2 percent intend to raise the funding in another way (e.g., benefit assessment, transient occupancy tax, budget appropriation, user tax, building materials use tax, or funding cap increase).

The majority of county land preservation voter referendums identified more than one proposal purpose to be implemented by the government proposal. In general, most referendums include "open space" which is reflected in the 94.8 percentile outcome for the mean of the environmental protection category. Other purpose means are: recreation (4.19 percent), watershed protection (25.2 percent) and farming and agriculture (21.5 percent).

47.8 percent of 2000 benchmark voter referendum elections were held on a non-presidential November date. 32.2 percent are part of the presidential November election ballots of 2000,2004 , or 2008.20 percent of the elections for voter referendums are held on other dates throughout the year.

\subsection{Application of the Heckman Two-Step Probit Model}

This study employs the Heckman two-step model to estimate the selection stage (step 1) and the voter passage or results stage (step 2). More specifically, the Heckman probit sample selection model (heckprob) is used because it is a 
variation of the classic Heckman 2-step model where the dependent response variables are binary. For example, the dependent variable for step 1 (selection) $=1$ if a county government approves a land preservation voter referendum, or $=0$ if not; the dependent variable for step 2 (passage) $=1$ if county citizens vote 'yes' for passage of a land preservation voter referendum at the ballot box.

\subsubsection{Heckman Step 1 (Selection Model)}

In the first step, the probit sample selection model equation is:

$$
\operatorname{Pr}\left(W_{i}=1\right)=f\left(D_{i}, S E_{i}, T_{i}, P_{i}, E_{i}, G_{i}, R_{i}\right)+\varepsilon_{i}
$$

where $W_{i}=1$ if the county or county equivalent ' $i$ ' chooses a voter referendum with a proposition to spend public funds for land preservation; and $W_{i}=0$ otherwise. The vectors are: $D_{i}$ for demographic variables; $S E_{i}$ for socio-economic variables; $T_{i}$ for terrain variables; $P_{i}$ for political preference variables; $E_{i}$ for environmental interest group variables; $G_{i}$ for governance and government structure variables; $R_{i}$ for regional variables; and is an error term.

The five identifying independent variables classified as governance and government ${ }^{12}$ are: a dummy variable that $=1$ if the county's state is determined to be exercising Dillon's Rule; Wolman et al.'s (2010) state categorical variables

\footnotetext{
12 A well-known impediment in implementing the Heckman model emerges when there is a high degree of multicollinearity between the independent variables and the inverse Mills ratio (IMR), which results in high standard errors on the coefficient estimates and factor instability. Effectively addressing this problem and controlling for sample selectivity bias requires the identification of at least one independent variable that plays a part in the referendum selection (equation 1) but does not impact the vote (equation 2). This study's assumption is that the citizens' vote for a land preservation referendum is not affected by the presence or absence of a governance and government contextual factors. Therefore, these independent variables are included in equation 1 (selection) but not in equation 2 (voter passage).
} 
measuring degree of autonomy on an interval scale that is delegated to local area government; a dummy variable that $=1$ dummy variable if the county's state is classified as one of two types of home rule, e.g., strong home rule or weak home rule (Geon and Turnbull, 2006); a dummy variable that $=1$ if there is a county government home rule charter ordinance; and a dummy variable that $=1$ if the county government operates with one of two reformed structure, e.g. elected executive with commission/council or county administrator with commission/council.

\subsubsection{Heckman Step 2 (Passage)}

The second stage (outcome) estimates the probability of a county registered voters adopting (with 'yes' vote) a land preservation voter referendum placed on the ballot by its county government. Study modeling for the second stage (outcome) employs a probit estimation. Let $\mathrm{i}=1, \ldots, \mathrm{C}$ index the subset of county or county entities that held a land preservation voter referendum at some point from 1988 through 1999 or from 2000 through 2009.

The selection bias-corrected referendum outcome equation for $\mathrm{i}=1, \ldots, \mathrm{C}$ is given in the reduced form by,

$$
\log \left(P_{i} / 1-P_{i}\right)=g\left(V R_{i}, D_{i}, S E_{i}, T_{i}, P_{i}, E_{i}, R_{i}\right)+\sigma \lambda_{i}+\varepsilon_{i}
$$

where $P_{i}$ is the proportion of total referendum votes recorded as "yes" votes in 'i's' referendum, $P_{i} / 1-P_{i}$ measures the odds of a "yes" vote in 'i's' referendum, $V_{i}$ is a vector of data describing the referendum in ' $i$ ', $\lambda_{i}$ is the estimated inverse Mill's ratio for the observation 'i' (Greene, 2003), and $\varepsilon_{\mathrm{i}}$ is an error term. 


\subsection{Findings}

Table 4.19

Estimating with Heckprob: Selection and Passage Equations

County Jurisdiction: Land Preservation Voter Referendum and Non-Referendum Two Benchmark Study Groups: 1990 (Years 1988-1999) and 2000 (Years 2000-2009)

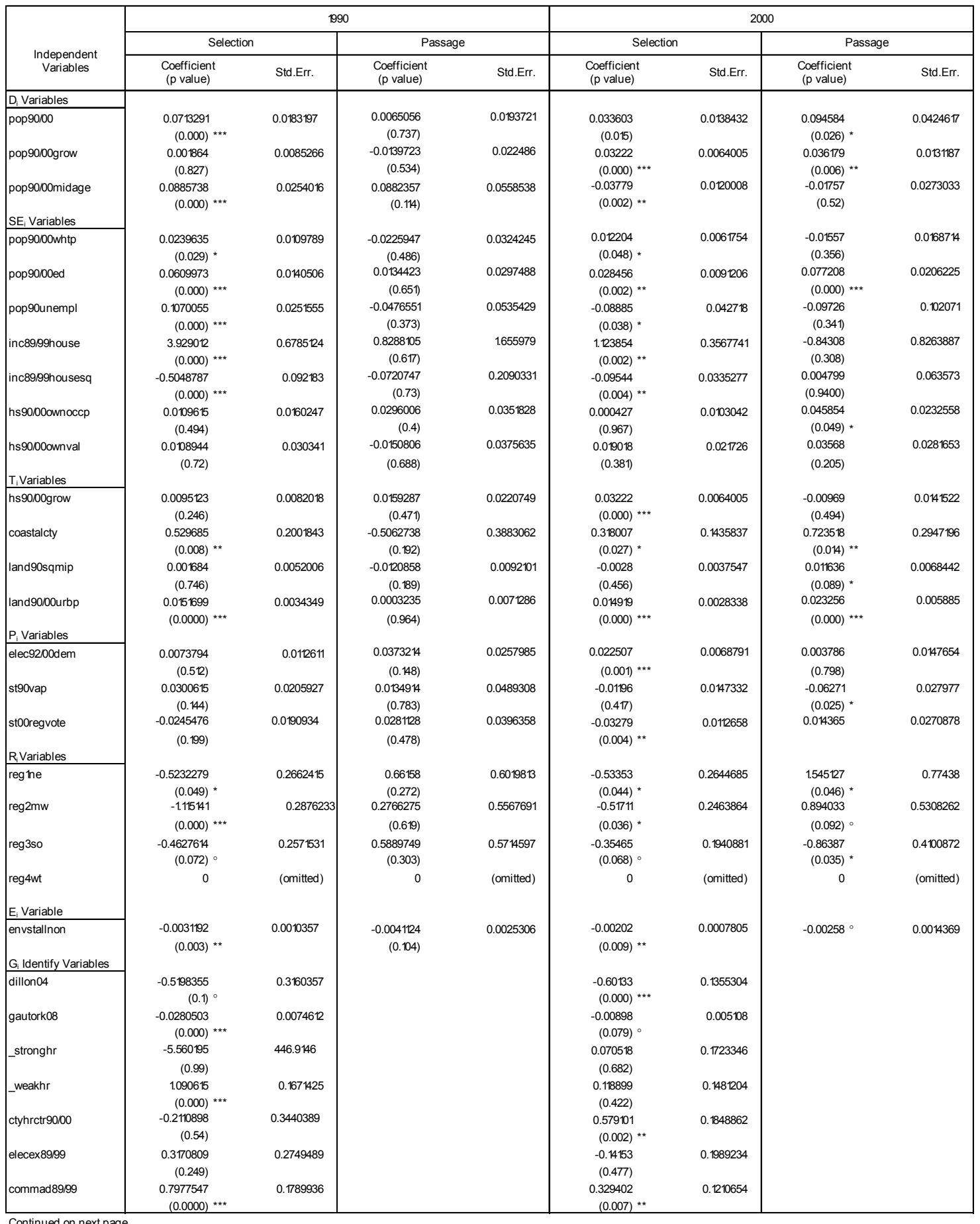




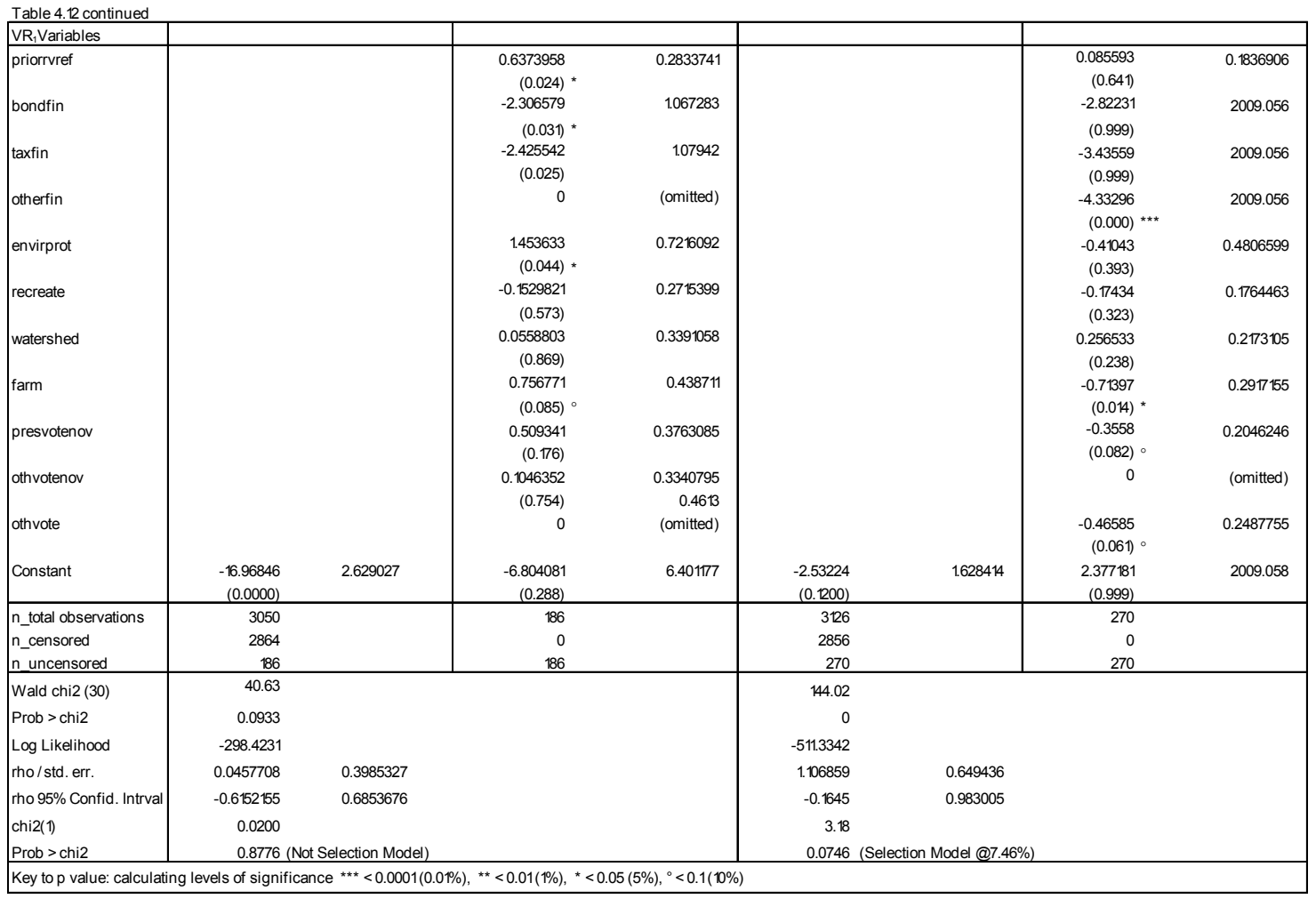

\subsubsection{Estimates of the Selection Equations}

Between 1980 and 2010, the U.S. Census Bureau data finds that the U.S. population grew steadily. The fastest-growing decade was 1990 to 2000 , when the population grew by 13.1 percent. See Table 3.3 in Chapter III.

The estimates of the selection equations for benchmark 1990 (years 19881999) and 2000 (years 2000-2009) are shown in Table 4.12. Treatment of the datasets with the 'heckprob' (dichotomous dependent variables only) application of Heckman's sample selection model yields a selection model with the 2000 dataset only. The following analysis is grounding primarily in estimates of the selection equation for the 2000 benchmark years (2000-2009). However, 
reference is made to the strength of the statistical significance ( $p$-value) for estimated coefficients in the 1990 benchmark group.

The benchmark 2000 variable for county's population count is significant for the estimate of the selection equation, with significance at $95 \%$ confidence. The $p$-value (significance) for the population count is highly significant at $99+\%$ for the coefficient of the 1990 benchmark group.

Confirming expectations, counties that exhibit population growth over time are more likely see their jurisdictional government select a land preservation voter referendum to preserve and protect the diminishing inventory of open space for possibly new parkland and other open space purposes. This outcome may be due to the greater likelihood of vacant land being transformed into residential sub-divisions for new housing and commercial properties to service the growth in county population. There is a highly significance coefficient for population growth factor (both 1990 and 2000) variables at the $99+\%$ level.

A contributory factor to this finding may be the likelihood that more populous counties have more environmental activists and grassroots residents to promote land preservation issues. Also, an increase in population could lead to greater demand for open space preservation and parks and recreation amenities because of increases in crowding, sprawl or limited access to diminishing nondeveloped land. Whether the impetus comes from government officials and land planners or community activists in the county, increasing population is a significant variable for selecting voter referendums. 
An increased share of county land that is designated urbanized by the U.S. Census Bureau $(1990,2000)$ A county with a higher share of urbanization is more likely experience government selection of a land preservation voter referendum. The statistical significance of this outcome for both 1990 and 2000 is at the $99+\%$ confidence level. The first and foremost reason of urban growth is increase in urban population.

Rapid growth of urban areas is the result of two population growth factors: (1) natural increase in population, and (2) migration to urban areas. In the recent time, the movement of people from rural to urban areas within this country (internal migration) is most significant. Although very insignificant comparing the movement of people within the country; international migration is also increasing. International migration includes labor migration, refugees and undocumented migrants. Both internal and international migrations contribute to urban growth. For both categories of migrants, urban counties and cities are perceived as offering better opportunities, higher salaries, better services (including parks), better education, and better lifestyles. However, people move into urban areas primarily to seek better economic opportunities. Resultantly urban areas can also have much more diverse, multicultural and social communities.

Much of the land planning literature refers to managing growth through Smart Growth and other methodologies. As a corollary to population growth, the factor of housing growth in a county is highly significant $(99+\%$ for 2000$)$ for its coefficient. As population and housing growth increase, there is a greater 
likelihood of a county selecting a voter referendum as a practice to fund land preservation projects.

Although the mean age and share of the white race are lower for referendum county populations than non-referendum counties, their estimates of the selection equation are both significant. However the negative mean age coefficient indicates that as the population ages, the probability of county government selecting a land preservation voter referendum decreases. A negative coefficient for the share of unemployed is significant to $99 \%$ in 2000 . As the level of unemployment increases, the estimate for the selection of a land preservation voter referendum decreases.

Endorsing findings of prior research in this field but for other types of governmental jurisdictions, the county government that selects a voter referendum proposal for voter consideration governs, in general, a more a highly educated citizenry. The analysis estimates that this factor is highly significant at $t$ $99+\%(1990)$ and $99 \%(2000)$.

These results show a statistically significant inverted $U$ relationship between the likelihood of selecting a land preservation voter referendum and the average household income in a county. Initial increases in household income have a positive effect on the probability of selecting a referendum. However, at higher income levels, marginal increases in the average household income are associated with a decrease in the probability of a voter referendum. Perhaps wealthier counties are more capable of acquiring protected lands through private resources and therefore government action is less likely. 
Verifying opinions found in prior studies, coastal counties are more likely to select a land preservation voter referendum than non-counties. The estimates of selection provide significance at 95\% confidence (2000) and 99\% (1990).

For the 2000, a county electorate that leans toward a more democratic political preference that holds a socially liberal and progressive platform increases the probability of a county government selecting a land preservation voter referendum. This factor is highly significant at $99+\%$. In turn, a greater presence of environmental organizations and grassroots activism most likely influence a county government to adopt conservation, preservation and ecologically-sensitive programs that are defined as the purpose behind land preservation voter referendums.

In the area of governance and government variables, there are several noteworthy findings in the selection estimate. For example, the coefficient for the Dillon's Rule state in which a county is found is highly significant for the 2000 benchmark for which a selection model exists. Yet the sign of the coefficient is negative. The interpretation of this finding indicates that the likelihood of a county selecting a voter referendum declines if found in a Dillon's Rule.

The Wolman et al. (2010) local government autonomy index for 50 states is used in this study as a measurement of state decentralization or local government self-government. The 1990 benchmark group coefficient for this factor is highly significant; however the 2000 benchmark estimate of the selection equation is only marginally significant at the $90 \%$ level. Both coefficients have a negative sign. The categorical number for the most autonomous state is the 
lowest; therefore this finding suggests that an increase in a county's state autonomy ranking would reduce its predictability of selecting a voter referendum. A reformed government structure with a board of county commissioners and an appointed administrator or manager is a significant predicator for selection in both time intervals. For the estimates of the 2000 selection model, its significance is at the $99 \%$ level; the significance is even large with the 1990 coefficient at the $99+\%$ level. The other reformed government structure with an elected executive is not found to be significant.

Geon and Turnbull's (2004) study adopted the wider view of the home rule concept as found in Kane, Rigos and Hill's (2001) overview of home rule in U.S. fifty states. Neither strong home rule nor weak home rule factors exhibit significance in the 2000 estimate of the selection model. However, the coefficient for the weak home rule factor is highly significant to the $99+\%$ level in the 1990 group. However, during the second 2000-2009 time interval, the presence of a county home rule charter is significant, yet not the 1989-1999 grouping. This finding could be interpreted as a parallel growth in local county government autonomy and execution of its powers with an institutionalization of that autonomy in the form of an official, resident-voter sanctioned charter.

\subsubsection{Estimates of the Outcome or Referendum Passage Equations}

Results of land preservation voter referendum elections, given by equation (2) of the Heckman heckprob model, are also shown in Table 4.12.

The success (passage with a 'yes' vote) of the 2000 benchmark is significantly driven by factors for an urbanized county and a population that is 
highly educated (above average number of persons with a bachelor degree or higher academic credentials).These findings substantiate similar findings in prior empirical studies of conservation voter referendums.

Additional factors that exhibit significance at the $99 \%$ level for the estimate of the passage equation are coastal county and communities with population growth. Some significance is found for counties with large population counts, voting age populations, large land areas (per square mile) and more owneroccupied housing. Finally, the influence of organized environmental public interest groups is only slightly significant to the 90 percentile.

The hypothesis that specifies the value of the population parameter is the null hypothesis which generally states that nothing changes. A small p-value provides evidence against the null hypothesis, because data have been observed that would be unlikely if the null hypothesis were correct. For the estimates of the selection and passage equations for the 2000 benchmark group, the p-value is sufficiently small (at the 92.54 percentile) to reject the null hypotheses for this sub-section.

\subsection{Summary}

Descriptive statistics of the variables are presented and discussed. Application of the Heckman heckprob Two-Step to study dataset of 1990 and 2000 benchmark groups. Only the 2000 benchmark group exhibits a selection model. The heckprob application tests for the strength of the predicted probability of the model, the sign and magnitude of the coefficients of independent variables, and $p$-value of individual independent variables. 
Significance is determined by a confidence level of 90 percent or greater. Findings determine the acceptance or rejection of the statistical hypotheses. Findings for the estimates of the selection and passage equations are discussed.

This analysis is limited by the lack of data for several factors not available to the researcher. For instance, the voters' understanding of the cost to each resident or households could influence a 'yes' or 'no' vote on a personal level. Another area of interest is the ability to factor in the ballot language and public service branding in terms of their bearing on voter behavior. Was the government's message transparent, clear and concise for the voter in terms of resident perception and understanding?

Also missing from this analysis is an awareness of potential project implementation and facility maintenance costs, and whether annual operating dollars are factored into the amount attached to the land preservation voter referendum. If the referendum's purpose includes addition or renovation of open space, park, cultural or historic facilities and amenities, this analysis is limited by not knowing the precise costs in lieu of estimations. Other omitted governmentrelated data speaks to information about the ballot which is presented to the voter - were there multiple county referendum on the same ballot, or did the voter face other public good referendums or amendments on the same ballot such as education or infrastructure needs for the county. Controlling for these types of voter choices based upon alternatives is important to understanding the depth and breadth of public support or non-support for land preservation voter referendums 
Also, helpful would be data relevant to whether the voter referendum was a new project, continuation of prior referendum project(s), and/or a shared project with other public jurisdictions. Finally, the outcome estimates of prediction could be improved with the inclusion of variables that speak to the tenor of the environment in which the referendum election is held - globally, nationally, statewide and local. An example would be the economic downturn of the late 2000s.

Chapter $\mathrm{V}$ discusses the qualitative component of the mixed methods design of this study. The qualitative analysis is factored into the quantitative approach to incorporate factors relevant to government and voter decisions that are difficult to measure in terms of figures, numbers and dollars. 


\section{CHAPTER V}

\section{QUALITATIVE CASE STUDY APPROACH}

\subsection{Introduction}

Chapter $V$ describes the qualitative case study approach for the study's mixed methodology, and draws conclusions from a pattern-matching analysis of written and verbal data collected about three Southeast Florida selected case voter referendum counties. First, the analytical framework for the qualitative approach is presented again to review the steps in the analysis. Then, three descriptive and explanatory sections of this dissertation provide a summary of the documentation data collected relative to each of the three South Florida case counties, as well their three case-specific phenomenon of interest and regional south Florida concerns. The verbal data collected from twelve expert witness interviews with case-specific county public administrators and/or managers is transcribed, summarized, coded and consolidated into several primary conceptual themes. The chapter concludes with a summary discussion of the quantitative findings of the qualitative analysis, grounded in weighted in-case and cross-case analyses.

\subsection{Analytical Framework for the Qualitative Approach}

The analytical framework is a diagram representing the research design and road map for the qualitative investigation of three South Florida case counties. Grounded in the study's theoretical concepts, research questions, the purpose of the qualitative analysis is to complement and enrich the qualitative 
statistical analysis of U.S. county referendum and non-referendum numbers.

Figure 5.1 is the diagram of the qualitative research design.

Figure 5.1 Analytical Framework for the Qualitative Case Study Approach

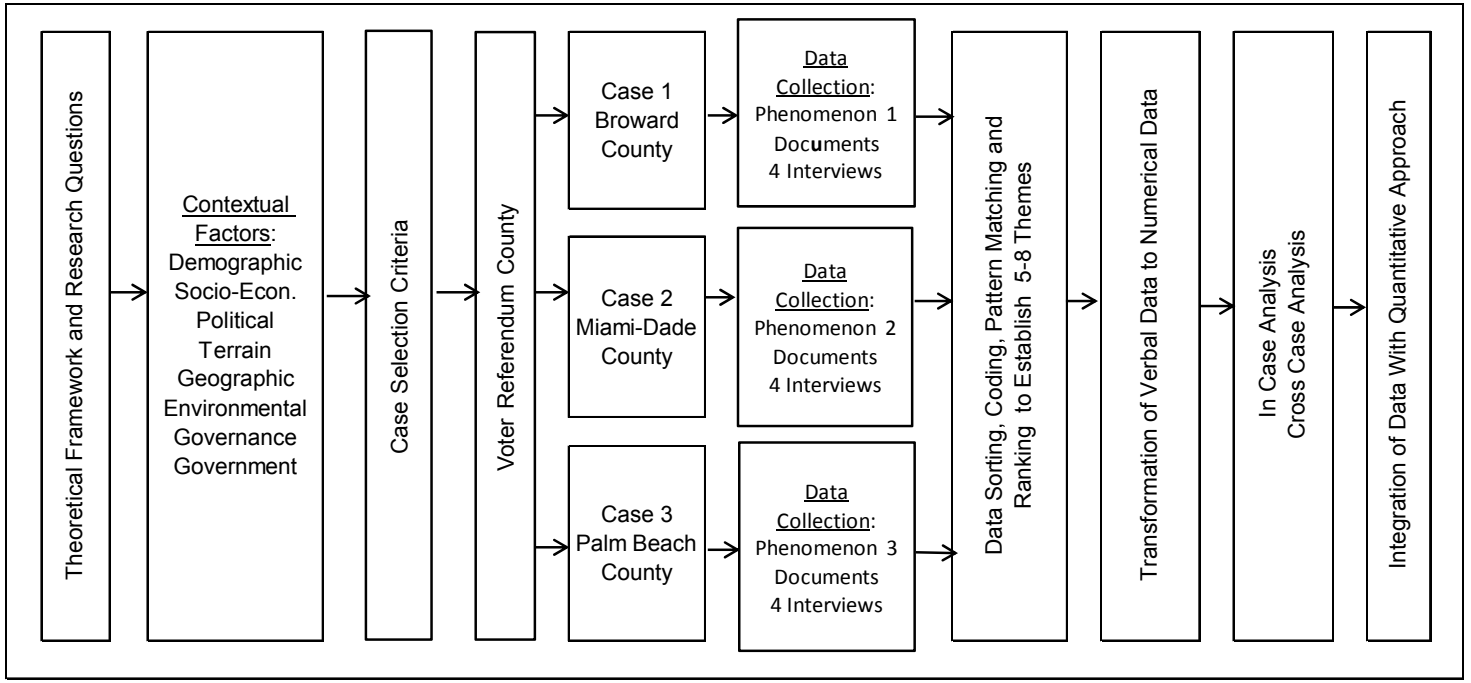

The primary functions of the analytical framework are to guide the researcher through judgmental decisions about the structure of the components and their interconnectedness and to ensure that the study will provide pragmatic answers to questions raised during the quantitative methodology of this research. The expectation is that the case study data will be complimentary and contribute a pragmatic and realistic understanding of how the county land preservation voter referendum process works in a sample of referendum counties, and why voters choose to vote 'yes' for approval at the ballot box.

- to understanding the meaning of events, situations, actions, and accounts of county public administrators and experiences;

- to identify the context within which the participants act, and the influence that this context has on their actions;

- to comprehend the process by which county land preservation voter referendum and related events take place; 
- to recognize unanticipated phenomena and influences; and

- to develop causal explanations.

Three South Florida referendum counties of Broward, Miami-Dade and Palm Beach Counties are selected by the most-different case selection method. Based upon the theoretical foundation of the study and research questions, the use of multiple sources of qualitative data is intended to be cumulative, complementary and contributory to the robustness and rigor of the case study design. Two primary sources of evidence and data for this qualitative approach are documentation and expert witness interviews.

\subsection{Collection of Document Data}

Case county documentation is obtained from state and case county archival records, letters, memoranda, agendas, study reports, public opinion polls, surveys, promotional materials, or any other paper records that relate to the case study counties and their phenomena of interest. Archival records are useful to a limited extent because they include service records, maps, charts, lists of names, survey data, and even personnal records. The validity of the documents is carefully reviewed to avoid the inclusion of incorrect data. One of the most important uses of documents is to corroborate evidence gathered from other resources.

Case county documentation is also gathered from national, state and county-specific websites and databases. These resources include the Trust for Public Lands LandVote $®$ database of land preservation voter referendums, U.S. 
Census Bureau's USA Counties ${ }^{\mathrm{TM}}$ database, NOAA's Coastal Counties in the United States, professional organizations targeting U.S. counties (e.g., GFOA, NACo, NCSC, ASPA), interest group databases, and scholarly research and theoretical books and articles. Addition secondary data is gathered from case county websites, documents, government databases, scholarly books and journals, and newspaper articles.

\subsubsection{Overview of South Florida and Three Case Counties}

The tri-county area of South Florida is a growing metropolitan region in the southeastern United States (U.S. Bureau of Census, 1950 - 2010) and a gateway to the Caribbean Islands and South America. The region reflects four key demographic trends: significant increase in population, immigration and multiculturalism; rise in both resident median income and poverty; escalation of land development and urbanization; and a surge in the resident older adult population as well as tourism and seasonal visitors (Taylor, 2003).

Figure 5.2 provides the geographic location of the three South Florida case counties in terms of State of Florida and its county jurisdictions.

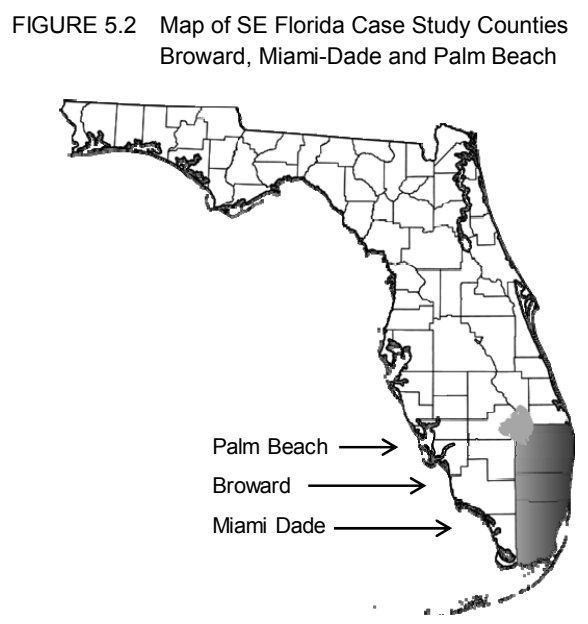


Table 5.1 summarizes the primary demographic, socio-economic, geographic, governance and government characteristics of the three selected county cases - Broward County, Miami-Dade County and Palm Beach County. In a number of factors, these three counties are similar - large population count and density in developed areas, significant population and immigration increases, and large portions of each county set aside as conservation areas.

Table 5.1 Three Identified County Cases: Main Features

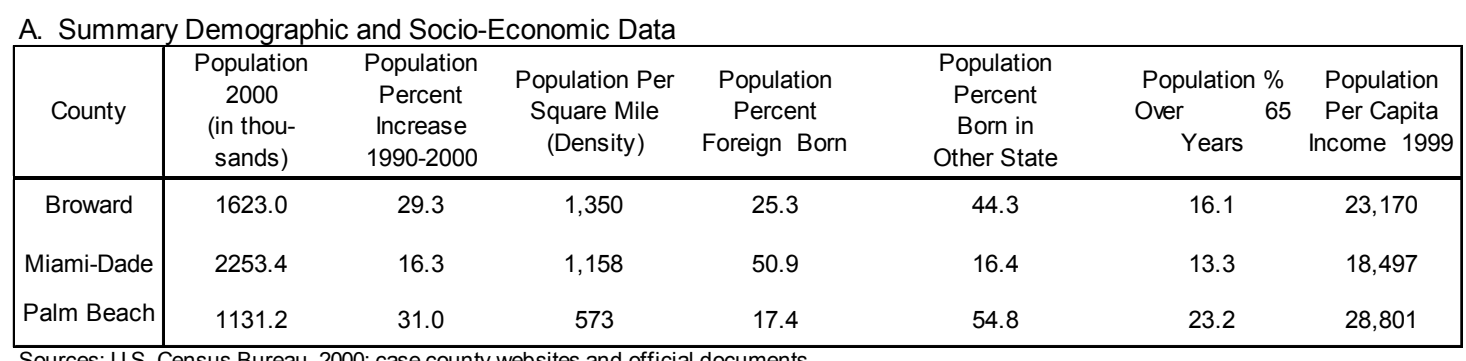

B. Summary Geographic Data

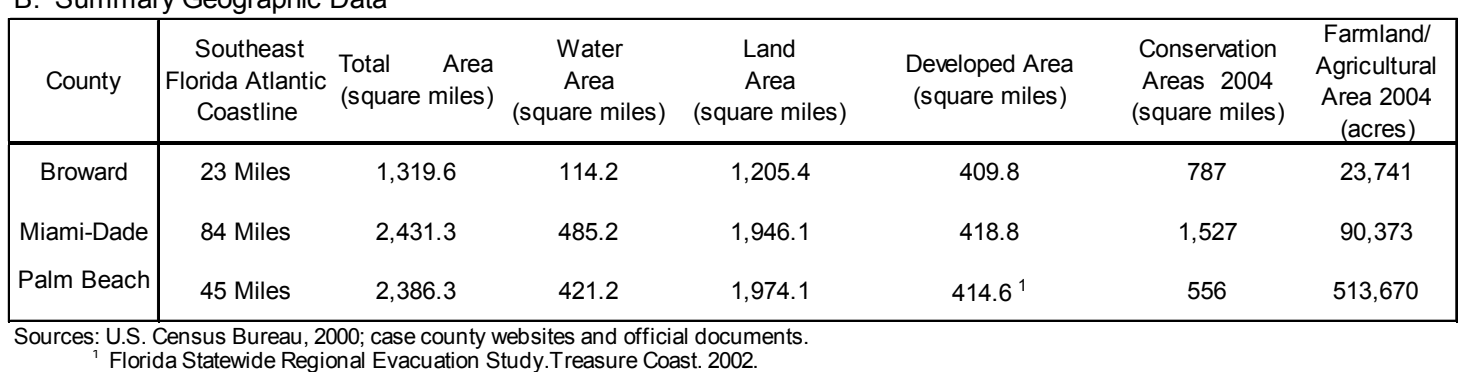

C. Summary Governance and Government Data

\begin{tabular}{|c|c|c|c|c|c|c|c|c|}
\hline County & Year & - Founded & Muncipalities & $\begin{array}{l}\text { Population } \\
\text { Residing in } \\
\text { Unincorp- } \\
\text { orated Areas }\end{array}$ & $\begin{array}{l}\text { Home Rule } \\
\text { Charter Voter } \\
\text { Adopted }\end{array}$ & $\begin{array}{c}\text { Reformed Government } \\
\text { Structure }\end{array}$ & $\begin{array}{c}\text { Number of } \\
\text { Successful } \\
\text { Referendums } \\
1988-2009 \\
\end{array}$ & $\begin{array}{l}\text { Theoretical } \\
\text { Construct of } \\
\text { Interest }\end{array}$ \\
\hline Broward & & 1915 & 31 & $8 \%$ & 1975 & $\begin{array}{c}\text { Commission (9) with } \\
\text { Appointed } \\
\text { Administrator }\end{array}$ & 2 & $\begin{array}{l}\text { Home Rule } \\
\text { Charter } \\
\text { History }\end{array}$ \\
\hline Miami-Dade & & 1836 & 35 & $52 \%$ & 1957 & $\begin{array}{c}\text { Commission (13) with } \\
\text { Elected Mayor and } \\
\text { Appointed City } \\
\text { Manager }\end{array}$ & 5 & $\begin{array}{l}\text { Public } \\
\text { Interest } \\
\text { Groups }\end{array}$ \\
\hline Palm Beach & & 1909 & 38 & $41 \%$ & 1985 & $\begin{array}{c}\text { Commission (7) with } \\
\text { Appointed } \\
\text { Administrator }\end{array}$ & 4 & $\begin{array}{l}\text { Land Use \& } \\
\text { Income } \\
\text { Diversity }\end{array}$ \\
\hline
\end{tabular}


Each county case presents a unique attribute that sets it apart for the other two South Florida county cases (see Table 5.2c). The construct of interest associated with Miami-Dade County is the phenomenon of its history of home rule (self-government) charter creation and voter amendment perpetuation. A relevant conceptual factor for the Broward County case is the influence of divergent developer and environmental interest groups over time. With precipitous development to the edge of the Everglades' protected wildlife and water conservation areas, the county developable land area is virtually built-out with little vacant residential and commercial land remaining. Finally, the study focus for Palm Beach County is the population's socio-economic and geographic land usage diversities (eastern wealthy enclaves to western transient migrant worker poor; from highly urban and suburban development to rural, agriculture/farming and environmentally protected lands.

There are several similar features that the three selected case study share. Each is a coastal county with its eastern border (beaches) adjacent to the Atlantic Ocean. Westward land development in each county case is restricted by the location of large land and water conservation areas. These conservation areas are part of state, regional and local efforts to preserve and maintain water resources and fragile ecosystems, e.g., the Florida Everglades, National Everglades Park, and National Biscayne Bay.

Figure 5.3 illustrates the juxtaposition of eastern urban development lands to the east in each of the case counties, and the western conservation areas. 
Figure 5.3 Three Cases: Palm Beach, Broward and Miami-Dade Counties Urbanized, Conservation and Rural/Agricultural Areas

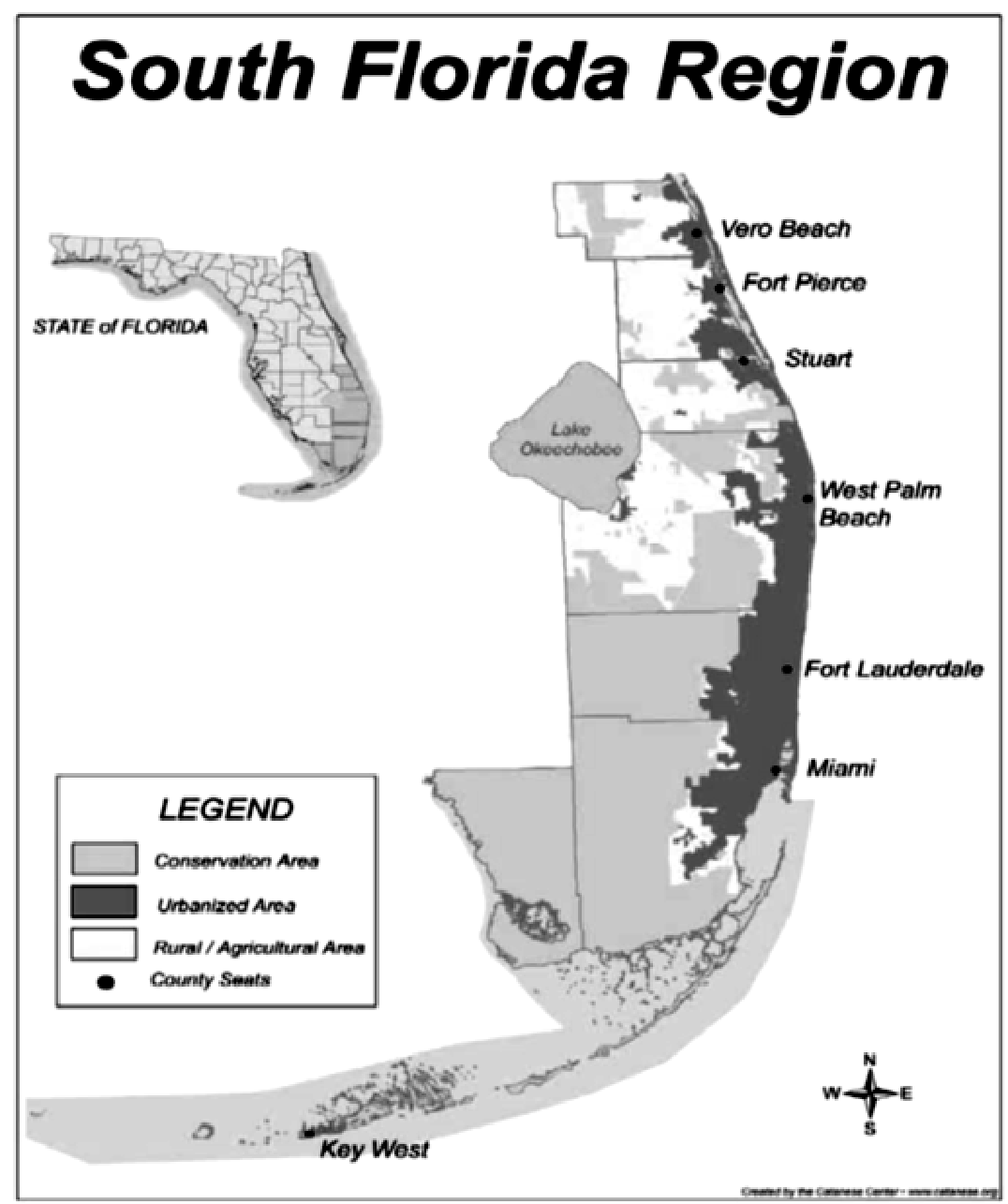

Source: 2007. Preserving Paradise: SoFlo's Call to Action. Florida Atlantic University Center for Urban and Environmental Solutions.

Another similarity between Broward, Miami-Dade and Palm Beach Counties is their state's governance and reformed government. The State of Florida legislation permits and delegates authority to local area governments. All case county governments operate under a home rule charter, although there are many features of the Miami-Dade County home rule charter history that sets this 
county apart from its neighboring case counties. A reformed administrative structure of county government is operational in each of the three county cases: Palm Beach and Broward County function with a commission/county administrator form; Miami-Dade County charter amendment authorized a strong elected mayor form. The number of local area municipalities in these three counties totals 103 , although a large percentage of the population in Miami Dade (52\%) and Palm Beach (41\%) reside in unincorporated areas of their respective counties.

Finally, all South Florida case county governments selected multiple land preservation voter referendums that voters passed by significant margins. Between 1988 and 2009, Broward, Miami-Dade and Palm Beach county governments selected eleven voter referendums. Table 5.2 outlines principle components of these eleven South Florida county voter referendums.

Table 5.2 List of Case County Land Preservation Voter Referendums (1988-2009)

\begin{tabular}{|c|c|c|c|c|c|c|}
\hline \multicolumn{2}{|l|}{ County, State } & \multirow{2}{*}{$\begin{array}{l}\text { Vote Date } \\
3 / 14 / 1989\end{array}$} & \multirow{2}{*}{$\frac{\text { Financing }}{\text { Bond }}$} & \multirow{3}{*}{$\begin{array}{c}\text { Purpose } \\
\text { Open space. } \\
\text { Parks, watershed } \\
\text { protection, wildlife habitat, } \\
\text { open space. }\end{array}$} & \multirow{2}{*}{$\begin{array}{c}\text { Funds Approved } \\
\$ 75,000,000\end{array}$} & \multirow{2}{*}{$\frac{\text { Pass Rate }}{58.70 \%}$} \\
\hline Broward & $\mathrm{FL}$ & & & & & \\
\hline Broward & $\mathrm{FL}$ & $11 / 7 / 2000$ & Bond & & $\$ 400,000,000$ & $73.59 \%$ \\
\hline Miami-Dade & $\mathrm{FL}$ & $5 / 8 / 1990$ & Propery Tax & Open space. & $\$ 90,000,000$ & $53.56 \%$ \\
\hline Miami-Dade & $\mathrm{FL}$ & $11 / 5 / 1996$ & Bond & $\begin{array}{c}\text { Parks, watershed } \\
\text { protection, recreation, } \\
\text { open space. }\end{array}$ & $\$ 200,000,000$ & $66.99 \%$ \\
\hline Miami-Dade & $\mathrm{FL}$ & $11 / 2 / 2004$ & Bond & $\begin{array}{c}\text { Parks, recreation, open } \\
\text { space. }\end{array}$ & $\$ 680,258,000$ & $66.10 \%$ \\
\hline Miami-Dade & $\mathrm{FL}$ & $11 / 2 / 2004$ & Bond & Open space, recreation. & $\$ 255,070,000$ & $58.26 \%$ \\
\hline Miami-Dade & $\mathrm{FL}$ & $11 / 2 / 2004$ & Bond & Open space, recreation. & $\$ 552,692,000$ & $65.42 \%$ \\
\hline Palm Beach & $\mathrm{FL}$ & 3/12/1991 & Bond & $\begin{array}{l}\text { Open space, } \\
\text { wildlife habitat. }\end{array}$ & $\$ 100,000,000$ & $66.51 \%$ \\
\hline Palm Beach & $\mathrm{FL}$ & 3/9/1999 & Bond & $\begin{array}{c}\text { Farmland, greenways, } \\
\text { open space. }\end{array}$ & $\$ 150,000,000$ & $66.14 \%$ \\
\hline Palm Beach & $\mathrm{FL}$ & $11 / 5 / 2002$ & Bond & $\begin{array}{c}\text { Parks, recreation, open } \\
\text { space. }\end{array}$ & $\$ 50,000,000$ & $62.41 \%$ \\
\hline Palm Beach & $\mathrm{FL}$ & $11 / 2 / 2004$ & Bond & $\begin{array}{l}\text { Open space, recreation, } \\
\text { watershed protection. }\end{array}$ & $\$ 50,000,000$ & $67.64 \%$ \\
\hline
\end{tabular}

Source: The Trust for Public Land LandVote ${ }^{\circledR}$ Database. 


\subsubsection{Case 1: Broward County, Florida}

\subsubsection{Broward County Land Preservation Voter Referendums}

Broward County approved two land preservation voter referendums between 1989 and 2009.

First, on March 14, 1989, voters in Broward County, Florida, approved a $\$ 75$ million bond issue referendum to acquire and manage environmentally sensitive lands (ESL) (TPL LandVote $®$ database, 2012). A portion of those funds were directed toward the purchase of additional pockets of property within West Lake Park (Hollywood, FL).

On November 7, 2000, Broward County voters approved the passage of the Safe Parks and Land Preservation Bond Referendum in the amount of $\$ 400$ Million. This referendum authorized Broward County Commission's expenditure of \$200 Million for park system expansion and improvements, Challenge Grant proposals, and additional or enhanced aquatic facilities for Safe Water Instructions Means Safety (SWIM) Central Program teaching children to swim. The referendum also authorized Broward County Commission's expenditure of \$200 Million for land preservation and protection by (1) acquiring undeveloped, natural lands for conservation, (2) securing green spaces as buffers between environmentally sensitive lands and conservation lands, and (3) obtaining and restoring open spaces for public parks. The implementation of this voter referendum program provided support to many county municipalities in their efforts to acquire, protect and manage undeveloped lands within their boundaries. An independent panel of Broward County citizens representing 
cities, law, environmentalists, academia, and other interests reviewed and recommended all acquisition contracts prior to a public hearing and the Board's final approval. The panel was devoid of representation from the development industry. By the end of 2010 , the program successfully acquired more than 1,000 acres of conservation lands, green spaces and open spaces.

\subsubsection{Broward County, Florida}

Broward County was created in 1915 by the Florida state legislature with Palm Beach County (north) and Dade County (south) each contributed nearly equal quantities of land area. The post-World War II build-up of the South Florida region was transformational. Table 5.3 provides an overview of Broward County's population by decade, and the percentage of change from 1920 through 2010 .

Table 5.3 Broward County, FL

Historical Population and Change by Decade

\begin{tabular}{rrr} 
Year & Population & Change \\
\hline 1920 & 5,135 & - \\
1930 & 20,094 & $291.30 \%$ \\
1940 & 39,794 & $98.00 \%$ \\
1950 & 83,933 & $110.90 \%$ \\
1960 & 333,946 & $297.90 \%$ \\
1970 & 620,100 & $85.70 \%$ \\
1980 & $1,018,200$ & $64.20 \%$ \\
1990 & $1,255,488$ & $23.30 \%$ \\
2000 & $1,623,018$ & $29.30 \%$ \\
2010 & $1,748,066$ & $7.70 \%$
\end{tabular}

Source: U.S. Census Bureau.

As of 2000, Broward County covers 1,319.63 square miles, of which $1,205.40$ square miles $(91.4 \%)$ is land and 114.24 square miles $(8.6 \%)$ is water. 
In 2010, the county boundaries contain 31 incorporated municipalities, and remaining pockets of non-annexed, unincorporated areas (U.S. Census Bureau).

Broward County property is divided into two major sectors. The eastern portion of 471 square miles (35.7\%) is the County's development land which is highly urbanized with a density of 3,740 per square mile (U.S. Census Bureau, 2000). The 848.63 square miles $(64.3 \%)$ to the west consists of Everglades wildlife management and water conservation areas. See Figure 5.4 below.

Figure 5.4 Map of Broward County, Florida Waterways Development Area and Water Conservation Areas)

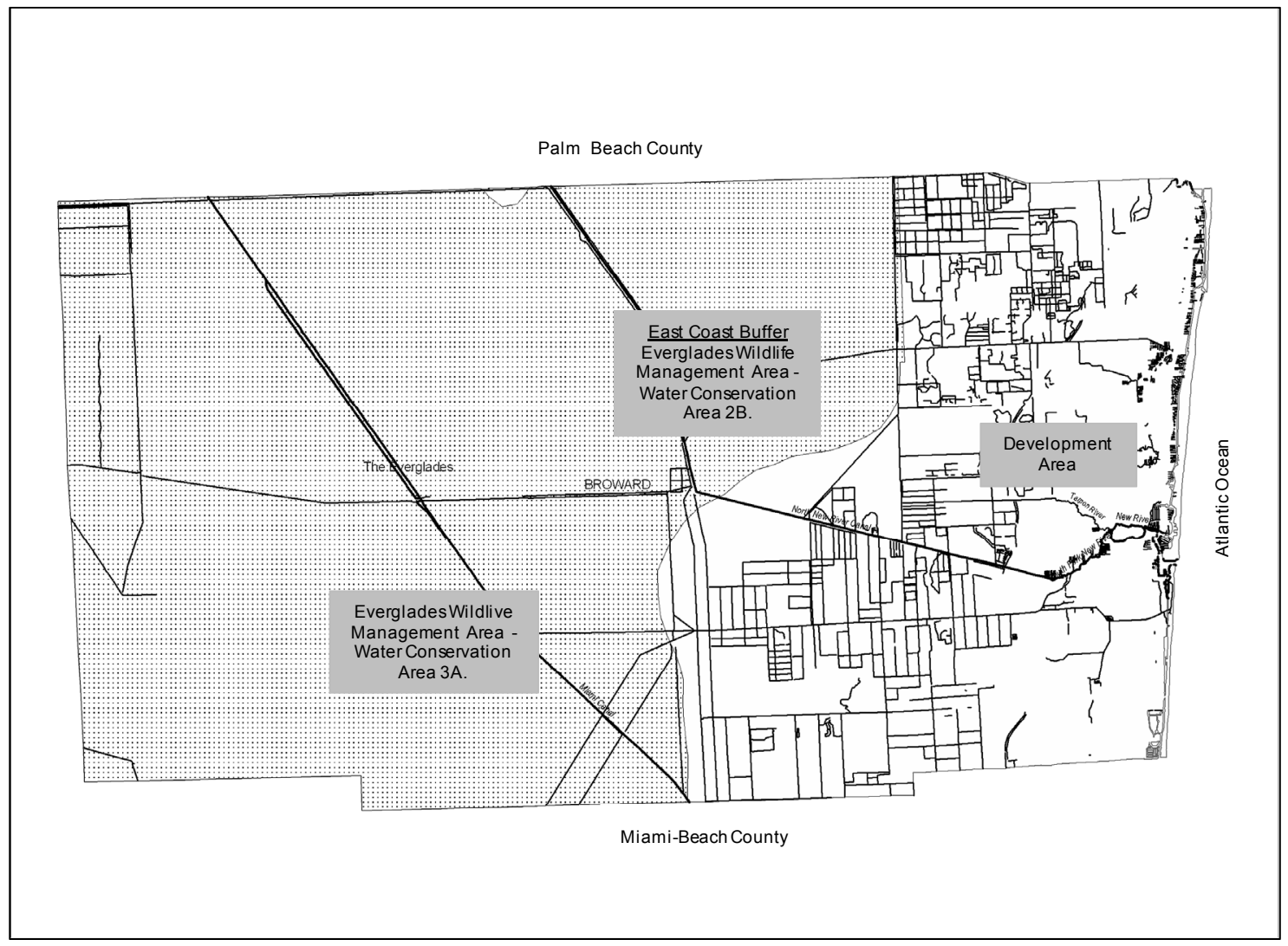

Source: Florida Center for Instructional Technology, Tampa, FL: University of South Florida. Map \#11297 Florida Waterways: Broward County Online without Labels, 2008.

Downloaded from Maps ETC at http://fcit.usf.edu/florida/maps/index.htm. 
5.3.2.3 Broward County 2000 Demographic, Socio-Economic and Other Indicators

As of 2000 , there were $1,623,018$ persons, 654,445 households, and 411,645 families residing in the county. The racial makeup of the county was 70.57 percent White (58 per cent were Non-Hispanic), 20.54 percent Black or African American, 0.24 per cent Native American, 2.25 per cent Asian, 0.06 per cent Pacific Islander, 3.00 percent from other races, and 3.35 percent from two or more races. 16.74 per cent of the population was Hispanic or Latino of any race.

The Seminole Tribe of Florida is a federally recognized Native American tribe with six reservations in central and south Florida and support more than 2,000 Seminoles (FL Division of Historical Resources, 2012). One tribal reservation and part of another are located within Broward County. First, the Seminole Hollywood (formerly Dania) Reservation covers approximately 500 acres in Broward County and is the most populated of the six. Second, the Seminole Big Cypress Reservation is located in northwest Broward, southwest Palm Beach County, and southeast Hendrie counties. It covers about 52,000 acres and has a resident population of 142 persons (U.S. Census Bureau, 2000).

In the Broward at 2000, the age spread of the population was as follows: 23.6 percent under the age of $18,7.2$ percent from 18 to $24,31.4$ percent from 25 to $44,21.7$ percent from 45 to 64 , and 16.1 percent who were 65 years of age or older. The median age was 38 years. For every 100 females there were 93.3 males. For every 100 females age 18 and over, there were 89.8 males (U.S. Bureau of Census, 2000). 
The 2000 median income for a household in the county is $\$ 41,691$, and the median income for a family is $\$ 50,531$. Males have a median income of $\$ 36,741$ versus $\$ 28,529$ for females. The per capita income for the County is $\$ 23,170$. About 8.7 percent of families and 11.5 percent of the population are below the poverty line, including 15.3 percent of those under age 18 and 10.0 percent of that age 65 or above (U.S. Census Bureau, 2000).

In relation to the ancestry of Broward County residents, in 2000, 9.4 percent were Italian, 7.4 percent American, 6.8 percent German, 6.7 percent Irish, and 4 percent English ancestry. About 5.0 percent were Jamaican and 4.0 percent Haitian alone (U.S. Census Bureau, 2000).

In 2000, about one-quarter of residents were foreign born, of which over two-thirds are immigrants from Latin America. In 1970 and 1980, the majority of foreign born residents came from Europe (including the former USSR), whereas in 1990 and 2000, most immigrants came from Latin America, including Haiti, Cuba, Jamaica, Colombia, and Brazil (Broward County Office of Urban Planning and Redevelopment, 2002).

As of 2000, 71.27 percent of all residents spoke English as their first language, while 16.33 percent spoke Spanish, 3.51 percent French Creole, 1.77 percent French, 1.13 percent Portuguese, 0.89 percent Italian, and 0.56 percent of the population spoke German as their first language. In total, 28.72 percent of the population spoke a language other than English at home (U.S. Bureau of Census, 2000). 
With the huge influx of immigrants since 2000, the population language figures have become outdated. Since many immigrants are coming from the Anglophone Caribbean where English is spoken, the first language of county residents may alter immigration data suggestions (U.S. Census Bureau, 2000).

In 2000 , there were 741,043 housing units with an average density of 615 per square mile. There were 654,445 households out of which 29.30 percent had children under the age of 18 living with them, 46.1 percent were married couples living together, 12.5 percent had a female householder with no husband present, and 37.1 percent were non-families. 29.6 percent of all households were made up of individuals and 12.4 percent had someone living alone who was 65 years of age or older. The size of the average household size was 2.45 and the average family size was 3.07 individuals (U.S. Bureau of Census, 2000).

Broward County population grew by $7.70 \%$ to $1,748,066$ from 2000 to 2010, and ranks second highest in the State of Florida. The population growth rate is much lower than the state average rate of $17.64 \%$ and is lower than the national average rate of $9.71 \%$. Broward county median household income is $\$ 51,694$ in $2006-2010$ and has grown by $23.99 \%$ since 2000 . The income growth rate is much higher than the state average rate of $14.40 \%$ and is higher than the national average rate of $19.17 \%$. Broward county median house value is $\$ 247,500$ in $2006-2010$ and has grown by $92.46 \%$ since 2000 . The house value growth rate is much higher than the state average rate of $55.64 \%$ and is much higher than the national average rate of $50.42 \%$. As a reference, the national Consumer Price Index (CPI) inflation rate for the same period is $26.63 \%$. 


\subsubsection{Broward County Regional Government}

Home rule charter government became effective in Broward County on January 1, 1975 after the voters of Broward County approved the Broward County Charter at the polls on November 5,1974 , by a vote of 77,889 to 59,898 . The Charter brought home rule to Broward County, which had become a County by an act of the Florida State Legislature in 1915. For the next 60 years, the County Commission was required to receive the State Legislature's approval of local bills effecting Broward County governmental operation.

In addition to bringing home rule to Broward County, the Charter expanded the County Commission from five to seven members elected at large, created a strong administrator form of County government, and established a countywide land use planning agency. The Charter also created a Charter Review Commission to study all phases of County government and propose changes in the Charter. Changes may also be proposed by the County Commission and by initiative of the people. Voters must approve all changes.

The Broward County Charter for self-government provides for a separation between the legislative and administrative functions of government. The Board of County Commissioners is the legislative branch of Broward County Government.

The 1999 Florida State Legislature, on the urging of the Broward Delegation, placed a charter amendment on the March 2000 ballot to form single member districts with an elected executive mayor, while retaining an appointed county administrator. The Broward Commission also placed an amendment on the ballot to modify the Commission structure to 9 single member districts. Only 
the Commission amendment passed, establishing a Board of Commissions with 9 members elected by 9 districts, and effective with the November 2000 election.

Each year the Commission elects a Mayor and Vice Mayor. The Mayor's functions include serving as presiding officer and the County's official representative. The Commission appoints a county administrator, attorney and auditor. The Commission also appoints many advisory and regulatory boards.

The language of Broward County Codes $^{13}$ of Ethics acknowledges it reliance on U.S. governance principles by citing its incorporation of components of the United States Code ${ }^{14}$ and Florida Statutes ${ }^{15}$.

On August 10, 2010, the Broward County Commission enacted Ordinance 2010-22 (Code of Ethics). On November 2, 2010, County voters approved this Code as an amendment to the Broward County Charter. Restrictions on the amendment are that the Board "may strengthen or supplement the restrictions or protections provided under this Code, but restrictions and protections hereof may be weakened or removed, in whole or in part, only by citizen initiative...". The Broward County Commission amended this Code of Ethics through approval of Ordinance 2011-19, enacted October 11, 2011 and effective January 2, $2012^{16}$.

The Codes of Ethics Ordinances define "'Lobbying' or 'Lobbying Activities' as communication, by any means, from a lobbyist to a covered individual (County elected and appointed personnel, and city officials and select staff and

\footnotetext{
${ }^{13}$ Broward County Code of Ordinances, Part II, Chapter 1, Sections 1-19 and 1-26.

${ }^{14}$ FL Statues, Chapter 112, Part III, Code of Ethics for Public Officers and Employees.

${ }^{15}$ Title 18, Chapter 63 of the United States Code.

${ }^{16}$ BC Code of Ordinances, Part II, Chapter 1, Sections 1-19 and 1-26.
} 
personnel) regarding any item that will foreseeably be decided by a final decision-making authority, which communication seeks to influence, convince, or persuade the covered individual to support or oppose the item"17. A "Lobbyist' means a person who is retained, with or without compensation, for the purpose of lobbying, or a person who is employed by another person or entity, on a fulltime or part-time basis, principally to lobby on behalf of that other person or entity" ${ }^{18}$. The lobbyist description does not include elected officials, County employees or appointees, a person who communicates for him/herself or another unless principally employed by the other, representative of a homeowner et al. association, an employee or officer or board member of a non-profit public interest group, a municipal official, and a vendor (supplier of goods and services applicable to local government.

The Broward County Lobbyist Registration Act was initiated in 2001, and significantly amended in 2009 and 2011 to parallel its Codes of Ethics ordinances. The Act is also included in the Broward County Code of Ordinances ${ }^{19}$. The purposed of this Act is to fully allow citizens to petition their county government for the redress of grievances and to express their opinions on legislation and issues; to clarify definitions and procedures; to maintain the integrity of those engaged in efforts to influence County Commissioners, its decision-making bodies, and its employees on matters within their official

\footnotetext{
${ }^{17}$ BC Code of Ordinances Part II, Chapter 1, Sections 1-19 and 1-26.

${ }^{18}$ BC Code of Ordinances Part II, Sections 1-19 and 1-26.

${ }^{19}$ BC Code of Ordinances, Part I, Sections 1-260 through 1-266.
} 
jurisdictions; to set parameters for direct communications as well as solicitation by others; and to publicly and regularly disclose BC lobbyist registrations.

\subsubsection{Phenomenon of Interest: Influence of Special Interests}

The phenomenon of interest for the case study of Broward County is the collective action of lobbyists and interest groups with the potential of influencing the proposal and passage of land preservation voter referendums.

An interest group, also called special interest group or pressure group, is any association of individuals or organizations, usually formally organized, that, on the basis of one or more shared concerns, attempts to influence public policy in its favor. All interest groups share a desire to affect government policy to benefit themselves or their causes. Their goal could be a policy that exclusively benefits group members or one segment of society (e.g., government subsidies for farmers) or a policy that advances a broader public purpose (e.g., improving air quality). They attempt to achieve their goals by lobbying-that is, by attempting to bring pressure to bear on policy makers to gain policy outcomes in their favor. (Encyclopedia Britannica ${ }^{20}$ ).

Broward County Lobbyists and Special Interests. 'Lobbying' has a strict legal and IRS definition for nonprofits which generally only includes activities that ask policymakers to take a specific position on a specific piece of legislation, or that ask others to ask the same. In contrast, the common language definition of lobbying usually includes any discussion of issues with policymakers.

\footnotetext{
${ }^{20}$ Retrieved online November 18, 2012 at http://www.britannica.com/EBchecked/topic/290136/interest-group)
} 
Conversely, 'advocacy' encompasses any activity that a person or organization undertakes to influence policies.

Since 2001 direct lobbying with Broward County Commissioners and its administration requires lobbyist registration. "Sections 1-260 through 1-266 of Chapter I, Broward County Code, may be cited as the 'Broward County Lobbyist Registration Act.' The Board of County Commissioners of Broward County, Florida, hereby determines and declares that the operation of responsible government requires that the fullest opportunity be afforded to the people to petition their county government for the redress of grievances and to express freely to the elected officials their opinions on legislation and other actions and issues......." ${ }^{21}$.

Grassroots lobbying (also called indirect lobbying) is a form of lobbying that focuses on raising awareness of a particular cause at the local level, with the intention of reaching the legislature and making a difference in the decisionmaking process. Grassroots lobbying is an approach that separates itself from direct lobbying through the act of asking the general public to contact legislators and government. Grassroots lobbying has four elements of communication. First, it is directed to the general public; second, it refers to specific legislation; third, it reflects a view on the legislation; and last, it encourages the recipient ...to take action with respect to the legislation ${ }^{22}$.

\footnotetext{
${ }^{21}$ Original Ordinance initiated in 2001, amended 2004, 2009. Retrieved on November 18, 2012 from http://library.municode.com/HTML/10288/level3/PTIICOOR_CH1AD_ARTXIIILOAC.html ${ }^{22}$ IRS Regulation 56.4911-2(b)(2)(ii).
} 
Full lobbyist registration and full public disclosure with Broward County through its Lobbyist Registration Act, did not occur until the final year of the county land preservation voter referendum research time frame. Therefore, official lists of Broward County government lobbyist were not available to researcher. For this case study research, obtaining data about the types and numbers Broward County lobbyists and special interest groups in business, environmental, voter referendum, and relevant mass media alliances came from other resources sources discussed below.

Business Lobbyists and Special Interests. The types of direct and indirect lobbying organizations and individuals are numerous. For this study, the U.S. Census Bureau's Business Register (U.S. Census Bureau County Business Patterns, 2002) is one data resource. This registry categorizes the types of 'establishments' included in U.S. State and County Business Patterns. They define an 'establishment' as a single physical location at which business is conducted, or services or industrial operations are performed. A company or 'enterprise' may consist of one or more establishments. A single-unit company owns or operates only one establishment; a multi-unit company owns or operates two or more establishments. A single-unit company's unique identifier is its U.S. Internal Revenue Service (IRS) employer/tax identification number (EIN). A multiunit company is associated with a cluster of one or more EINs, and EINs can be associated with one or more establishments (U.S. Census Bureau County Business Patterns, 2002). 
The North American Industry Classification System (NAICS), a web-based resource was developed under the direction and guidance of the U.S. Office of Management and Budget (OMB) as the standard for use by Federal statistical agencies in classifying business establishments. Use of this standard provides uniformity and comparability in the presentation of statistical data. NAICS is based on a production-oriented concept, meaning that it groups 'establishments' into industries according to similarity in the processes used to produce goods or services (U.S. Census Bureau NAICS, 2002).

There is a potential for any of these identifiable NAICS-coded industries or 'establishments' to function as a lobbyist at the federal, state, county or local area government level. Table 5.4 identifies 21 NAICS-coded industries that conduct business in Broward County, Florida as of U.S. Census Bureau data of 2002.

Table 5.4 2002 Broward County Businss Patterns by NAICS Code Number of Paid Employees and Industy Establishments by Employment-Size Classification

\begin{tabular}{|c|c|c|c|c|c|c|c|c|c|c|c|c|c|c|}
\hline \multirow{2}{*}{$\begin{array}{l}\text { NAICS } \\
\text { Code }\end{array}$} & \multirow{2}{*}{$\begin{array}{l}\text { NAICS Code } \\
\text { Description }\end{array}$} & \multirow{2}{*}{$\begin{array}{l}\text { Total } \\
\text { No. Paid } \\
\text { Employees }\end{array}$} & \multirow{2}{*}{$\begin{array}{l}\text { Rank } \\
\text { Total No. } \\
\text { Paid } \\
\text { Employees }\end{array}$} & \multirow{2}{*}{$\begin{array}{l}\text { Total } \\
\text { No. } \\
\text { Establish- } \\
\text { ments }\end{array}$} & \multirow{2}{*}{$\begin{array}{l}\text { Rank } \\
\text { Total No. } \\
\text { Establish- } \\
\text { ments }\end{array}$} & \multicolumn{9}{|c|}{ No. Industry Establishments by Employment-Size Classification } \\
\hline & & & & & & '14' & '5-9' & '10-19' & '20-49' & '50-99' & '100-249' & '250-499' & '500-999' & '1000 or more' \\
\hline ----- & Total & 619,401 & & 50,328 & & 31,876 & 8,119 & 4,844 & 3,231 & 1,230 & 745 & 203 & 60 & 20 \\
\hline 11--- & $\begin{array}{l}\text { Forestry, fishing, } \\
\text { hunting \& agriculture }\end{array}$ & $100-249$ & 20 & 58 & 19 & 44 & 12 & 2 & 0 & 0 & 0 & 0 & 0 & \\
\hline $21--$ & Mining & $0-19$ & 21 & 6 & 21 & 5 & 1 & 0 & 0 & 0 & 0 & 0 & 0 & \\
\hline 22---- & Utilities & 1,091 & 18 & 24 & 20 & B & 2 & 1 & 6 & 0 & 1 & 0 & 1 & \\
\hline 23---- & Construction & 41,754 & 6 & 4,037 & 6 & 2,666 & 564 & 384 & 267 & 98 & 42 & 12 & 3 & \\
\hline $31-$. & Manufacturing & 36,689 & 8 & 1,937 & 11 & 973 & 341 & 264 & 186 & 100 & 62 & 10 & 0 & \\
\hline |42--- & Wholesale trade & 42,181 & 5 & 4,509 & 5 & 2,915 & 704 & 456 & 287 & 89 & 44 & 10 & 4 & \\
\hline 44--- & Retail trade & 97,919 & 1 & 7,051 & 1 & 3,891 & 1,488 & 816 & 442 & 182 & 181 & 51 & 0 & \\
\hline |48---- & $\begin{array}{l}\text { Transportation \& } \\
\text { warehousing }\end{array}$ & 16,300 & B & 1,139 & 12 & 769 & 144 & 81 & 73 & 38 & 24 & 8 & 1 & \\
\hline $51 \ldots$ & Information & 18,078 & 11 & 877 & 13 & 516 & 107 & 94 & 86 & 48 & 13 & 8 & 3 & \\
\hline 52---- & Finance \& insurance & 34,372 & 9 & 3,055 & 9 & 1,910 & 535 & 349 & 168 & 53 & 26 & 9 & 4 & \\
\hline |53---- & $\begin{array}{l}\text { Real estate \& rental \& } \\
\text { leasing }\end{array}$ & 7,155 & 2 & 2,520 & 10 & 1,866 & 370 & 160 & 75 & 23 & 17 & 8 & 1 & \\
\hline 54--- & $\begin{array}{l}\text { Professional, scien- } \\
\text { tific \& technical serv }\end{array}$ & 38,104 & 7 & 6,916 & 2 & 5,381 & 835 & 387 & 215 & 62 & 19 & 16 & 0 & \\
\hline 55---- & $\begin{array}{l}\text { Manage company \& } \\
\text { enterprises }\end{array}$ & 13,259 & 14 & 250 & 17 & 97 & 36 & 33 & 33 & 20 & 22 & 2 & 6 & \\
\hline |56----- & $\begin{array}{l}\text { Admin, support, waste } \\
\text { mgt, remediation }\end{array}$ & 69,987 & 3 & 3,531 & 7 & 2,319 & 465 & 276 & 207 & 106 & 105 & 35 & 15 & \\
\hline $61-$ & $\begin{array}{l}\text { Educational services } \\
\text { Health care and social }\end{array}$ & 2,375 & 15 & 472 & 16 & 259 & 62 & 60 & 57 & 22 & 8 & 3 & 0 & \\
\hline |62---- & $\begin{array}{l}\text { assistance } \\
\text { Arts, entertain \& }\end{array}$ & 74,933 & 2 & 4,606 & 4 & 2,592 & 1,006 & 526 & 273 & 101 & 71 & 14 & 77 & \\
\hline 71--- & $\begin{array}{l}\text { recreational serv } \\
\text { Accommodation \& } \\
\text { food services }\end{array}$ & 0,021 & 16 & 705 & $\begin{array}{l}14 \\
8\end{array}$ & 466 & 78 & 63 & 50 & 24 & 21 & 1 & 2 & \\
\hline $\begin{array}{l}72--- \\
81--\end{array}$ & $\begin{array}{l}\text { Other services (not } \\
\text { pub adm) }\end{array}$ & 32,711 & 10 & 4,735 & 3 & 3,224 & 806 & 401 & $2 \pi$ & 55 & 24 & 7 & 1 & \\
\hline 95----- & $\begin{array}{l}\text { Auxiliaries (exc } \\
\text { corporate, subsidiary \& } \\
\text { regional mngt) }\end{array}$ & 3,801 & $\pi$ & 60 & 18 & 26 & 8 & 4 & B & 3 & 2 & 2 & 1 & \\
\hline 99--- & $\begin{array}{l}\text { Unclassified } \\
\text { establishments }\end{array}$ & 887 & 19 & 678 & 15 & 626 & 40 & 8 & 4 & 0 & 0 & 0 & 0 & \\
\hline
\end{tabular}


Referring to Table 5.4, more than half of the listed industry 'establishments' in Broward County are staffed with less than five paid employees. The top ten industries ranked by the number of 'establishments' are: arts; construction; insurance; healthcare; transportation; real estate; recreation; food services; social services; and entertainment. (U.S. Census Bureau County Business Patterns by NAICS Code, 2002).

Another special interest group related to Broward County is the Seminole Hollywood Native American Tribe. The Seminole Hollywood Native American Tribe is a unique special interest group in Broward County because it functions as both a business and historic group. The Seminole Tribal Council's first major business success in 1975 was a tax-free cigarette. In 1979, the tribe pursued a high-stakes bingo operation on their land in Hollywood, FL, becoming the first major Indian gaming location in the United States (Fixico, D.L., 2006). Subsequently the Tribal Council Seminole Tribe opened two casinos in Broward County: Seminole Casino Hollywood and Seminole Casino Coconut Creek. In 2007, the Tribe purchased the Hollywood Hard Rock Hotel and Casino. Other economic industries of the Florida Seminole Tribe include agriculture (citrus groves) and cattle farming on the Brighton and Big Cyress Reservations, tourism, and forestry (Pritzker, 2000).

Non-Profit Environmental Special Interests. Another lobbyist supporting land preservation voter referendums is the collective action of environmental organizations and grassroots activists. In 2005, the IRS files include over 26,000 organizations whose primary mission is conservation and protection of the 
natural and human environment. Of those, 30 percent filed a Form 990 return in 2005, providing current information on their finances and activities (Straughan and Pollak, The Urban Institute, 2008). The remainder did not, possibly because their annual revenues were below $\$ 25,000$. The public charities included in this study range from neighborhood groups with small budgets and no assets to established institutions like The Nature Conservancy, which had almost a billion dollars in revenues in 2005 . The overwhelming majority (79.5 percent) of the organizations that filed Form 990s had revenues of less than $\$ 600,000$.

The Trust for Public Land is a national non-profit organization based in San Francisco, CA, that operates 36 other offices throughout the United States ${ }^{23}$. There are two offices in the State of Florida - Tallahassee and South Miami, FL.

Table 5.5 Florida Environmental Organizations (81)

\begin{tabular}{|c|c|c|}
\hline Alachua Audubon Society & Green Horizon Land Trust & Sierra Club - Florida Chapter \\
\hline Alachua Conservation Trust & Halifax River Audubon Society & Sierra Club - Central Chapter \\
\hline Arthur R. Marshall Foundation ${ }^{3}$ & Hernando Audubon Society & Sierra Club - Daytona Chapter \\
\hline Apalachee Audubon Society & Indian River Land Trust & Sierra Club - Ft. Lauderdale Chapter ${ }^{1}$ \\
\hline $\begin{array}{l}\text { Audubon Society of the Everglades }{ }^{3} \\
\text { Bay County Audubon Society }\end{array}$ & $\begin{array}{l}\text { Kissimmee Valley Audubon Society } \\
\text { Lake Region Audubon Society }\end{array}$ & $\begin{array}{l}\text { Sierra Club - Ft. Myers Chapter } \\
\text { Sierra Club - Ft. Walton Chapter }\end{array}$ \\
\hline $\begin{array}{l}\text { Broward County Audubon Society }{ }^{1} \\
\text { Calusa Land Trust }\end{array}$ & $\begin{array}{l}\text { Lemon Bay Conservancy } \\
\text { Manatee County Audubon Society }\end{array}$ & $\begin{array}{l}\text { Sierra Club - Gainsville/Ocala Chapter } \\
\text { Sierra Club - Jacksonville Chapter }\end{array}$ \\
\hline $\begin{array}{l}\text { Citrus County Audubon Society } \\
\text { Clearwater Audubon Society }\end{array}$ & $\begin{array}{l}\text { Martin County Audubon Society } \\
\text { Myakka Conservancy }\end{array}$ & $\begin{array}{l}\text { Sierra Club - Miami Chapter }{ }^{2} \\
\text { Sierra Club - Nassau Chapter }\end{array}$ \\
\hline $\begin{array}{l}\text { Collier County Audubon Society } \\
\text { Conservancy } \\
\text { Conservation Trust for Florida } \\
\text { Duval Audubon Society } \\
\text { Earth Justice Florida }\end{array}$ & $\begin{array}{l}\text { Nature Conservancy }{ }^{2} \\
\text { North Florida Land Trust } \\
\text { Oklawaha Valley Audubon Society } \\
1000 \text { Friends of Florida } \\
\text { Orange Audubon Society }\end{array}$ & $\begin{array}{l}\text { Sierra Club - St. Petersburg Chapter } \\
\text { Sierra Club - Sarasota Chapter } \\
\text { Sierra Club - Tallahassee Chapter } \\
\text { Sierra Club - Tampa Chapter } \\
\text { Sierra Club - Turtle Coast Chapter }\end{array}$ \\
\hline Environmental Action Group & Peace River Audubon Society & Sierra Club - West Palm Beach ${ }^{3}$ \\
\hline $\begin{array}{l}\text { Everglades Foundation }{ }^{2} \\
\text { Florida Bat Center } \\
\text { Florida Defenders of the Environment } \\
\text { Florida League of Conservation Voters }\end{array}$ & $\begin{array}{l}\text { Pelican Island Audubon Society } \\
\text { Republicans for Environmental Protection } \\
\text { St Johns County Audubon Society } \\
\text { St. Lucie Audubon Society }\end{array}$ & $\begin{array}{l}\text { Southern Alliance for Clean Energy } \\
\text { Space Coast Audubon Society } \\
\text { Tampa Audubon Society } \\
\text { Tampa Bay Conservancy }\end{array}$ \\
\hline $\begin{array}{l}\text { Florida Native Plant Society }{ }^{1,2,3} \\
\text { Florida Panther Society }\end{array}$ & $\begin{array}{l}\text { St. Petersburg Audubon Society } \\
\text { Sanibel-Captiva Audubon Society }\end{array}$ & $\begin{array}{l}\text { Tampa Baywatch } \\
\text { Tropical Audubon Society }\end{array}$ \\
\hline $\begin{array}{l}\text { Florida Trail Association }{ }^{1,2,3} \\
\text { Florida Wildlife Federation }\end{array}$ & $\begin{array}{l}\text { Sarasota Audubon Society } \\
\text { Sarasota Conservation Foundation }\end{array}$ & $\begin{array}{l}\text { Trust for Public Lands }{ }^{2} \\
\text { Weston (Francis) Audubon Society }\end{array}$ \\
\hline $\begin{array}{l}\text { Friends of the Everglades }{ }^{2} \\
\text { Friends of the Myakka River } \\
\text { Gopher Tortoise Council } \\
\text { Great Outdoors Conservancy }\end{array}$ & $\begin{array}{l}\text { Save the Homosassa River Alliance } \\
\text { Save the Manatee Club } \\
\text { Seminole Audubon Society }\end{array}$ & $\begin{array}{l}\text { West Pasco Audubon Society } \\
\text { West Volusia Audubon Society } \\
\text { WildLaw }\end{array}$ \\
\hline
\end{tabular}

${ }^{23}$ Retrieved from http://www.tpl.org/about/offices/ on January 10, 2012. 
Their website claims that this organization is "The national leader" at creating public funds for conservation.....helping states, counties, and cities plan preservation solutions, raise funds, and complete conservation transactions.

Established environmental organizations operating solely within Broward County are few. However, many more environmentally-minded volunteers function in the county, state or nationally, either operating as part of a multiindustry "establishment" or loosely-organized grassroots groups. Table 5.5 lists 81 Florida Environmental Organizations.

For this study additional environmental 'establishments' are added to the list of NAICS-coded industries that may be identified as Broward County interest group lobbyists. The Trust for Public Lands LandVote ${ }^{\circledR}$ database identifies specific purposes for which state, county and local area referendums were designed to be financed. These purposes are as follows: the acquisition or upgrade of land preservation or conservation of open space, parks, recreation, wildlife habitat (and endangered), watershed protection (including water service, ground water, aquifer, and everglades), trails, forests, farmland (and agriculture), greenways, ranchland, and historical/geological preservation (and native American Indian history and historical societies).

Finally, environmental literature and the local communication resources have discussed the following Broward County topics or actions between 1988 through 2009. They are: population growth, immigration, and diversity; urban sprawl and build-out to the Everglades Wildlife Management and Conservation Areas; adequate roads and road development; acquisition of vacant properties 
by developers for residential or commercial development purposes; large single and multi-family housing projects; Florida State growth management legislation; storms and beach renourishment; tourism activity; marine industry and boating; homelessness and homeless services; gambling and casinos; and the economy at the national, state and county levels.

There are a number of reviews of existing scholarly research using newspaper event data (Franzosi, 1987; Koopmans and Rucht, 1999; Olzak 1989 and 1992; Earl, Martin, McCarthy and Soule, 2004). Most major research traditions in collective action social movements benefit from analysis of newspaper data (Earl, Martin, McCarthy and Soule, 2004)

However, scholars and researchers have published some criticisms of the quality of such data, and these criticisms suggest possible limitations on their utilization. One set of criticisms addresses researchers' collection practices. Another suggests that newspaper data may have flaws, regardless of the collection method used. In particular, some scholars argue that newspapers selectively report events ("selection bias") or that they erroneously report information ("description bias") (McCarthy et al., 1996). Others have also discussed "researcher bias," which is introduced through coding and data entry errors (Franzosi, 1987). Finally, some critics argue that when events resonate with more general social concerns, they are more likely to be reported. This is referred to as the "issue attention cycle" (Downs, 1972) or media attention cycle (McCarthy et al., 1996). 
A review of the use of newspaper data in studying collective action by Earl, Martin, McCarthy and Soule (2004) demonstrates that despite growth in research on the quality and potential limitations of newspaper data, strong conclusions on its strengths and weaknesses remain indefinable. Indeed, research on both selection and description bias shows that even though some aspects of data (e.g., soft news) may be affected by bias, other aspects have withstood a great deal of critical evaluation.

NewsBank, Inc. has been one of the world's premier information providers for more than 40 years. NewsBank's comprehensive, web-based research products satisfy the diverse needs of public libraries, colleges and universities, schools, military and government libraries, professionals and researchers.

To capture the frequency of articles that identify each of the Broward County NACIS-coded industry 'establishments', plus supplemental environmental, voter referendum, and topical issue special groups, NewsBank, Inc. is accessed and programed to identify the number articles found in the South Florida (formerly Ft. Lauderdale) Sun-Sentinel newspaper annually, from 1988 through 2009. That data was organized and tabulated, and the "establishments' ranked according to the total number of articles for the 22 years. The Broward County government 'establishment' was not included because of the large number of irrelevant public notices published; had this 'establishment' been included, it is ranked as number one.

Broward County Voter Referendum Lobbyists and Special Interests. In the pursuit of Broward County government's selection of the land preservation voter 
financing referendum tool, and the citizens' vote for its passage or not, involve more 'establishment' activities. These public and private sector activities are also added to the list of NCICS-coded industries. The 'establishment' actions are: citizenship, county government, public administration, voter referendum, special interest group, lobbyist, and election.

Mass Media Broward County Lobbyists and Special Interests. Finally, environmental literature and the local communication resources have discussed the following Broward County topics or actions from 1989 through 2009. They are: population growth, immigration, and diversity; urban sprawl and build-out to the Everglades Wildlife Management and Conservation Areas; adequate roads and road development; acquisition of vacant properties by developers for residential or commercial development purposes; large single and multi-family housing projects; Florida State growth management legislation; storms and beach renourishment; tourism activity; marine industry and boating; homelessness and homeless services; gambling and casinos; and the economy at the national, state and county levels.

NewsBank: Collection of Lobbyist and Special Interests Data. There are a number of reviews of existing scholarly research using newspaper event data (Franzosi, 1987; Koopmans and Rucht, 1999; Olzak 1989 and 1992; Earl, Martin, McCarthy and Soule, 2004). Most major research traditions in collective action social movements benefit from analysis of newspaper data (Earl, Martin, McCarthy and Soule, 2004) 
However, scholars and researchers have published some criticisms of the quality of such data, and these criticisms suggest possible limitations on their utilization. One set of criticisms addresses researchers' collection practices. Another suggests that newspaper data may have flaws, regardless of the collection method used. In particular, some scholars argue that newspapers selectively report events ("selection bias") or that they erroneously report information ("description bias") (McCarthy et al., 1996). Others have also discussed "researcher bias," which is introduced through coding and data entry errors (Franzosi, 1987). Finally, some critics argue that when events resonate with more general social concerns, they are more likely to be reported. This is referred to as the "issue attention cycle" (Downs, 1972) or media attention cycle (McCarthy et al., 1996).

A review of the use of newspaper data in studying collective action by Earl, Martin, McCarthy and Soule (2004) demonstrates that despite growth in research on the quality and potential limitations of newspaper data, strong conclusions on its strengths and weaknesses remain indefinable. Indeed, research on both selection and description bias shows that even though some aspects of data (e.g., soft news) may be affected by bias, other aspects have withstood a great deal of critical evaluation.

NewsBank, Inc. has been one of the world's premier information providers for more than 40 years. NewsBank's comprehensive, Web-based research 
products satisfy the diverse needs of public libraries, colleges and universities, schools, military and government libraries, professionals and researchers ${ }^{24}$.

To capture the frequency of articles that identify each of the Broward County NACIS-coded industry 'establishments', plus supplemental environmental, voter referendum, and topical issue special groups, NewsBank, Inc. is accessed and programed to identify the number articles found in the South Florida (formerly Ft. Lauderdale) Sun-Sentinel newspaper annually, from 1988 through 2009. That data was organized and tabulated, and the "establishments' ranked according to the total number of articles for the 22 years. The Broward County government 'establishment' was not included because of the large number of irrelevant public notices published; had this 'establishment' been included, it is ranked as number one.

\begin{tabular}{|c|c|c|c|}
\hline \multirow{2}{*}{$\begin{array}{l}\text { Table } 5.6 \\
\text { NAICS } \\
\text { Code }\end{array}$} & \multicolumn{3}{|c|}{$\begin{array}{l}\text { Broward County's Top } 15 \text { Special Interest Industries or Groups } \\
\text { Resource: Sun Sentiel Newspaper Articles from } 1988 \text { through } 2009\end{array}$} \\
\hline & $\begin{array}{l}\text { NAICS Code } \\
\text { Description }\end{array}$ & $\begin{array}{l}\text { Total Number } \\
\text { of Articles }\end{array}$ & $\begin{array}{l}\text { Rank by Number } \\
\text { of Articles }\end{array}$ \\
\hline 81--- & Other serv: county govt ${ }^{1}$ & 32104 & 0 \\
\hline 71---- & Arts & 25163 & 1 \\
\hline 23--- & Construction & 23442 & 2 \\
\hline 99---- & Unclass estab: election & 18993 & 3 \\
\hline 81--- & Other serv: voter & 16858 & 4 \\
\hline 52--- & Insurance & 14406 & 5 \\
\hline 62---- & Health care & 13502 & 6 \\
\hline 48---- & Transportation & 13267 & 7 \\
\hline 81--- & Other serv: developer & 11354 & 8 \\
\hline 53--- & Real estate & 10467 & 9 \\
\hline 71--- & Recreation & 10277 & 10 \\
\hline 81--- & Other serv: road develpment & 9902 & 11 \\
\hline 81--- & Other serv: environment & 9659 & 12 \\
\hline 72--- & Food services & 9335 & 13 \\
\hline 62--- & Social services & 9023 & 14 \\
\hline 71--- & Entertainment & 8767 & 15 \\
\hline Source: & $\begin{array}{l}\text { s World News, News Bank. re } \\
\text { nfoweb.newsbank.com.ezprox }\end{array}$ & nuary 9,2013 & hese \\
\hline
\end{tabular}

\footnotetext{
${ }^{24}$ Available at http://www.newsbank.com/index.cfm?content=99.
} 
Table 5.6 presents the outcome of the newspaper research, a list of the top fifteen 'establishments' with the probability of performing as a significant Broward County special interest groups and/or lobbyists related to this study.

Broward County Conceptual Lobbyist and Special Interests Trends. There are three trends impacting the potential for lobbyist and special interest group activism in Broward County from 1988 through 2009.

Trend 1: Population, Density, Foreign Born, and Migration Challenges.

Table 5.7 reveals the change indicators for three South Florida Case Counties over three decades (decennial data from 1980 through 2010). For Broward County, the percent of population increase was highest from 1980 to 1990 . However, the population density (persons per square mile) is highest at the conclusion of the thirty years (2010). The development area of Broward County is almost fully urbanized or built out by 2010 with 99.98 percent of the population residing within the urban area. Finally, the percent of housing (development) increase was highest in the earliest decade (1980-1990) with a steady decline to 9.4 percent in 2000-2010. This measurement contributes to the conclusion that the potential for new development in Broward County is small. 
Table 5.7 Change Indicators for USA, Florida and 3 South Florida (FL) Case Counties for Three Decades Encompassing the Research: 1980 through 2010

\begin{tabular}{|c|c|c|c|c|c|c|}
\hline \multirow[b]{3}{*}{ USA } & \multicolumn{3}{|c|}{ a. Percent Population Increase } & \multicolumn{3}{|c|}{ b. Population Density (per sq. mile) } \\
\hline & $1980-1990$ & $1990-2000$ & $2000-2010$ & 1990 & 2000 & 2010 \\
\hline & 9.8 & 13.1 & 9.7 & 70.3 & 79.6 & 87.4 \\
\hline Florida & 32.7 & 23.5 & 17.6 & 239.9 & 296.4 & 350.6 \\
\hline Broward & 23.3 & 29.3 & 7.7 & $1,038.9$ & $1,349.9$ & $1,444.9$ \\
\hline Miami-Dade & 19.2 & 16.3 & 10.8 & 996.1 & $1,157.9$ & $1,315.5$ \\
\hline \multirow[t]{3}{*}{ Palm Beach } & 49.7 & 31.0 & 16.7 & 437.4 & 573.0 & 670.2 \\
\hline & \multicolumn{3}{|c|}{ c. Percent Population in Urban Areas } & \multicolumn{3}{|c|}{ d. Percent Housing Increase } \\
\hline & 1990 & 2000 & $2010^{1}$ & $1980-1990$ & $1990-2000$ & $2000-2010$ \\
\hline USA & 75.2 & 79.0 & 80.70 & 15.7 & 13.3 & 13.6 \\
\hline Florida & 84.8 & 89.3 & 91.16 & 39.3 & 19.7 & 23.1 \\
\hline Broward & 98.9 & 99.9 & 99.98 & 29.3 & 17.9 & 9.4 \\
\hline Miami-Dade & 98.8 & 99.3 & 99.60 & 15.9 & 10.5 & 16.1 \\
\hline Palm Beach & 94.7 & 98.3 & 98.96 & 56.2 & 20.5 & 19.4 \\
\hline
\end{tabular}

Source: U.S. Census Bureau; USA Counties, 1980, 1990, 2000, 2010; Florida OEDR.

${ }^{1} 2010$ US Census Bureau revised methodology of calculating urban and rural population: Urban $=$ Urbanized Areas have 50,000 or more people, and Urban Clusters have at least 2,5000 people and less than 50,000; Rural = less than 2,500 people.

Table 5.8 displays the growth of the foreign born population in Broward County (U.S. Census decennium data, 1970 through 2000).

Table 5.8 Growth of Diversity: 1970 to 2000 Broward County, Florida

\begin{tabular}{lrrrr} 
Population & 1970 & 1980 & 1990 & 2000 \\
\hline U.S. Native & 570,531 & 904,861 & $1,057,222$ & $1,212,631$ \\
Foreign Born & 49,604 & 113,339 & 198,274 & 410,379 \\
& 8.69436 & 12.52557 & 18.75424 & 33.84203
\end{tabular}

Source: U.S. Census Bureau, 2000.

Domestic migration is an important variable to consider in the analysis of the Broward County case study. Utilizing data from the U.S. Bureau of Census and the U.S. Internal Revenue Service (IRS), Broward County Environmental Protection and Growth Management Department, Planning and Redevelopment 
Division developed in/out migration indicates that domestic immigrants are more likely to move into Broward County from other Florida counties than from elsewhere in the United States. The majority (60 percent) of out-migrants from Broward County remain mostly within the State of Florida. However, when considering the State of Florida, more tax filers move from Broward County to other Florida Counties, than move to Broward from other Florida Counties. Refer to Table 5.9 showing domestic in/out migration between counties.

In the early morning of August 24, 1992, the eye of Category 5 Hurricane Andrew made landfall near Homestead in Miami-Dade County. Evacuations had previously been ordered in nine Florida counties - Broward, Charlotte,

Table 5.9 Broward County, FL Population In/Out Migration [According to U.S. Internal Revenue Service (IRS) Data of Primary Tax Filers and their Exemptions]

\begin{tabular}{|llr|}
\hline \multicolumn{3}{|c|}{ Top 15 U.S. Counties, In-Migration } \\
Tax Exemptions to Broward County \\
\hline \multicolumn{3}{|c|}{2001 - 2007 } \\
Rank & County & IRS Exemptions \\
1 & Miami Dade County, FL & 195,049 \\
2 & Palm Beach County, FL & 52,122 \\
3 & Queens County, NY & 13,548 \\
4 & Kings County, NY & 9,880 \\
5 & Orange County, FL & 9,032 \\
6 & Nassau County, NY & 6,497 \\
7 & Hillsborough County, FL \\
8 & Cook County, IL & 5,987 \\
9 & Suffolk County, NY & 5,846 \\
10 & Bronx County, NY & 5,419 \\
11 & New York County, NY & 5,287 \\
12 & Los Angeles County, CA & 4,693 \\
13 & Duval County, FL & 4,136 \\
14 & Pinellas County, FL & 3,711 \\
15 & Westchester County, NY & 3,583 \\
\hline
\end{tabular}

\begin{tabular}{|llr|}
\hline \multicolumn{3}{|c|}{ Top 15 U.S. Counties, Out-Migration } \\
Tax Exemptions from Broward County \\
\hline \multicolumn{3}{|c|}{2001 - 2007 } \\
Rank & County & IRS Exemptions \\
1 & Palm Beach County, FL & 100,193 \\
2 & Miami Dade County, FL & 98,825 \\
3 & St Lucie County, FL & 17,518 \\
4 & Orange County, FL & 15,050 \\
5 & Hillsborough County, FL & 10,184 \\
6 & Lee County, FL & 9,045 \\
7 & Brevard County, FL & 8,992 \\
8 & Marion County, FL & 6,727 \\
9 & Duval County, FL & 6,037 \\
10 & Polk County, FL & 5,762 \\
11 & Volusia County, FL & 5,043 \\
12 & Gwinnett County, GA & 5,042 \\
13 & Seminole County, FL & 4,922 \\
14 & Lake County, FL & 4,637 \\
15 & Collier County, FL & 4,369 \\
\hline
\end{tabular}

Collier, Lee, Martin, Miami-Dade, Monroe, Palm-Beach and Sarasota Counties (Post, Buckley, Schuh, Jernigan, Inc., 1993). In Miami-Dade County, a 
combination of strong winds, storm surge, and rainfall contributed to 40 fatalities and the destruction of structures (homes and businesses), infrastructure, power and water grids, farmlands, vegetation, and more, estimated to be valued at $\$ 25$ billion (1992 USD) (Rappaport, 1993, 2005). In the decade after the storm, Hurricane Andrew may have contributed to the massive and sudden housing boom in Broward County. Located just north of Miami-Dade County, residents who had lost their homes migrated to the western sections of that county which were just beginning to be developed. The result was record growth in places like Miramar, Pembroke Pines and Weston (Lovelace and McPherson, 1998).

Trend 2: Broward County Land Development Challenges. Between 1982 and 2002, land in the United States was consumed for development at three times the rate of population growth (Murley, 2008). Broward County is essentially built out and most of its new development will be infill. Redevelopment of older urban cores and first-ring suburbs is a planning tool that redirects development away from undeveloped land; reduces stress on the Everglades, agricultural lands, and aquifer recharge areas; reduces infrastructure costs; promotes economic development such as the revitalization of failing strip malls and surrounding neighborhoods; and fosters compact development that increases opportunities for residents and employees to use public transit, walk, or bicycle (Murley, 2008).

The U.S Census Bureau Building Permit Survey collects information about future local, regional, state and national construction. The building permit data provides an accurate estimate of construction on future projects because the 
request for a building permit is the first step to the construction of any new residential structure. Building permits data is also utilized by the U.S. Federal Reserve Board to measure economic conditions both regionally and nationally.

Between 1980 and 2003 in Broward County, over 305,000 housing units were built in Broward County. Fifty-three percent of these units were single family units while the remaining 47 percent were multi-family. The number of building permits issued in Broward County has been cyclical. During times of economic downturns (1981 to 1982 and 1991 to 1992), the number of permits decreased dramatically. 1986 and 1987 had the highest number of permits. (BC Office of Urban Planning and Redevelopment, June 2004).

Between 2000 and 2003, the number of single family building permits dropped 57 percent from 9,200 to 3,900 . Multi-family units increased 59 percent from 2,600 to 4,100 units in the same period. In 2002 , over 6,300 multi-family permits were issued in Broward County, the highest number since 1989. Between 2000 and 2003, the municipality of Miramar (southwest) posted the highest number of single family building permits at 7,722 ; and the southwestern cities of Weston and Pembroke Pines were respectively second and third. The City of Ft. Lauderdale (eastern location) issued the highest number of multifamily building permits at 3,684; and the municipalities of Coral Springs in the northwest and Miramar in the southeast were respectively second and third. (BC Office of Urban Planning and Redevelopment, June 2004).

Trend 3: Governance- Preservation and Land Planning Challenges. From the beginning of the modern era, Florida has relied on both regulatory programs 
and taxpayer-financed (voter referendum) land acquisition programs as strategies to meet the challenges of rapid growth and land development. Further, modern growth policy in the State of Florida has sought to balance the competing interests of environmental protection, economic development, community wellbeing, and private rights. Finally, local and state governments have shared decision-making authority over some land development issues that historically were only local in nature (Powell, 2000).

During the time span of this county land preservation voter referendum study (1988 and 2009), the State of Florida actively supported county and local area governments in their acquisition efforts of lands for preservation and conservation efforts. The Preservation $2000 \mathrm{Act}^{25}$ (and Chapter 380, Part III, The Florida Communities Trust Act, Florida Statutes) was created to financially assist local governments implement the conservation, recreation and open space, and coastal management elements of their comprehensive plans. This program accepted and processed grant awards to local governments to acquire land for the purposes of natural resource conservation and outdoor recreation (Florida Department of Environmental Protection [FL-DEP], 2012).

Florida Forever (2001 to present) is the State of Florida's current land acquisition program for conservation and recreation. It is the Florida Department of Environmental Protection's plan for conserving natural resources and renewing Florida's commitment to conserve the state's natural and cultural heritage. Florida Forever replaced the Preservation 2000 program, together

\footnotetext{
${ }^{25}$ Rulemaking Authority 380.507(11) FS. Law Implemented 259.101, 375.045, 380.501.515 FS. History-New 11-3-91, Amended 11-1-92, 2-9-98, Formerly 9K-4.001.
} 
considered one of the largest public land acquisition program of its kind in the United States. With approximately 9.9 million acres managed for conservation in Florida, more than 2.5 million acres were purchased under the Florida Forever and Preservation 2000 programs (FLDEP, 2012).

In Addition, the State of Florida engineered one of the nation's most comprehensive and ambitious planning programs in 1985 (Wickersham, J.H., 1994). Incorporating many of the recommendations of the governor-appointed Environmental Land Management Study Committee II (DeGrove, J.M., 1994) the legislature amended the Florida State Comprehensive Planning Act of $1972^{26}$, and passed the Florida Growth Management Act of $1985^{27}$ (GMA1985).

GMA1985 gives state officials authority over local governments on approvals for marinas, airports, changes in land use and other development projects. Any changes a local government proposes to its land use plan require State approval. This legislation mandated that the Florida Regional Planning Councils employ regional plans consistent with the newly adopted State plan. Local governments were required to adopt detailed comprehensive plans by 1992. Also, GMA1985 required that local plans be consistent with the goals and policies of both the regional and state plans, and those local governments implement their plans through consistent local land development regulations and land use decisions (DeGrove, 1994). It mandated that local governments choose

\footnotetext{
${ }^{26}$ Ch. 72-295, 1972 Florida Laws (codified as amended at F.S. Chapter 186 (1995).

${ }^{27}$ Ch. 85-57, 1985 Florida Laws (codified as amended at F.S. Chapter187 (1995) and 163.3161163.3215 (1995).
} 
a specific level of service for water, sewer, solid waste, drainage, conservation, recreation and open space.

GMA1985 mandated "concurrency," requiring that facilities and services needed by new development be in place in time to serve that development (Powell, D.L., 1993). Concurrency is designed to accomplish two major goals: (1) to ensure that the impact of new development is realistically assessed before it is approved; and (2) to eliminate the lag time between development and provision of services. Therefore, local governments had to commit to providing these services when a new development creates a need for them (Powell, D.L., 1993).

However, campaign donors who identified themselves as developers, home builders, architects, contractors or in building or construction made $\$ 2.7$ million in contributions to state and local area candidates in the 2000 election. One of the reasons for these special interest contributions was because the Florida 2000 legislature was proposing to rewrite GMA1985. Seiber (a commission member) stated that a proposed revision would make it easier for developers to develop county lands without charges for their services (Wallman, B., 2000). In 2012, FL legislature ${ }^{28}$ eventually implemented sweeping changes to the GMA1985 that relaxed land development regulations (Turner, K., 2011).

\subsubsection{Case 2: Miami-Dade County (MDC), Florida}

\subsubsection{Miami-Dade County Land Preservation Voter Referendums}

\footnotetext{
${ }^{28}$ Effective July 1, 2012: Laws of Florida House Bill 503 (Chapter 2012-205) and Bill 979 (Chapter 2012-75).
} 
Miami-Dade County government selected five land preservation voter referendums, and resident votes approved them by significant margins (see Table 5.12 for a summary of characteristics).

\section{(1) Environmentally Endangered Lands (EEL)}

In 1990, Miami-Dade County voters approved a two-year ad valorem property tax (1990 to 1992) of $\$ 90$ million to fund the acquisition, protection, and maintenance of threatened native forests and wetlands. The county government also established its Environmentally Endangered Land (EEL) program to implement the project6. EEL is administered by the county's Department of Environmental Resources Management. Additional funding for the program comes from state, county and private sources.

The EEL program continues to protect natural areas within the urban and agricultural matrix of eastern Miami-Dade County. The endangered sites proposed, and many since acquired, are important for the conservation of rare endemic upland plants and home to a variety of animal species. Their preservation also offers a series of ecosystem services that directly and indirectly benefit the community, i.e., flood control and aquifer recharge (Alonso and Heinen, 2011).

(2) Safe Neighborhood and Parks Act

On November 5, 1996, voters approved a $\$ 200$ million general obligation bond measure to fund capital improvements at countywide park and recreation facilities. Entitled the Safe Neighborhood and Parks Act, the purpose of the voter referendum was to unite the county and its municipalities in a common cause: to 
demonstrate how parks and recreation programs can make a community safer and improve the residents' quality of life.

Impetus for selecting a land preservation voter referendum tool in 1996 arose from a "no new taxes" environment, budget reductions, and six prior failed attempts by Dade County Parks and Recreation Department staff to encourage the County's selection of a capital improvement bond measure on the ballot. According to Kelly and Ziepler (2001), a coalition of Parks and Recreation Department staff and a network of local, state and national experts implemented the following strategic steps that resulted in the County selection of a voter referendum: research and professional polling; measured design; fundraising, message development, and communications via a grassroots campaign; analysis of other ballot measures; and planning for results and implementation.

A national public opinion firm polled a sample of County voters to ascertain their concerns (crime, juvenile violence, government mismanagement, and rampant growth and development). Voters also expressed willingness-to-pay no more than $\$ 7-10$ per household per annum with a cap of $\$ 200$ million total.

A second opinion poll provided the project name, respected spokespeople, election timing, and critical swing voters (Kelly and Ziepler, 2001).

A coalition of business and civic leaders formed the Trust for Safe Neighborhood Parks (The Trust) to screen potential EEL projects. Its draft of the overall referendum proposal, or Ordinance, would require adoption by the Board of County Commissioners for Miami-Dade County. The Trust addressed citizen concerns about crime (in its 'safe' title and Ordinance language), government 
mismanagement of public funds (creation of a Citizen's Oversight Committee, detailed list of projects and costs, and independent annual audits), and a series of mandatory public forums throughout the County (Kelly and Ziepler, 2001).

Once the County approved the referendum Ordinance, the public relations campaign was designed with two purposes: first, a grassroots effort headed by the local office of a national non-governmental organization (NGO) and their political action committee (PAC); and second, a media campaign organized by a Citizens Advisory Committee (CAC) which incorporated the Trust. Fundraising efforts were also undertaken at both the grassroots and corporate levels to pay for professional political consultants, airtime, and the production of Spanish and English television commercials (Kelly and Ziepler, 2001).

The presence of competing issues on the same election day ballot was addressed by offering a positive benefits-based message. Not only was there the potential for voters to "drop out" once they cast their vote in a presidential election, but other ballots controversies stimulate a vote of 'no' for all or confusing issues. For the most part, the November 5, 1996, election ballot offered a group of negative issues that played on public fears of over-taxation, government waste, and environmental damage in the form or a contested race for the executive mayor's office, a no new taxes/anti-government proposal, a "Save the Everglades" amendment, and a referendum to build a new arena for the local professional basketball team (Kelly and Ziepler, 2001). 
On election day, volunteers in "Vote My Park" t-shirts, carrying placards and handing out palm cards, were stationed precinct polling stations. The measure passed with a 67 percent "yes" vote.

(3) Building Better Communities (3 referendums)

On November 2, 2004, Miami-Dade County voters passed the $\$ 2.9$ billon Building Better Communities (BBC) General Obligation Bond (GOB) Program. Voters approved each of the eight ballot questions resulting in what was in 2004 , according to Bond Buyer, the largest bond program of its kind in the southeastern United States, and the third largest in the nation.

Three ballot questions rank as single land preservation voter referendums.

Bond Question 2: To construct and improve neighborhood and regional parks and other recreational areas to include athletic fields and gymnasiums, courts, pools, playgrounds, marinas, restore beaches, and the preservation of endangered lands described in Resolution No. 913045, adopted July 20, 2004, shall Miami-Dade County issue General Obligation Bonds to pay cost of such projects in a principal amount not exceeding $\$ 680,258,000$, bearing interest not exceeding maximum legal rate, payable from ad valorem taxes?

Voter results: $\quad 449,293$ Yes

230,415 No

Ballot Question 6: To construct and improve public service outreach facilities to meet code and service requirements and to increase neighborhood and community access to services, described in Resolution 
No. 917-04, adopted July 20, 2004, shall Miami-Dade County issue General Obligation Bonds to pay cost of such projects in a principal amount not exceeding $\$ 255,070,000$, bearing interest not exceeding maximum legal rate, payable from ad valorem taxes?

Voter results: $\quad 383,238$ Yes

274,604 No

Ballot Question 8: To construct and improve libraries, cultural facilities, and Head Start learning centers for pre-school children to offer multicultural educational opportunities and activities, described in Resolution No. 917-04, adopted July 20, 2004, shall Miami-Dade County issue General Obligation Bonds to pay cost of such projects in a principal amount not exceeding $\$ 552,692,000$, bearing interest not exceeding maximum legal rate, payable from ad valorem taxes?

Voter results: $\quad 441,287$ Yes

233,279 No

\subsubsection{Miami-Dade County, Florida}

Dade County was created on January 18, 1836, under the Territorial Act of the United States. The county was named after Major Francis L. Dade, a soldier killed in 1835 in the Second Seminole War. At the time of its creation, Dade County encompassed the land that now contains Broward and Palm Beach Counties, together with the Florida Keys from Bahia Honda Key north. In 1899, the county seat returned to Miami. (Muir, 1953). 
On November 13, 1997, voters approved a County charter amendment changing its name from Dade County to Miami-Dade County. The ballot measure received a 51.9 percent approval rating (Charter Amendments, 1997). The County is unofficially referred to as Miami, Miami-Dade, Dade County, Dade, Metro-Dade or Greater Miami.

The history of Miami-Dade County's population growth reflects periods of dramatic growth and diversity within the late 19th and 20th centuries. Table 5.11 indicates that the number of people more than quadrupled during the 1920 s and 1930's, despite the American financial depression. After 1959, when Fidel Castro came to power, a large number of Cuban refugees immigrated to MiamiDade County. Another group of Cuban refugees arrived during the Mariel boatlift in1980. Refugees immigrated to Miami-Dade County from other counties in Latin America and the Caribbean during the 1980 's ${ }^{29}$.

$\begin{array}{ll}\text { Table 5.10 } & \text { Miami-Dade County, FL } \\ & \text { Population Change: } 1840-2010\end{array}$

\begin{tabular}{lrr} 
Year & Population & Change \\
\hline 1840 & 446 & 0 \\
1850 & 159 & $-64.3 \%$ \\
1860 & 83 & $-47.8 \%$ \\
1870 & 85 & $2.4 \%$ \\
1880 & 257 & $202.4 \%$ \\
1890 & 861 & $235.0 \%$ \\
1900 & 4,955 & $475.5 \%$ \\
1910 & 11,933 & $140.8 \%$ \\
1920 & 42,753 & $258.3 \%$ \\
1930 & 142,955 & $234.4 \%$ \\
1940 & 267,739 & $87.3 \%$ \\
1950 & 495,084 & $84.9 \%$ \\
1960 & 935,047 & $88.9 \%$ \\
1970 & $1,267,792$ & $35.6 \%$ \\
1980 & $1,625,781$ & $28.2 \%$ \\
1990 & $1,937,094$ & $19.1 \%$ \\
2000 & $2,253,362$ & $16.3 \%$ \\
2010 & $2,496,435$ & $10.8 \%$
\end{tabular}

Source: U.S. Census Bureau.

\footnotetext{
${ }^{29}$ The League of Women Voters of Miami-Dade County, Florida, Inc., 2004.
} 
According to the 2000 census, Miami-Dade County is the third largest county in the State of Florida in terms of land area. The County covers 2,431.26 square miles, of which $1,946.06$ square miles $(80 \%)$ is land and 485.19 square miles $(20 \%)$ is water (U.S. Census Bureau). Most of the water area is found in Biscayne Bay, with water areas adjacent to the Atlantic Ocean.

Miami-Dade County property is divided into two major sectors: first, a highly urbanized area within the Urban Development Boundary consisting of about 500 square miles; and second, a rural, agricultural and mostly protected natural area outside the UBD, including Biscayne Bay National Park $(172,924$ acres), Everglades National Park (1,228,500 acres) and Everglades Water Conservation Areas.

Figure 5.5 Map of Miami-Dade County

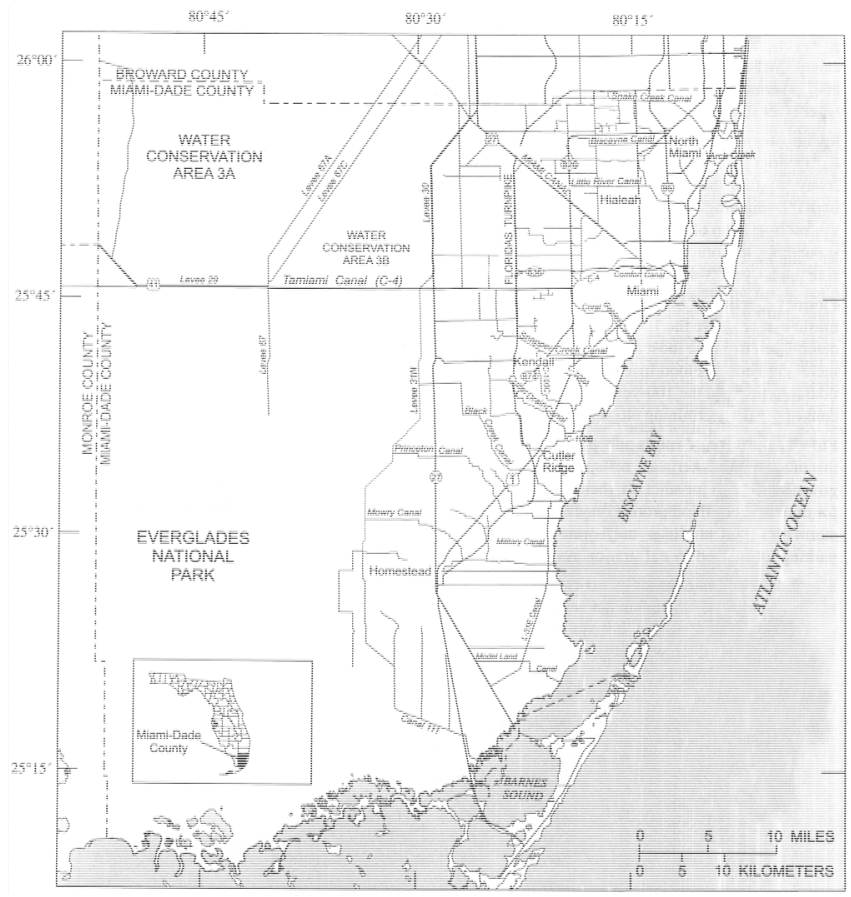

Source: David A. Chin, USGS Open-File Report 2004-1346 (Reston, VA: U. S. Geological Survey, 2004) Downloaded from Maps ETC, on the web at http://etc. usf.edu/maps [map \#99069] 
During the term of this research study, Miami-Dade County faced many of the same growth issues that challenge communities in the United States, the State of Florida, and particularly the three case counties. The Urban Development Boundary (UDB) encases the thirty five highly urbanized incorporated cities and large unincorporated areas, including the county seat in the City of Miami. Land areas outside the UDB is either owned by the federal government, protected as Everglades Wildlife Management/water conservation areas, used for agricultural cultivation (about 67,000 acres), and some private ownership (5-acre minimum) or undeveloped usage. (U.S. EPA, 2012).

Figure 5.6 Miami-Dade County Urban Development Boundary (2006)

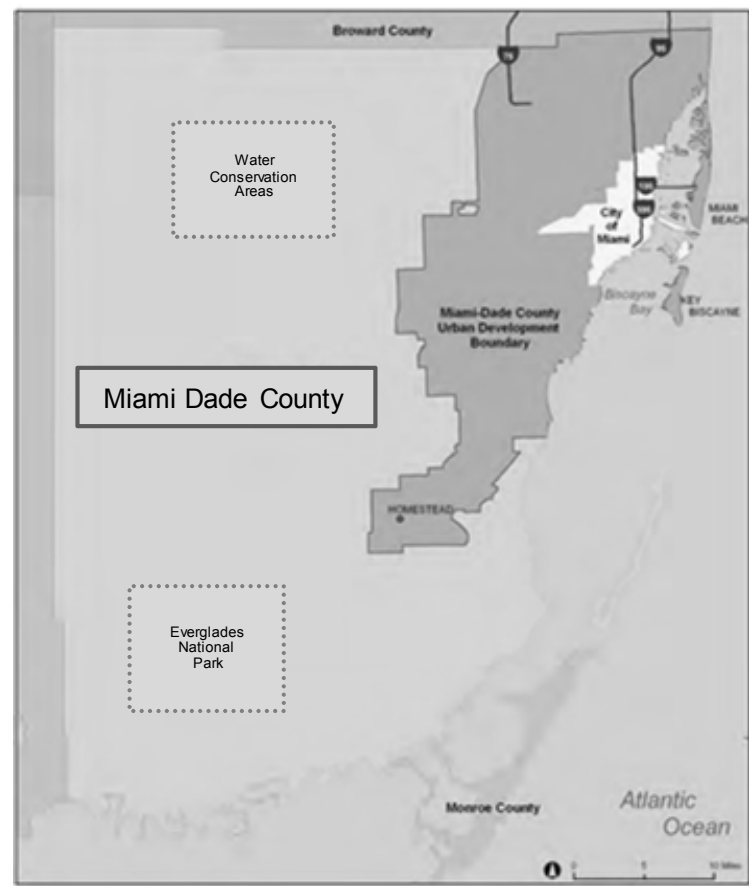

Source: American Forests, 2008. 


\subsubsection{Miami-Dade County Demographic, Socio-Economic, and Other}

Indicators.

2000 U.S. Census Bureau imparts most demographic, geographies, socioeconomic and housing information for Miami-Dade County because it is the approximate median year of county land preservation voter referendums utilized in this research. As of 2000 , there are $2,253,362$ people, 776,774 households, and 548,402 families residing within the County. The population density is 1,158 people. With 852,278 housing units, the housing density is 438 per square mile.

The racial makeup of the County is 69.7 percent White (20.7 percent NonHispanic White), 20.3 percent African American and Black (a large part of Caribbean origin), 0.20 percent Native American, 1.4 percent Asian, 0.01 percent Pacific Islander, 4.60 percent from other races, and 3.80 percent from two or more races. 57.3 Percent of the population is Hispanic or Latino of any race.

Miccosukee Tribe of Indians is a federally recognized Native American tribe located in the Florida Everglades. The Miccosukee Indian reservation is the homeland of its members, and is located in parts of Broward and Miami-Dade Counties. The Tamiami Trail (MDC) portion, 40 miles west of Miami, is the area with the largest tribal population and the site of most tribal operations. The Alligator Alley $(\mathrm{BC})$ area is the largest with an alley substation. Krome Avenue (MDC) is the smallest area, home to the Miccosukee Resort and Casino. The Tribe holds a perpetual lease with the State of Florida to use 189,000 acres in 
the South Florida Water Management District's Water Conservation Area 3A South for hunting, fishing, frogging and subsistence agriculture ${ }^{30}$.

In Miami-Dade County at 2000 , the age spread of the population is 24.8 percent under the age of $18,9.1$ percent from 18 to $24,31.0$ percent from 25 to 44, 21.7 percent from 45 to 64 , and 13.3 percent who were 65 years of age or older. The median age is 36 years. For every 100 females, there are 93.5 males. For every 100 females age 18 and over, there were 90.2 males (U.S. Census Bureau, 2000).

The median income for a household in Miami-Dade County in 2000 is $\$ 35,966$, and the median income for a family was $\$ 40,260$. Males have a median income of $\$ 30,120$ versus $\$ 24,686$ for females. The per capita income for the county is $\$ 18,497$. About 14.5 percent of families and 18.0 percent of the population was below the poverty line, including 22.9 percent of those under age 18 , and 18.9 percent of people 65 years or over.

With regard to ancestry in 2000 (excluding the various Hispanic and Latino ancestries), 5 percent are Haitian, 5 percent American, 2 percent Italian, 2 percent Jamaican, 2 percent German, 2 percent Irish, and 2\% English ancestry ${ }^{31}$.

$1,147,765$ of Miami-Dade residents, or 50.9 percent of the total population, are foreign-born, a percentage greater than that of any other county in the United States. 47 percent of the foreign-born population is naturalized U.S. citizens. Among the foreign-born population, the most common countries of origin are

\footnotetext{
${ }^{30}$ Miccosukee Tribe of Indians of Florida. Retrieved on January 15 at http://www.miccosukee.com/tribe

31 "Miami-Dade County, FL Detailed Profile". city-data.com. Retrieved 2008-06-23.
} 
Cuba (42 percent), Nicaragua (16 percent), Colombia (6 percent), Haiti (6 percent), the Dominican Republic (3 percent), and Jamaica (3 percent) ${ }^{32}$.

As of $2000,66.75$ percent of residents speak Spanish as their first language, 25.45 percent English, 5.20 percent Haitian Creole, 0.76\% French $^{33}$. Other languages that are spoken in 2000 include Portuguese at 0.41 percent, German at 0.18 percent, Italian at 0.16 percent, Arabic at 0.15 percent, Chinese at 0.11 percent, and Greek at 0.08 percent of the population. The City of Miami is one of the largest populations in the United States whose residents speak a first language other than English at home (74.55\%). Because residents who are English-speaking are moving away from the County, the percentage of residents who speak only English is expected to continue to decline.

There were 776,774 households in Miami-Dade County. 33.8 percent of these households have children under the age of 18 living with them, 47.7 percent are married couples living together, 17.2 percent have a female householder with no husband present, and 29.4 percent were non-families. 23.3 percent of all households consist of individuals, and 8.6 percent have someone living alone who is 65 years of age or older. The average household size is 2.84 and the average family size was 3.35 (U.S. Census Bureau, 2000).

Miami-Dade County population grew by $10.79 \%$ to $2,496,435$ from 2000 to 2010, and ranks highest in the State of Florida. However, the population growth rate is much lower than the state average rate of $17.64 \%$ and is higher than the national average rate of $9.71 \%$. Miami-Dade county median household income is

\footnotetext{
32 "Miami-Dade County, FL Detailed Profile". city-data.com. Retrieved 2008-06-23.

33 "Data Center Results - Miami, Florida". Modern Language Association. Retrieved 2010-01-05.
} 
$\$ 43,605$ in $2006-2010$ and has grown by $21.24 \%$ since 2000 . The income growth rate is higher than the state average rate of $14.40 \%$ and is higher than the national average rate of $19.17 \%$. Miami-Dade county median house value is $\$ 269,600$ in $2006-2010$ and has grown by $117.42 \%$ since 2000 . The house value growth rate is much higher than the state average rate of $55.64 \%$ and is much higher than the national average rate of $50.42 \%$. As a reference, the national Consumer Price Index $(\mathrm{CPI})$ inflation rate for the same period is $26.63 \%$.

\subsubsection{Miami-Dade County Two-Tiered Government}

Miami-Dade County operates a two-tiered government system comprised of 35 municipalities and a large unincorporated area. The upper tier is county government. Miami-Dade County's thirty-five cities comprise the lower tier. Each municipality elects its own mayor, maintains its own government and provides city services that are financed by city taxes and fees.

The Miami-Dade Board of County Commissioners (Board) currently consists of thirteen commissioners, each representing one of the 13 districts of unincorporated Miami Dade County. The Board is the governing body of unincorporated Miami-Dade County's, and has broad, regional powers to establish policies for services that transcend municipal geographic boundaries (exceptions are public schools, courts and South Florida water management). County government also provides city-type services for residents of the unincorporated areas, known as the Unincorporated Municipal Service Area (UMSA). 
The County's government structure consists of three parts: legislative, administrative and judicial branches. The executive Mayor (elected countywide to serve a four-year term) and thirteen commissioners comprise the legislative branch. An appointed County Manager once led the administrative branch of public servants; in January 2007, the County Mayor was granted powers to provide administrative oversight. Finally, the judicial branch of the circuit and county court system is organized by the County Clerk's office.

Thirteen members of the Board of County Commissioners hold the power and authority to develop county policy. Originally elected at-large, each County Commissioner is now elected from each of Miami-Dade County's 13 districts by district voters, and serve a four-year term.

The Executive Mayor is elected countywide and is not a member of the commission. The Mayor holds the power to veto actions of the Commission within ten days of their adoption. An Elected Mayor may serve no more than two consecutive four-year terms.

\subsubsection{Construct of Interest: Miami-Dade County Home Rule Charter}

In November 1956, an amendment to the Florida constitution, specifying a home rule charter for populous Dade County, was overwhelmingly approved in a state-wide referendum election. This Dade County home rule charter, drafted by a seventeen person charter board appointed by the governor, was approved by a slight majority of approximately twenty-six percent of Dade County's registered voters on May 21, 1957 (Sofen, 1961). 
The 1957 voter adoption and government implementation of a home rule charter in Dade County (as it was known then) has been characterized as "one of the world's most remarkable experiments in government" for areas experiencing population growth and governmental inefficiencies (Sofen, 1963; Adams, 1959). It was the first county home rule charter in the state of Florida. The scope of the powers individual county or local governments may exercise, and the limitations to which they are subject, varies widely because of their state constitutions and laws as well as the span of power the state delegated to the county.

Prior to 1968, Dillon's rule prevailed in Florida with limited and notable exceptions $^{34}$. By a majority of voters, the State of Florida adopted home rule in $1968^{35}$ for local and county governments (Wolf and Morrison, 1989). Home rule powers granted to Florida counties were originally cited as Article VIII, Section 1(f), of the Florida Constitution (1968), and by Section 125.01, Florida Statutes. Since 1968, state amendments modified home rule powers.

For counties that sought home rule rights, the 1968 Florida constitutional grant is generally is delegation of self-governance authority with residual power over local affairs, subject only to the state legislature's authority to preempt or

\footnotetext{
${ }^{34}$ Fla. Const. art. VIII, $§ 6(e)(1968)$ preserved certain prior home rule option provisions of the 1885 Constitution, concerning Jacksonville and Duval County, Key West and Monroe County, Dade County and Hillsborough County. Of these, Dade County is the only government with home rule power existing prior to the 1968 Constitution. The Dade County's Home Rule Charter was also constitutionally preserved, and the county still operates under the home rule provisions of the 1885 Constitution.

${ }^{35}$ Coffey, 1997.
} 
deny the power by enacting general laws or special laws approved by referendum ${ }^{36}$.

County governments in Florida have self-executing home rule authority (DeGrove and Turner, 1991). This broad authority may derive from Florida voters' desire to control their own tax and budget destinies (Frederick, 1991, 1992). However, home rule counties in Florida have weak autonomy and authority as a result of the state's legislature's continued use of special legislation (Rigos and Bertalan, 1996).

Serino (1958) and Sofen (1963) each focus on governmental consolidation. Wolf and Morrison (1989) take a legalistic analysis of Florida's home rule evolution. As editor of the journal, Huckshorn (1991) examines government and politics in Florida. The political dynamics of a growth management approach to government and politics in Florida (DeGrove, 1979).

The basic argument in favor of home rule is its design to give local voters, and the local officials they elect, more authority and control over the operation of their government. The primary criticism of home rule is citizen fear that locally elected officials will abuse those powers, in particular the power to levy taxes (Wood, 2011). Additional proponent and opponent arguments are listed below.

Arguments in favor of county/local government home rule powers ${ }^{37}$ :

- Equipped to assess local needs to develop local solutions.

- Familiarity with local problems and local residents' preferences.

- Elected to promote and protect the interests of local residents.

\footnotetext{
${ }^{36}$ Lieberman and Morrison, 1994.

${ }^{37}$ Wood, 2011.
} 
- Capable of experimenting with alternative solutions to local problems.

- Promote civic education by encouraging citizens to study issues.

- Allocate scare resources to the highest priority needs of each community.

- Local elected officials can be more easily held accountable by local voters for the way in which they manage local affairs.

Arguments made against county/local government home rule powers ${ }^{38}$ :

- Act in an arbitrary and capricious manner by favoring political friends when making policy and budgetary decisions.

- Make it more difficult for state government to address regional problems.

- Be deprived of the economies of scale made possible by centralized control and by the superior expertise and technical resources available to state government.

- Home rule will lead to a lack of uniformity with regard to services, structures, and actions taken by local governments, causing inequities between and within communities.

- Home rule will result in some local governments with fewer resources being unable to solve their own problems because of such income inequities.

Table 5.11 lists Florida counties with home rule charters.

Table 5.11 Home Rule Charter Counties in Florida

\begin{tabular}{|c|c|c|c|}
\hline \multicolumn{2}{|l|}{ By County } & \multicolumn{2}{|c|}{ By Year Effective } \\
\hline Alachua & 1987 & Dade* & 1957 \\
\hline Brevard & 1994 & Duval & 1967 \\
\hline Broward & 1975 & Sarasota & 1971 \\
\hline Charlotte & 1986 & Volusia & 1971 \\
\hline Clay & 1991 & Broward & 1975 \\
\hline Columbia & 2002 & Pinellas & 1980 \\
\hline Dade* $^{*}$ & 1957 & Hillsborough & 1983 \\
\hline Duval & 1967 & Palm Beach & 1985 \\
\hline Hillsborough & 1983 & Charlotte & 1986 \\
\hline Lee & 1996 & Orange & 1986 \\
\hline Leon & 2002 & Alachua & 1987 \\
\hline Orange & 1986 & Seminole & 1989 \\
\hline Osceola & 1992 & Clay & 1991 \\
\hline Palm Beach & 1985 & Osceola & 1992 \\
\hline Pinellas & 1980 & Brevard & 1994 \\
\hline Polk & 1998 & Lee & 1996 \\
\hline Sarasota & 1971 & Polk & 1998 \\
\hline Seminole & 1989 & Leon & 2002 \\
\hline Volusia & 1971 & Columbia & 2002 \\
\hline Wakulla & 2008 & Wakulla & 2008 \\
\hline
\end{tabular}

${ }^{38}$ Wood, 2011. 
Dade County Home Rule Charter (1957). Due to the extraordinary growth in population and subsequent urban sprawl during the pre- and post-World War II years of 1930's through 1950's, Dade County (as it was known then) faced the problem of providing efficient and effective public services. In the early 1950's, the City of Miami unsuccessfully tried to expand its boundaries to encompass the entire county through a city-county consolidation effort (League of Women Voters of Miami-Dade County, Inc., 2004). Additional restructuring proposals ensued, also failed. On November 6, 1956, the Florida state legislature proposed a home rule constitutional amendment, specifying governmental prerequisites for Dade County (Sofen, 1961). If implemented, this legislation would make Dade County the first and unique home rule charter sub-division of the State of Florida. Prior to the development of this proposal, all Florida county and local governments were "resident agents" of the state. These jurisdictions had only those powers expressly granted by the Florida constitution and state laws ${ }^{39}$. However, local laws could be enacted by a special act of the state legislature.

Not until 1968 was a resolution proposed by a Senate Joint Resolution to revise the Constitution of the State of Florida to authorize local home rule powers for its municipalities and charter counties. The State electorate ratified this legislative resolution on November 5, $1968{ }^{40}$.

The 1956 legislative proposal to create a strong Dade County home rule charter was drafted by a seventeen-person Governor-appointed Charter Board.

\footnotetext{
${ }^{39}$ See 2012 Florida Statutes, Titles XI (County Organization and Intergovernmental Relations at http://www.leg.state.fl.us/statutes/.

${ }^{40}$ See Florida Consitition, Article VIII (Local Government) at http://www.leg.state.fl.us/Statutes/ index.cfm? Mode=Constitution\&Submenu=3\&Tab=statutes\#A8S01
} 
Dan Paul, a former attorney for the charter board, said "We wrote the strongest charter we could write" (Adams, 1959). On November 6, 1956, the proposed state constitutional amendment was resoundingly approved by the electorate in a statewide referendum ballot. Subsequently, only $26 \%$ of Dade County registered voters narrowly $\left(51 \%^{41}\right)$ approved its new home rule charter on May 21, 1957 (Sofen, 1961). Dade County's metropolitan experiment, the first in the United States, went into effect two months later.

Dade County's Home Rule Charter provides a unique metropolitan system of government. Unlike a consolidated city-county, where city and county governments merge into a single entity, the assembly of Metro Dade County jurisdictions became a two-tiered federation of a county government and its twenty-five "suburbs" (Adams, 1959). The first tier relates to Metro Dade County which oversees unincorporated areas and countywide regional services; the second tier correlates with the County's municipalities, each with their own governments and municipal services.

The first of a series of obstacles developed between municipalities and county government soon after enactment of the Metro Dade home rule charter, associated with a handful of controversial ordinances which the cities alleged infringed on their municipal rights (Sofen, 1961). The cities' mayors proposed an amendment, and collected the required number of resident signatures, in order to hold a special countywide election. This amendment would have preserved for the cities all of their pre-Metro Dade County powers, and possibly undermined

\footnotetext{
${ }^{41}$ Retrieved on 11/16/2012 through Miami-Dade County Home Rule Charter Historical Archives at http://www.miamidade.gov/charter/historical-archives.asp
} 
the effectiveness of County government (Adams, 1959). Three days before the election, a court order deferred the election and deferred the amendment's constitutionality to the State Supreme Court. To some the charter meant complete consolidation; to others the charter indicated a few changes to the status quo. The charter, as clarified by the courts, gives Metro Dade control over water supply, sewer, transportation and traffic, central planning and those municipal powers considered regional in nature (Sofen, 1961). Eventually, the special election for the "autonomy amendment" was held in September 1958, and rejected by resident voters by a significant margin ${ }^{42}$.

The new Metro Dade Charter provided for the new council-manager form of government, replacing a commission form. This met with particular opposition from some senior department heads and sitting commissioners who would continue in office until January 1961. Also, six new commissioners were elected on September 30, 1958, increasing the size of the Board of County Commissioners from five to eleven, and compounding the internal discord. Finally, friction developed between Metro Dade's first County Manager and the Board of Commissioners resulting in attempts to remove him from office (Sofen, 1961; Adams, 1959).

In 1986, a group of prominent Dade County citizens organized a commission to propose three charter reform proposals for Metro Dade County government (Brierly and Moon, 1991). These reforms sought to institute district elections for county commissioners, a strong mayor form of government, and

\footnotetext{
${ }^{42}$ Miami-Dade County website at http://www.miamidade.gov/charter/home.asp.
} 
parochial elections. From a 1987 public opinion poll, this coalition learned that citizens favored district elections and a strong mayor. The reform proposals did not reach the ballot box, and the status quo was chosen by default. This outcome differed from the dominant coalition (with Anglos, Jewish, and some African Americans) of 1957 which was able to impose its policy preferences of the progressive structure of Metro Dade County home rule charter.

However, by the 1980's the initial coalition in the electorate cycled out, because its interests were no longer served, and ceased to be meaningful. Brierly and Moon's (1991) study of the electoral coalition model finds that stability is the result of both coalitions and rules (i.e., characteristics of charter revision). When a majority coalition forms and does not cycle, it can enforce its preferences. Without a coalition, the rules maintain stability by upholding the status quo. The end result is a reduction in the possibility of instability, while limiting the ability of resident voters to alter their government.

Dade County Home Rule Charter Amendments. Between the 1957 voter approval of the Dade County Home Rule Charter and the end of calendar year 2012, more than 100 charter amendment proposals turned up at both special and regular countywide elections. Several trends are noticeable: first, in the earlier years, charter amendment proposals appeared at the ballot box as special elections with lower voter turnout than regular election dates ${ }^{43}$; second, multiple amendment proposals appeared on the same ballot ${ }^{44}$ (with the highest for

\footnotetext{
${ }^{43}$ Sources: Miami-Dade County Home Rule Charter website and Elections Office website.

${ }^{44}$ Miami-Dade County website at http://www.miamidade.gov/charter/home.asp.
} 
November 2002 at eleven and November 2012 at ten); and third, some proposals that voters failed to approve were reintroduced again at a later election (i.e., salary revisions proposal - introduced fourteen times ${ }^{45}$ ).

Leadership Responsibilities. Some informed observers believe that a fundamental cause of Metro Dade County charter difficulties arise from a lack of consistent community and county government leadership (Sofen, 1961; Brierly and Moon, 1991). The evolution of charter amendments speaks to the government leadership revisions that were proposed and implemented. First is the fluctuating empowering and authority-diminishment for the county manager and commission-appointed mayor positions. Then, in 2007 voters adopted of a strong elected mayor form of government. Finally, in 2012 the Board-appointed county manager position was eliminated subsequent to preceding charter amendments delegating its authority.

Intergovernmental Relations. One of the administrative functions of the Miami-Dade County Office of Intergovernmental Affairs ${ }^{46}$ is the coordination of the County's intergovernmental relations at the federal, state and local levels. Also, it represents Miami-Dade County's residents and interests along with the 25 elected officials that make up the Miami-Dade County Legislative Delegation work as advocates for varied constituent interests, developing an ever expanding legislative agenda, as well as addressing the concerns of their own particular districts. Locally, Miami-Dade County's interface with municipalities is incorporated in several parks, aquatic preserves and preservation lands charter

\footnotetext{
${ }^{45}$ Miami-Dade County Office of Commission Auditor Report, July 17, 2012,

${ }^{46} \mathrm{http}: / /$ www.miamidade.gov/commission/intergovernmental/home.asp
} 
amendments. In November 2012, voters passed two relevant charter amendments: the first is entitled changes in municipal boundaries and creation of new municipalities; the second requires a two-third Board of County Commissioner approval to include additional land within the Urban Development Boundary. Finally, in March 1984, the name of Dade County was changed to Miami-Dade County by charter amendment.

Despite periodic disputes concerning whether governance powers are countywide or municipal, the answer will continue to be a mixed matter of law and reality that may finally be determined by the judicial system.

In July 2002, the Miami-Dade County Board of County Commission passed Resolution R-898-02 to allocate $\$ 1.8$ million to "The Committee to Save Local Control" for the purpose of retaining Ikon Public Affairs to undertake a statewide campaign to defeat a proposed amendment to the Florida Constitution which would allow the Florida Legislature to propose unspecified amendments to the Miami-Dade County Home Rule Charter. Once adopted by the State legislature, the final step to adoption of its charter amendment would be ratification by registered voter of Miami-Dade County and successfully circumventing its government. Media coverage was extensive, with southeast Florida news encouraging a "no" vote on state amendment 3 . The rejection rate by registered voters was 52.15 percent.

Community and Citizen Rights. Registered voters of Miami-Dade County have the power to propose to the Board of County Commissioners the passage or repeal of ordinances and to vote on the question if the Board refuses action 
according to the initiative and recall procedures incorporated into the County's home rule charter ${ }^{47}$. Several adopted charter amendments modified initiative and recall qualifications and procedures. In September 1976, an introductory Citizens Bill of Rights was adopted; in 1996 the Bill of Rights was amended to create an independent commission on Ethics and Public Trust, including a five-member board and authority to enforce County and municipal Code of Ethics ordinance; and on September 10, 2002, the Commission Auditor position was created by charter amendment. Finally, on October 5, 1978, voters approved a charter amendment requiring that ballot language be impartial, using concise language that provided clear understanding.

Board of County Commissioners (Board). The Board is the legislative and governing body of the county. It has the power to carry on a central metropolitan government with responsibilities enumerated in the Charter ${ }^{48}$. Multiple amendments proposed a variety of structures, elected at large or by district, different consecutive term limits, succession plans, and salary increases; most failed at the ballot box. In November 1963, the Board's structure was amended to nine members with eight commissioners and a mayor. Also adopted was a special election procedure to choose commissioners to succeed appointed members under certain conditions. In September 2002, voters approved an amendment that empowered the county commissioners in several ways. In that same election, and in accordance with federal court orders, the size of the Board changed to thirteen members elected from single-member districts. Finally, the

\footnotetext{
${ }^{47}$ Miami-Dade County Home Rule Amendment and Charter, Article 8.01 and 8.02.

${ }^{48} \mathrm{http} / / / \mathrm{www} . \mathrm{miamidade.gov/charterreview/library/charter.pdf}$
} 
Board's authority to communicate with government staff was first restricted to the county mayor, then expanded to departments in regard to citizen issues ${ }^{49}$.

A Charter Review Task Force convened twice (2008 and 2012) to review the Home Rule Charter of Miami Dade County, conduct public hearings and meetings, and provide written recommendations to the Board of Commissioners.

Administrative Organization and Procedure. Miami-Dade County government's administrative component consists of departments, procedures, financial management, property assessment and tax collection, personnel, law, planning and boards. Early charter amendments that voters passed appointed department heads by county manager (1962), provided for election canvas by County Canvassing Board, created consolidated Miami-Dade Water and Sewer Authority, required county budget process, joint appointment of County Finance Director by County Manager and Clerk of Courts, and services and departments were consolidated or realigned.

Miami-Dade County Home Rule Charter Challenges. The challenges facing urban counties like Miami-Dade County demand new approaches to government, including modernization of old and ineffective forms of public administration. And because many of the new problems, from urban sprawl to environmental preservation, transcend county or municipal government boundaries, these new approaches generally seek cooperation among jurisdictions at the local, state and national level.

\footnotetext{
${ }^{49} \mathrm{http} / / /$ www.miamidade.gov/charterreview/library/charter.pdf
} 
During the last few decades counties nationwide have assumed responsibility for regional public services once provided by sub-counties. For example, a survey conducted by the National Association of Counties ${ }^{50}$ found that of respondents, twenty-five percent assumed responsibilities for jails and correction, thirty-five percent for library management, forty-five percent for planning previous conducted at the local level, and twenty percent for roads, highways, sewage, refuse collection and public welfare.

Counties should command more respect, authority, political power and cooperation from other levels of government. Accompanying the rise in the charter movement over the past few decades, came a drive to modernize the forms of county government to improve administration and impact. Finally, the current challenges of county governments is twofold: first, expand county government's capacity to address local challenges; second, insure a "seat at the table" when city, county, state and federal authorities collaborate ${ }^{51}$.

Based upon information and data obtained as a result of the case study, Miami-Dade County and its Home Rule Charter will be challenged by continuing community unpredictability, uncertainty of intergovernmental relationships, and intra-governmental fluctuations.

Preservation and Restoration of the Everglades in South Florida. MiamiDade County covers 2,431.26 square miles, of which $1,946.06$ square miles $(80 \%)$ is land and 485.19 square miles $(20 \%)$ is water (U.S. Census Bureau). Most of the water area is found in Biscayne Bay, with another significant portion

\footnotetext{
${ }^{50}$ http://www.naco.org/Counties/Pages/HistoryofCountyGovernmentPartll.aspx

${ }^{51}$ http://www.naco.org/Counties/Pages/HistoryofCountyGovernmentPartll.aspx
} 
of water areas adjacent to the Atlantic Ocean. Table 5.12 presents existing (2009) land uses within the County.

$\begin{array}{cc}\text { Table 5.12 } & \begin{array}{l}\text { Existing Land Uses } \\ \text { Miami-Dade County }\end{array}\end{array}$

\begin{tabular}{lrrr} 
Land Use & $\begin{array}{c}\text { Area } \\
\text { (acres) }\end{array}$ & $\begin{array}{c}\text { Area } \\
\text { (square miles) }\end{array}$ & $\begin{array}{r}\text { Percent } \\
\text { Land Cover }\end{array}$ \\
\hline Agricultural & 61474.1 & 96.1 & $4.8 \%$ \\
Commercial & 13975.9 & 21.8 & $1.1 \%$ \\
Transient (hotel-motel) & 724.7 & 1.1 & $0.1 \%$ \\
Industrial & 17515.4 & 27.4 & $1.4 \%$ \\
Inland Water & 40963.9 & 64.0 & $3.2 \%$ \\
Institutional (public-private) & 14287.4 & 22.3 & $1.1 \%$ \\
Parks-Conservation-Recreation & 790647.7 & 1235.4 & $62.2 \%$ \\
Residential & 109442.4 & 171.0 & $8.6 \%$ \\
Transportation-Utilities & 87598.6 & 136.9 & $6.9 \%$ \\
Undeveloped (vacant land) & 134608.0 & 210.3 & $10.6 \%$ \\
\hline Total & 1271238.0 & 1986.3 & $100.0 \%$ \\
\hline
\end{tabular}

Source: Miami-Dade County Department of Planning and Zoning, Planning Research

Section, July 2009 at http://www.miamidade.gov/greenprint/planning/library/

milestone_one/land_use.pdf

Population growth and urban sprawl have led to the depletion and deprivation of important environmental resources, including the loss of agricultural lands (Freilich et al., 2003; Freilich and Davis, 1981). Government agencies have played a significant role in the purchase of agricultural land for conservation purposes in Miami-Dade County. Between 1975 and 1998, more than 10,300 acres of farmland were purchased by governmental agencies, in particular by the South Florida Water Management District (SFWMD). In 2000, it is estimated that the South Florida Water Management District leased approximately 5,000 acres to private individuals (Denger, et al, 2003).

Acknowledging the need to establish a comprehensive environmental program for Miami-Dade County, the Board of County Commissioners created 
the Department of Environmental Resources Management (DERM) in 1974 to regulate and manage activities affecting the county's natural areas environment.

Established in 1947, Everglades National Park consists of $1.5+$ billon acres located at the southern tip of the Florida Everglades. It is a hundred-milelong subtropical wilderness of saw-grass prairie, jungle-like hammock, and mangrove swamp that originally ran from Lake Okeechobee to Florida Bay. Water, essential to the survival of this ecosystem, once flowed south from the Lake unhindered. But as the urbanization of South Florida increased, canals, levees, and dikes have increasingly diverted the water to land developments and agri-businesses. Vast irrigated farmlands have spread to the park's borders. The waning of the ibis carries a warning: watery habitats in the park are shrinking because not enough water is getting to Everglades ${ }^{52}$.

Water pollution continues to threaten Everglades National Park. The greatest concern for environmental protection groups in South Florida, such as Friends of the Everglades, is the introduction of high levels of phosphorus in the waters of the Everglades National Park ${ }^{53}$. Excess phosphorus and sulfur is released into the Everglades from runoffs of farms to the north of the park. This has become a concern because too much phosphorus creates chemical and biological changes that deteriorate the natural system and harm the native flora and fauna within the Park. Environmentalists attempted to regulate phosphorus with the phosphorus rule. This rule was proposed by the Florida Department of

\footnotetext{
${ }^{52}$ http://travel.nationalgeographic.com/travel/national-parks/everglades-national-park/

${ }^{53}$ http://ournationalparks.us/index.php/site/story_issues/water_pollution_continues_to_threaten
} 
Environmental Protection and would identify provisions of Florida's Water Quality Standards. However, the Federal Environmental Protection Agency (EPA) disapproved provisions of this rule as not new or revised water quality standards.

A small part of the Big Cypress National Preserve occupies northwestern Miami-Dade County. The fresh waters of the Big Cypress Swamp, essential to the health of the adjacent Everglades, also support the rich marine estuaries along the southwest coast of Florida. Protecting over 729,000 acres of swampland, Big Cypress National Preserve contains a mixture of tropical and temperate plant communities and wildlife, including the Florida panther.

Biscayne National Park was established in 1968 and consists of about 172 thousand acres. The park is located along the southeastern margin of the Florida peninsula near the City of Miami. It encompasses about two-thirds of Biscayne Bay, making it one of the largest marine parks in the National Park System. Biscayne National Park protects part of the third-largest coral reef system in the world. With the longest stretch of mangrove forest remaining along Florida's east coast, the underwater Park providing habitat and nursery grounds for most of the region's important commercial and recreational fish, shellfish, and crustaceans, as well as a number of threatened or endangered wildlife species including the West Indian manatee, American crocodile, and Schaus swallowtail butterfly ${ }^{54}$.

The primary threat to Biscayne National Park is irresponsible recreational boating. Because of the Park's proximity to the urban population of Miami-Dade County, recreational boats run aground on coral reefs or in sea grass beds which

\footnotetext{
${ }^{54}$ http://www.npca.org/parks/biscayne-national-park.html
} 
severely damage these ecosystems. Protected manatees and sea turtles, which are often near the surface, are also at risk of being hit by boats.

The South Miami-Dade County watershed, an approximately 370 square mile area located in the southeastern portion of Miami-Dade County, is increasingly recognized as one of the most critical watersheds in Florida. The watershed plays a vital role in the health of Biscayne Bay as well as providing for the urban and agriculture needs of the County ${ }^{55}$.

The County's Environmentally Endangered Land (EEL) program maintains endangered natural areas within the urban and agricultural matrix of eastern Miami-Dade County. Many species of non-native flora (i.e., Brazilian pepper, melaleuca, and Australian pine) and fauna (i.e., animal abandonment from the exotic pet trade like invasive pythons, and non-native animal species from other sources) invade these endangered lands, as well as Everglades National Park and other protected areas. The constant removal of invasive species is timeconsuming and the use of herbicide chemicals costly.

Waste products damage protected natural areas. Florida's 18 million residents and 80 million visitors generated over 32 short tons (29t) million of solid waste in 2010. In addition, uncollected trash dispersed by visitors to protected areas is a major source of damaging pollution.

\footnotetext{
${ }^{55}$ http://southmiamidadewatershed.net/WorkProducts/SMDWM-Webfiles/SUBTASK\%201.7\%20Land\%20Inventory.pdf
} 
As mandated by Florida statutes and adopted in $1989^{56}$, the Miami-Dade County Comprehensive Development Master Plan (CDMP) endorses land conservation as essential to improving the quality of life for its residents. This requires the protection of well fields and recharge areas, working farms, and environmental lands essential to the health of the Everglades and Biscayne National Parks, South Miami-Dade County watershed, water conservation area Number 3, and Big Cypress Swamp.

Urban Sprawl and the Urban Development Boundary (UDB). The UDB was created in 1975 by the MDC Comprehensive Development Master Plan as a central element of the county's growth management system. This action sought to prevent growth and development too close to endangered areas, as Broward County government has permitted growth to the edge of the Everglades. The UDB is an invisible line along the western and southern regions of Miami-Dade County that separates low-density and urban zoning. It separates urban development from rural and open lands, by creating a buffer strip. It is also used as a guide to zoning and land use decisions. Miami-Dade is the only county in Florida to have established an UDB.

Figure 5.7 displays two maps of Miami-Dade County's UDB. One shows the entire county, featuring the western and southern environmental preservation and protection areas and the outline of the UDB to the east and north. The other map provides a concentrated view of the urbanized land area encased within the UDB, as well as anticipated changes to the UDB by 2015 and 2025.

\footnotetext{
${ }^{56}$ See Ch. 163, Part II, Fla. Stat., and Rule 9J-5, Fla. Admin. Code. See also Statement of Legislative Intent, CDMP, codified by Section 2-114 (c), Miami-Dade County Code.
} 
Figure 5.7 Miami-Dade County Urban

Development Boundary (2006)

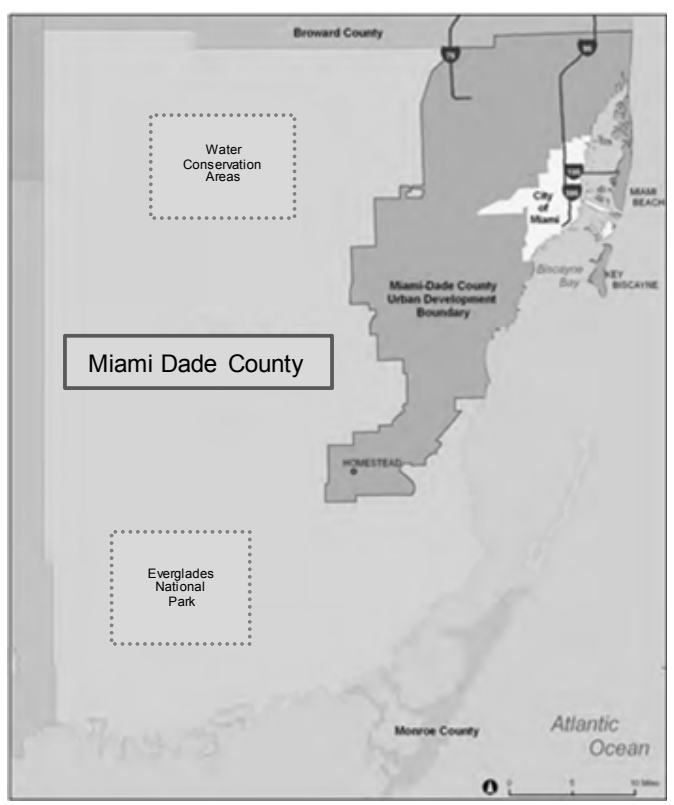

Source: American Forests, 2008
2015 Urban Development Boundary 2025 Urban Expansion Areas

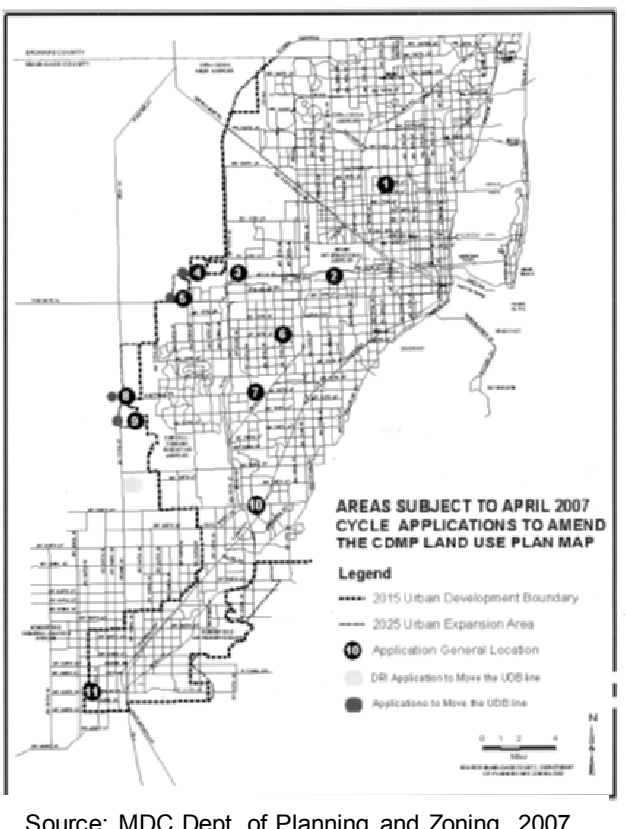

The Urban Development Boundary (UDB) is the mechanism used by the Miami-Dade County government to separate the urban and sub-urban parts of the County from the rural and natural resource protection areas. The main objectives of the UDB are preservation of open space and agricultural land; encouragement of urban revitalization, infill, and compact development; clearly defining and separating urban and rural uses; ensuring the orderly transition of land from rural to urban uses; and the promotion of a sense of unified community (Staley, Edgens and Mildner, 1999).

The UDB is required to contain a 15-year residential land supply (10 years of supply plus 5 additional years' supply in reserve). Miami-Dade County may 
also designate "Urban Expansion Areas" (UEA) outside the boundary which are areas considered appropriate places for future growth to occur (U.S. EPA Office of Sustainable Communities, 2012).

When first created in 1975, the UDB contained about 233,000 acres (364 square miles). Since then the UDB has increased to 269,000 acres (420 square miles) or approximately 15 percent. In comparison, nearly one million acres in Miami-Dade County sit outside the UDB, most of it permanently preserved. According to the U.S. EPA study (2008) that transpired between 2004-2006, about six percent of the land within the UDB is undeveloped.

Changes to the Miami-Dade County UDB have occurred periodically during the ensuing years. Any proposed changes occur through the plan amendment process which requires the review and approval of the County Commission, as well as review and comment from the Florida Department of Community Affairs (U.S. EPA Office of Sustainable Communities, 2012).

The County Commission considers UDB amendments once every two years. By County ordinance, an affirmative vote of two-thirds of the full County Commission (9 of 13 members) is required to modify the UDB. Miami-Dade County government's planning staff developed many proposals for UDB expansion; however, the majority of proposals had been submitted from private individuals or groups.

On November 6, 2012, resident voters approved a Miami-Dade County home rule charter amendment requiring an extraordinary voter (two-thirds of the 
Board of County Commissioners) to include additional land within the UDB established by the County's Comprehensive Development Master Plan.

Unincorporated Areas. The land areas of Miami-Dade County that do not fall within municipal boundaries comprise the unincorporated area of MiamiDade, also referred to as the Unincorporated Municipal Service area (UMSA). The population of the UMSA is estimated to exceed one million persons ${ }^{57}$.

On September 7, 2007, the Board of County Commissioners adopted an ordinance suspending the process and consideration of any proposed incorporations until the County Manager submitted a report ${ }^{58}$. That report was to include information relevant to whether municipalities near unincorporated areas were interested in annexing those areas as the preferred way to change boundaries. Incorporation is the process whereby a new city, town, or village is created upon the majority vote by the electorate contained within the area to be considered pursuant to requirements contained in the Miami-Dade County Code $^{59}$. Annexation is the process whereby an established municipality amends its boundaries by adding lands that were previously outside of its boundaries pursuant to requirements contained in the Miami-Dade County Code ${ }^{60}$. However, allowing citizens to exercise self-determination regarding the boundaries of their city while ensuring an equitable delivery of countywide

\footnotetext{
${ }^{57} \mathrm{http}: / /$ www.miamidade.gov/info/about_miami-dade.asp.

${ }^{58}$ Miami-Dade County Board of County Commissioners' Auditor's report dated April 3, 2012.

${ }^{59} \mathrm{http}: / /$ www.miamidade.gov/managementandbudget/incorporation-annexation.asp.

${ }^{60} \mathrm{http} / / / \mathrm{www} . \mathrm{miamidade.gov/managementandbudget/incorporation-annexation.asp.}$
} 
services to Miami-Dade residents residing in both municipal and UMSA is a challenge for Miami-Dade County government ${ }^{61}$. The Commission Auditor's Legislative Analysis Report dated April 3, 2012 outlined previous legislative action impacting incorporation and annexation issues, policy or code.

The July 17, 2012, final report of the current Miami-Dade County Charter Review Task Force includes a recommendation that the Charter be amended to provide that changes in municipal boundaries require a two-third vote of the Board of County Commissioners; that the Board no longer have the sole authority to create new municipalities; and that incorporation by the initiatory petition (modeled after the initiatory petition for ordinances and charter amendments) be added to the County Charter ${ }^{62}$

On November 6, 2012, resident voters approved a Charter amendment pertaining to changes in municipal boundaries and creation of new municipalities. The Board of County Commissioners is required to consider the benefits of any proposed annexation of commercial areas when approving an annexation, and to establish an alternative procedure for the creation of new municipalities in unincorporated areas by petition with a single election process instead of two.

The impetus to create new municipalities from enclaves within the unincorporated areas of Miami-Dade County is now defined. Supporters of incorporation argue that the County inefficiently provides municipal services to unincorporated areas. However, new municipalities require the appropriate financial and administrative support for new mayors and/or city managers, city

\footnotetext{
${ }^{61}$ Miami-Dade County Board of County Commissioners' Auditor's report dated April 3, 2012.

$62 \mathrm{http}: / /$ www.miamidade.gov/charter/home.asp
} 
commissioners, city departments, and a large number of public employees. Fortunately, affected residents in unincorporated areas are required to approve any incorporation legislation before the concept is ratified.

Several alternatives to incorporation are options to reduce the size of and County responsibility for unincorporated areas. Annexation is another method of resolving the problem if large local governments appropriate unincorporated areas which permit the larger city to well serve their new residents while providing value-added benefits to them. However, annexation requires County monitoring to prevent municipal poaching of thriving commercial or high property tax revenues areas in unincorporated areas, while stranding less lucrative property and unincorporated area residents. A third alternative is a consolidated city-county merger into one unified jurisdiction. A consolidation in Miami-Dade would necessitate the abolishment of almost all municipalities and the creation of one regional super-government.

Whatever the incentive, it appears that momentum is building to reduce Miami-Dade County's role as a municipal service provider for its unincorporated areas, and narrow responsibilities to that of a regional provider of transportation, water and sewer, public safety and firefighting, and economic development.

\subsubsection{Case Study 3: Palm Beach County, Florida}

\subsubsection{Palm Beach County Land Preservation Voter Referendum}

In April 1984, members of 14 environmental groups in Palm Beach County convened to discuss the preservation of a significant portion of the Yamato Scrub 
which had been proposed for development. They concluded that the native ecosystems in the county were disappearing at an alarming rate and formed the Coalition for Wilderness Islands (CWI) to work on this issue. In May 1984, the Royal Palm Audubon Society, representing CWI, proposed a program to the Board of County Commissioners for the establishment of "wilderness islands" representing the variety of plant and animal communities native to the county. In 1987, the Board contracted with Florida Atlantic University (FAU) to conduct a study, known as the "Inventory of Native Ecosystems in Palm Beach County," to identify the remaining undeveloped lands in Palm Beach County that contained high-quality native ecosystems.

Based upon the outcome of this two-year study, the Board approved the formation of ERM and set up a citizens' advisory group, the Environmentally Sensitive Lands Acquisition Advisory Committee to advise the Board on which lands to acquire. This advisory committee identified thirty-eight sites as suitable for acquisition and recommended that 14 of these be designated as high priority. In March 1991, after an effective citizen-supported educational campaign, Palm Beach County voters approved a $\$ 100$ million bond referendum to buy these lands and others on the acquisition list.

Following passage of the 1991 land preservation voter referendum, the County applied to the State's recently-developed \$3 billion Preservation 2000 Program and obtained state matching funds through the Conservation and Recreation Lands, Florida Communities Trust, and Save Our Rivers programs. Non-profit environmental organizations contributed assistance. Through the 
efforts of The Nature Conservancy, with some support from The Conservation Fund, the County's contractors for negotiations with landowners, the County saved money by acquiring land at less than appraised value.

Palm Beach County voters approved another bond referendum in March 1999 , this time for $\$ 150$ million. Of that amount, $\$ 50$ million was for the acquisition of conservation lands, water resource lands, and lands for open space, and $\$ 100$ million was for acquisition of agricultural lands to preserve farming in the Agricultural Reserve.

On November 5, 2002, a bond referendum was passed by the voters of Palm Beach County in the amount of $\$ 50$ million for issuance of general obligation bonds for the purpose of financing the acquisition, construction of and/or improvements to certain recreation and cultural facilities. The proposed list of projects earmarked $\$ 4$ million for construction of a new South Florida Science Museum.

On November 2, 2004, another land preservation voter referendum was passed by the voters of Palm Beach County in the amount of $\$ 50$ million for the issuance of general obligation bonds for the purpose of financing the acquisition, construction, and/or improvements to waterfront access in Palm Beach County.

\subsubsection{Palm Beach County, Florida}

Palm Beach County, the largest county in Florida, covers an area of 2,034 square miles between the Atlantic Ocean on the east and Lake Okeechobee on the northwest. As of the 2010 U.S. Census, it had a population of 1,320,134, ranking third in the state. The county consists of 38 incorporated municipalities, 
containing $57 \%$ of its population as well as 29 unincorporated communities. See Figure 5.7 for geographic distribution of incorporated and unincorporated areas. Despite being the wealthiest county in Florida, it is highly diverse. Atlantic seashore high income resort communities such as Palm Beach and Boca Raton are part of Florida's "Gold Coast". In contrast, the western portions of the county are quite rural with active farming, sugar cane, and equestrian industries. The county also contains the most northern parts of the Everglades ecosystem.

Palm Beach County was founded in 1909, when due to population growth it was carved out of Dade County. Its first non-native American settlement grew up around a U.S. Army fort in 1838. Two railroads, the Jupiter and Lake Worth were built in 1888 and by the early 20th century Henry Flagler completed the Florida East Coast Railroad, connecting Jacksonville to Key West. With its beautiful beaches and climate, Palm Beach County rapidly became a tourist destination and by the mid-twentieth century, an attractive location for regional, national and global corporation.

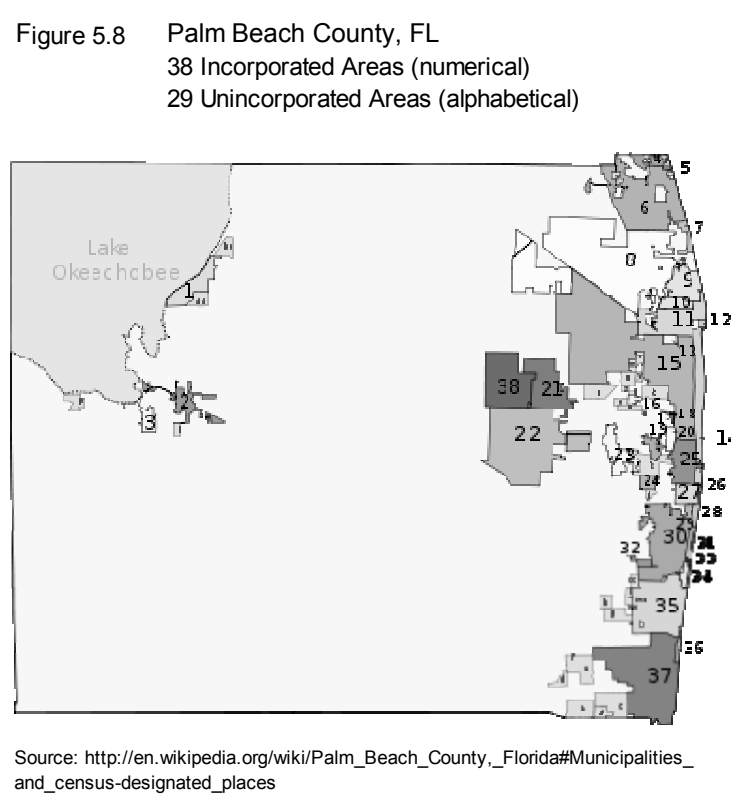




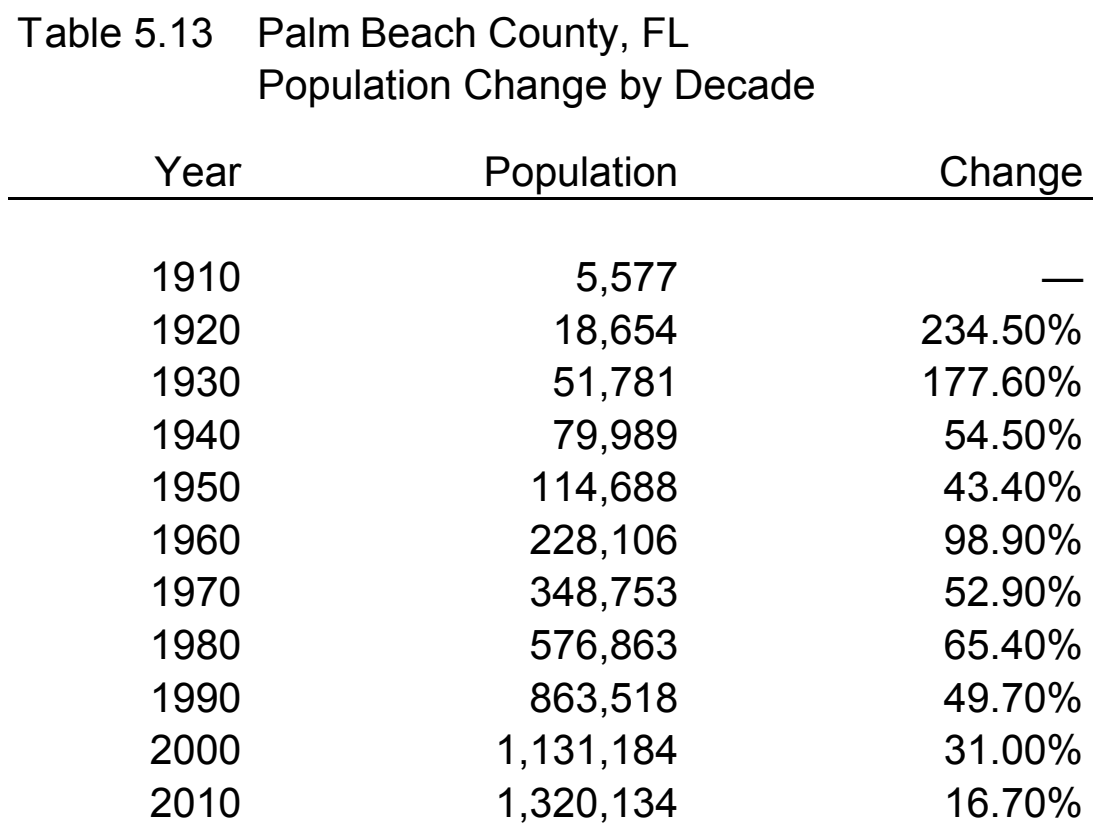

Source: U.S. Census Bureau, 2012.

According to the 2000 census, Palm Beach county has a total area of 2,386.33 square miles, of which $1,974.11$ square miles (or $82.73 \%$ ) is land (making it the second-largest Florida county by land area, after Collier County) and 412.22 square miles (or $17.27 \%$ ) is water, much of it in the Atlantic Ocean and Lake Okeechobee. There are more than 400,000 acres of conservation lands. 
Figure 5.9 Map of Palm Beach County, Florida

Wildlife and Conservation Areas

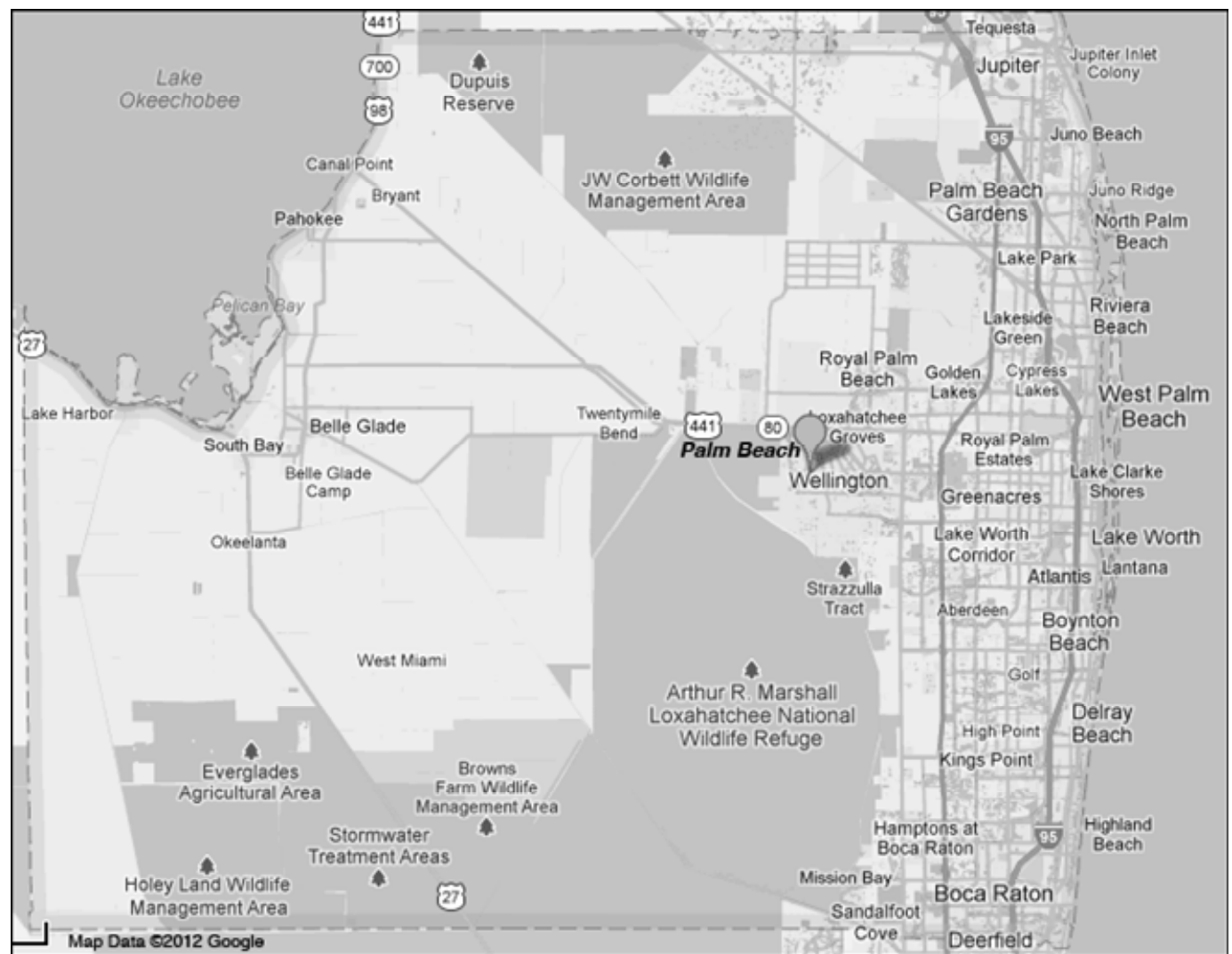

Source: Retrived on 11/18/12 from http://www.floridacountiesmap.com/palm_beach_county.shtml.

5.3.4.3 Palm Beach County 2000 Demographic, Socio-Economic and Other Indicators.

As of the 2000 U.S. Census, there were 1,131,184 people, 474,175 households, and 303,946 families residing in the county. The population density was 573 people per square mile. Approximately $41 \%$ of Palm Beach County's population resides in unincorporated areas within the county. There were 556,428 housing units at an average density of 282 per square mile.

The racial makeup of the county was $80.05 \%$ White $(70.6 \%$ were NonHispanic White,) $13.80 \%$ Black or African American, 0.22\% Native American, 
$1.51 \%$ Asian, $0.06 \%$ Pacific Islander, $2.98 \%$ from other races, and $2.38 \%$ from two or more races. $12.44 \%$ of the population is Hispanic or Latino of any race. In relationship to ancestry (excluding the various Hispanic and Latino ancestries), 10\% were Italian, 9\% German, $8 \%$ Irish, 8\% American, 6\% English, 4\% Russian, and $4 \%$ Polish ancestry according to Census 2000.

As of $2000,78.36 \%$ of all residents spoke English as a primary language, while $11.89 \%$ spoke Spanish, 2.81\% French Creole, 1.12\% French, 0.76\% Italian, $0.68 \%$ German, and $0.52 \%$ of the population spoke Yiddish. In total, $78.36 \%$ spoke English as a primary language, while $21.64 \%$ spoke languages other than English.

There were 474,175 households out of which $24.90 \%$ reported children under the living in the household, $50.80 \%$ were married couples living together without children, $9.70 \%$ had a female householder with no husband present, and $35.90 \%$ were non-related individuals. $29.20 \%$ of all households were made up of individuals and $14.60 \%$ had someone living alone who was 65 years of age or older. The average household size was 2.34 . The average family size was 2.89 .

Age ranges found in the county were $21.30 \%$ under the age of $18,6.60 \%$ aged 18 to $24,27.00 \%$ aged 25 to $44,22.00 \%$ aged 45 to 64 , and $23.20 \% 65$ years of age or older. The median age was 42 years. Overall, the female to male ratio was 100:93. The female to male ratio for those over 65 was 100:91.

The median household income was $\$ 45,062$, and the median income for a family was $\$ 53,701$. Males had a median income of $\$ 36,931$ versus $\$ 28,674$ for females. The per capita income for the county was $\$ 28,801$. About $6.90 \%$ of 
families and $9.9 \%$ of the population were below the poverty line, including $14.30 \%$ of those under age 18 and $6.60 \%$ of those aged 65 or over.

Palm Beach County population grew by $16.70 \%$ to $1,320,134$ from 2000 to 2010, and ranks third in the State of Florida. The population growth rate is lower than the state average rate of $17.64 \%$ and is much higher than the national average rate of $9.71 \%$. Palm Beach county median household income is $\$ 53,242$ in $2006-2010$ and has grown by $18.15 \%$ since 2000 . The income growth rate is higher than the state average rate of $14.40 \%$ and is lower than the national average rate of $19.17 \%$. Palm Beach county median house value is $\$ 261,900$ in $2006-2010$ and has grown by $93.71 \%$ since 2000 . The house value growth rate is much higher than the state average rate of $55.64 \%$ and is much higher than the national average rate of $50.42 \%$. As a reference, the national Consumer Price Index (CPI) inflation rate for the same period is $26.63 \%$.

\subsubsection{Palm Beach County Government}

The voter-approved Palm Beach County Home Rule Charter became effective in 1985. The Board of County Commissioners is granted the authority to create, through a public hearing ordinance procedure, local ordinances that do not conflict with, or a specifically prohibited by, the State of Florida constitution and general law. This self-government ability allows Palm Beach County government to preside over local issues without having to submit all requests for local laws to the Florida legislature.

The Palm Beach County Charter and Chapter 125 of the Florida statutes establish the powers and responsibilities of the Board of County Commissioners. 
This legislative branch of County government consists of seven members who are elected to office in single member districts. The Board elects a chairperson to preside over the commission meetings and serve as the ceremonial head of Palm Beach County government. There is also a vice chair selected to assume the duties in the absence of the chair

A county administrator is appointed by the Board of County Commissioners. The duties and responsibilities of this position are to implement the Board's policies. Under the county administrator's direction, more than 30 departments, divisions and offices provide residents with community services and programs. An independent five-member Commission on Ethics (COE) receives and investigates complaints, and is charged with enforcement of the Palm Beach County Code of Ethics, lobbyist registration and post-employment ordinances.

5.3.4.5 Phenomenon of Interest: Diversity of Socio-Economic and Land Use Factors.

Palm Beach County is the largest county in the state of Florida in total area, and third in population. With wealthy coastal towns such as Palm Beach, Jupiter, Manalapan, and Boca Raton, as well as Wellington (with an equestrian focus) and Palm Beach Gardens (with a golfing, emphasis), in 2004 Palm Beach County is Florida's wealthiest county, with a per capita income of $\$ 44,518$. Palm Beach County (primarily the western portion of the county) records the most migrant and season workers and dependents in the State of Florida with an average individual income range of $\$ 10,000$ and $\$ 12,499$. 
Palm Beach County encompasses 2,386 square miles, situated between the Atlantic Ocean to the east and Lake Okeechobee and the Everglades to the west. The region contains environmentally sensitive ecosystems and significant agricultural areas. The county's economy depends upon its agriculture, tourism, seasonal population and growth. Fifty years of suburban growth have threatened to reduce the quality and quantity of urban, suburban and rural lifestyle choices. In 1999, Palm Beach County government adopted a 'Managed Growth Tier System ${ }^{63}$, to manage the framework of future growth in order to protect the future quality of life. Five tiers are created to accommodate the diversity of land use, agriculture and conservation areas.

Past growth, and anticipated growth, has had many unintended consequences. Debatably the most significant consequence is the threatening of a fragile Everglades ecosystem and the region's current and future water supply system. Multi-county regional water managers, in conjunction with state and federal governments, have begun one of the largest ecosystem restoration projects in the world.

Diversity: Wealth versus Poverty. Affluence in the United States refers to an individual's or household's state of being in an economically favorable position in contrast to a given reference group. While there are no precise guidelines or thresholds for what may be considered affluent, the United States Department of Commerce's Bureau of the Census does provide detailed statistical data on the economic state of America's population.

${ }^{63}$ Palm Beach County Department of Planning, Zoning and Building, 1999. 
The U.S. Census Bureau offers income data by household and individual. $42 \%$ of households have two income earners; thus making households' income levels higher than personal income levels ${ }^{64}$ The 2005 economic survey revealed the income distribution for households and individuals whereby the top $5 \%$ of individuals had six figure incomes (exceeding $\$ 100,000$ ) and the top $10 \%$ of individuals had incomes exceeding $\$ 75,000^{65}$. The top $5 \%$ of households, three quarters of whom had two income earners, had incomes of $\$ 166,200$ (about 10 times the 2009 minimum wage in the US) or more ${ }^{66}$ with the top $10 \%$ having incomes well in excess of $\$ 100,000^{67}$. The top $1.5 \%$ of households had incomes exceeding $\$ 250,000$ with 146,000 households, the top $0.12 \%$, having incomes exceeding $\$ 1,600,000$ annually.

Palm Beach County's median household income is much higher than the median values for Florida and the United States. See Table 5.14.

The town of Palm Beach is a barrier island sixteen miles long located on the eastern coast of Palm Beach County. To the east is the Atlantic Ocean and to the west is the Intracoastal Waterway, which separates Palm Beach from the

\footnotetext{
${ }^{64}$ Retrieved 12-28-2011. US Census Bureau, income quintile and top 5\% household income distribution and demographic characteristics, 2006.

${ }^{65}$ Retrieved 12-28-2012. US Census Bureau, personal income distribution, age 25+, 2006.

${ }^{66}$ Retrieved 12-28-2011. US Census Bureau, income quintile and top 5\% household income distribution and demographic characteristics, 2006.

${ }^{67}$ Retrieved 12-28-2012. US Census Bureau, overall household income distribution, 2006". Archived from the original on 4 January 2007.
} 
Table 5.14 Household Income, Palm Beach, Florida, U.S., 2011 Estimates

\begin{tabular}{|c|c|c|c|c|}
\hline & \multicolumn{2}{|c|}{ Palm Beach } & \multirow{2}{*}{$\begin{array}{c}\text { Florida } \\
\text { Percent }\end{array}$} & \multirow{2}{*}{$\begin{array}{r}\text { United States } \\
\text { Percent }\end{array}$} \\
\hline & Number & Percent & & \\
\hline Income $\$ 200,000$ - $\$ 499,999$ & 25,507 & 4.78 & 2.71 & 3.04 \\
\hline Income $\$ 500,000$ and over & 7,373 & 1.38 & 0.64 & 0.64 \\
\hline
\end{tabular}

Source: The Nielsen Company, Claritas

Compiled by: Health Council of Southeast Florida, 2012

cities of West Palm Beach and Lake Worth. The year-round population is 10,000 and the seasonal population is about 30,000 . Palm Beach has been named America's richest zip code, according to a recent Bloomberg BusinessWeek study ${ }^{68}$. The report claims that zip code 33480 has 5,505 households, each with an average income of $\$ 370,136$. The average household net worth is $\$ 1,486,123$. Palm Beach is known for its high-end shopping and dining, polo, golf, tennis, yachting and deep-sea fishing. According to the study, the majority of Palm Beach's residents are executives and professionals in their ' 50 s and '60s with no children. The median age, according to 2010 census data, is 67.5 .

Poverty is a state of privation or lack of the usual or socially acceptable amount of money or material possessions ${ }^{69}$. The most common measure of poverty in the United States is the "poverty threshold" set by the U.S. government. This measure recognizes poverty as a lack of those goods and services commonly taken for granted by members of mainstream society. The official threshold is adjusted for inflation using the consumer price index. The number of people in the U.S. who are in poverty is increasing to record levels

\footnotetext{
${ }^{68}$ Retrieved 12-28-2012. http://images.businessweek.com/slideshows/20111206/america-srichest-zip-codes-2011\#slide52

${ }^{69}$ Zweig, Michael (2004) What's Class Got to do With It, American Society in the Twenty-first Century. ILR Press. ISBN 978-0-8014-8899-3
} 
with the ranks of working-age poor approaching 1960s levels that led to the national War on Poverty ${ }^{70}$.

Palm Beach County accommodates the most migrant and seasonal worker and their dependents in the State of Florida. According to the national Migrant and Seasonal Farmworker Enumeration Profiles Study for Florida (Larson, 2000), there are more than 30,000 workers and their dependents for farming and non-farming industries.

Table 5.15 Palm Beach County, FL - Migrant and Seasonal Farmworkers (MSFW) Field Agriculture, Nursery/Greenhouse and Food Processing

\begin{tabular}{lrr} 
& Florida & * Palm Beach \\
\hline Adjusted MSFW Farmworker Estimate & 194,817 & 21,198 \\
Migrant Farmworkers & 120,430 & 13,104 \\
Seasonal Farmeworkrs & 74,387 & 8,094 \\
Non Farmworkers in Migrant Households & 44,556 & 4,848 \\
Non Farmworkers in Seasonal Households & 43,914 & 4,778 \\
Reforestation (statewide)) & 3,438 & \\
\hline MSFW Farmworkers and Non Farmworkers & 286,725 & ${ }^{*} 30,824$ \\
Source: Larson, 2000. & & \\
* Highest number for all Florida counties. & &
\end{tabular}

Farm workers live throughout Palm Beach County, but most are concentrated in the Glades area near Lake Okeechobee. The labor in the sugar cane fields, pick vegetables, and work in vegetable packing sheds preparing agricultural products for the market. Many farm workers live full time in Palm Beach County, while other migrate north during the summer months to find work $^{71}$ Palm Beach County farm workers come from different ethnicities and

\footnotetext{
${ }^{70}$ Retrieved 12-28-2012. US poverty on track to post record gain in 2009 - Yahoo! News". News.yahoo.com. 2009-04-13.

${ }^{71}$ Farmworker Coodinating Council of Palm Beach County, Retrieved 1-24-2013. www.farmworkercouncil.org/fwpbc.htm.
} 
nationalities. Many of the newly arrived agricultural farm workers are from rural Mexico, Guatemala and Haiti. In the Glades area, many African American families have a long term history of working agriculture in the area.

Farm workers in Palm Beach County, and nationwide, face a number of barriers. Many live in poverty, lack basic services and endure unfair labor practices $^{72}$. The 2001-2001 National Agricultural Workers Survey (NAWS) found the average individual income range is between $\$ 10,000$ and $\$ 12,499$, and the average family income range is $\$ 15,000$ and $\$ 17,499$. Thirty percent of all farm workers had total family incomes that were below the poverty guidelines.

Beside low wages and periodic unemployment, farm workers do not receive the same employment benefits, cannot afford health insurance, are excluded from worker's compensation insurance, and do not receive vacation days or overtime pay ${ }^{73}$. Another barrier is that many speak little or no English.

Diversity: Areas of Urbanization, Agriculture, and Conservation. The Urban/Suburban Tier of the Palm Beach County's 'Managed Growth Tier System' lies along the coast and occupies less than one-quarter of the County. It includes 37 cities with moderate to high densities, to lower density, unincorporated suburbs located inland. A smaller area of the Urban/Suburban Tier is located adjacent to Lake Okeechobee on the County's western border. This area includes several small agriculture towns.

\footnotetext{
${ }^{72}$ Farmworker Coodinating Council of Palm Beach County, Retrieved 1-24-2013. www.farmworkercouncil.org/fwpbc.htm.

73 Farmworker Coodinating Council of Palm Beach County, Retrieved 1-24-2013. www.farmworkercouncil.org/fwpbc.htm.
} 
The Exurban Tier is primarily semi-rural and located in the central portion of the County just west of the Urban/Suburban Tier. This Tier includes rural subdivisions with 1.25 to 2.5 acre homesteads that support small, private agriculture and equestrian uses. Projected growth and development pressures have required a better mix of uses and limited urban services. The challenge is to plan for growth while protecting and maintaining the area's semi-rural lifestyle.

The Rural Tier generally lies in the central and northern part of Palm Beach County. This Tier includes large areas of citrus groves, sod farms, and nurseries. It also maintains $5-10$ acre homesteads, small agricultural industries and equestrian uses. The countryside is characterized by mature tree canopies, abundant open space, and unpaved roads.

The Agricultural Reserve Tier inhabits southern Palm Beach County. This 21,000 -acre area acts as a buffer between the suburbs and the Loxahatchee National Wildlife Refuge. It also is critical to Everglades restoration. Farms in this Tier are a significant source of the nation's winter vegetables. The objective is to perpetuate agricultural, preserve environmental, and water resources, while accommodating some of the County's growth pressure with limited and clustered residential development.

The Glades Tier is the largest of the five tiers, covering the western twothirds of the County. This Tier contains several towns located along Lake Okeechobee, large tracts of agricultural land planted with sugar cane, rice and vegetables, the Loxahatchee National Wildlife Refuge, and the J.W. Corbett Wildlife Management Area. This Tier's objective is to preserve the region's 
unique characteristics, protect the economically important agricultural industry, and revitalize its rural towns.

With an estimated $\$ 1.42$ billion in total agricultural sales for $2010-11$, Palm Beach County leads the State of Florida, all counties east of the Mississippi River, and is one of the ten largest agricultural sellers in the United States. It leads the state in agricultural wages and salary with over $\$ 316$ million. Palm Beach County also leads the nation in the production of sugarcane, fresh sweet corn, and sweet bell peppers. It leads the State in the production of rice, lettuce,

Figure 5.10 Palm Beach County, FI Managed Growth Tier System, 1999.

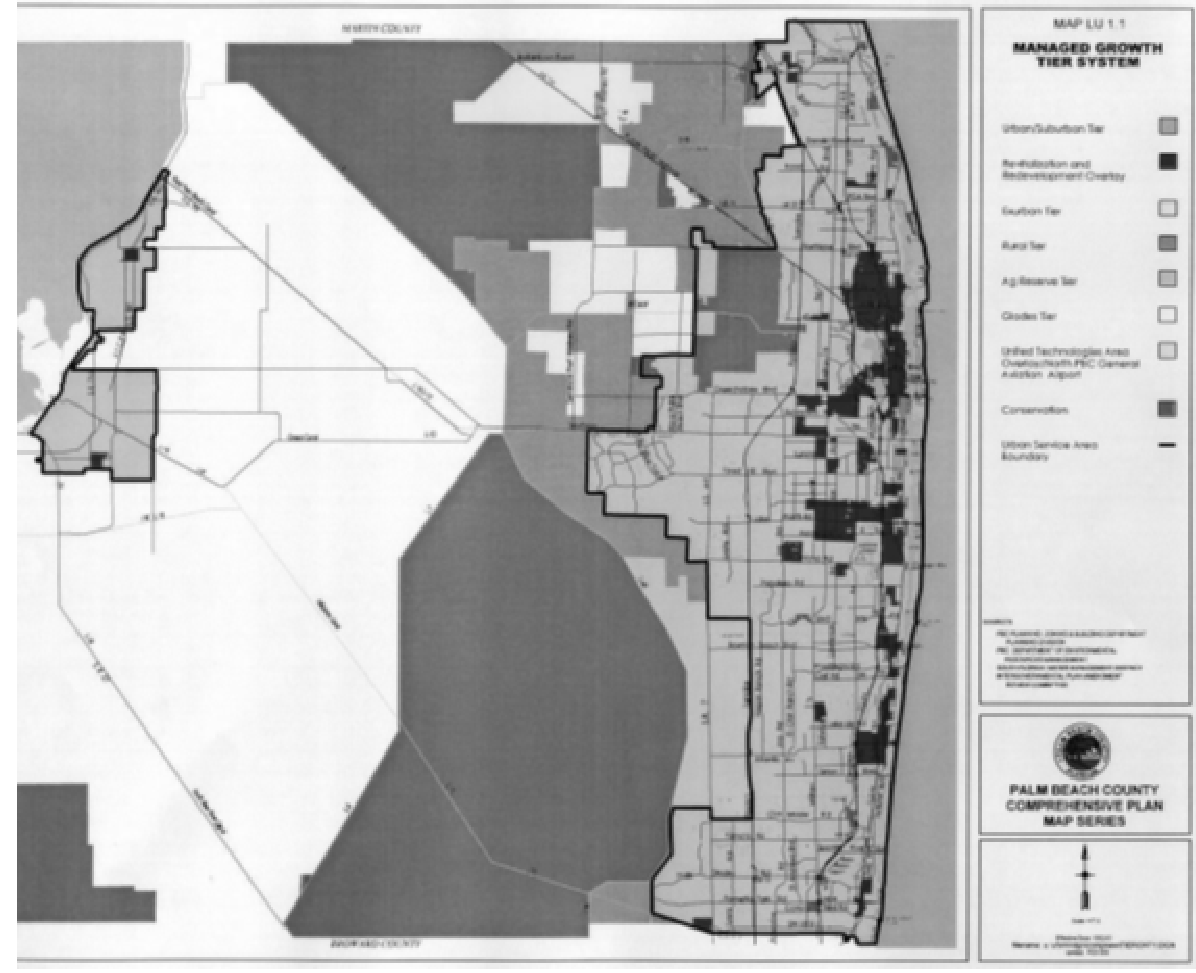

Source: Palm Beach County, FL: Department of Planning, Zoning, and Building.

radishes, Chinese vegetables, specialty leaf, and celery. The County's agricultural infrastructure includes: three major sugar manufacturing mills, 476 
horticultural nurseries, a major hydroponic tomato growing operation, a rice processing and packaging mill, and more.

More than 400,000 acres of conservation land are scattered throughout Palm Beach County. These areas range from small municipal sites to vast areas devoted to wildlife refuge and management areas. These areas act as a buffer between the developed coastal communities and the Glades' Tier agriculture area. The conservation areas are intended to protect natural resources, wildlife, and surface water and groundwater quality.

Challenge 1: Recognizing its land use diversity, Palm Beach County adopted its Managed Growth Tier System in 1999. Growth has been the major influencing factor for South Florida. Palm Beach County has drawn national attention for its sprawl-related problems. The Sierra Club identified West Palm Beach as the fourth most "sprawl-threatened" medium-sized city in the nation. According to the Surface Transportation Policy Project, West Palm Beach-Boca Raton is the seventh most dangerous large metropolitan area in the country for pedestrians, due in large part to its sprawling development patterns. And the American Farmland Trust identified the Florida Everglades and associated area as the sixth most threatened prime farmland in the nation, due to the impacts of sprawling urban development.

Palm Beach County is projected to grow by 400,000 new residents in the two decades to come. Studies by Rutgers University and the Palm Beach County Planning Department estimate that the county could save between $\$ 14$ and $\$ 22$ million annually if it discouraged growth in rural and agricultural areas, 
and promoted growth in the more urbanized east coast area. This would reduce road, sewer and water infrastructure requirements, save over 8,000 acres of agriculturally and environmentally sensitive land, and consume 5,600 fewer developable acres of land.

Challenge 2: Socio-economic Diversity. The challenge of the bureaucracy is only one issue faced by public administrators. Equity, particularly as it concerns social equity, is the second challenge. Themes of social equity have long been suggested in the field of public administration. In fact, the field of public administration has led toward equitable, socially acceptable diverse outcomes in society and in public service (Frederickson, 2005; McGregor, 1960). As Frederickson (2005) stated, both Henri Fayol (1949) and Woodrow Wilson (1887) had themes of social equity in the role of public administration in society and bureaucratic manager in the workplace.

The challenge of the public administrator is more an opportunity to advance the field of public administration rather than to constrain it. Hart (1974) defines social equity as the "habit of fairness, justness and right-dealing" that should define the interactions between persons. However, Frederickson (2005) sees social equity as a contemporary foundation of public administration, one based on social equity like the Rawlsian notions of justice and fairness, particularly basic liberties provided individuals and managing socio-economic disparities to benefit those who lack the most in society. Chitwood (1974) also sees social equity in terms of the allocation of public resources grounded in budgetary constraints that allows people in society to meet a minimum standard 
of living. Perry and Wise (1990) describe social equity in terms of improving life for minorities and other lacking political and economic resources.

To summarize, the challenges for public officials and administrators in Palm Beach County is to acknowledge the existence of socio-economic diversity, emphasize fairness and justness in governmental management, and deliver pragmatic public services for the community.

\subsection{In-Case/Between-Case Data Analysis}

An in-case/between case analysis matrix is generated to integrate document and verbal interview data. Based upon the frequency of occurrence, numerical information is recorded for each of the two types of qualitative data based upon the times the topic of the theme arose. Each piece of numerical information is weighted by an ordinal rank based upon the judgment of the researcher's experience: 3=strong, 2=average, 1=weak. Finally, totals are calculated and in-case/between case themes are prioritized. Table 5.16 provides the thematic context for the in-case/between case analysis.

Table 5.16 Thematic Contexts for In-Case / Cross-Case Analysis of three Case Counties

\begin{tabular}{|c|c|c|}
\hline Case 1 Themes & Case 2 Themes & Case 3 Themes \\
\hline $\begin{array}{l}\text { 1. Resource Protection } \\
\text { 2. Parks and Recreation } \\
\text { 3. Funding } \\
\text { 4. Agency Administration } \\
\text { 5. Government - Politics } \\
\text { 6. Environmental Groups }\end{array}$ & $\begin{array}{l}\text { 1. Resource Protection } \\
\text { 2. Agency Administration } \\
\text { 3. Land Development } \\
\text { 4. Parks, Recreation, Culture } \\
\text { 5. Public Education } \\
\text { 6. Timing }\end{array}$ & $\begin{array}{l}\text { 1. Resource Protection } \\
\text { 2. Regionalization } \\
\text { 3. Agriculture/Farming } \\
\text { 4. Land Planning } \\
\text { 5. Municipalities } \\
\text { 6. Environmental Groups }\end{array}$ \\
\hline All Case Themes & 2 CaseThemes & 1 Case Themes \\
\hline 1. Resource Protection & $\begin{array}{l}\text { 1. Parks and Recreation } \\
\text { 2. Land Development/Planning } \\
\text { 3. Environmental Groups } \\
\text { 4. Agency (Public) Administration }\end{array}$ & $\begin{array}{l}\text { 1. Regionalization } \\
\text { 2. Funding } \\
\text { 3. Government - Politics } \\
\text { 4. Culture } \\
\text { 5. Public Education } \\
\text { 6. Timing } \\
\text { 7. Municipalities } \\
\text { 8. Agriculture/Farming }\end{array}$ \\
\hline
\end{tabular}


The timing of County policymaking is a function of its Board of County Commissioners' investment strategy in its community goods and services. As one interviewee states, land preservation voter referendums came to "the right place (South Florida), at the right time". County case interviewees contributed a variety of comments of concern in relationship to South Florida population increases, immigration and emigration, commercial property and residential housing growth, and resultant urban sprawl of the 1980s and 1990s marked by the sizeable loss of vacant land to new roads, commercial ventures, and residential subdivisions.

The political environment is the state, government and its institutions and legislations, as well as the public and private stakeholders who function, interact and possibly influence public officials and administrators in those systems of governance and governments. However, the stability of the political environment and county government can impact the community and municipalities within its boundaries through the types, quantities and qualities of the public goods and services that county government provides. Interviewees claim that the political environment is extremely important to the art and science policy development and project implementation. Some interviewers claim that Miami-Dade County's political history of home rule charter implementation and frequent amendment proposals for citizen voter brought a degree of instability to governance and government, more so than Broward and Palm Beach County. None could provide 
precise reasons for this perception of instability, but felt it was an important factor from which county governments could learn.

According to case county interviewees, the concept of selecting a county land preservation voter referendum was, for the most part, initiated by county department heads and staff because of their perceived community needs. However, Broward and Palm Beach County public administrators told of looseknit environmentalists who brought conservation concepts and problems to government community-generated wilderness inventories, concerns for threatened lands and ecosystems, outdated parks and recreation facilities, potential loss of cultural properties, and historical archeological sites.

The case counties' project planning begins with a community needs assessment. Some case counties fund public opinion polls implemented by national pollsters to determine brand sensitivity and priorities of citizens. Others enlist special interest groups (e.g., Urban Wilderness Advisory Board in Broward County) or contract for studies (1987-88 FAU "Inventory of Native Ecosystems in Palm Beach County") that provided environmental expertise through a countywide inventory of available vacant land classified as endangered (threat of ecosystem extinction), conservation (ecosystem mostly intact) or natural area (open space). However, according to interviewees, public administrators with professional expertise in urban planning, environmental resource management, parks and recreation, finance, elections, land acquisition and public relations were at the core of the planning process. 
Interviewees state that success in achieving their County Mayor or Administrator and Board of County Commissioners' project approval was the comprehensiveness of their research in identifying, categorizing, pricing and prioritizing potential land acquisitions, park and recreation renovations or expansions, cultural and historical preservation projects, agricultural lands, and other specifications of the various voter referendums. Helpful for these public administrators was the awareness of a county commissioner with a history of championing environmental policies.

Interviewees discussed their voter referendum public education programs. By definition, democratic governments should reflect public opinion and work best when the citizens are well-informed. Public relations should have a natural and welcome role in U.S. government, but is does not. The Gillett Amendment, part of the 1913 Appropriations Act for the U.S. Department of Agriculture, simply states that, "Appropriated funds may not be used to pay a publicity expert unless specifically appropriated for that purpose ${ }^{74}$." While this provision doesn't prohibit government public relations, it is often described as being a ban on government public relations with an interpretation that its workers may not be employed in the practice of public relations. The most often-used and wide-spread euphemism for public relations in government is "public information" or education.

Several interviewees discussed the branding of county land preservation voter referendums to encourage public recognition of referendum branding, and therefore cast a favorable vote of 'yes' for passage. Both Miami-Dade (1990)

\footnotetext{
${ }^{74}$ See National Association of Government Communicators at http://www.nagc.com/AboutNAGC/ HistoryNAGC.asp
} 
and Broward Counties (1989) named their voter referendums respectively, Environmentally Endangered Lands (EEL) and Environmentally Sensitive Lands (ESL). According to interviewees, this branding conveys a sense of urgency to protect and preserve select "endangered" or "sensitive" environmental ecosystems found on remaining vacant land parcels in the county.

More examples of land preservation voter referendum naming or branding that interviewees considered are Miami-Dade County's 1996 Safe Neighborhood Parks bond referendum and Broward County's 2000 Safe Parks and Land Preservation bond referendum. Interviewees representing both counties referred to their national public opinion polls that found that citizens were primarily concerned about safety and security in their communities and parks. As a result of these polls, both counties chose to herald their referendum selection accordingly by including the initial word "safe" in their branding. When interviewees were asked why land preservation voter referendum ballot questions which voters viewed at the ballot box sometimes did not match the county's Board of County Commissioners' official ordinance language, there were no substantive responses. One interviewee response mentioned that the official ballot language was restricted to a maximum number of words.

Some referendum promotional efforts were underwritten by citizens' groups or supportive non-governmental organizations. In all counties the educational efforts sought countywide exposure to inform as well as to respond to individual questions. A frequent citizen question focused on cost to the individual; reportedly, speaker responses included that the voter referendum 
annual cost for a family of four would approximate the price of an average dinner out or going to a movie.

A voter referendum speakers' bureau was established to interact with business groups, municipalities, homeowner/condominium associations, school groups, and many more. Several counties ran public service announcements, newspaper articles, and informational TV spots. Written materials, placards, buttons, t-shirts and similar were produced and circulated. A Miami-Dade County interviewee described Optimist Club youth wearing t-shirts at polling sites on voting day.

\subsection{Integration with Pattern Matching}

Because this study utilizes an explanatory, sequential mixed methodology, the "interpretive approach" that Chi, Feltovich and Glasser (1981) applies in some of their research is utilized for this mixed methods research. The predominant emphasis is on the initial quantitative data. Patterns found in the findings of the qualitative approach are treated as similarity judgment data and aid in the interpretation and understanding of the quantitative findings.

Pattern matching involves an attempt to link two patterns where one is a theoretical pattern and the other is an observed or operational one. A theoretical pattern is a hypothesis about what is expected in the data. The observed pattern consists of the data that are used to examine the theoretical model. The major differences between pattern matching and more traditional hypothesis testing approaches are that pattern matching encourages the use of more complex or 
detailed hypotheses and treats the observations from a multivariate rather than a univariate perspective.

Table 5.17 provides the significant findings of the quantitative analysis of referendum and non-referendum county factors. The confidence level or strength of the significance for each factor is found in parentheses.

Table 5.17 Key Observations of the Quantitative Approach

\begin{tabular}{|c|c|c|c|}
\hline Contextual & $\mathrm{H}_{1}$ & $\begin{array}{l}\text { Estimates of Selection Eq. }{ }^{*} \\
\text { (Strength of Significance) }\end{array}$ & $\begin{array}{l}\text { Estimates of Passage Eq. } \\
\text { (Strength of Significance) }\end{array}$ \\
\hline $\begin{array}{l}\text { Governance } \\
\text { Factors }\end{array}$ & 1 & $\begin{array}{l}\text { State Dillon's Rule }+(<0.0001) \\
\text { State Local Govt Autonomy Index }-(<0.1)\end{array}$ & Not Applicable \\
\hline $\begin{array}{l}\text { Government } \\
\text { Factors }\end{array}$ & 2 & $\begin{array}{l}\text { County Home Rule Charter }+(<0.05) \\
\text { Appointed County Administrator with Board } \\
\text { of Commissioners }+(<0.05)\end{array}$ & Not Applicable \\
\hline $\begin{array}{l}\text { Environmental } \\
\text { Factors }\end{array}$ & 3 & Environmental Organizations $-(<0.05)$ & Environmental Organizations $-(<0.1)$ \\
\hline $\begin{array}{l}\text { Community } \\
\text { Factors }\end{array}$ & 4 & $\begin{array}{l}\text { Population Count }+(<<0.05) \\
\text { Population Growth }+(<0.0001) \\
\text { Median Houshold Income }+(0.01) \\
\text { Median Household Income Sq }-(<0.01) \\
\text { Population Median Age }-(<0.01) \\
\text { Population White }+(<0.05) \\
\text { Population Higher Education }+(<0.01) \\
\text { Population Unemployed }+(<0.05) \\
\text { Housing Growth }+(<0.01) \\
\text { Coastal County }+(<0.05) \\
\text { Urban Land }(>50,000)+(<0.0001) \\
\text { Democratic Presidential Vote }+(<0.0001) \\
\text { State Registered Voters Vote }-(<0.05) \\
\text { Regions } 1 \& 2-(0.05) \\
\text { Region 3 }-(<0.1)\end{array}$ & $\begin{array}{l}\text { Population Count }+(<<0.05) \\
\text { Population Growth }+(<0.01) \\
\text { Population Higher Education }+(<0.0001) \\
\text { Owner-Occupied Housing }+(<0.05) \\
\text { Housing Growth }+(<0.01) \\
\text { Coastal County }+(<0.05) \\
\text { Urban Land }(>50,000)+(<0.0001) \\
\text { Voting Age Population Vote }-(<0.05) \\
\text { Regions } 1 \& 3-(<0.05) \\
\text { Region } 2-(<0.1)\end{array}$ \\
\hline $\begin{array}{l}\text { Voter } \\
\text { Referendum } \\
\text { Factors }\end{array}$ & 5 & Not Applicable & $\begin{array}{l}\text { Other Financing Mechanism }-(0.0001) \\
\text { Farming }-(0.05) \\
\text { Vote Presidential Nov }-(<0.1) \\
\text { Vote Dates Not Nov }-(<0.1)\end{array}$ \\
\hline
\end{tabular}

Note: $\mathrm{H}_{1}$ refers to the alternate hypotheses that relate to the five contextual factors of this study.

* Refers to 2000 Benchmark Group 
Table 5.18 outlines the key observations of the three county case studies.

Table 5.18 Key Observations of the Qualitative Case Studies

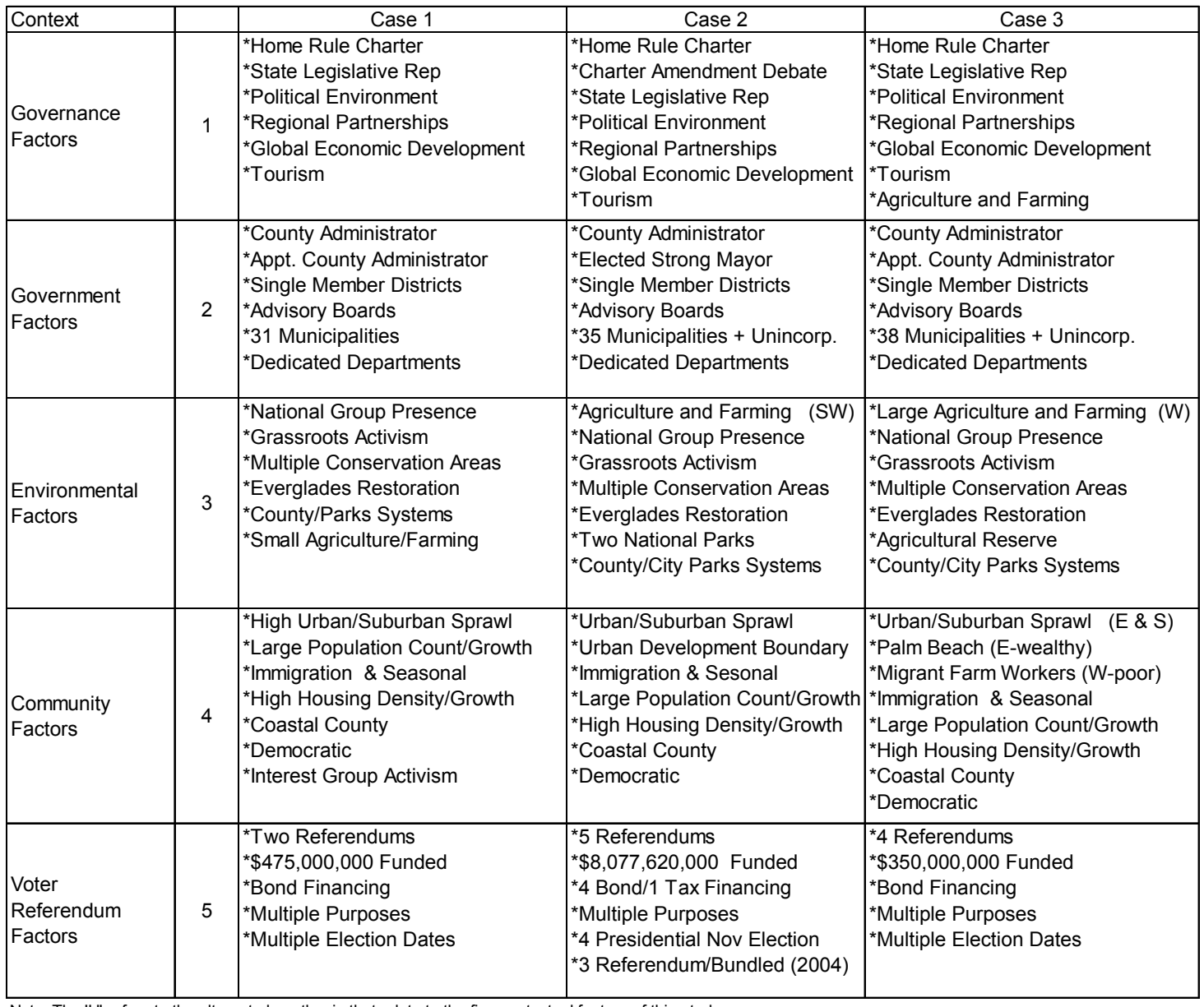

Note: The ' $\mathrm{H}$ ' refers to the alternate hypothesis that relate to the five contextual factors of this study.

The study's five research hypotheses are grounded in the conceptual

foundation. These hypotheses provide the theoretical patterns. All theories imply

some pattern. In general, these theories postulate structural relationships

between key constructs. The theory can be used as the basis for generating

patterns of predictions. This study predicted the rejection of the five null

hypotheses presented in Chapter III. 
By observing the patterns of integrated quantitative and qualitative data, it is predicted that the strength of the collective data is strong enough to reject the five null hypotheses and accept the alternative hypotheses of this research.

Table 5.19 displays this conclusion.

Table 5.19 Hypothesis Testing After Data Integration

\begin{tabular}{|l|l|}
\hline \multicolumn{1}{|c|}{ Atlternative Research Hypotheses } & Integrated Data \\
\hline $\begin{array}{l}\text { H1: As a result of its county home rule charter ordinance, there is a } \\
\text { greater probability that a county government will select a land } \\
\text { preservation voter referendum. }\end{array}$ & \\
\hline $\begin{array}{l}\text { H2: With a reformed county government structure (e.g., a board of } \\
\text { commissioners with an appointed administrator/manager or elected } \\
\text { executive/mayor), there is a greater likelihood that a county government } \\
\text { will select a land preservation voter referendum. }\end{array}$ & \\
\hline $\begin{array}{l}\text { H3: The influence of state, regional, and local area environmental interest } \\
\text { groups and grassroots activism improve the prospects of a county } \\
\text { government selecting, and citizens passing, a county land preservation } \\
\text { voter referendum. }\end{array}$ & + \\
\hline $\begin{array}{l}\text { H4: Some county demographic, socio-economic, terrain, regional, and } \\
\text { political preference factors improve the prospect of a county government } \\
\text { selecting and voters passing a land preservation voter referendum. }\end{array}$ & + \\
\hline $\begin{array}{l}\text { H5: The results of the analysis of qualitative county case study } \\
\text { documentation, case-specific phenomena of interest, and expert public } \\
\text { administrator intervews confirm, corroborate, complement and enhance } \\
\text { the quantitative results; when quantitative and qualitative results are } \\
\text { integrated, the findings provide a comprehensive and nuanced } \\
\text { understanding of the factors for success of county land preservation voter } \\
\text { referendums. }\end{array}$ & \\
\hline
\end{tabular}

Scale: +: confirming; -: disconfirming; 0: neither conforming or disconforming; N/A: not applicable.

\subsection{Summary}

Chapter $V$ describes in detail the qualitative case study research approach of this research methodology and draws conclusions from an analysis of three South Florida metropolitan counties - Broward, Miami-Dade and Palm Beach

Counties. First, an overview of the application of the case study strategy is explored within the discipline of qualitative research, including a discussion of its characteristic strengths and challenges. 
Descriptive sections for each of the three study county cases follow. The multiple sources of information and data are documentation; national, state and county-specific websites and databases; archival records; government and stakeholder records, agendas, reports, public education materials, surveys, public opinion polls, and much more.

Twelve semi-structured interviews were conducted with twelve experienced public managers/administrators who are, of have been, affiliated with at least one of these three county cases. From transcripts of these interviews, a number of main themes emerged within and between county cases. These themes are coded, consolidated, sorted and classified into the following six relevant categories: timing (for selecting and proposing county land preservation voter referendums), the political environment of the county, administrative planning, citizen (county resident) education, regional partnerships, and the uncertainty of the future. These categories are ranked and weighted for integration with the prior quantitative method's findings.

Integration of quantitative and qualitative data is completed by pattern matching. The results of hypotheses testing are a rejection of the null hypotheses, and acceptance of the predicted alternative hypotheses. 


\section{CHAPTER VI}

\section{INTEGRATION OF THE MIXED METHODS RESEARCH}

\subsection{Introduction}

Chapter VI presents the concluding analysis of the implications derived from the outcomes of the mixed methods analysis of county land preservation voter referendum and non-referendum counties in the 50 American states.

The chapter is divided into three sections. First, there is a discussion of consolidated conclusions drawn from both the quantitative and qualitative research approaches. Second, limitations of the study are considered. Finally, suggestions for future research are presented.

\subsection{General Conclusions}

As an academic field, public affairs research is obligated to advance both theoretical and pragmatic understanding of governmental institutions and processes (Wright, Manigault and Black, 2004). Such understanding, however, cannot be achieved only through acquisition of current knowledge by education and training; it also requires the input of new knowledge achieved through credible research (Liebman, 1963). Research has a special role in a practitioneroriented field such as public administration by serving not only to guide needed theory development, but also to positively influence the practices and decisions public administrators and managers.

The research questions important to public administration do not always lend themselves to scientific study in the same way found in the natural sciences. 
Rather, the important issues facing public administration are complex and involve phenomena not easily identified, isolated, manipulated, or even directly observed. Therefore, application of a mixed methods is suitable for the scholarly study of topics in the field of public affairs.

First, the concept of "good governance" often emerges as a model to compare ineffective economies or political bodies with viable economies and political bodies. The research demonstrates that the path to voter success of land preservation voter referendums often progresses when a county government exercises self-governing power through a reformed government structure because of its home rule charter ordinance or home rule authority granted by its state legislature or constitution. Without this second order federalism permitting counties to authorize public voting on a land preservation voter referendum, localized public environmental protections at the county level could be neglected.

Outcomes from the research analysis conclude that governance (presence of a home rule charter) and a reformed government structure (appointed county administrator with a board of commissioners) variables are significant factors in government selection and voter passage of county land preservation voter referendums.

Second, results indicate that certain counties are more likely to allocate public dollars to acquire locally-managed conservation, unimproved or recreational land than others. While some of these probabilities seem to be driven by land scarcity or loss of ecosystems concerns, it is also clear that county land preservation is largely the domain of older, richer, more economically- 
secure, more educated, and more environmentally-sensitive communities. Continuation of the trend throughout the United States could lead to an increasingly uneven distribution of pocket-sized lots of county land that are either isolated or extensions of larger conservation or watershed areas.

Third, in matters of land preservation management by county governments, public administrators who are charged with implementing the terms and conditions of voter referendums are knowledgeable and pragmatic about the necessity of developing and maintaining regional partnerships to develop long range goals for inter and intra-county government protected land, wildlife and water areas. State and neighboring counties, regional water management authorities, environmental activist organizations and grassroots groups, as well as other organizations seeking to protect natural environments are major stakeholders.

Competition for vacant land (government and/or private) presents a variety of expectations about the future and a variety of development demands. Often these competitors make decisions on their own to meet individual expectations for the future of vacant land and developer demands. With an efficient and effective network of public and private service managers in place, the probability of experiencing unanticipated activity and expenses (e.g., land maintenance costs) affiliated with land preservation voter referendum might decrease.

Forth, the political climate within the state, county and local areas is an important factor in predicting the success of land preservation voter referendums. Politics is the art or science of influencing people on a civic matter. Although 
politics is thought of in America as the method by which registered voters choose or elect government officials, land preservation voter referendum is a form of direct democracy in which voters make decision concerning public policy. Environmental politics is the study of political theories and ideas as they relate to the environment. It occurs at multiple geopolitical levels, and influences the selection and success of land preservation voter referendums either directly or indirectly. Political influence could guide the referendum's selection and purposes, financial mechanism, ballot language, referendum branding and public education, and election date. In turn, public interest groups will continue to lobby or communicate with governmental policy decision-makers in order to promote themselves and their products, services and long range plans.

Fifth, voter status and ability to cast a vote are significant factors in the success of land preservation voter referendums. In direct democracy, voters choose part of their county's land preservation public policy according to the voter referendum specifications established by the Board of County Commissioners. Without registration though the Supervisor of Elections, a voter is unable to cast a vote. The study demonstrates the significance of the number of state-registered county residents. Unaddressed by this study is an understanding of the willingness of the registered voter to cast that vote on election day. Finally, a sense of the voter's knowledge and understanding of the ballot measure is another limitation of the study in terms of the electorate.

Finally, the topic of America's future is always fashionable. In recovery from an economic recession and budgetary cutbacks, county governments are 
downsizing, prioritizing and streamlining public services. Most land preservation voter referendum regions are significant factors in referendum selection (stage 1), indicating that public land preservation is not geographically isolated. Progressive reformed county governments will find visionary methods to accommodate the service needs of their residents. Perhaps the future success of county land preservation voter referendums is simply being at the "the right place, at the right time".

\subsection{Limitations of the Study}

The research adds to the body of knowledge concerning land preservation voter referendum through the study of the American county or county entity. In addition, it has contributed to a better understanding of the dynamics of the mechanisms of direct democracy by adopting a mixed methods approach that relies on the analysis of values of quantitative and qualitative variables. However, there are several limitations that require mention.

First, there may be omitted variables that might have influenced the outcomes of land preservation voter referendum. One example is the composition of the entire ballot which includes a specific referendum of interest. Was there more than one land preservation referendum on the ballot? Was the voter asked to vote for other public good referendums on the same ballot, such as education or infrastructure improvements? Given that the literature suggests that multiple ballot items that propose funding increases negatively affect voter support, the additional information could add weight to the analysis. 
In addition, voters may not be privy to the details regarding each proposed land preservation voter referendum. In general, the public receives little detailed information about the quality, quantity or cost of land acquisitions or new/renovated park amenities. The study finds that the selection and success of land preservation voter referendums may be affected by its finance mechanism (taxation or bond issue). Knowledge of less discernible cost, structure and administrative burdens could add to the body of knowledge concerning the success or failure of the referendum process.

Second, there may already be significant amounts of publically protected conservation or preservation land within the county or within the region. Solecki, Mason and Martin (2004) found that New Jersey municipalities adjacent to the Pinelands National Reserve and other open space reserves were less likely to support a state-wide open space referendum. The overall public demand for land preservation may be satisfied by the prior efforts of national non-profit groups like The Trust for Public Land or The Nature Conservancy. However, the study found that the South Florida tri-county area of Miami-Dade, Broward and Palm Beach Counties, which incorporates parts of the regional South Florida Everglades system, successfully passed eleven land preservation voter referendums. Nevertheless, an understanding of resident voter perception about adjacent and publically-owned conservation lands would add to the research data.

Third, a benchmark methodology of data collection requires the dividing county land preservation voter referendums two groups in order to avoid confounding the analysis with independent variables that are outdated. This is 
due to the specific limitations of the data dates used by the variety of database resources utilized for this study. Therefore, the years of data collection were standardized to conform, or closely align, with either the U.S. Census Bureau decennial year 1990 for referendum selected during 1988-1999, and year 2000 for referendum selected during 2000-2009.

Forth, although this study examined the public acknowledgement of public interest group activities via newspaper articles, additional evidence concerning the competing interests of development pressures and environmental activism for the preservation of specific plots of land could affect the pattern of government and community support of voter referendums. The data is currently unavailable for analysis and reporting.

Lastly, although a series of interviews and site visits were conducted as part of the study's qualitative case study approach of the mix methods design, accessibility to high-level public officials such as Boards of County Commissioners was difficult to obtain. To the contrary, public administrators and managers proved to be accessible, helpful and transparent.

\subsection{Suggestions for Future Research}

The preservation of land for farmland, wildlife habitat, urban parks, recreational trails, and protecting water supplies and floodplains is emerging as an integral component of smart growth programs. Both the government and nonprofit organizations have been willing to spend billions of dollars on land preservation because of a perception that traditional land use planning and regulation are not successfully accommodating growth or protecting valuable 
natural resources. The literature on smart growth has largely overlooked the potential of land preservation to contain sprawl and to build livable communities. On the other hand, the literature on land preservation has focused on the mechanics of conservation easements and land purchases rather than on how land preservation can fit into the comprehensive planning process to achieve community smart growth goals. More research needs to be done on the strategic use of land preservation in shaping and directing growth as part of a comprehensive planning effort.

The study finds that farmland is a significant factor in the success of land preservation voter referendums. Agricultural land preservation constitutes sensible resource management for sustainable agriculture. It also stands on its own as a local, state, or national policy goal to mitigate land fragmentation and haphazard development. Various tools, resources, and model programs are available to facilitate agricultural land preservation. Each individual and community has unique goals, challenges, and collective knowledge that will determine the appropriate mix of tools to guide its private and public actions in crafting effective local land-use management and policy. Two of the three South Florida case counties maintain significant agricultural lands that provide many types of value to landowners, private citizens, communities, and society at large. Additional research should be directed toward the value of sustainable agricultural lands for county government administrative planning and community services. 
According to a presidential memorandum ${ }^{75}$ for the heads of executive departments and agencies, government should be transparent, participatory and collaborative. The ballot-stated purposes of county land preservation voter referendum can be varied yet generalized. In most cases, a registered voter's understanding of a land preservation voter referendum is the summary language found on the election ballot, public service announcements and other educational efforts of the selecting government. Additional research should be conducted on the details of each voter referendum, including features of its stated purpose(s); ballot language and/or branding; fiscal breakdown of proposed acquisitions, renovations, and cultural or historical preservation; proposed implementation program; annual land maintenance and other costs.

Finally, the research topic of county environmental preservation governance could touch upon variables relative to the interrelated and integrated system of formal and informal networks of public and private stakeholders. Future research is needed to reflect the dynamics of this political regime, changes within each level of government, and the resultant impact on natural resources and the public.

\footnotetext{
${ }^{75}$ http://www.whitehouse.gov/the_press_office/TransparencyandOpenGovernment
} 


\section{LIST OF REFERENCES}

Adams, J.K. (1959) Miami's mighty metro. The Rotarian. 95:4 (April). 16-19. Retrieved on 1/5/2013 at http://books.google.com/books?id=NTcEAAA AMBAJ\&pg=PA13\&lpg=PA13\&dq=The+rotarian+april+1959\&source=bl\&ots=nrL C2Ih6AX\&sig=IN9-b-VIbYXZVZsUmxaLDSovUYo\&hl=en\&sa=X\&ei=JUsJU cq5MNHpqAHm2YCgBQ\&ved=0CC0Q6AEwAA\#v=onepage\&q=The $\% 20$ rotarian\%20april\%201959\&f=false.

Advisory Commission on Intergovernmental Relations (ACIR). (1993) Local Government Autonomy: Needs for State Constitutional, Statutory and Judicial Clarification (A-127). Washington, D.C.: Government States Printing Office.

Agranoff, R. (2006) Inside collaborative networks: ten lessons for public managers. Public Administration Review. Supplement to 66. p. 56-65.

Agranoff, R., McGuire, M. (2003) Collaborative Public Management: New Strategies for Local Governments. Georgetown University Press:Washington, DC.

Alchian, A.A. and Demsetz, H. (1973) Production, information costs, and economic organization. The American Economic Review. 62 (5): 777-795.

Alinsky, S.D. (1989) Rules for Radicals: A Pragmatic Primer for Realistic Radicals. New York, NY: Vintage.

Alonso, J. and Heinen, J.T. (2011) Miami dade county's environmentally endangered lands program: local efforts for a global cause. Natural Areas Journal 31:2. 183-189.

Almond, G.A. and Verha, S. (1963) The Civic Culture: Political Attitudes and Democracy in Five Nations: An Analytical Study. Boston, MA: Little, Brown.

Amirkhanyan, A.A. (2009) Collaborative performance measurement: examining and explaining the prevalence of collaboration in state and local government contracts. Journal of Public Administration Research and Theory. 19 (3): 523-55).

Ansell, C., Gash, A. (2008) Collaborative governance in theory and practice. Journal of Public Administration Research and Theory. 18 (4): 543-571.

Argranoff, R., Mcguire, M. (2001) Big questions in public network management research. Journal of Public Administration Research and Theory. 11(3): 295-326.

Argranoff, R., Radin, B.A. (1991) The comparative case study approach in public administration. J.L. Perry (Ed.) Research in Public Administration. 1: 203-231. Greenwich, CT:JAl. 
Aristotle (350BC) Politics. Translated by Benjamin Jowett. Retrieved 06/02/2011 on http://classics.mit.edu/Aristotle/politics.html.

Baldassare, M. (2001) PPIC statewide survey: special survey on growth. Public Policy Institute of California. Retrieved January 11, 2005, from www.ppic.org/content/pubs/S_501MBS.pdf.

Banducci, S. A. (1998) Attitude consistency on ballot propositions. Citizens as Legislators: Direct Democracy in the American States. Shaun Bowler, Todd Donovan, and Caroline Tolbert (Eds.). Ohio State University Press.

Banzhaf, H.S., Oates, W.E., Sanchirico, J.N. (2008) The conservation movement: success through the selection and design of local referenda. In Social Science Research Network Working Paper Series. April 2008. Retrieved September 21, 2008 from http://papers.ssrn.com/abstract=1247903.

Banzhaf, H. S., Oates, W.E., Sanchirico, J.N. (2010) Success and design of local referenda for land conservation. Journal of Policy Analysis \& Management 29(4): 769.

Barber, B. (1984) Strong democracy: participatory politics for a new age. Berkeley, CA: University of California Press.

Bardach, E. (1998) Getting Agencies to Work Together: The Practice and Theory of Managerial Craftsmanship. Washington, DC: Brookings Institution.

Bardach, E. (2001) Developmental dynamics: interagency collaboration as an emergent phenonmenon. Journal of Public Administration Research and Theory. 11(2): 149.

Bartlett, R.V., Baber, W.F. (2005) Ethics and environmental policy in democratic governance: John Rawls, public reason, and normative precommitment. Public Integrity. 7(3): 219.

Barner, C. and Rosenwein, R.E. (1985) Psychological Perspectives on Politics. Englewood Cliffs, NJ: Prentice-Hall.

Baumgartner, F.R. and Jones, B. (1993) Agendas and Instability in American Politics. Chicago, IL: University of Chicago Press.

Becker, G.S. (1983) A theory of competition among pressure groups for political influence. Quarterly Journal of Economics. 98: 371-400.

Bellah, R. N. (1995) Community Properly Understood: A Defense of "Democratic" Communitarianism. Retrieved 6/2/2011 on http://hdl.handle.net/1961/584 
Benbasat I., Goldstein D.K., and Mead M. (1987) The case research strategy in studies of information systems. MIS Quarterly.11(3): 369-386

Benton, J. E. (1996) Fiscal aid and mandates: the county experience. In Donald C. Menzel (Ed.) The American County: Frontiers in Knowledge. University, AL: University of Alabama Press.

Benton, J. E. (2002a). Counties as Service Delivery Agents: Changing Expectations and Roles. New York: Praeger.

Benton, J. E. (2002b). County government service delivery: does government structure matter? Public Administration Review, 62 (4): 471-479.

Benton, J. E. (2003a). County government. In Jack Rabin (Ed.) Encyclopedia of Public Administration and Public Policy. New York: Marcel Dekker.

Benton, J. E. (2003b). County government structure and county revenue policy: what's the connection? State and Local Government Review, 35 (Spring): 78-89.

Benton, J. E. ( 2003c) The impact of structural reform on county government service provision. Social Science Quarterly. 84 (4): 858-874.

Benton, J. Edwin (2005). An assessment of research on American Counties. Public Administration Review. 65 (4).

Benton, J.E., Byers, J., Cigler, B.A., Klase, K.A., Menzel, D.C., Salant, T.J., Streib, G., Svara, J.H., Waugh, W.L.Jr. (2007) Conducting research on counties in the 21st century: a new agenda and database considerations. Public Administration Review, 67 (6): 968-983.

Berger B. (2001). Private issues and public policy: locating the corporate agenda in agenda-setting theory. Journal of Public Relations Research. 13(2): 91-126.

Berkowitz, D. (1992) Who sets the media agenda? The ability of policymakers to determine news decisions. In Kennamer, J.D. Public opinion, the Press, and Public Policy 2: 81-102. Westport, CT: Praeger.

Berner, M.M, Amos, J.M., Morse, R.S. (2011) What constitutes effective citizen participation in local government? Views from city stakeholders .Public Administration Quarterly. 35 (1): 128.

Berry, J.M. (1989). The advocacy explosion. In Theodoulou, S. \& Cahn, M (Eds.) Public Policy: The Essential Readings. New Jersey: Prentice Hall. 
Besley, T. and Coate, S. (2001) Issue unbundling via citizen's initiatives. Paper prepared for presentation at the annual meeting of the Public Choice Society, San Antonio. March 9-12, 2001.

Bhattacherjee, A. and Premkumar, G. (2004) Understanding changes in belief and attitude toward information technology usage: a theoretical model and longitudinal test. MIS Quarterly. 28:2. 229-254.

Bingham, L., Nabatchi, T. and O'Leary, R. (2005) The new governance: practices and processes for stakeholders and citizen participation in the work of government. Public Administration Review. 36:140.

Black, H.C. (1990) Black's Law Dictionary. St. Paul, MN: West Publishing.

Bluestein, F.S. (2006) Do North Carolina local governments need home rule? North Carolina Law Review. 90: 1-115.

Bogner, A., Littig, B. and Menz, W. (2009) Expert Interviews: An Introduction to a New Methodological Debate. New York, NY: Palgrave Macmillian.

Bowler, S. and Donovan, T. (2002) Democracy, institutions and attitudes about citizen influence on government. British Journal of Political Science 32: 371-90.

Bowler, S., Nicholson, S.P. and Sequra, G.M. (2006) Earthquakes and aftershocks: race, direct democracy, and partisan change. American Journal of Political Science. 50: 146-159.

Bowman, A.O'M. and Kearney, R.C. (2012) Are U.S. cities losing power and authority? Perceptions of local government actors. Urban Affairs Review. 48: 528-546.

Box, R.C. (1998) Citizen Governance Leading American Communities into the 21st Century. Thousand Oaks, CA: Sage.

Box, R.C. (1999) Running governments like a business: implications for public administration theory and practice. American Review of Public Administration. 29(1): 19-43.

Boyle, J. (1912) The Initiative and Referendum: Its Folly, Fallacies, and Failure. Columbus, OH: A.H. Smythe.

Boyne, G.A., Farrell, C., Law, J., Powell, M., Walker, R.M. (2003) Evaluating Public Management Reforms: Principles and Practices. Buckingham, UK: Open University Press. 
Boyne, G.A., Powell, M. Ashworth, R. (2001) Spatial equity and public services: an empirical analysis of local government finance in England. Public Management Review. 3(1): 19-34.

Brewer, R. (2003). Conservancy: The Land Trust Movement in America. Hanover, NH: University Press of New England.

Brewer, J., and Hunter, A. (1989). Multimethod Research: A Synthesis of Styles. Newbury Park, CA: Sage.

Brierly, A.B. and Moon, D. (1991) Electoral coalitions and institutional stability: the case of metropolitan reform in Dade County, Florida. Journal of Politics. 53:3. 701-719.

Briffault, R. (2000). Symposium on regionalism: Localism and regionalism. Buffalo Law Review 48: 1.

Bryman, A. (2006). Integrating quantitative and qualitative research: How is it done? Qualitative Research. 6: 97-113.

Bryson, J.M., Crosby, B.C., Stone, M.M. (2006) The design and implementation of cross-sector collaborations: propositions from the literature. Public Administration Review. Supplement to 66: 44-55.

Buchanan, J.M. and Tullock, G.(1962) The Calculus of Consent: Logical Foundations of Constitutional Democracy. Ann Arbor, MI: University of Michigan Press.

Budge, I. (1996) The New Challenge of Direct Democracy. Cambridge: Cambridge University Press.

Burchell, R. W., Listokin, D. (1995) Land, Infrastructure, Housing costs, and Fiscal Impacts Associated with Growth: The Literature on the Impacts of Traditional versus Managed Growth. Lincoln Institute for Land Policy Research Papers, Cambridge, MA.

Burns, N. and Grove, S.K. (2001) The Practice of Nursing Research: Conduct, Critique and Utilization. $4^{\text {th }}$ Edition. Philadelphia, PA: Saunders Company.

Butler, D. and Ranney, A. (1994) Referendums Around the World: The Growing Use of Direct Democracy. Washington, DC: AEI Press.

Caracelli, V.J. and Green, J.C. (1993) Crafting mixed-method evaluation design. In: J.C. Green and V.J. Caracelli (Eds.) Advances in Mixed-Method Evaluation: The Challenges and Benefits of Integrating Diverse Paradigms. San Francisco, CA: Jossey-Bass. 
Cerami, J.R. (2003) Review Essay: Rohr, Frederickson and Wolin on The "Big Questions" and the Future of Public Administration. Retrieved on 2/9/2003 from httpL//wwwlpamij.com/ 99_4_4_Ceramihtml.

Cerami, J. R. (2003) The future of freedom: illiberal democracy at home and abroad. Parameters 33(4).

Chi, M. T. H.. Feltovich, P. and Glaser, R. (1981) Categorization and representation of physics problems by experts and novices. Cognitive Science. 5. 121-152.

Christ, T.W. (2007) A recursive approach to mixed methods research in a longitudinal study of postsecondary education disability support services. Journal of Mixed Methods Research. 1(3): 226-241.

Citrin, J. (1996) Who's the boss? Direct democracy and popular control of government. In Craig, S. (Ed.) Broken Contract? Changing Relationships between Americans and their Government. Boulder, CO: Westview Press.

Clark, G. L. (1984). A theory of local autonomy. Annals of the Association of American Geographers. 74: 195-208.

Clark, R.L. (2011) Looking for the Light at the End of the Tunnel: a National Survey of County Elected Officials on the Economy, Budgets and Politics. A Publication of the Carl Vinson Institute of Government. The University of Georgia. July 2011.

Clark, S.J. (1998) A populist critique of direct democracy. Harvard Literature Review. 434: 435-37, 478-79.

Clary, D.A. (1986) Timber and the Forest Service. Lawrence, KS: The University Press of Kansas.

Clausen, C. (2009) John stuart mill's very simple principle.Wilson Quarterly, 33(2). p. 40-6.

Clingan, C. and Rodbell, P. (2011) Building Resilent Communities: Green Infrastructure for Counties. A Publication of the National Association of County's Green Infrastructure Project. Washington, D.C.

Colby, S.M. and Murrell, W. (1998). Child welfare and substance abuse services: from barriers to collaboration. In Hampton, R.L., Senatore, V. and Gullotta, T.P. (Eds); Substance Abuse, Family Violence, and Child Abuse: Bridging Perspectives; Thousand Oaks, CA:Sage Publications. 
Conlan, T. (1998) From New Federalism to Devolution: Twenty Five Years of Intergovernmental Reform. Washington, D.C.: Brookings Institution Press.

Converse, P.E. (1975) Voting systems and the representation of public opinion. In: Handbook of Political Science. Greenstein, F.I. and Polsby, N.W. (Eds.).

Cooper, T.L., Bryer, T.A, Meek, J.W. (2006) Citizen-centered collaborative public management. Public Administration Review. Supplement to 66: 76-88.

Cox, G. and Munger, M.C. (1989) Closeness, expenditures and turnout in the 1982 U.S. House elections. American Political Science Review. 83: 217-231.

Craig, S., Kreppel, A., and Kane, J. (2001) Public opinion and direct democracy: a case study. In Mendelsohn, M. and Parkson, A. (Eds) Referendum Democracy: Citizens, Elites and Deliberation in Referendum Campaigns. New York: Palgrave.

Creswell, J.W. (1994) Research Design: Qualitative and Quantitative Approaches. Thousand Oaks, CA: Sage Publications.

Creswell, J. W. (1998). Qualitative Inquiry and Research Design: Choosing Among Five Designs. Thousand Oaks, CA: Sage Publications.

Creswell, J. W. (2002). Educational Research: Planning, Conducting, and Evaluating Quantitative and Qualitative Approaches to Research. Upper Saddle River, NJ: Merrill/Pearson Education.

Creswell, J. W. (2003). Research Design: Quantitative, Qualitative, and Mixed Methods Approaches (2nd ed.). Thousand Oaks, CA: Sage.

Creswell, J.W. and Clark, V.L.P. (2011) Designing and Conducting Mixed Methods Research, 2nd Edition. Thousand Oaks, CA: Sage Publications, Inc.

Creswell, J. W., Plano Clark, V. L., Gutmann, M. L., \& Hanson, W. E. (2003) Advanced mixed methods research designs. In A. Tashakkori and C. Teddlie (Eds.), Handbook of Mixed Methods in Social and Behavioral Research. Thousand Oaks, CA: Sage.

Cronin, T. E. (1989) Direct Democracy: The Politics of Initiative, Referendum and Recall. Cambridge, MA: Harvard University Press.

Crossett, K.N., Culliton, t.J., Wiley, P.C., and Goodspeed, T.R. (2004) Population trends along the coastal United States, 1980-2008. NOAA National Ocean Service Special Projects Office, Silver Spring, MD.

Dahl, R.A. (1963) Who Governs? Democracy and Power in an American City. New Haven, CN: Yale University Press. 
Dahl, R.A. (1989) Democracy and Its Critics. New Haven, CT: Yale University Press.

Darke, P., Shankes, G. and Broadbent, M. (1998) Successfully completing case study research: combining rigor, relevance and pragmatism. Info Systems Journal. 8: 273-289.

Davis, D. (1997) Shaping the tools of re-invention: good citizens, better communities. Adapted from Participation Tools for Better Land-Use Planning (2nd ed.). In Local Government Commission. Retrieved on January 11, 2005, from www.lgc.org/freepub/ land_use/articles/ reinvention.html.

Dearing, J. and Rogers, E. (1988) Agenda-setting research: whater has it been, where is it going? Communication Yearbook. 11: 555-594.

De Tocqueville, A. (1835-40) Democracy in America and Two Essays on America. Isaac Krammick (Ed.) Gerald Bevan, Translator. (2003) New York: Penguin Books Ltd.

Deacon, R.T., Shapiro, P. (1975) Private preference for collective goods revealed through voting on referenda. American Economic Review. 65(5): 943-55.

Degner, R.L., Stevens T.J., and Morgan K.L. (2003) Miami-Dade county agricultural land retention study, appendix A. Florida Agricultural Market Research Center, Institute of Food and Agricultural Sciences. Gainsville, Florida.

DeGrove, J.M. (1976) Analysis of home rule and intergovernmental relations: the case of florida. In Partnership with the States: Local Self-Government in the Federal System. (S. Cole ed.).

DeGrove, J.M. (1979) The political dynamics of the land and growth management movement. Land and Contemporary Problems. 43(2): 111-143.

DeGrove, J. M. (1989) Growth management and governance. In D.Brown et al., Understanding Growth Management. Washington, DC: Urban Land Institute.

DeGrove, J.M. (1994) State and regional planning and regulatory activity: The florida experience and lessons for other jurisdictions. C930 American Law Institute-American Bar Association. 397: 426 (1994).

DeGrove, J. M. and Lawrence, C. (1977) County government service delivery. In Decade for Decision: 1976-1986. Ganschinietz, L. (Ed.) Washington, D.C.: National Association of Counties. 
DeGrove, J. M. and Turner, R. (1991) Local government in Florida: coping with massive and sustained growth. Government and Politics in Florida, R. J. Huckshorn, ed. Gainesville: Univ. of Florida Press. 226-265.

Dell, K.D. (2009) The grassroots are greener: Democratic participation and environmental policies in state politics. Review of Policy Research. 26 (6): 699727.

Delli Carpini, M.X. and Keeter, S. (1996) What Americans Know About Politics and Why It Matters. New Haven, CT: Yale University Press.

Denzin, N. and Lincoln, Y. (1994). Handbook of Qualitative Research. Thousand Oaks, CA: Sage.

DeSantis, V. (1989) County government: a century of change. In: The Municipal Year Book. Washington, D.C.: International City/County Management Association.

DeSantis, V. and Renner, T. (1993) Contemporary patterns and trends in municipal government structures. In: The Municipal Yearbook. Washington, DC: International City/County Management Association.

DeSantis, V. and Renner, T. (1994) The impact of political structures on public policies in American counties. Public Administration Review. 54 (3): 291-295.

Diamond, M. (1959) Democracy and 'The Federalis't, a reconsideration of the framers' intent. American Political Science Review. 53 (1): 52.

Donovan, T., Tolbert, C.J., and Smith, D.A. (2008) Priming presidential voters by direct democracy. Journal of Politics. 70: 1217-1231.

Downs, A. (1957) An Economic Theory of Democracy. New York: Harper and Row.

Downs, A. (1972) Up and down with ecology - the issue attention cycle. Journal of Public Interest Law. 28: 38-50.

Driscoll, D.L., Appiah-Yeboah, A., Salib, P., Rupert, D.J. (2007) Merging qualitative and quantitative data in mixed methods research: how to and why not. Ecological and Environmental Anthropology 3(1): 2007.

Duncombe, H.S. (1977) Modern County Government. Washington, D.C.: National Association of Counties. 
Dunlap, R.E., Van Liere, K.D., Mertig, A.G., and Jones, R.E. (2000) Measuring endorsement of the new ecological paradigm: A revised NEP scale. Journal of Social Issues. 56: 425-442.

Earl, J., Martin, A., McCarthy, J.D., and Soule, S.A. (2004) The use of newspaper data in the study of collective action. American Review of Sociology. 30: 65-80.

Eckstein, H. (1975) Case studies and theory in political science. In Handbook of Political Science. Vol. 7 of Political Science: Scope and Theory, ed. Fred I. Greenstein and Nelson W. Polsby, 79-138. Reading, MA: Addison-Wesley.

Eggers, W. and O'Leary, J. (1995) Revolution at the Roots: Making our Government Smaller, Better and Closer to Home. New York: Free Press.

Eisenhardt, K. (1989), Building theories from case study research. The Academy of Management Review, 14(4): 532-550.

Elazar, D.J. (2006) Federalism. In Federalism in America: An Encyclopedia, Vol.1. Joseph R. Marbvach, Ellis Katz and Troy E. Smith, Eds. Westport, CT: Greenwood.

Elliot, E., Seldon, B.J. and Regens, J.L. (1997) Political and economic determinants of individual's support for environmental spending. Journal of Environmental Management. 51: 15-27.

Ely, R. J. (1994). The effects of organizational demographics and social identity on relationships among professional women. Administrative Science Quarterly. 39: 203-238.

Erbring, L., Goldenberg, E.N., and Miller, A.H. (1980) Front-page news and realworld cues: a new look at agenda-setting by the media. American Journal of Political Science. 24: 16-49.

Eskridge, W.N.Jr., Frickey, P.P. and Garrett, E. (2006) Legislation and Statutory Interpretation, $2^{\text {nd }}$ Edition. Minneapolis, MN: West Publishing.

Ewing, R., Kostyack, J., Chen, D., Stein, B. and Ernst, M. (2005) Endangered by sprawl: how runaway development threatens America's wildlife. Washington, D.C.: National Wildlife Federation, Smart Growth, America, and NatureServe.

Fair, R.C. and Shiller, R.J. (1987) Econometric modeling as information aggregation. Cowles Foundation Discussion Papers 833R, Cowles Foundation, Yale University, revised Jan 1988. 
Fausold, G.J. and Lilieholm, R.J. (1996) The economic value of open space. Lincoln Institute of Land Policy Land Lines. 8 (5).

Flick, U. (2006). An Introduction to Qualitative Research. London: Sage Publishing.

Fiorino, D.J. (1990) Citizen participation and environmental risk; $A$ survey of institutional mechanisms. Science, Technology and Human Values. 15: 226-243.

Fischel, W. A. (1979) Determinants of voting on environmental quality: a study of a New Hampshire pulp mill referendum. Journal of Environmental Economics and Management, 6(2):107-118.

Fiset, T. (1998) Home rule: charter and non-charter. Stetson Law Review. 27 (3): 1051-1052.

Flick, U. (1998) An Introductopm to Qualitative Research. Thousand Oaks, CA:Sage Publications.

. Florida Local Government Formation Manual 2011-2012. (2012) House of Representatives.Economic Affairs Committee. Community and Military Affairs Subcommittee, Representative Workman, Subcommittee Chair.

Tallahassee, FL. Retrieved 1/22/2012 at http://www.myfloridahouse.gov.

Francis, R.M. (1999) Predictions, patterns, and policymaking: a regional study of devolution. In: Schram, S.F. and Beer, S.H. (Eds.) Welfare Reform: A Race to the Bottom. Washington, D.C.: Woodrow Wilson Center Press.

Franzosi R. 1987. The press as a source of socio-historical data. Historical. Methods. 20: 5-16

Frederickson, H.G. (1980) New Public Administration. University, AL: University of Alabama Press.

Frederickson, H.G. (1982) The recovery of civism in public administration. Public Administration Review. 42(6): 501.

Frederickson, H.G. (1997) The Spirit of Public Administration. San Francisco, CA: Jossey-Bass.

Frederickson, H.G. and Smith, K.B. (2003) The Public Administration Theory Primer. Boulder, CA: Westview Press.

Freilich, R.H., Smith, T., Paster, E. and Freilich, Leitner \& Carlise. (2003) Agriculture and Rural Area Study: Analysis of Agricultural Land Retention 
Strategies. Task 2.B. Retrieved on 10/20/2012 at

http://www.miamidade.gov/business/library/reports/land-retention-strategies.pdf

Freilich, R.H. and Davis,L.K. (1981) Saving the Land: The Utilization of Modern Techniques of Growth Management to Preserve Rural and Agricultural America, 13 URB. LAW. 27, 29.

Frumkin, H. (2001) Beyond toxicity human health and the natural environment. American Journal of Preventative Medicine. 20: 234-240.

Fung, A. and Wright, E.O. (2001) Deepening democracy: innovations in empowered participatory governance. Politics and Society. 29(1): 5-41.

Fung, A. and Wright, E.O. (2003) Deepening Democracy: Institutional Innovations in Empowered Participatory Governance. London, UK: London Verso.

Garman, C., Haggard, S., and Willis, E. (2001) Fiscal decentralization: a political theory with Latin American cases. World Politics. 53 (1): 205-236.

Garson, G.D. (1978) Group Theories of Politics. California: Sage Publications, Inc.

Garvey, G. (1997) Public Administration: The Profession and the Practice. New York: St. Martin's Press.

Gazey, P.J. (1971) Direct democracy—a study of the american referendum. Parliamentary Affairs 24 (Spring): 123-39.

Geon, G., and Turnbull, G. K. (2006). Local Government Internal Structure, External Constraints, and the Median Voter. Public Choice. 129: 487-506.

George, A. and Bennett, A. (2005), Case Studies and Theory Development in the Social Sciences. Cambridge: MIT Press.

Gerber, E.R. (1996) Legislative response to the threat of popular initiatives. American Journal of Political Science. 40 (1): 99-128.

Gerber, E.R. (1999) The Populist Paradox: Interest Group Influence and the Promise of Direct Legislation. Princeton, NJ: Princeton University Press.

Gerber, E.R. and Phillips, J.H. (2004) Direct democracy and land use policy: exchanging public goods for development rights. Urban Studies. 41 (2): 463479. 
Gere, E.A. (1982) Dillon's rule and the Cooley doctrine: reflections of the political culture. Journal of Urban History. 8 (3): 271-298.

Gerri, L.R. (2001) New public management and the reform of international organizations. International Review of Administrative Sciences. 67(3). p. 445460.

Gerring, J. (2004), What is a case study and what is it good for? American Political Science Review, 98 (2): 341-354.

Gerston, L.N. and Haas, P.J. (1993) Political support for regional government in the 1990s: growing in the suburbs? Urban Affairs Review. 29 (1): 154-163.

Gibson, D. (2003) Environmentalism: Ideology and Power. Hauppaguge, NY: Nova Science Publishers, Inc.

Gioia and Pitre (1990). Multiparadigm perspectives on theory building. Academy of Management Reveiw, 15 (4): 584-602.

Glaser, B.G., Strauss, A.L. (1967) The Discovery of Grounded Theory: Strategies for Qualitative Research. New York: Aldine.

Glickfeld, M., Jacques, S., Kieser, W., and Olson, T. (1995) Implementation techniques and strategies for conservation plans. Reprinted from Land Use and Environmental Forum 4:1. In Economic and Planning Systems. Retrieved January 11, 2005, from www.epsys.com/ resources.html.

Goldberg, D., McCann, B., and Bailey, J. (2002) Measuring sprawl and its impact: the character and consequences of metropolitan expansion. In Smart Growth America. Retrieved January 11, 2005, from www.smartgrowthamerica.com/ sprawlindex/ MeasuringSprawl.pdf.

Goldblatt, D. (1996) Social Theory and the Environment. Cambridge, UK: Polity Press.

Goldsmith, S., Eggers, W.D. (2004) Governing by Network. Washington, D.C.:Brookings Institute.

Goerdel, H.T. (2006) Taking initiative: proactive management and organizational performance in networked environments. Journal of Public Administration Research and Theory. 16(3): 351-368.

Goodwin, B. (1992) Using Political Ideas, 3rd ed. Chichester, UK: John Wiley \& Sons. 
Gore, A. (2006) An Inconvenient Truth: The Planetary Emergency of Global Warming and What We Can Do about It. New York: Rodale.

Gray, B. (1989) Collaborating: Finding Common Ground for Multi-Party Problems. Jossey Bass.

Greene, W.H. (2003) Econometric Analysis. 5th ed. Upper Saddle River, NJ: Prentice Hall.

Greene, J. C., Caracelli, V. J., and Graham, W. F. (1989). Toward a conceptual framework for mixed-method evaluation designs. Educational Evaluation and Policy Analysis. 11: 255-274.

Greene, J. C., and Caracelli, V. J. (Eds.). (1997). Advances in Mixed-Method Evaluation: The Challenges and Benefits of Integrating Diverse Paradigms New Directions for Evaluation, No. 74. San Francisco, CA: Jossey-Bass.

Greene, J. C., and Caracelli, V. J. (2003). Making paradigmatic sense of mixed methods practice. In A. Tashakkori \& C. Teddlie (Eds.), Handbook of Mixed Methods in Social and Behavioral Research. Thousand Oaks, CA: Sage.

Guba, E. G., and Lincoln, Y. S. (1981) Effective Evaluation: Improving the Usefulness of Evaluation Results through Responsive and Naturalistic Approaches. San Francisco,CA: Jossey-Bass.

Guba, E. G. and Lincoln, Y. S. (1989). Fourth Generation Evaluation. Newbury Park, CA: Sage Publications.

Gupta, P. (1994) Coordination and control in government agency: contingency and institutional perspectives on GAO audits - General Accounting Office. Administrative Science Quarterly. June 1994. Retrieved September 27, 2008 from hhtp://findarticles.com/p/articles/mi_m4035/is_n2_v39/ai_16063199.

Guyton, E.M. (1988) Critical thinking and political participation development and assessment of a causal model. Theory and Research in Social Education. 16: 23.

Haass, R.N. (1999) The Bureaucratic Entrepreneur: How to be Effective in any Unruly Organization. Washington, D.C.: Brookings Institute.

Hackney, R. A., Jones, S., and Losch, A. (2007) Towards an e-government efficiency agenda: the impact of information and communication behaviour on ereverse auctions in public sector procurement. European Journal Information Systems.16:2. 178-191. 
Hagen, M. and Lascher, E. (1998) Public opinion about direct democracy. Paper presented at the Annual Meeting of the American Political Science Association. Boston, MA.

Hajnal, Z.L. and Lewis, P.G. (2003) Municipal institutions and voter turnout in local elections. Urban Affairs Review. 38: 645-668.

Hall, T.E. and O'Toole, L.J. (2004) Shaping formal networks through the regulatory process. Administration and Society. 36(2). p. 186-207.

Hall, T.E., O'Toole, L.J. (2000) Structures for policy implementation: an analysis of national legislation, 1965-1966 and 1993-1994. Administration and Society. 31: 667-686.

Hamilton, A., Madison, J. and Jay, J. (1961) The Federalist. Jacob E. Cook, Ed. Hanover, NH: University Press of New England (Wesleyan University Press.

Hayes, S. (1993) Three decades of environmental politics. In M. J. Lacey (Ed.) Government and Environmental Politics: Essays on Historical Developments since World War Two. Cambridge, UK: Woodrow Wilson Center Press.

Healey, P. (1997). Collaborative planning: Shaping Places in Fragmented Societies. London, UK, MacMillan.

Heckman, J.J. (1979) Sample selection bias as a specification error. Econometrica. 47(1): 153-161.

Hedge, D.M. and Scicchitano, M.J. (1992) Devolving regulatory authority: the federal and state response. Policy Studies Review. 11: 81-90.

Heimlich, R.E. and Anderson, W.D. (2001) Development at the urban fringe and beyond: impacts on agriculture and rural land. ERS Agricultural Impact Economic Report No. 803. Washington, D.C.:U.S. Department of Agriculture.

Held, David. (1987) Models of Democracy. Cambridge, MA: Polity Press.

Held, David (1997) Democracy and globalization. Global Governance, 3(3): 1-28.

Held, David (1996) Rethinking democracy: the cosmopolitan mode. Politics Review, 5(3): 7-11.

Herriott, R.E. and Firestone, W. A. (1983) Multisite qualitative policy research: optimizing description and generalizability. Educational Researcher. 12: 14-19. 
Hill, C.J. and Lynn, L.E.Jr. (2005) Is hierarchical government in decline? evidence from empirical research. Journal of Public Administration Research and Theory. 15(2): 173-195.

Hill, D. and McKee, S. (2006) The electoral college, mobilization, and turnout in the 2000 presidential election. American Politics Research. 33 (5): 700-725.

Hobbs, F. and Stoops, N. (2002) Democratic trends in the 20th century. U.S Census Bureau, Census 2000 Special Reports, Series CENSR-4, U.S. Government Printing Office, Washington, D.C.

Hojnacki, M., Kimball, D.C., Baumgartner, F.R., Berry, J.M., and Leech, B.L. (2012) Studying organizational advocacy and influence: reexamining interest group research. Annual Review of Political Science. 15 (9): 1-21.

Holbrook, T. and McClurg, S. (2005) The mobilization of core supporters: campaigns, turnout, and electoral composition in the United States presidential elections. American Journal of Political Science. 49: 689-703.

Holcombe, R. G. (1990) Distributional aspects of Florida's concurrency requirements. Florida Policy Review. 5. 8-14.

Holcombe, R.G. (1990) Growth management in Florida: lessons for the national economy. Cato Journal. 10:1. 109-125.

Hood, C. (2002) Control, bargains and cheating: the politics of public service reform. Journal of Public Administration Research and Theory. 12(3): 309-32.

Hooper, K. and Cook, E. (2004) Conservation Finance Handbook: How Communities are Paying for Parks and Land Conservation. San Francisco, CA: The Trust for Public Lands.

Hotelling, H. (1929) Stability in competition."Economic Journal. 39: 41-57.

Huckshorn, R.J. ed. (1991) Political parties and campaign finance. Government and Politics in Florida. Gainsville, FL: University Presses of Florida.

Hug, S. (2004) Occurrence and policy consequences of referendums: a theoretical model and empirical evidence. Journal of Theoretical Politics.16 (3): 321-356.

Hug, S. (2011) Policy consequences of direct legislation theory, empirical models and evidence. Qualitative and Quantitative. 45: 559-578.

Hug, S. and Sciarini P. (2000) Referendums on European integration: do institutions matter in the voter's decision? Comparative Political Studies 33:3-36. 
Hug, S. and Tsebelis, G. (2002) Veto players and referendums around the world. Journal of Theoretical Politics. 14 (4): 465-515.

Hunter, Floyd (1953) Community Power Structure. Chapel Hill, NC: University of North Carolina Press.

Imperial, M.T. (2005) Using collaboration as a governance strategy. Administration and Society. 37(3): 281-320.

Imperial, M.T., Hennessey, T. (2000) Environmental Governance in Watersheds: The Importance of Collaboration to Institutional Performance. National Academy of Public Administration:Washington, D.C.

Ingerson, A. (Ed.) (1995) Managing land as ecosystem and economy. Lincoln Institute of Land Policy. Retrieved January 11, 2005, from www.lincolninst.edu/pubs/pub-detail.asp?id=866.

Innes, J. and Booher, D. (1999) Consensus building and complex adaptive systems - a framework for evaluating collaborative planning. American Planning Association Journal. 65(4): 412-423.

Ivankova, N.V., Creswell, J.W., and Stick, S. (2006) Using mixed methods sequential explanatory design: From theory to practice. Field Methods. 18 (1): 3.

Jeffery, B.R., Salant, T.J., and Boroshok, A.L. (1989) County Government Structure: A State by State Report. A publication of the The National Association of County. Washington, D.C. July 1989.

Jick, T. D. (1979). Mixing qualitative and quantitative methods: triangulation in action. Administrative Science Quarterly. 24: 602-11.

Johnson, B., \& Gray, R. (2010). A history of philosophical and theoretical issues for mixed methods research. In A. Tashakkori \& C. Teddlie (Eds.), Sage Handbook of Mixed Methods in Social and Behavioral Research (2nd ed.). Thousand Oaks, CA: Sage.

Johnson, R.B. and Onwuegbuzie, A.J. (2004) Mixed methods research: a research paradigm whose time has come.American Educational Research Association. 33(7): 14-26.

Jones, R.E. and Dunlap, R.E. (1992) The social bases of environmental concern: have they changed over time? Rural Sociology. 57: 28-47. 
Kahn, M. E. and Matsusaka, J.G. (1997) Demand for environmental goods: evidence from voting patterns on California initiatives. Journal of Law and Economics, 40(1): 137-73.

Key, V.O. Jr. and Crouch, W.W. (1939) The Initiative and the Referendum in California. Berkeley, CA: University of California Press.

Krane, D., Rigos, P. N., and Hill, M. B., Jr. (2001). Home Rule in America: A Fifty-State Handbook. Washington, DC: CQ Press.

Kaufmann, D., Kraay, A. and Mastruzzi, M. (2005) Governance matters IV: governance indicators 1996-2004. The World Bank Group Working Papers. Retrieved November 7, 2005 from http://www.worldbank.org/wbi/governance/pubs/govmatters4.html.

Kelleher, C.A. and Yackee, S.W. (2004) An empirical assessment of devolution's policy impact. The Policy Study Journal. 32 (2): 253-270.

Kelly, M.C.H. and Zieper, M. (2001) Strategies for Passing a Bond Referendum. Government Finance Review.June 1, 2001: 27-29. Retrived online 11/17/12 from http://www.thefreelibrary.com/ Strategies+for+ Passing+a+Bond+Referendum.a076941399.

Kemp, R. (2008) County government: past, present, and future.In Public Management 90 (6): 5-8.

Kenyon, D.A. and Kincaid, J. Eds. (1991) Competition among States and Local Governments: Efficiency and Equity in American Federalism. Washington, D.C.: Urban Institute Press.

Kettl, D.F. (2000) The Global Public Management Revolution: A Report on the Transformation of Governance. Washington, DC: Brookings Institute.

Kettl, D.F. (2002) The Transformation of Governance: Public Administration for the Twenty-First Century. Baltimore, MD: John Hopkins University Press.

Kettl, D. F. (2005) The Global Public Management Revolution: A Report on the Transformation of Governance. Washington, DC: Brookings Institution.

Kincaid, J. (1998) The devolution tortoise and the centralization hare. New England Economic Review. May/June: 13-40.

Kincaid, J. (2001) Devolution in the United States: rhetoric and reality. In: Nicolaidis, K. and Howse, R. (Eds.) The Federal Vision. Oxford: Oxford University Press. 
King, C.M., Feltey, K.M., and Susel, B. (1998) The question of participation toward authentic public participation in public administration. In Public Administration Review 58(4). p. 317.

King, J.D. (2000) Changes in professionalism in U.S. state legislatures. Legislative Studies Quarterly 25(2): 327-43.

Kingdon, J.W. (1995) Agendas, Alternative, and Public Policies ( ${ }^{\text {nd }}$ Edition). New York, NY: Harper Collins College

Kirlin, J.J. (1996) The big questions of public administration in a democracy. Public Administration Review 56(5): 416-23.

Kline, J.D. (2006) Public demand for preserving local open space. Society and Natural Resources. 19: 645-659.

Kline, J.D., Alig, R.J. and Garber-Yonts, B. (2004) Forestland social values and open space preservation. Journal of Forestry. 102(8): 39-45.

Kline, J.D. and Wichelns, D. (1996) Public preferences regarding the goals of farmland preservation programs. Land Economics 72: 538-549.

Kline, J. and Wichelns, D. (1994) Using referendum data to characterize public support for purchasing development rights to farmland. Land Economics, 70(2): 223-33.

Knudson, P.T. (2011) Building regional capacity for land-use reform: environmental conservation and historic preservation in the Hudson River Valley. Human Ecology Review 18 (1): 53-66.

Koontz, T. M. (2005) We finished the plan, so now what? Impacts of collaborative stakeholder participation on land use policy. The Policy Studies Journal. 33 (3): 459-481.

Koontz, T. M. and Craig W. Thomas, C.W. (2006) What do we know and need to know about the environmental outcomes of collaborative management? Public Administration Review. Vol. 66 (6): 109-119.

Koopmans, R. and Rucht, D. (1999) Protest event analysis-where to now? Mobilization 4:123-30.

Kotchen, M.J. and Powers, S.M. (2006) Explaining the appearance and success of voter referenda for open-space conservation. Journal of Environmental Economics and Management. 52 (1). p. 373-390. 
Kousser, T. (2005) Term Limits and the Dismantling of State Legislative Professionalism. New York: Cambridge University.

Krane, D., Rigos, P.N., and Hill, M.B. Jr. (2001) Home Rule in America: A FiftyState Handbook. Washington, D.C.: CQ Press.

Krieger, D. (2003) Miami-Dade county agricultural land retention study, vol 1. Florida Agricultural Market Research Center, Institute of Food and Agricultural Sciences. Gainsville, Florida. Retrieved on 10/20/2012 at http://www.miamidade.gov/business/library/reports/contingent-valuation.pdf

Kymlicka, W. (1998) Introduction: an emerging concensus? Ethical Theory and Moral Practice. 1 (2).

Kymlicka, W. and Norman, W. (1994) Return of the citizen: a survey of recent work on citizenship theory. Ethics 104 (2): 381.

Ladd, E.C. and Bowman, K. (1996) Public opinion on the environment. Resources. 124: 3-10.

Laird, F.N. (1993) Participatory analysis, democracy, and technological decision making. Science, Technology and Human Values. 18: 341-361.

Lake, L. (1983) The environmental mandate: activistists and the electorate. Political Science Quarterly. 98 (2): 215-233.

Landy, M. and Teles, S.M. (2001) Beyond devolution: from subsidiarity to mutuality. In: Nicolaidis, K. and Howse, R. (Eds.) The Federal Vision. Oxford, UK: Oxford University Press.

Lang, G.E. and Lang, K. (1981) Watergate: an exploration of the agenda-building process. In Wilhout, G.C. Mass Communication Review Yearbook. 2: 447-468. Beverly Hills, CA: Sage Publishing.

Lang, R. (2004). Are the boomburbs still booming? Metropolitan Institute at Virginia Tech. Retrieved 8/10/2012 on http://content.knowledgeplex.org/kp2/cache/documents/50072.pdf

Lang, R. and J. LeFurgy. (2007) Boomburb "buildout": The future of development in large, fast-growing suburbs. Urban Affairs Review 42 (4): 533-552

Lazarus, R.J. (1993) Pursuing "environmental justice": the distributional effects of environmental protection. Georgetown University Faculty Publications. January 2010. 87 Nw. U. L. Rev87: 787-857. 
Leach, W.D. (2006) Collaborative public management and democracy: evidence from western watershed partnerships. Public Administration Review. Supplement to 66. p. $100-110$.

. (2004) League of Women Voters $®$ of Miami - Dade County, Florida, Inc. Spotlight on Miami-Dade County - A Guide to County Government. Retrieved on 12/12/12 from http://www.Iwvmiamidade.org/.

Liebman, C. S. (1963) Teaching public administration: can we teach what we don't know? Public Administration Review, 23(3), 167-169.

. Leip's Atlas of U.S. Presidential Elections.

http://uselectionatlas.org/.

Libecap, G. (1989) Contracting for Property Rights. New York: Cambridge University Press.

Light, P.C. (1998) Sustaining Innovation: Creating Nonprofit and Government Organizations that Innovate Naturally. San Franciso, CA: Jossey-Bass.

Lijphart, A. (1971) Comparative politics and the comparative method. American Political Science Review 65(3): 682-93.

Lijphart, A. (1975) The comparable cases strategy in comparative research. Comparative Political Studies 8:158-77.

Local Government Commission (LGC). (2004.) Land conservation. Retrieved January 11, 2005, from www.lgc.org/environment/land.html.

Locke, John (1690) Second Treatise on Government. Retrieved 6/2/2011 http://libertyonline.hypermall.com/Locke/second/second-frame.html.

Lowe, L. (1996) Immigrant Acts. Durham, NC: Duke University Press.

Lubell, M. (2002) Environmental activism as collective action. Environment and Behavior. 34 (4): 431-454.

Lubell, M., Feiock, R.C., and Ramirez, E. (2005) Political institutions and conservation by local governments. Urban Affairs Review. 40: 706-729.

Lubowski, R.N., Vesterby, M., Bucholtz, S., Baez,A. and Roberts, M.J. (2006) Major Uses of Land in the United States, 2002. United States Department of Agriculture. Economic Research Service. Economic Information Bulletin Number 14. May 2006. 
Lupia, A. (1994) Shortcuts versus encyclopedias: information and voting behavior in California insurance reform elections. American Political Science Review 88: 63-76

Lupia A. and Johnson, R. (2001) Are voters to blame? Voter competence and elite maneuvers in public referendums. In Referendum Democracy: Citizens, Elites, and Deliberation in Referendum Campaigns, Mendelsohn, M. and Parkins, A.(Eds) Toronto: Macmillian/St. Martin's Press.

Lupia, A. and Matsusaka, J.G. (2004) Direct democracy: new approaches to old questions. Annual Review of Political Science 7:463-482.

Lupia, A. and McCubbins, M.D. (1998) The Democratic Dilemma: Can Citizens Learn What They Need to Know. New York: Cambridge University Press.

Lynn, L.E., Heinrich, C.J., and Hill, C.J. (2000) Studying governance and public management: challenges and prospects. Journal of Public Administration Research and Theory. 10 (2): 233-261.

Lynn, L.E., Heinrich, C.J., and Hill, C.J. (2001) Improving Governance: A New Logic for Empirical Research. Washington, D.C.: Georgetown University Press.

Machiavelli, Niccolo (1517) Discourses Upon the First Ten Books of Titus Livy. Retrieved 6/2/2011 on http://www.constitution.org/mac/disclivy_.htm.

MacManus, S.A. (1996) County board, partisanship, and elections. In Donald C. Menzel (Ed.), The American County: Frontiers in Knowledge. University, AL: University of Alabama Press.

Madison, J., Hamilton, A.. and Jay, J. (1788) The Federalist Papers. I. Kramnick (Ed.) New York: Penguin Books (1987).

Magleby, D. B. (1984) Direct Legislation: Voting on Ballot Propositions in the United States. Baltimore, MD: Johns Hopkins Press.

Manski, D.F., Lerman, S.R. (1977) The estimation of choice probabilities from choice based samples. Econometrica 45 (8): 1977-88.

Maohai, P. (1985) Public concern and elite involvement in environmental conservation issues. Social Science Quarterly. 66: 820-838.

Marando, V.L. and Reeves, M.M. (1993) County government structural reform: influence of state, region, and urbanization. Publius: The Journal of Federalism 23 (1): 41-52. 
Margerum R.D. (2008) A typology of collaboration efforts in environmental management. Environmental Management. 41: 487-500.

Mariano, C. (1995). The qualitative research process. In L.A. Talbot (Ed.), Principles and Practice of Nursing Research : 463- 491. St. Louis, MO: Mosby.

Martin, L.L. and Nyhan, R.C. (1994) Determinants of county charter home rule. International Journal of Public Administration. 17 (5): 955.

Mathers, E. (2010) Collaboration is all good. Public Management. 92 (6): 24.

Matsusaka, J.G. (1992) Economics of direct legislation. Quarterly Journal of Economics 107: 541-571.

Matsusaka, J.G. (2000) Fiscal effects of the voter initiative in the first half of the twentieth century. Journal of Law and Economics. 43 (2): 619-644.

Matsusaka, J.G. and McCarty, N.M. (2001) Political resource allocation: the benefits and costs of voter initiatives. Journal of Law and Economics.17: 413448.

Matsusaka, J.G. (2004) For the Many or the Few: How the Initiative Process Changes American Democracy. Chicago, IL: University of Chicago Press.

Matsusaka, J.G. (2005) Direct democracy works. Journal of Economic Perspectives. 19 (2): 185-206.

McCarthy, J.D., McPhail, C., and Smith, J. (1996) Images of protest: dimensions of selection bias in media coverage of Washington demonstrations, 1982 and 1991. American Sociological Review. 61:478-99.

McCarty, C., and Smith S.K. (1996) Demographic effects of natural disasters: a case study of hurricane Andrew. Demography. 33. 2: 265-275.

McCombs, M.E. and Shaw, D.L. (1972) The agenda-setting function of mass media. The Public Opinion Quarterly. 36(2): 176-187.

McCombs, M. E., Shaw, D. L., and Weaver, D. H. (1997). Communication and Democracy: Explorining the Intellectual Frontiers in Agenda-setting Theory. Mahwah, NJ: Erlbaum.

McGuire, M. (2006) Collaborative public management: assessing what we know and how we know it. Public Administration Review. Supplement to 66: 33- 43. 
McLaurin, J. (2008) A Look at County Revenue Authority: A State by State Report. . A Publication of the Research Division of the National Association of County's County Services Department. September 2008. Washington, D.C.

McLennan, A. (1998) Consequences of the condorcet jury theorem for beneficial information aggregation by rational agents. American Political Science Review. 92 (2): 413-18.

McQueen, M. and McMahon, E. (2003) Land Conservation: Financing The Conservation Fund. Washington D.C: Island Press.

Means, M. L. and Voss, J. F. (1985) Star Wars: A developmental study of expert and novice knowledge structures. Journal of Memory and Language. 24: 746757.

Meier, K.J. and O'Toole, L.J. (2003) Public management and educational performance: the impact of managerial networking. Public Administration Review. 63(6): 689-699.

Meier, K.J. and O'Toole, L.J. (2001) Managerial strategies and behavior in networks: a model with evidence for U.S. public education. Journal of Public Administrative Research and Theory. 11(3): 271-293.

Meredith, M. (2009) The strategic timing of direct democracy. Economics and Politics. 21 (1): 159-177.

Merton, R.K. (1957) Social Theory and Social Structure. Chapter VI. Glencoe, IL: Free Press. 195-206. Retrieved 1/25/2013 from http://media.pfeiffer.edu//ridener/courses/MERTONR2.HTML

Mikva, A.J. and Lane, E. (1997) An Introduction to Statutory Interpretation and the Legislative Process. New York: Aspen Law and Business.

Miles, M. B. and A. M. Huberman (1994) Qualitative Data Analysis: An Expanded Sourcebook. Thousand Oaks, CA: Sage Publications.

Milesi, C., Elvidge, C.D., Nemani, R.R., Running, S.W. (2003) Assessing the impact of urban land development on net primary productivity in the southeastern United States. Remote Sensing of Environment. 86: 401-410.

Mill, J.S. (1861) Considerations on Representative Government. Retrieved 6/2/2011 http://maartens.home.xs4all.nl/philosophy/mill/Government/ RepresentativeGovernment\%20TOC.htm.

Mills, C. W. (1956). The Power Elite. New York: Oxford University Press. 
Milward, H.B. and Provan, K.G. (1993) The hollow state: private provision of public services. In Public Policy for Democracy, Ingram H. and Smith, S.R. (Eds.) Washington, D.C.: Brookings Institution.

Mingers, J., and Brocklesby, J. (1997) Multimethodology: towards a framework for mixing methodologies. Omega. 25:5. 489-509.

Moncrief, G. F., Niemi,R.G., and Powell, L.W. (2004) Time, term limits, and turnover: trends in membership stability in U.S. state legislatures. Legislative Studies Quarterly 29(3): 357-81.

Moore, E.A. and Koontz, T.M. (2003) A typology of collaborative watershed groups: citizen-based, agency-based, and mixed partnerships. Society and Natural Resources. 16 (5): 451-460.

Morgan, D. L. (1998). Practical strategies for combining qualitative and quantitative methods: Applications to health research. Qualitative Health Research. 8: 362-376.

Morse, R.S. (2007) Developing public leaders in an age of collaborative governance. Workshop 4 - Leading a Multi-Sector Environment. In Leading the Future of the Public Sector: The Third Transatlantic Dialogue. Newark, DE:University of Delaware.

Moser, P. (1996) Why is Swiss politics so stable? Zeitschrift fur Volkswirtschaft Und Statistik. 132 (1): 31-60.

Muir, H. (1953) Miami, U.S.A. Coconut, FL: Hurricane House Publishers.

Munshi, I. (2000) Environment in sociological theory. Sociological Bulletin. 49(2): 253-266. Retrieved 2/3/2013 at

http://www.unipune.ac.in/snc/cssh/HistorySociology/A\%20DOCUMENTS\%20ON \%20HISTORY\%20OF\%20SOCIOLOGY\%20IN\%20INDIA/A\%205\%20Syllabus\% 20and\%20Discussions/B\%20Discussions/A\%205\%20B\%2004.pdf

Murley, J.M. (2008) Preserving Paradise: SoFlo's Call to Action. Florida Atlantic University's Center for Urban and Environmental Solutions. Ft. Lauderale, FL.

Murphy, K. (2009) County Government Structure: A State by State Report. A Publication of the Reseach Division of the National Association of County's County Services Department. Washington, D.C. March 2009.

Murray, C. (1984) Losing Ground: American Social Policy, 1950-1980. New York: Basic Books. 
Myers, P. (1999) Livability at the ballot box: state and local referenda on parks, conservation, and smarter growth, election day 1998. Discussion paper prepared for The Brookings Institution, Center on Urban and Metropolitan Policy.

Naake, L.E. (1996) Taking the measure of county government. National Civic Review. 85 (3): 41-45.

Nathan, R.P. and Gais, T.L. (1998) Early findings about the newest new federalism for welfare. Publius: The Journal of Federalism. 28: 95-104.

. National Association of Counties (NACo). (2010) Building Resilient Coastal Communities: Counties and the Digital Coast. Retrieved on 2/18/2013 at http://www.naco.org/research/pubs/ Documents/Infastructure\%20 and\% 20Sustainability/Digital_Coast_Issue_Brief.pdf

. National Association of Counties (NACo). (2010) County Sustainability Strategies. NACo Green Initiative. Washington, D.C.

. National Association of Counties (NACo). (2011) Smart Governance Best Practices: 2011 Achievement Awards. Washington, D.C.

Nelson, E. Uwasu, M. Polasky, S. (2007) Voting on open space: what explains the appearance and support of municipal-level open space conservation referenda in the United States? Ecological Economics. 62(3-4): 580-593.

Nicholson, S.P. (2005) Voting the Agenda: Candidates, Elections, and Ballot Propositions. Princeton, NJ: Princeton University Press.

Nowak, D.J. and Walton, J.T. (2005) Projected urban growth (2000-2050) and its estimated impact on the U.S. forest resource. Journal of Forestry. 383-389.

O'Lonney, J. (2004) The new home rule: a regionalism alternative, supplement, or distraction? National Civic Review. 93 (1): 16-26.

Oates, W.E. (2005) Property taxation and local public spending: the renter effect. Journal of Urban Economics. 57: 419-431.

Olson, M. (1965) The Logic of Collective Action. Cambridge, MA: Harvard University Press.

Olson, M. (1986) A theory of incentives facing political organizations. Internatinal Political Science Review. 7: 165-189.

Olzak, S. (1989) Analysis of events in studies of collective actions. Annual Review of Sociology. 15:119-41. 
Olzak S. (1992) The Dynamics of Ethnic Competition and Conflict. Stanford, CA: Stanford University Press.

Onwuegbuzie, A.J. and Collins, K.M.T. (2007) A typology of mixed methods sampling designs in social science research. The Qualitative Report 12(2). Retrieved from http://www.nova.edu/ssss/QR/QR12-2/onwuegbuzie2.pdf.

Onwuegbuzie, A.J. and Leech, N.I. (2006) Linking research questions to mixed methods data analysis procedures. In: The Qualitative Report. 11(3): 474. Retrieved from http://www.nova.edu/ssss/QR/QR11-3/onwuegbuzie.pdf.

Onwuegbuzie, A.J. and Teddlie, C. (2003) A framework for analyzing data in mixed methods research. In: A. Tashakkori and C. Teddlie (Eds.) Handbook of Mixed Methods in Social and Behavioral Research. Thousand Oaks, CA: Sage Publishing, Inc.

Orlikowski, W.J. and Baroudi, J.J. (1991) Studying information technology in organizations: research approaches and assumptions. Information Systems Research. 2:1-28.

Osbourne, D. (1988) Laboratories of Democracy. Boaston, MA: Harvard Business School Press.

Osborne, D. and Gaebler, T. (1991) Reinventing Government: How the Entrepreneurial Spirit Is Transforming the Public Sector. Reading, MA: Addison Wesley.

Pagano, M.A. and Johnston, J.M. (2000) Life at the bottom of the fiscal food chain: examining city and county revenue decisions. Publius: The Journal of Federalism. 41 (4): 662-685.

Paine, Thomas (1776) Common Sense. Retrieved 6/2/2011 http://www.ushistory.org/ paine/commonsense/

Pasick, R. J., Burke, N. J., Barker, J. C., Galen, J., Bird, J. A., Otero-Sabogal, R., et al. (2009) Behavioral theory in a diverse society: Like a compass on Mars. Health Education Behavior, 36(5). 11S-35S.

Pelltier, L.G., Legault, L.R., and Tuscon, K.M. (1996) The environmental satisfaction scale: a measure of satisfaction with local environmental conditions and government environmental policies. Environment and Behavior. 28: 5-26.

Peters, B.G. (1996) Governing: Four Emerging Models. Lawrence: University Press of Kansas. 
Peters, B.G., Pierre, J. (1998) Governance without government? rethinking public administration. Journal of Public Administration Research and Theory. 8 (2): 223244.

Peterson, P. (1981) City Limits. Chicago, IL: University of Chicago Press.

Peterson, P. (1996) The Price of Federalism. Washington, D.C.: Brookings Institution Press.

Peterson, P. and Rom, M, (1989) American federalism, welfare policy, and residential choices. The American Political Science Review. 83: 711-728.

Peterson, P. and Rom, M. (1990) Welfare Magnets: A New Case for the National Standard. Washington, D.C.: Brookings Institution Press.

Piccoli, G. and Ives, B. (2003) Trust and the unintended effects of behavior control in virtual teams. MIS Quarterly. 27:3. 365-395

Piele, P.K. and Hall, J.S. (1973) Budgets, Bonds, and Ballots. Lexington, MA: D.C. Heath and Co.

Plano Clark, V. L. and Badiee, M. (2010). Research questions in mixed methods research. In A. Tashakkori \& C. Teddlie (Eds), Handbook of Mixed Methods Research (2nd ed.) 275-304. Thousand Oaks, CA: Sage Publications, Inc.

Plano Clark, V. and Creswell, J.W. (2008) The Mixed Methods Reader. Thousand Oaks, CA: Sage Publications, Inc.

Pohjola, M.V. and Tuomisto, J.T. (2011) Openness in participation, assessment, and policy-making upon issues of environment and environmental health: a review of the literature and recent project results. Environmental Health: A Global Access Science Source. 10: 58-75.

Polit, D.F. and Hungler, B.P. (1999) Nursing Research: Principles and Methods. $6^{\text {th }}$ Edition. Phildelphia, PA: Lippincott.

Pollitt, C. and Bouckaert, G. (2000) Public Management Reform: A Comparative Analysis. Oxford, UK: Oxford University Press.

Posner, R.A. (1990) The Problems of Jurisprudence. Cambridge, MA: Harvard University Press.

Powell, D.L. (1993) Managing florida's growth: The next generation. Florida State University Law Review. 21: 223, 226. 
Powell, D.L. (2000) Growth Management: Florida's Past as Prologue for the Future. Based on presentations which the author made to the Growth Management Study Commission in Tallahassee on August 28, 2000, and to the annual convention of the Florida League of Cities in Fort Lauderdale on August 11, 2000. Retrieved on January 8, 2013 from http://www.law.fsu.edu/journals/ lawreview/downloads/282/Powell.pdf.

Press, D. (2002) Saving Open Space: The Politics of Local Preservation in California. Berkeley, CA: University Press.

Pritzker, B. (2000) A Native American Encyclopedia: History, Culture, and Peoples. Oxford University Press.

Provan, K.G. (2008) Modes of network governance: structure, management, and effectiveness. Journal of Public Administration Research and Theory. 18(2): 229252.

Przeworski, A, and Teune, H. (1970) The Logic of Comparative Social Inquiry. New York: John Wiley.

Przyborski, A. and Wohlrab-Sahr M. (2008) Qualitative Sozialforschung. Ein Arbeitsbuch. München: Oldenbourg Wissenschaftsverlag.

Ragas, M. and Roberts, M. (2009). Agenda setting and agenda melding in an age of horizontal and vertical media: a new theoretical lens for virtual brand communities. Journalism and Mass Communication Quarterly 86(1): 45-64.

Ragin, C.C. (1994) Constructing Social Research: The Unity and Diversity of Method. Thousand Oaks, CA:Sage/Pine Forge Press.

Rappaport, E. (December 10, 1993). "Hurricane Andrew Preliminary Report". National Hurricane Center. Retrieved November 23, 2011.

Rawls, John (1971) A Theory of Justice. Boston, MA: Belknap Press of Harvard University Press.

(1980) Reorganizing our Counties: A Catalogue of County Government Reorganization Experience in America. Cleveland, $\mathrm{OH}$ : Governmental Research Institute

Richardson, J.J. Jr. (2011) Dillon's rule is from Mars, home rule is from venus: local government autonomy and the rules of statutory construction. Publius: The Journal of Federalism. 41 (4): 662-685.

Richardson, J.J. Jr., Gough, M.Z., and Puentes, R. (2003) Is home rule the answer? Clarifying the influence of Dillon's rule on growth management. A 
discussion paper prepared for The Brookings Institution Center on Urban and Metropolitan Policy. January 2003.

Rogers, W. (2001) Envisioning and implementing our open space legacy.

Remarks by TPL President at Green Space Design Conference. Park City, Utah.

Rohr, John A. (1986). To Run a Constitution: The Legitimacy of the Administrative State. Lawrence: University of Kansas Press.

Rohrschneider, R. (1990) The roots of public opinion toward new social movements: an empirical test of competing explanations. American Journal of Political Science. 34: 1-30.

Romer, T. and Rosenthal, H. (1978) Political resource allocation, controlled agendas, and the status quo. Public Choice 33: 27-43.

Romer, T. and Rosenthal, H. (1979) Bureaucrats versus voters: on the political economy of resource allocation by direct democracy. Quarterly Journal of Economics. 93: 563-587.

Rosenberger, R.S. (1998) Public preferences regarding the goals of farmland preservation programs: comment. Land Economics. 74 (4): 557-65.

Rousseau, Jean Jacques (1762) The Social Contract or Principles of Political Right. Retrieved 6/2/2011 on http://www.constitution.org/jjr/socon.htm.

Rubin, H, Ruin I. (1995) Qualitative Interviewing: The Art of Hearing Data. Sage Publications, Thousand Oaks, CA.

Runeson, P. and Host, M. (2009) Guidelines for conducting and reporting case study research in software engineering. In Empir Softward Eng. 14: 131-164.

Smart Growth America (SGA) (2000) National survey on growth and land development. Retrieved January 11, 2005, from www.smartgrowthamerica.com/databand/html.

Sabatier, P.A. (2007), The need for better theories. In Sabatier, P. Ed. Theories of Policy Process. Boulder: Westview Press. 3-17.

Sabatier, P.A. (1999) Theories of the Policy Process. Boulder, CO: Westview.

Salamon, L.M. (1981) Rethinking public management: third party government and the changing forms of public action. Public Policy. 29: 255-275.

Salka, W.M. (2000) Determinants of countywide voting behavior on environmental ballot measures: 1990-2000. Rural Socialgy. 68 (2): 253-277. 
Samdahl, D.M. and Robertson, R. (1989) Social determinants of environmental concern. Environment and Behavior. 21: 57-81.

Satori, A.E. (2003) An estimator for some binary-outcome selection models without exclusion restrictions. Political Analysis. 11:111-138.

Sawyer (1969) Modern Federalism. London: Watts.

Schneider, M. and Park, K.O. (1989) Metropolitan counties as service delivery agents: the still forgotten governments. Public Administration Review. 49:315324.

Schultz, P.W. (2000) New environmental theory: emphathizing with nature: the effects of perspective taking on concern for environmental issues. Journal of Social Issues. 56(3): 391-406.

Seawright, J. and Gerring, J. (2008) Case selection techniques in case study research: a menu of qualitative and quantitative options. Political Research Quarterly. 61: 294-308.

Seguin, C., Pelletier, L.G., and Hunsley, J. (1998) Toward a model of environmental activism. Environment and Behavior. 30: 628-652.

Selin, S. and Chavez, D. (1995) Developing a collaborative model for environmental planning and management. Environmental Management, 19 (2): 189-195

Sellers, M. (2010) County Authority: A State by State Report. A Publication of the Research Division of the National Association of County's County Services Department. December 2010. Washington, D.C.

Serino, G. (1958) Miami's metropolitan experiment. Public Administration Clearing Service. Gainsville, FL: University of Florida Gainesville.

Shah, S.K. and Corley, K.G (2006) Building better theory by bridging the quantitataive-qualitative divide. Journal of Management Studies. 43 (8): 18211835.

Sherer, Paul (2006) The Benefits of Parks: Why America Needs More City Parks and Open Space. A Publication of The Trust for Public Land.

Simler, B.S. (2001) The Changing Roles of Environmental Interest Groups in National Policy-Making: A Marine Conservation Case Study. Thesis in partial fulfillment for the degree of Master of Science. Oregon State University. May 24, 2001 
Skelcher, C. (2007) Does democracy matter? A transatlantic research design on democratic performance and special purpose governments. Journal of Public Administration Research and Theory. 17: 61.

Skowronek, S. (1982) Building the New American State: The Expansion of National Adaptive Capacities, 1877-1920. Cambridge, UK: University Press.

Smith, C.R. (2009) Institutional determinants of collaboration: an empirical study of county open state protection. Journal of Public Administration Research and Theory. 19 (1): 1-21.

Snider, C.F. (1952) American county government. A mid-century review. American Political Science Review. 41 (1): 66-80.

Sofen, E. (1963) The Miami Metropolitan Experiment. Bloomington, IN: Indiana University Press.

Sofen, E. (1961) Probems of metropolitan leadership: the Miami experience. Midwest Journal of Political Science. 5:1. 18-38.

Soffer, P. and Hadar, I. (2007) Applying ontology-based rules to conceptual modeling: A reflection on modeling decision-making. European Journal of Information Systems. 16:5. 599-611.

Sokolow, Alvin (1993) State rules and the county-city arena: competition for land and taxes in California's central valley. Publius: The Journal of Federalism. 23 (1): 53-69.

Solecki, W., Mason, R., Martin, S. (2004) The geography of support for openspace initiatives: a case study of New Jersey's 1998 ballot measure. Social Science Quarterly. 85. 624-639.

Soss, J., Fording, R.C. and Schram, S.F. (2008) The color of devolution: race, federalism, and the politics of social control.American Journal of Political Science. 52(3): 536-553

Spetalnick, M. (2007) Nobel is sweet revenge for Gore, blow to Bush. Reuters Analysis. October 12, 2007. Retrieved on 8/23/2012.

Squire, P. (1992) Legislative professionalization and membership diversity in state legislatures. Legislative Studies Quarterly 17(1): 69-79.

Squire, P. (2007) Measuring legislative professionalism: the squire index revisited. State Politics and Policy Quarterly 7(2): 211-27. 
Stachowiak, S. (2007) Pathways for Change: 6 Theories About How Policy Change Happens. Organizational Research Services. Retrieved December 12, 2012 at http://www.organizationalresearch.com/publicationsandresources/ pathways_for_change_6_theories_about_how_policy_change_happens.pdf

Stake, K. (1998). Case studies. In N. Denzin and Y. Lincoln (Eds.), Strategies of Qualitative Inquiry :86-109. Thousand Oaks, CA: Sage Publishing.

Staley, Edgens and Mildner. (1999) A line in the land: Urban growth boundaries, smart growth and housing affordability. Reason Public Policy Institute. retrieved at http://www.rppi.org/urban/ps263.html on 10/10/2012.

Staton, Jeffrey K. (2006) Constitutional review and the selective promotion of case results. American Journal of Political Science 50:98-112.

Steunenberg, B. (1992) Referendum, initiative, and veto power. Kyklos. 45 (4): 501-529.

Stevens, G. Ross (1974) State centralization and the erosion of local autonomy. The Journal of Politics. 36 (1): 44-76.

Stigler, G.J. (1971) Theory of economic regulation. Bell Journal of Economics and Management Science. 5: 3-21.

Strauss, A., Corbin, J. (1990) Basics of Qualitative Research: Grounded Theory procedures and techniques. Newbury Park, CA: Sage.

Streeck, W. (2003) Theories and practices of neo-corporatism. In: A Handbook of Political Sociology: States, Civil Societies and Globalization. Janoski, Alford, Hicks and Schwartz (Eds.) New York: Cambridge University Press.

Sundberg, J. (2006) Voting for public funding of open space. Working Paper. Cambridge, MA. Lincoln Institute of Land Policy. Retrieved on 8/23/2012. http://www.lincolninst.edu/ pubs / PubDetail. aspx?pubid=1172.

Susskind, L., Cruikshank, J. (1987) Breaking the Impasse: Consensual Approaches to Resolving Public Disputes. Basic Books:New York.

Svara, J.H., Nelson, K.L. Taking stock of form and structure in county government. Public Management 90 (11): 21-27.

Szabo, P.S. (2007) Noah at the ballot box: status and challenges. In: BioScience 57 (5): 424.

The Trust for Public Land (TPL) (2012) LandVote - 1988-2009.

Retrieved August 23, 2012, from www.tpl.org. 
The Trust for Public Land (TPL) (2010) LandVote - 1988-2009.

Retrieved January 5, 2011, from www.tpl.org.

The Trust for Public Land (TPL) (2009) LandVote - 1988-2008.

Retrieved October 10, 2009, from www.tpl.org.

The Trust for Public Land (TPL) (2006) LandVote. Retrieved

September 20, 2008, from www.tpl.org.

The Trust for Public Land and Land Trust Alliance. (2003)

LandVote 2003: Americans invest in parks and open space. Retrieved January

11, 2005, from www.ita.org/public policy/landvote_2003.

Tannenwald, R. (1998) Come the devolution, will states be able to respond? New England Economic Review. May/June: 53-73.

Tashakkori, A. and Teddlie, C. (1998) Mixed Methodology: Combining Qualitative and Quantitative Approaches. Thousand Oaks, CA: Sage Publishing Inc.

Tashakkori, A. and Teddlie, C., Eds. (2003) Handbook of Mixed Methods in Social and Behavioral Research. Thousand Oaks, CA: Sage Publishing Inc.

Taylor, L. (2003) Changing demographics and implications for local governance: the southeast florida (tri-county) experience. In PA Times of The American Society for Public Administration. 25 (4): 3

Teddlie, C. and Tashakkori, A. (2009) Foundations of Mixed Methods Research: Integrating Quantitative and Qualitative Approaches in the Social and Behavioral Sciences. Thousand Oaks, CA: Sage Publishing Inc.

Teddlie, C., Yu, F. (2007) Mixed methods sampling: a typology with examples. Journal of Mixed Methods Research. 1(1): 77.

Teddlie, C., and Tashakkori, A. (2003) Major issues and controversies in the use of mixed methods in the social and behavioral sciences. Handbook of Mixed Methods in Social and Behavioral Research, A. Tashakkori and C. Teddlie (eds.), Thousand Oaks, CA: Sage Publications.

Tellis, Winston, (1997). Introduction to Case Study. The Qualitative Report. 3:2 (July). Retrieved from http://www.nova.edu/ssss/QR/QR3-2/tellis1.html.

Tercheck, R.J. and Conte, T.C., Eds. (2001) Theories of Democracy; A Reader. Lanham, UK :Rowman and Littlefield. 
Thompson, A.M. and Perry, J.L. (2006) Collaboration processes: inside the black box. Public Administration Review. Supplement to 66: 20-32.

Tiebout, C. (1956) A pure theory of local expenditures. Journal of Political Economy. 64: 416-424.

Timmons, M., Grant, J., Popp, T., and Westby, H. (1993) County home rule comes to Minnesota. William Mitchell Law Review. 19: 811-870.

Trabasso, T. and van den Brock. P. (1985) Causal thinking and the representation of narrative events. Journal of Memory and Language. 24: 612630.

Truman, D. B. (1951). The Governmental Process. New York: Knopf

Tsebelis, G. (2000) Veto players in political analysis. Governance. 13 (3): 441474.

Turner, B. (1992) Outline of a theory of citizenship. In Mouffe, Chantal (Ed.) Dimensions of Radical Democracy: Pluralism, Citizenship, Community. London: Verso.

Tversky, A. and Kahneman, D. (1981) The framing of decisions and the psychology of choice. Science. 211 (4481): 453-458.

Ulrich, R. S. (1984) View through a window may influence recovery from surgery. Science, 224, 420-421.

Ulrich, R. S. (1993) Biophilia, biophobia, and natural landscapes. In Kellert, S. R. and Wilson, E. O. (eds) The Biophilia Hypothesis. Shearwater Books/Island Press, Washington D.C., pp. 73-137.

Ulrich, R. S., Dimberg, U. and Driver, B. L. (1991a) Psychophysiological indicators of leisure benefits. In Driver, B. L., Brown, L. R. and Peterson, G. L. (eds) Benefits of Leisure. State College, PA:Venture Publishing. pp. 73-89.

Ulrich, R. S., Simons, R. F., Losito, B. D., Fiorito, E., Miles, M. A. and Zelson, M. (1991b) Stress recovery during exposure to natural and urban environments. Journal of Environmental Psychology. 11: 231-248.

van den Brock, P. (1989) Causal reasoning and inference making in judging the importance of story statements. Child Development. 60: 286-297.

VanMaanen, J. (1979). Reclaiming qualitative methods for organizational research: a preface. Administrative Science Quarterly. 24: 520-526. 
U.S. Environmental Protection Agency. (2012) Growing for a Sustainable Future: Miami-Dade County Urban Development Boundary Assessment. Office of Sustainable Communities Smart Growth Program, Development, Community and Environmental Division (now the Office of Sustainable Communities). Washington, D.C.

Venkatesh, V., Brown, S. and Bala, H. (2013) Bridging the qualitative-quantitative divide: guidelines for conducting mixed methods research in information services. MIS Quarterly. 10:10. 1-34. Retrieved online on 2/3/2013 at http://vvenkatesh. com/ Downloads/ Papers/fulltext/pdf/Venkatesh_Brown_Bala_ MISQ_forthcoming.pdf

Verba, S., Nie, N.H., and Kim, J. (1978) Participation and Political Equality: A Seven-Nation Comparison. Cambridge, MA: Cambridge University Press.

Verba, S., Schlozman, K.L., and Brady, H. (1995) Voice and Equality: Civic Voluntarism in American Politics. London: Harvard University Press.

Videras, J. Community homogeneity and revealed preferences for environmental goods. Contemporary Economic Policy. 30 (2): 262-282. +

Vigoda, E. (2001) Administrative agents of democracy? A structural equation modeling of the relationship between public-sector performance and citizen involvement. Journal of Public Administration Research and Theory 12(2): 241.

Vigoda, E, (2002) From responsiveness to collaboration: governance, citizens, and the next generation of public administration. Public Administration Review. 62: 527 .

Vigoda-Gadot, E. (2007) Citizen's perceptions of politics and ethics in public administration: a five-year national study of their relationship to satisfaction with services, trust in governance, and voice orientations. Journal of Public Administration Research and Theory. 17 (2): 285-206.

Walgrave, S. and Van Aelst, P (2006). The contingency of the mass media's political agenda setting power: toward a preliminary theory. Journal of Communication 56: 88-109.

Wallman, B. (2000, October 19) Growth Interests Shell Out Cash - Developers Put Up Dollars to Build Political Support. Sun-Sentinel Company, Broward Metro Edition, Local Section. 1A.

Walls, D. (2008) Environmental Movement. Retrieved on 8/24/2012 from http://www.sonoma.edu/users/w/wallsd/environmental-movement.shtml. 
Walsham, G. (1995) Interpretive case studies in IS research: nature and method. European Journal of Information Systems. 4: 74-81.

Wang, X. (2001) Assessing public participation in U.S. cities. Public Performance and Management Review. 69: 518.

Waters, M.D. (2003) The Initiative and Referendum Almanac: A Comprehensive Reference Guide to the Initiative and Referendum Process. Raleigh Durham, NC: Carolina Academic Press.

Webb, E. J., Campbell, D. T., Schwartz, R. D. and Sechrest, L. (1966). Unobtrusive Measures: Nonreactive Research in the Social Sciences. Chicago, IL: Rand McNally.

Weber, E., and Khademian, A.M. (2008) Managing collaborative processes: common practices, uncommon circumstances. Administration and Society. 40 (5): p. 431-464.

Weeks, J.D. and Hardy, P.T. (1984) The legal aspects of local government. In Small Cities and Counties: A Guide to Managing, J.M. Banovetz (Ed.). Washington, D.C.: International City/County Management Association.

Welch, J. (1999) Home rule doctrine and state pre-emption - The lowa Supreme Court resurrects Dillon's Rule and blurs the line between implied pre-emption and inconsistency. Goodell v. Humboldt County, 575 N.W.2D 486 (lowa 1998).

Rutgers Law Journal. 30: 1548-1564.

Wickersham, J.H. (1994) The quiet revolution continues: The emerging new model for state growth management statutes. Harvard Environmental Law Review.18: 489, 490.

Wilson, Edward O. (1984). Biophilia. Cambridge, MA: Harvard University Press.

Winthrop, Gov. John (1630) A Model of Christian Charity. Retrieved 6/2/2011 on http://religiousfreedom.lib.virginia.edu/sacred/charity.html.

Winship, C. and Mare, R.D. (1992) Models for sample selection bias. Annual Review of Sociology. 18: 327-50.

Wolin, Sheldon (1989). The Presence of the Past: Essays on the State and the Constitution. Baltimore, MD: Johns Hopkins University Press.

Wolman, H. and Goldsmith, M. (1990) Local autonomy as a meaningful analytical concept: comparing local government in the United States and the United Kingdom. Urban Affairs Review. 26 (3): 3-27. 
Wolman, H., McManmon, R., Bell, M., and Brunori, D. (2010) Comparing local government autonomy across states, In: The Property Tax and Local Autonomy, M.E. Bell, D. Brunori, and J. Youngman (Eds.),Cambridge, MA: Lincoln Institute of Land Policy.

Wondolleck, J. and S. Yaffee. (2000) Making Collaboration Work: Lessons from Innovation in Natural Resource Management. Washington, DC: Island Press.

Wood, C. (2002) Voter turnout in city elections. Urban Affairs Review. 38: 209231.

Wood, C. (2011) Do home rule governments work better? A new and different perspective. Northern Illinois University Center for Governmental Studies Policy Profiles. 10:1. 1-8.

Wright, B., Manigault, L., and Black, T. (2004) Quantitative research measurement in public administration: An assessment of journal publications. Administration and Society 35:747-64.

Yin, R.K. (1994) Case Study Research: Design and Methods, Second Edition. Thousand Oaks, CA: Sage Publications, Inc.

Young, I. M. (1998) Polity and group difference: a critique of the ideal of universal citizenship. In, G. Shafir (ed.) The Citizenship Debates: A Reader. Minneapolis, MN: University of Minnesota Press.

Zeman, A.R., Hilliker, M., Koles, M., Marcouiller, D. (2003) Ensuring open space: an assessment of factors that explain state-sponsored land protection programs. Working paper 03-1, Department of Urban and Regional Planning, University of Wisconsin-Madison/Extension.

Ziedonis, R. H. (2004). Don't fence me in: fragmented markets for technology and the patent acquisition strategies of firms. Management Science. 50: 804-20. 


\section{APPENDIX}




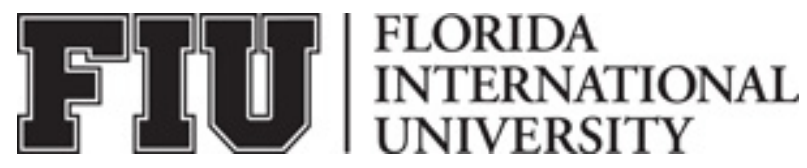

\section{ADULT CONSENT TO PARTICIPATE IN A RESEARCH STUDY ENTITLED \\ SELECTION AND PASSAGE OF COUNTY LAND PRESERVATION VOTER REFERENDUM: THE ROLE OF GOVERNMENT}

\section{PURPOSE OF THE STUDY}

You are being asked to participate in a research study. The purpose of this study is to investigate the two-step voter referendum process. This process is when a county jurisdiction proposes a land preservation program, followed by its citizens' vote at the ballot box. More specifically, the investigator is interested in understanding the factors that either facilitate or impede the selection of a referendum by county government, and the circumstances that encourage or discourage a 'yes' vote on election day.

\section{NUMBER OF STUDY PARTICIPANTS}

If you decide to be in this study, you will be one of twelve people in this study.

\section{DURATION OF THE STUDY}

Your participation will require approximately 45 minutes of your time.

\section{PROCEDURES}

If you agree to be in the study, we will ask you to do the following things:

1. In a one-on-one interview with the researcher, you are asked to respond to questions related to omissions in the preliminary findings of this study. The format is based on the criteria of a semi structured interview technique.

2. As an expert witness, the study questions ask about your views, opinions and experiences concerning land preservation voter referendums in general and in relationship to your county government of employment.

3. The interview will be tape recorded and the investigator might take written notes in order to capture the highest accuracy of your answer.

\section{RISKS AND/OR DISCOMFORTS}

It is not anticipated that you will not be harmed by participating in the study. If you feel uncomfortable during the interview, you may choose to end your interview at any time.

\section{BENEFITS}

Your participation would be extremely valuable to the present research, as well as to county or county entities which may be planning to or are in the process of selection a land preservation voter referendum.

\section{ALTERNATIVES}


There are no known alternatives available to you other than not taking part in this study. However, any significant new findings developed during the course of the research which may relate to your willingness to continue participation will be provided to you.

\section{CONFIDENTIALITY}

The records of this study will be kept private and will be protected to the fullest extent provided by law. In any sort of report we might publish, we will not include any information that will make it possible to identify a subject. Research records will be stored securely and only the researcher team will have access to the records. However, your records may be reviewed for audit purposes by authorized University or other agents who will be bound by the same provisions of confidentiality.

\section{COMPENSATION \& COSTS}

You will not receive a payment of for your participation. You will not be responsible for any costs to participate in this study.

\section{RIGHT TO DECLINE OR WITHDRAW}

Your participation in this study is voluntary. You are free to participate in the study or withdraw your consent at any time during the study. Your withdrawal or lack of participation will not affect any benefits to which you are otherwise entitled. The investigator reserves the right to remove you without your consent at such time that they feel it is in the best interest.

\section{RESEARCHER CONTACT INFORMATION}

If you have any questions about the purpose, procedures, or any other issues relating to this research study you may contact Dr. Allan Rosenbaum or Susan P. Beaghen, 305-348-1271 or 305-348-5890, and rosenbau@fiu.edu or sbeagh01@fiu.edu.

\section{IRB CONTACT INFORMATION}

If you would like to talk with someone about your rights of being a subject in this research study or about ethical issues with this research study, you may contact the FIU Office of Research Integrity by phone at 305-348-2494 or by email at ori@fiu.edu.

\section{PARTICIPANT AGREEMENT}

I have read the information in this consent form and agree to participate in this study. I have had a chance to ask questions I have about this study, and they have been answered. I understand that I am entitled to a copy of this form after it has been read and signed. 
Printed Name of Participant

Signature of Person Obtaining Consent

Date 


\section{FIU|}

Interview No:

\section{Semi-Structured Interview Questionnaire}

Interview Protocol

Introduction

(5 minutes)

Thank you for your time and willingness to participate in my dissertation research as a practitioner and expert witness in the field of public affairs and management. I am a doctoral candidate in the Department of Public Affairs at Florida International University. As agreed, our conversation is being tape recorded and I will also be taking notes as we talk.

The protocol is a semi-structured interview format. It is a component of three case studies of Broward, Miami-Dade and Palm Beach Counties. There are a few key points that I would like for us to cover, but the process is intended to be informal and conversational. The intent of conducting this interview with you and other public administrators is to gather data about your practical and professional experiences as they relate to the topic of my research.

Research Project: Selection and Passage of County Land Preservation Voter Referendum: The Role of Government. This study investigates the 456 U.S. county-level land preservation voter referendums that have been selected by 227 county governments, and proposed to county registered voters at the ballot box from 1988 through 2009. Voters passed 340 (74.6 percent) of these ballot measures, approving nearly $\$ 75.4$ billion in future spending for a variety of local open space, parks, recreation, preservation and conservation projects.

My investigation began with a quantitative analysis of 227 referendum counties and all nonreferendum counties in 50 U.S. States. The variables analyzed included demographic, socioeconomic, geographic, political, government, elections and referendum-specific.

Your responses are treated as totally confidential. Neither your name nor any identifying information will be included in the dissertation. All notes, audio-tapes and transcriptions are security-protected.

Do you have any questions about the study or the interview protocol?

Main Questions Secondary Questions

Clarifying Questions

Topic 1:

Public Need

(10 minutes)

opic 2:

Government

Selection

Process

(10 minutes)
1. How does this county assess the need for land preservation, open space, parks and recreation, ecosystem and wildlife protection, watershed maintenance or other related conservation measures?

2. Why did this county decide to select a voter referendum tool to achieve its land preservation goals? What is your opinion on the voter referendum specifications? (i.e., amount,purpose, finance mechanism, promotion, language, election date)
- Under what circumstances did the topic arise? What was the scope?

- How did the county learn about it?

- How were projects ranked?

- What was the citizen participation?

- What locations in the county were most affected? Why?

- Have you noticed a need for land preservation in past few years?

- What are your experiences with citizens or the public?

- Which agency (ies) initiated it?

- Were interest groups involved in the process? Cities? Others?

- What was the participation and input of the community/citizens?

- How did the County Manager or County Mayor participate?

- What was the scope of the Board's review and approval process?

- Single most important factor is
- Can you expand on this a little?

- Can you tell me more about ?

- Do you remember any relevant experiences?

- Can you provide any stories or examples?

- Can you expand on this a little?

- Can you tell me more about $?$

- Do you remember

- any relevant experiences?

- Can you provide any stories or examples? 


\begin{tabular}{|l|l}
\hline Topic 3: & \\
Voter Passage & \\
Process &
\end{tabular}

(10 minutes)
3. In your opinion, did any community characteristics (i.e., residential demographics, socioeconomic, labor, political, land/water use or other) make a difference in whether voters cast yes or no ballots on election day?
- Describe the county community and its citizens.

- Are there any strong, different, or distinguishing characteristics?

- Any specific projects sought?

- Socio-economic or labor?

- Political preferences?

- Describe the county's citizen education program. Who participated and why.

- What areas in the county were the strongest (weakest) supporters?

- Did the referendum language differ from the County ordinance?

- Explain a little about this issue?

- Who provides leadership?

- How does the public participate?

- How does government participate?

- What areas of the county are most impacted and why?

- Have you noticed any changes in the past few years?

- In your opinion, could anything have been done differently in this county?

- What do you know of its history?

-Who provides leadership?

- How do citizens participate?

- What is government's response?

- What areas in the county are most affected?

- Does it impact the selection or passage of LP Voter Referendum.

- Have you noticed any changes in the past few years?

- In your opinion, could anything have been done differently by this county?
- Can you expand on this a little?

- Can you tell me more about $?$

- Do you remember any relevant experiences?

- Can you provide any stories or examples?
- Can you expand on this a little?

- Can you tell me more about

- Do you remember any relevant experiences?

- Can you provide any stories or examples?
2 BC Groups 3 PBC - Pop and Land Use Diversity

(10 minutes) from agriculture to high density urbanism.

\section{Conclusion of Interview}

Final

Thoughts

(5 minutes)

Are there any other county or land preservation voter referendum topics that we have not discussed that you think would be important to this research?
- Select any of the secondary questions or similar.
- Can you expand on this a little?

- Can you tell me more about

- Do you remember any relevant experiences?

- Can you provide any stories or examples? 
VITAE

\section{SUSAN PEABODY BEAGHEN}

Birthplace: $\quad$ Pelham, New York

1987

B.A. Liberal Arts (Biology Major)

Wells College

Aurora, New York

$1989-2012$

Master Degree in Health Systems/Services Administration

Department of Health and Urban Affairs

Florida International University

North Miami, Florida

1987-1989

Research Assistant

Southeast Florida Center on Aging

Florida International University

North Miami, Florida

$\begin{array}{ll}\text { 1989-2012 } & \text { Public Administration and Manageme } \\ & \text { Broward County Board of County Com } \\ & \text { Fort Lauderdale, Florida } \\ & \text { Agencies: Human Services, Parks and } \\ & \text { Property, Facilities Management, Humar } \\ \text { and Wastewater Services } & \\ & \\ & \text { Doctor of Philosophy in Public Affairs } \\ & \text { Department of Public Administration } \\ & \text { Florida International University } \\ & \text { Miami, Florida }\end{array}$

PUBLICATIONS AND PRESENTATIONS

Rothman, M.B., Pelaez, M. and Gibbons, S. Beaghen. (1988) The Homemaker Program of Dade County's Elderly Services Division Department of Human Resources: An Evaluation. Southeast Florida Center on Aging, Florida International University.

Terry, W.C., Gibbons, S. Beaghen, and Rothman, M.B. (1988) Policing Miami's Housing Projects for Older Persons: An Evaluation. Southeast Florida Center on Aging, Florida International University. 